Florida International University FIU Digital Commons

$3-2-2011$

\title{
A preliminary characterization of mercury uptake by the sulfate-reducing bacteria Desulfovibrio desulfuricans
}

Amaury Pedro Betancourt III

Florida International University

DOI: $10.25148 /$ etd.FI14051132

Follow this and additional works at: https://digitalcommons.fiu.edu/etd

Part of the Environmental Engineering Commons

\section{Recommended Citation}

Betancourt, Amaury Pedro III, "A preliminary characterization of mercury uptake by the sulfate-reducing bacteria Desulfovibrio desulfuricans" (2011). FIU Electronic Theses and Dissertations. 1649.

https://digitalcommons.fiu.edu/etd/1649 
Miami, Florida

\title{
A PRELIMINARY CHARACTERIZATION OF MERCURY UPTAKE BY THE SULFATE-REDUCING BACTERIA DESULFOVIBRIO DESULFURICANS
}

\author{
A thesis submitted in partial fulfillment of the \\ requirements for the degree of \\ MASTER OF SCIENCE \\ in
}

ENVIRONMENTAL ENGINEERING

by

Amaury Pedro Betancourt III 
To: Dean Amir Mirmiran

College of Engineering and Computing

This thesis, written by Amaury Pedro Betancourt III, and entitled A Preliminary Characterization of Mercury Uptake by the Sulfate-Reducing Bacteria Desulfovibrio desulfuricans, having been approved in respect to style and intellectual content, is referred to you for judgment.

We have read this thesis and recommend that it be approved.

Yelena Katsenovich

Shonali Laha

Georgio Tachiev

Hector R. Fuentes, Major Professor

Date of Defense: March 30, 2011

The thesis of Amaury Pedro Betancourt III is approved.

Dean Amir Mirmiran

College of Engineering and Computing

Interim Dean Kevin O'Shea

University Graduate School

Florida International University, 2011 


\section{DEDICATION}

I dedicate this thesis to my parents Mariana and Amaury, my sister Cecile, my brother-inlaw Oscar, my nieces Catalina and Natalia, and my grandmother Maria. Thank you for everything. 


\section{ACKNOWLEDGMENTS}

I would like to first thank my friends and family for everything. I would also like to thank my Major Professor Dr. Hector R. Fuentes for all of his help during my graduate studies at Florida International University (FIU) and for his sincere interest in my success and for the success of my fellow students; my Mentor and Department of Energy (DOE) Fellowship Program Director Dr. Leonel Lagos for his genuine concern for my future and the futures of all the DOE Fellows; my Mentor Dr. Georgio Tachiev for providing me with a great learning experience while I have been working at the Applied Research Center (ARC) at FIU; my Mentor Dr. Yelena Katsenovich for teaching me valuable techniques in the laboratory and for helping me finalize the experiments of my thesis; my professor and thesis committee member Dr. Shonali Laha for her helpful input to my thesis; DOE Fellow Alexander Henao and Dr. Guangliang Liu for using ICP-MS to analyze my samples from my experiments; DOE Fellow Jose Rivera for assisting me with ordering the equipment and supplies I needed for the experiments; my professors Dr. Fernando Miralles-Wilhelm and Dr. Michael Sukop for valuable information on environmental modeling from the classes that each of them taught; my former Mentor Dr. Vekalet Tek for teaching me about laboratory work with anaerobic bacteria; my Summer Mentor Dr. Dwayne Elias from Oak Ridge National Laboratory (ORNL) for allowing me to research in his laboratory and for helping me design the experiments for my thesis; my Summer Supervisors Meghan Drake and James Moberly for their support throughout my entire Summer internship; Dr. Carrie Miller and Dr. Abir Biswas for assisting in the planning of different parts of the experiments for my Summer internship; DOE Fellow

Denny Carvajal and ORNL Scientist Sue Carroll for assisting in training me to count 
cells with a cell counting slide and a light microscope; and ORNL Scientists Dr. Steven Brown and Dr. Ji Won Moon for helping me by allowing me to use their laboratory facilities. Much of the content of this thesis came from my DOE Fellows Summer Internship Technical Report, which was edited by Peggy Shoffner (DOE-Environmental Management (EM), Oak Ridge, TN) and Angelique Lawrence (ARC-FIU). Special thanks go to my friends for their continued assistance at school. This research was done through the DOE-FIU Science \& Technology Workforce Development Initiative (DOE Fellows Program). The work was funded by the U.S. Department of Energy Office of Environmental Management (DOE-EM). The Contract No. is DE-FG01-05EW07033. 


\title{
ABSTRACT OF THE THESIS
}

\section{A PRELIMINARY CHARACTERIZATION OF MERCURY UPTAKE BY THE} SULFATE-REDUCING BACTERIA DESULFOVIBRIO DESULFURICANS

\author{
by
}

Amaury Pedro Betancourt III

Florida International University, 2011

Miami, Florida

Professor Hector R. Fuentes, Major Professor

The focus of this research is to determine if a relationship exists between the stability constant and the initial uptake rate of a mercury species by bacteria. Cultures of the sulfate-reducing bacteria (SRB) strain Desulfovibrio desulfuricans G20 were washed with a bicarbonate buffer solution containing either lactate and sulfate or pyruvate and fumarate. The washed cell solutions were then spiked with either mercury bound to natural organic matter $(\mathrm{Hg}-\mathrm{NOM})$ or neutral mercury chloride $\left(\mathrm{HgCl}_{2}\right)$, followed by sampling over time to provide kinetic data. Despite the significantly different stability constants for $\mathrm{Hg}-\mathrm{NOM}$ and $\mathrm{HgCl}_{2}$, the calculated initial rate constants for mercury uptake for these two types of complexes appeared to be comparable. Uptake of mercury sulfide species was inconclusive due to possible formation of cinnabar. A simple model that is based on assumptions of passive diffusion and facilitated uptake of mercury by bacteria was evaluated for its potential to simulate the uptake. The model results only agreed with experimental data for $\mathrm{HgCl}_{2}$ uptake. 


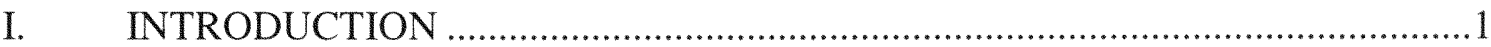

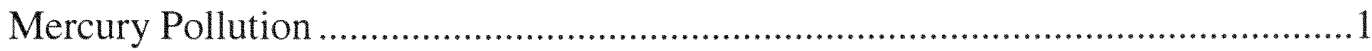

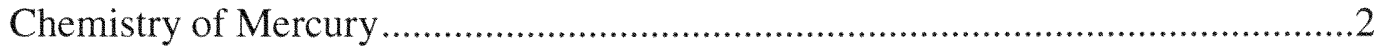

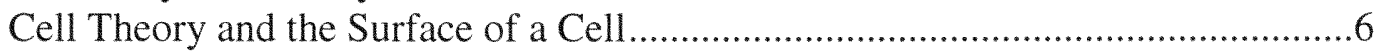

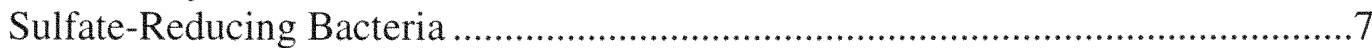

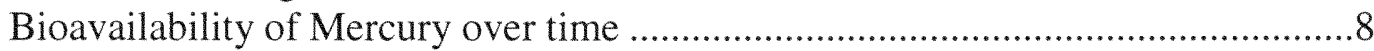

Transport of Substances through the Plasma Membrane of a Cell ..........................9

Research Suggesting Mercury Uptake by Cells via Passive Diffusion ..................10

Research Suggesting Mercury Uptake by Cells via Active/Facilitated

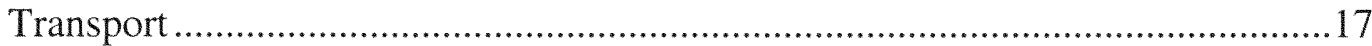

Simple Model for Mercury Uptake and Accumulation by Bacteria ......................26

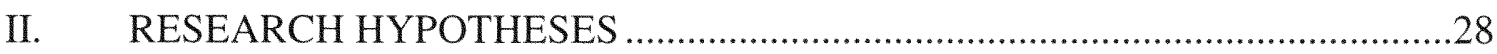

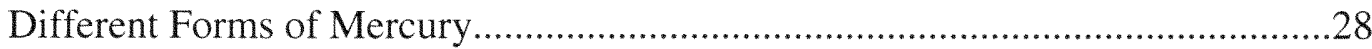

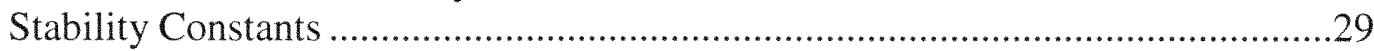

Possible Effects of NOM on Mercury Uptake by Bacteria.....................................30

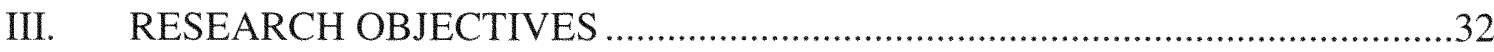

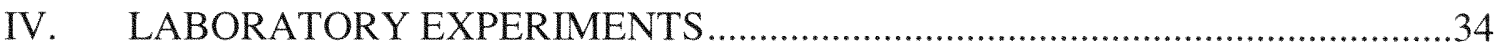

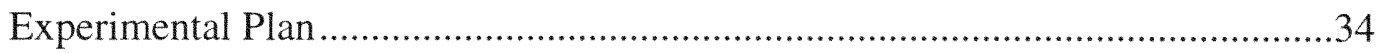

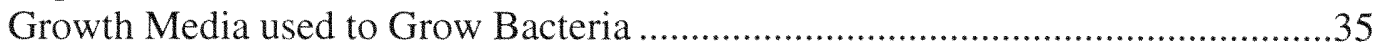

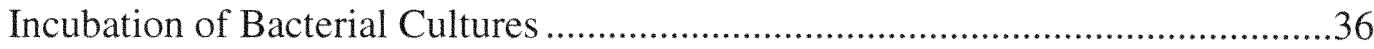

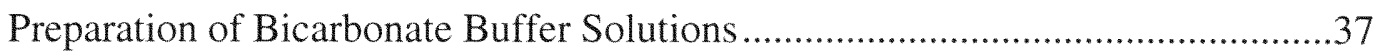

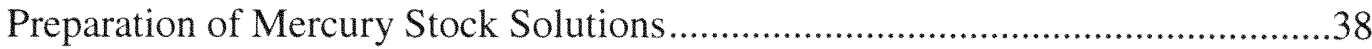

Washing Bacterial Cells and Preparing Samples for Cell Counting......................40

Mercury Spikes into Washed Cell Solutions ........................................................45

Estimated Speciation of Mercury - Pyruvate/Fumarate Solutions ........................47

Estimated Speciation of Mercury - Lactate/Sulfate Solutions ...............................48

Uncertainty of Cinnabar Formation in Lactate/Sulfate Solutions............................50

Uncertainty of Hg-NOM Speciation in Lactate/Sulfate Solutions ........................50

Preparing Experimental Samples, Controls and Cell Counting..............................51

Sample Analysis using Direct Mercury Analyzer 80 (DMA 80) ..........................53

Sample Analysis using Inductively Coupled Plasma - Mass Spectrometry

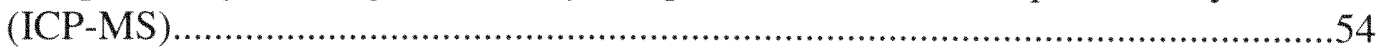

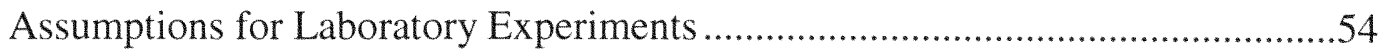

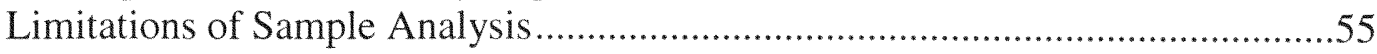

V. MODELING MERCURY UPTAKE BY CELLS ….........................................57

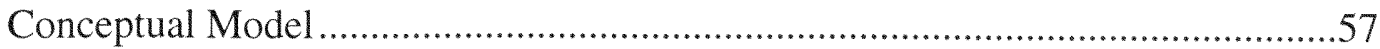

Modeling Parameters for Mercury Uptake by Cells via Passive Diffusion...........58 
Modeling Parameters for Mercury Uptake by Cells via Active/Facilitated

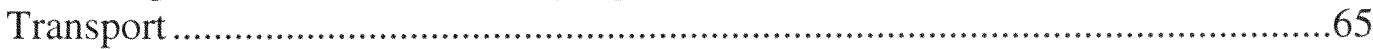

Summary of Model for Mercury Uptake ……..................................................71

Chemistry of Mercury with Natural Organic Matter and Sulfide..........................72

Equilibrium of Mercury Stock Solutions............................................................75

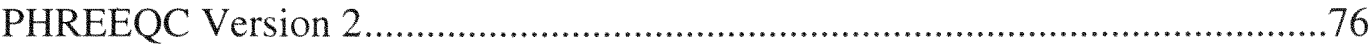

Assumptions for Modeling Mercury Uptake by Bacteria.....................................77

VI. RESULTS FROM LABORATORY EXPERIMENTS ….................................79

Analysis of Supernatant Samples and Test Tube Walls Samples by using the

Direct Mercury Analyzer 80 (DMA 80) .............................................................79

Analysis of Cell Pellet Samples and Supernatant Samples by using

Inductively Coupled Plasma - Mass Spectrometry (ICP-MS) ..............................79

Difference in Results from the DMA 80 and Results from ICP-MS .....................92

Mass Balance Discrepancy for Results of ICP-MS Analysis ................................94

Usefulness of Laboratory Experiment Results .....................................................95

Estimates for Initial Mercury Uptake Rates........................................................96

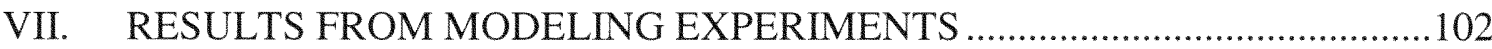

Initial Assumed Parameters for Models ...............................................................102

Additional Thermodynamic Equilibrium Reaction Data Added to Model..........103

Initial Conditions for the Pyruvate/Fumarate Models .........................................105

Initial Conditions for the Lactate/Sulfate Models................................................106

Model for the Pyruvate/Fumarate Experiments spiked with $\mathrm{HgCl}_{2} \ldots \ldots \ldots \ldots \ldots \ldots . . . .108$

Model for the Pyruvate/Fumarate Experiments spiked with Hg-NOM ...............111

Model for the Lactate/Sulfate Experiments spiked with $\mathrm{HgCl}_{2} \ldots \ldots \ldots \ldots \ldots \ldots \ldots \ldots \ldots . . . .114$

Model for the Lactate/Sulfate Experiments spiked with Hg-NOM ....................117

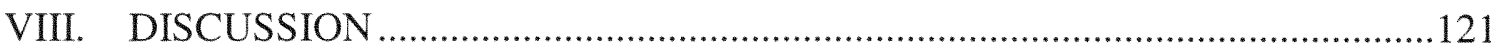

Limitations in the Results of the Laboratory Experiments ..................................121

Mercury Uptake by Bacteria in the Pyruvate/Fumarate Experiments .................122

Mercury Uptake by Bacteria in the Lactate/Sulfate Experiments .......................123

Stability Constants of Mercury Species and Mercury Uptake Rates ....................124

Model of Mercury Uptake by Bacteria ..............................................................125

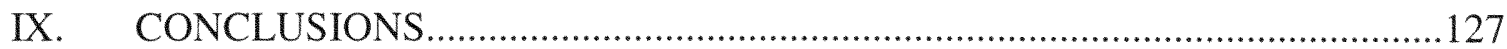

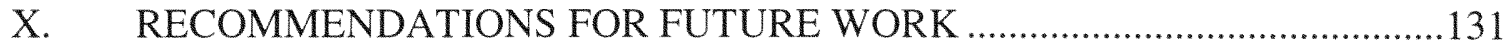

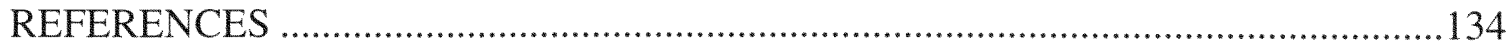

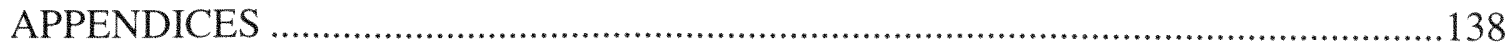




\section{LIST OF TABLES}

TABLE

PAGE

Table 1: Membrane permeabilities and octanol-water partition coefficients for different mercury species.

Table 2: Results of the cell pellet samples, aqueous supernatant samples, and two samples of the test tube walls that were analyzed for the lactate/sulfate experiments, analyzed using ICP-MS.

Table 3: $\quad$ Measured and calculated masses of mercury for the samples from the lactate/sulfate experiments, analyzed using ICP-MS, and the ratio of the mass of mercury in the cell pellet sample to the mass of mercury in the aqueous supernatant sample for each washed cell solution.

Table 4: Results of the cell pellet samples, aqueous supernatant samples, and two samples of the test tube walls that were analyzed for the pyruvate/fumarate experiments, analyzed using ICP-MS.

Table 5: $\quad$ Measured and calculated masses of mercury for the samples from the pyruvate/fumarate experiments, analyzed using ICP-MS, and the ratio of the mass of mercury in the cell pellet sample to the mass of mercury in the aqueous supernatant sample for each washed cell solution. 88

Table 6: Comparison of thermodynamic equilibrium constants ( $\log \mathrm{K}$ ) of formation of the calculated dominant mercury species in each set of experiments to the estimated initial rate constants for mercury uptake by cells.

Table 7: Initial estimated parameters for passive diffusion and facilitated uptake model.

Table 8: Chemical reactions and thermodynamic equilibrium constants added to the model for mercury sulfide species and mercury bound to NOM.

Table 9: Initial input concentrations of elements for the model for the pyruvate/fumarate experiments that were spiked with $\mathrm{HgCl}_{2}$.

Table 10: Initial input concentrations of elements for the model for the pyruvate/fumarate experiments that were spiked with $\mathrm{Hg}-\mathrm{NOM}$.

Table 11: Initial input concentrations of elements for the model for the lactate/sulfate experiments that were spiked with $\mathrm{HgCl}_{2}$ 
Table 12: Initial input concentrations of elements for the model for the lactate/sulfate experiments that were spiked with $\mathrm{Hg}-\mathrm{NOM}$.

Table 13: Calculated initial speciation of mercury for the washed cell solutions in the pyruvate/fumarate experiments that had been spiked with $\mathrm{HgCl}_{2}$. Mercury speciation was calculated using PHREEQC

Table 14: Calculated initial speciation of mercury for the washed cell solutions in the pyruvate/fumarate experiments that had been spiked with Hg-NOM. Mercury speciation was calculated using PHREEQC.

Table 15: Calculated initial speciation of mercury for the washed cell solutions in the lactate/sulfate experiments that had been spiked with $\mathrm{HgCl}_{2}$. Mercury speciation was calculated using PHREEQC.

Table 16: Calculated initial speciation of mercury for the washed cell solutions in the lactate/sulfate experiments that had been spiked with $\mathrm{Hg}-\mathrm{NOM}$. Mercury speciation was calculated using PHREEQC.

Table 17: Wall's Medium (or Wall Media) by Judy Wall and Dwayne Elias. Edited by Amaury Betancourt on 08/01/2010.

Table 18: Average cell counts for each washed cell solution prior to mercury spikes, counted two times for each washed cell solution, with resulting number of cells $/ \mathrm{mL}$ in each washed cell solution prior to mercury spikes.

Table 19: Calculations and Measurements for the Method Detection Limit (MDL) determination for the Direct Mercury Analyzer 80 (DMA 80).

Table 20: Average absorbance height and standard deviation in the first MDL run for the blank sample boats and the sample boats that contained $0.2 \mathrm{ng}$ of $\mathrm{Hg}$.

Table 21: Results for the analysis of the supernatant samples from the pyruvate/fumarate experiments, analyzed using the DMA 80 .

Table 22: Results for the analysis of the samples of the test tube walls from the pyruvate/fumarate experiments, analyzed using the DMA 80.

Table 23: Results for the analysis of the supernatant samples from the pyruvate/fumarate experiments, analyzed using the DMA 80 . 158

Table 24: Results for the analysis of the samples of the test tube walls for the lactate/sulfate experiments, analyzed using the DMA 80. 
Table 25: Calculated concentrations of mercury in aqueous supernatant solutions, using DMA 80, for solutions with concentrations above the method detection limit (MDL) for the DMA 80.

Table 26: Source code for the model of mercury uptake by cells via passive diffusion and facilitated uptake for the lactate/sulfate experiments that had been spiked with $\mathrm{Hg}-\mathrm{NOM}$

Table 27: Partial output for the model for mercury uptake by cells via passive diffusion and facilitated uptake for the lactate/sulfate experiments with $\mathrm{Hg}-\mathrm{NOM}$ 


\section{LIST OF FIGURES}

FIGURE

PAGE

Figure 1: Experimental plan for mercury accumulation rate experiments. 35

Figure 2: A photograph of an anaerobic glovebag similar to the anaerobic glovebag used in the experiments. Manufactured by COY Laboratories

Figure 3: Estimated speciation for the pyruvate/fumarate experiments that had been spiked with $\mathrm{HgCl}_{2}$.

Figure 4 Estimated speciation for the lactate/sulfate experiments that had been spiked with $\mathrm{HgCl}_{2}$

Figure 5: Some possible chemical and physical processes occurring inside a bacterial cell, as well as in and on the cell membrane of a bacterial cell.

Figure 6: Mass of mercury in the cell pellet sample and the supernatant sample, for each washed cell solution in the lactate/sulfate experiments that had been spiked with $\mathrm{HgCl}_{2}$. One sample of the test tube walls was analyzed.....84

Figure 7: Mass of mercury in the cell pellet sample and the supernatant sample for each washed cell solution in the lactate/sulfate experiments that had been spiked with Hg-NOM. One sample of the test tube walls was analyzed.

Figure 8: Mass of mercury in the cell pellet sample and the supernatant sample for each washed cell solution in the pyruvate/fumarate experiments that had been spiked with $\mathrm{HgCl}_{2}$. One sample of the test tube walls was analyzed.....90

Figure 9: Mass of mercury in the cell pellet sample and in the supernatant sample for each washed cell solution in the pyruvate/fumarate experiments that had been spiked with Hg-NOM. One sample of the test tube walls was analyzed.

Figure 10: Supernatant concentrations of mercury versus time, with calculated initial uptake rates of mercury.

Figure 11: Initial uptake rate constants versus stability constants for each set of experimental conditions.

Figure 12: Model results and experimental data for the washed cell solutions from the pyruvate/fumarate experiments that had been spiked with $\mathrm{HgCl}_{2}$ 
Figure 13: Model results and experimental data for the washed cell solutions from the pyruvate/fumarate experiments that had been spiked with $\mathrm{Hg}-\mathrm{NOM} . . .113$

Figure 14: Concentration of different mercury sulfide species versus the estimated total concentration of sulfide in solution for the washed cell solutions in the lactate/sulfate experiments that had been spiked with $\mathrm{HgCl}_{2}$

Figure 15: Model results and experimental data for the washed cell solutions from the lactate/sulfate experiments spiked with $\mathrm{HgCl}_{2}$

Figure 16: Model results and experimental data for washed cell solutions from the lactate/sulfate experiments spiked with $\mathrm{Hg}-\mathrm{NOM}$.

Figure 17: Calibration curve for the DMA 80, using only quartz sample boats, for the mass of mercury range of $0.2 \mathrm{ng}$ of $\mathrm{Hg}$ to $5.0 \mathrm{ng}$ of $\mathrm{Hg}$ 


\section{INTRODUCTION}

\section{Mercury Pollution}

Mercury is an environmental pollutant of serious concern throughout Earth. One of the most well known cases of mercury poisoning was in Minamata Bay, Japan, starting in the 1950's. Pollack (1997) discusses that thousands of people in southern Japan suffered due to eating fish contaminated with mercury that had been dumped into Minamata bay by the Chisso Corporation's chemical factory. Some victims were poisoned in their mother's womb and born with deformities (Pollack, 1997). Pollack (1997) discusses that sometime near late July to early August 1997, there was an announcement that the fish in Minamata Bay were once again safe to eat.

Mercury pollution is also a problem in the Oak Ridge Reservation (ORR) in Oak Ridge, Tennessee (USA), as has been described in the work of Dong et al. (2010) and Miller et al. (2009). Dong et al. (2010) discussed remedial actions in the East Fork Poplar Creek (EFPC) in Oak Ridge, Tennessee, which have resulted in reduced $\mathrm{Hg}$ loading into local streams. However, the corrective actions have not been as successful in reducing mercury levels in fish, and the concentration of toxic methylmercury in fish remains relatively constant and exceeds the United States Environmental Protection Agency (EPA) regulatory criterion of $0.3 \mu \mathrm{g} \mathrm{g}^{-1}$.

Mercury is a global environmental pollutant. Anthropogenic (man-made) sources of mercury contribute significantly to mercury contamination in the environment. Mason et 
al. (1994) estimate an average value for direct anthropogenic $\mathrm{Hg}$ emission to the atmosphere of $20 \mathrm{Mmol} / \mathrm{year}$ [or Megamoles per year], which is approximately $57 \%$ of the total emission (from both natural and anthropogenic sources). Removal of mercury from contaminated environments and safe storage of mercury poses a significant challenge around the world.

\section{Chemistry of Mercury}

In the environment, mercury $(\mathrm{Hg})$ can exist in numerous forms and can bind to many different substances. The particular chemical form in which an element exists in water is its speciation (Stumm and Morgan, 1996). Stumm and Morgan (1996) discuss that any combination of cations (positively-charged ions) with molecules or anions (negativelycharged ions) containing free pairs of electrons is called coordination, or complex formation, and can be electrostatic, covalent, or a mixture of both. Stumm and Morgan (1996) discuss that the metal cation in a coordination is called the central atom, and the anions or molecules with which it forms a coordination are called ligands.

In addition, Stumm and Morgan (1996) distinguish between two types of complex species: ion pairs and complexes. Ion pairs are formed when ions of opposite charge approach within a critical distance from each other and no longer are electrostatically effective, and the metal ion or the ligand or both retain the coordinated water molecule or molecules when the ion pair is formed (Stumm and Morgan, 1996). In addition, Stumm and Morgan (1996) state that most stable entities that result from the formation of largely covalent bonds between a metal ion and an electron-donating ligand - the interacting 
ligand is immediately adjacent to the metal cation - are called complexes (inner-sphere complexes).

Mercury can form many different complexes in nature. Each chemical reaction that results in the formation of a complex has a unique stability constant $\beta$. It is assumed in the present research that a reaction is said to have a stability constant when the reaction involves the formation of a complex from one or more metal cations and from the molecules or anions of the complex that is the product of the reaction. The stability constant is a specific type of thermodynamic equilibrium constant, both of which describe the equilibrium speciation of one or more species, depending on the reaction, the temperature at which the reaction is occurring, and other parameters. In the present research, the terms stability constant and thermodynamic equilibrium constant may be used interchangeably. Dong et al. (2010, and reference therein) report the following reaction and stability constant for the formation of the complex of $\mathrm{HgCl}_{2}$ :

$$
\mathrm{Hg}^{+2}+2 \mathrm{Cl}^{-}=\mathrm{HgCl}_{2} \quad \log \beta=14.00
$$

In the above equation, the $\log \beta$ value represents the stability constant of the reaction. The $\log \beta$ is a way to measure how strongly a reaction proceeds in the direction in which it is written, as well as the stability of the complex produced in the reaction. If $\log \beta$ is positive, the reaction is thermodynamically favorable in the direction in which it is written, and if $\log \beta$ is negative, the reaction is thermodynamically favorable in the direction that is reverse from the way it is written. In addition, if $\log \beta$ is equal to 0 , then 
the reaction is as thermodynamically favorable in the direction in which it is written as it is in the reverse direction. The above discussion for stability constants also applies to the logarithm of a thermodynamic equilibrium constant $(\log \mathrm{K})$, and thermodynamic equilibrium constants are used for chemical reactions in general, whereas the terminology of a stability constant appears to be used for chemical reactions that produce a complex. Chemical reactions and stability constants are used for predicting the speciation of a solution assuming conditions of thermodynamic equilibrium are present, that is, the chemistry of the solution is no longer changing in time and is at steady state. For some reactions, the logarithm of the equilibrium constant, $\log \mathrm{K}$, is either the same or related to the logarithm of the stability constant, $\log \beta$. Depending on the ligand, the formation of different forms of mercury may depend on both thermodynamic equilibrium and on kinetics of mercury speciation.

The stability constant does not convey information about the kinetics of a reaction. Thus, a reaction may be thermodynamically favorable and have a large, positive stability constant, but may take a very long time to occur. Regarding aqueous speciation reactions, Tebes-Stevens et al. (1998, and reference therein) discuss that, with the exception of aqueous redox reactions, most aqueous speciation reactions, including complexation and acid-base reactions, occur rapidly in comparison with the rate of flow of groundwater, and it is usually valid in groundwater modeling to treat aqueous speciation reactions as if they proceed instantaneously to thermodynamic equilibrium. 
The complexation chemistry between mercury and organic substances, including natural organic matter (NOM), dissolved organic matter (DOM), and dissolved organic carbon (DOC), have been studied by different researchers (Barkay et al., 1997; Benoit et al., 1999; Benoit et al., 2001; Kelly et al., 2003; Miller et al., 2007; Miller et al., 2009; Zhong and Wang, 2009; Dong et al., 2010). The kinetics of NOM complexation with mercury was studied by Miller et al. (2009). In their research, Miller et al. (2009) concluded that the kinetics of mercury complexation with NOM needs to be evaluated the dominant complexes of $\mathrm{Hg}$ in aquatic systems receiving input of inorganic $\mathrm{Hg}$. Moreover, Miller et al. (2009) stated that equilibrium conditions cannot be assumed in such systems due to the heterogeneity of NOM and the competitive interactions among various functional moieties of NOM for binding with $\mathrm{Hg}$.

In addition, Miller et al. (2009) discuss that when sulfide is not present in freshwater systems, complexes between $\mathrm{Hg}$ and $\mathrm{NOM}$ are the dominant form of mercury because of reduced sulfur functional groups on NOM that provide strong binding sites for $\mathrm{Hg}$. However, as Miller et al. (2009, and references therein) state, the interaction between mercury and reduced sulfur functional groups on NOM is not completely understood.

Miller et al. (2009), in the Supporting Information to their research, give two reactions between mercury and NOM, and each reaction has a range of possible values for the stability constant, and the range of values of the stability constants for each reaction come from different references within Miller et al. (2009, and references therein). Miller et al. (2009, and references therein) give the following two reactions for mercury with NOM, 
where the component $\mathrm{RS}^{-}$represents an organic group $\mathrm{R}$ bound to a sulfide group $\mathrm{S}^{2-}$ on a representative species of NOM:

$$
\begin{array}{ll}
\mathrm{Hg}^{2+}+\mathrm{RS}^{-}=\mathrm{HgRS}^{+} & \mathrm{Log} \mathrm{K} \text { is between } 21.6 \text { to } 33.5 \\
\mathrm{Hg}^{2+}+2 \mathrm{RS}^{-}=\mathrm{Hg}(\mathrm{RS})_{2} & \mathrm{Log} \mathrm{K} \text { is between } 43.2 \text { to } 47.7
\end{array}
$$

The range of $\log \mathrm{K}$ values for the above two reactions come from various references within Miller et al. (2007, and references therein). In addition, these ranges of values may result from the heterogeneity of NOM and from different possible sources of NOM affecting the equilibrium constant of formation of a $\mathrm{Hg}-\mathrm{NOM}$ complex.

\section{Cell Theory and the Surface of a Cell}

Cell theory, as discussed by Raven et al. (2008), includes the following three principles:

1. All organisms are composed of one or more cells, and the life processes of metabolism and heredity occur within these cells.

2. Cells are the smallest living things, the basic units of organization of all organisms.

3. Cells arise only by division of a previously existing cell.

Raven et al. (2008) discuss the surface of a cell as providing the only opportunity for interaction with the environment because all substances enter and exit a cell via this surface, and state that the plasma membrane encloses a cell and separates its contents from its surroundings. Moreover, Raven et al. (2008) state that the membrane surrounding the cell plays a key role in controlling cell function, and because smaller 
cells have more surface area per unit volume than larger cells, control is more effective when cells are relatively small.

According to de Duve (1984), the maintenance of cellular life depends on the continuous passage of many different substances - most of them highly hydrophilic (able to dissolve in water or be attracted to water molecules) - into and out of cells across the plasma membrane. Raven et al. (2008) describe prokaryotes as being the simplest organisms. According to Raven et al. (2008), prokaryotic cells are small and consist of a plasma membrane encased in a rigid cell wall, and unlike eukaryotes, prokaryotes have no distinct interior compartments. Moreover, Raven et al. (2008) state that the two domains of prokaryotes are archaea and bacteria, and that most bacterial cells are encased by a strong cell wall.

\section{Sulfate-Reducing Bacteria}

According to Postgate (1979), sulfate-reducing bacteria are adaptable to almost any natural environment on this planet except, strangely enough, the most common, which is an ordinary aerobic (oxygen present) environment. Voorduow (1995) states that sulfate reducers contribute to the reduction and immobilization of heavy metals, which is generally desirable except in the case of formation of the hazardous environmental pollutant methylmercury.

Not all sulfate-reducing bacteria, however, are capable of methylating mercury (producing methylmercury) and even within the same genus and species of bacteria, 
some strains are capable of methylating mercury and some are not. For example, Desulfovibrio desulfuricans G20 is not known to methylate mercury (Elias 2010, personal communication), but Desulfovibrio desulfuricans LS has been found to methylate mercury (Pak and Bartha, 1998). Because the focus of this research is on mercury uptake, and not methylmercury production, D. desulfuricans G20, which is not known to produce methylmercury, was chosen for this research. In addition, it is important to note that Postgate and Campbell (1966) describe the genus Desulfovibrio as nonsporulating, gram-negative vibrios, sometimes sigmoid or spirilloid and occasionally straight, which is in reference to their shape. Thus, it is assumed in the present research that the strain Desulfovibrio desulfuricans G20 is gram-negative.

\section{Bioavailability of Mercury over time}

Benoit et al. (2001a) conducted research with the sulfate-reducing bacteria (SRB) strain Desulfobulbus proprionicus (1pr3). In their research, Benoit et al. (2001a) tested the bioavailability (availability of a substance to organisms) of inorganic mercury $\left(\mathrm{Hg}_{\mathrm{I}}\right)$ over time in two different types of cultures: culture bottles labeled "A" signified that mercury and sulfide were added to the medium after inoculation with bacteria and culture bottles labeled "B" signified that mercury and sulfide were added to the medium before inoculation with bacteria. Benoit et al. (2001a) state that they considered $\mathrm{MeHg}$ (methylmercury) production to be a surrogate for mercury bioavailability and uptake. Benoit et al. (2001a) state that five hours after the additions, subsamples were taken from the "A" cultures for filtered and unfiltered $\mathrm{Hg}_{\mathrm{T}}$ (total mercury) and $\mathrm{MeHg}$ in order to determine the short-term methylation rate. 
Benoit et al. (2001a) found from their bioavailability time course experiments that the methylation rate in the A cultures was faster for the first five hours of the experiments than for the time between five hours and three days, and faster than the overall methylation rate over the three days of the experiments. In addition, in the work of Benoit et al. (2001a), the overall methylation rate of the A cultures over the three days of the experiments was much faster than the overall methylation rate of the B cultures over the three days of the experiments. Benoit et al. (2001a) state that an important implication of some of the results of their research is that $\mathrm{Hg}$ spiked into culture medium, and probably other matrices, is initially highly bioavailable.

Transport of Substances through the Plasma Membrane of a Cell

Regarding the plasma membrane of a cell, de Duve (1984) discusses that there is considerable two-way traffic across a boundary (the cell membrane) that is largely made up of a continuous phospholipid bilayer that is almost impermeable to most hydrophilic molecules. Moreover, de Duve (1984) discusses three conditions to support the traffic across a cell membrane, adapted as follows:

1. A large enough surface area.

2. Occurrence of appropriate conduits across the lipid bilayer.

3. Availability of energy.

About the third condition, availability of energy, de Duve (1984) states that the decisive factor is whether the direction of transport is down a concentration gradient, from where the substance is more concentrated to where it is less, or up a gradient. 
In addition, de Duve (1984) also differentiates between four different types of transport processes: diffusion, permeation, facilitated transport, and active transport. According to de Duve (1984), downhill transport can occur spontaneously, but it tends to level the concentration gradient that supports it and thereby to exhaust its source of energy, and downhill transport is called diffusion if it is unhampered and permeation if it is restricted by a permeability barrier. The transport is said to be facilitated when it is helped by some sort of carrier or translocator system acting catalytically, according to de Duve (1984). In addition, de Duve (1984) states that when transport occurs against a concentration gradient, the process must be directly supplied with energy, and the machinery involved is correspondingly more complex, and the systems that carry out such active transport are generally referred to as pumps. Although there is a clear difference between active and facilitated transport through the cell membrane, these two terms are used interchangeably in the present research to signify any cellular processes in which a substance is transported through the cell membrane with the help of a pump, a carrier, or a translocator system.

Research Suggesting Mercury Uptake by Cells via Passive Diffusion

Mason et al. (1996) conducted research on mercury uptake by the marine diatom Thalassiosira weissflogii. In their work, Mason et al. (1996) state that their research demonstrates that passive uptake of uncharged, lipophilic (attracted to lipid-based substances, such as oils) chloride complexes is the principal accumulation route of both methylmercury and inorganic mercury in phytoplankton. Mason et al. (1996) studied how the overall octanol-water partition coefficient $\left(D_{o w}\right)$ of both mercury and methylmercury 
affects mercury and methylmercury uptake, respectively, by a marine diatom. The overall octanol-water partition coefficient $\left(\mathrm{D}_{\mathrm{ow}}\right)$ is related to the individual octanol-water partition coefficient $\left(\mathrm{K}_{\mathrm{ow}}\right)$ of each mercury species in a solution by the following equation from Mason et al. (1996),

$$
\mathrm{D}_{\mathrm{ow}}=\Sigma\left(f_{\mathrm{i}}\left(\mathrm{K}_{\mathrm{ow}}\right)_{\mathrm{i}}\right)
$$

where $f_{\mathrm{i}}$ is the mole fraction of the total mercury present as the species $\mathrm{i}$ (Mason et al., 1996). Stumm and Morgan (1996) discuss the importance of the octanol-water partition coefficient $\left(\mathrm{K}_{\mathrm{ow}}\right)$ and state that the solvent $n$-octanol, $\mathrm{CH}_{3}\left(\mathrm{CH}_{2}\right)_{7} \mathrm{OH}$, is a kind of surrogate for many kinds of environmental and physiological organic substances and it has become a reference phase for organic phase water partitioning of organic solutes. In addition, Stumm and Morgan (1996) state that $n$-octanol is, because of the $\mathrm{OH}$ groups, only partially nonpolar and can dissolve, in addition to nonpolar substances, also partially polar compounds containing $\mathrm{O}$ and $\mathrm{N}$ functional groups.

Stumm and Morgan (1996) state that the distribution equilibrium of a compound between $n$-octanol and water, $\mathrm{K}_{\mathrm{ow}}$, can be determined experimentally in the following equation:

$$
\mathrm{K}_{\mathrm{ow}}=[\mathrm{A}(\mathrm{oct})] /[\mathrm{A}(\mathrm{aq})]
$$

where $[\mathrm{A}(\mathrm{oct})]$ is the concentration of substance $\mathrm{A}$ in octanol and $[\mathrm{A}(\mathrm{aq})]$ is the concentration of substance $\mathrm{A}$ in water. 
Mason et al. (1996) calculated the $\mathrm{K}_{\mathrm{ow}}$ values for various relatively lipophilic mercury species, including $\mathrm{HgCl}_{2}, \mathrm{CH}_{3} \mathrm{HgCl}, \mathrm{Hg}(\mathrm{OH})_{2}$, and $\mathrm{CH}_{3} \mathrm{HgOH}$. Specifically, Mason et al. (1996) found a $\mathrm{K}_{\text {ow }}$ of 3.33 for $\mathrm{HgCl}_{2}$, a $\mathrm{K}_{\text {ow }}$ of 0.05 for $\mathrm{Hg}(\mathrm{OH})_{2}$, a $\mathrm{K}_{\text {ow }}$ of 1.20 for $\mathrm{HgClOH}$, and a $\mathrm{K}_{\text {ow }}$ of 1.7 for $\mathrm{CH}_{3} \mathrm{HgCl}$ (the same $\mathrm{K}_{\text {ow }}$ of $\mathrm{CH}_{3} \mathrm{HgCl}$ was also reported by another researcher, see reference within Mason et al., 1996), and Mason et al. (1996) reported a $\mathrm{K}_{\text {ow }}$ of 0.07 for $\mathrm{CH}_{3} \mathrm{HgOH}$ found by another researcher (same reference as the $\mathrm{K}_{\mathrm{ow}}$ for $\mathrm{CH}_{3} \mathrm{HgCl}$, see reference within Mason et al., 1996).

The researchers Mason et al. (1996) conducted a variety of experiments, including experiments that varied the calculated concentration of $\mathrm{HgCl}_{2}$ in some of their experimental media, as well as the concentration of $\mathrm{CH}_{3} \mathrm{HgCl}$ in some of their experimental media. Mason et al. (1996) found that the uptake rate of inorganic mercury generally appeared to decrease as the calculated concentration of $\mathrm{HgCl}_{2}$ decreased in some of their experimental media, and they also found that the uptake rate of methylmercury generally appeared to decrease as the calculated concentration of $\mathrm{CH}_{3} \mathrm{HgCl}$ decreased in some of their experimental media.

Mason et al. (1996) also conducted experiments where marine diatoms (Thalassiosira weissflogii) that contained either inorganic mercury or methylmercury were fed to Massachusetts Bay copepods (Acartia tonsa, Temora longicornis, Centropages sp.) to determine the assimilation efficiency of mercury by the copepods. Mason et al. (1996) then compared the assimilation efficiencies of either inorganic mercury or methylmercury by the copepods to the percentages of inorganic mercury or methylmercury that were 
found to be present in the cell membrane or in the cytoplasm of the marine diatoms. Mason et al. (1996) discuss that in their research, they found that $63 \%$ of the methylmercury was in the cytoplasmic fraction of the diatoms and $62 \%$ was assimilated by the copepods; on the other hand, for inorganic mercury, only $9 \%$ was in the diatom cytoplasm and only $15 \%$ was assimilated by the copepods. Mason et al. (1996) state that, consistent with their observation that reactivity of mercury with particulate cellular material is greater for inorganic mercury than methylmercury, inorganic mercury is concentrated predominantly $(91 \%)$ in diatom cell membranes while only $37 \%$ of accumulated methylmercury is membrane-bound.

Barkay et al. (1997) tested the effects of dissolved organic carbon (DOC) and salinity on bioavailability of mercury. Barkay et al. (1997) used two bacterial strains of Escherichia coli, HMS174(pRB28) and HMS174(pRB27), the cells containing a mer-lux bioindicator. Barkay et al. (1997) discuss the mer-lux bioindicator used in their research and state that they used a previously described molecular fusion (see reference within Barkay et al., 1997) between the regulatory region of the mercury resistance (mer) operon and the luminescence (lux) gene from Vibrio fischeri. Furthermore, Barkay et al. (1997) state that bacteria harboring the fusion emit light in proportion to the quantity of bioavailable $\mathrm{Hg}(\mathrm{II})$ in their environment (see reference within Barkay et al., 1997).

Barkay et al. (1997) conducted experiments that show that as the concentration of $\mathrm{NaCl}$ increases in the assay buffer, the speciation of mercury shifts from neutral mercury chloride $\left(\mathrm{HgCl}_{2}\right)$ species to negatively charged mercury chloride species $\left(\mathrm{HgCl}_{3}{ }^{-}\right.$and 
$\mathrm{HgCl}_{4}{ }^{-2}$ ), and this is accompanied by a decrease in light production byHMS174(pRB28). According to Barkay et al. (1997), the results of their experiments show that uncharged mercuric chloride more readily reaches the bacterial cytoplasm than do electrochemically charged forms. It is interesting to note here that the results of Mason et al. (1996) suggest that $91 \%$ of inorganic mercury, presumably $\mathrm{HgCl}_{2}$, was present in the cell membranes of the marine diatoms used in their studies. On the other hand, the results of Barkay et al. (1997) suggest that $\mathrm{HgCl}_{2}$ was entering the cytoplasms of the bacteria used in their research. Thus, uptake of inorganic mercury via passive diffusion may result in a type of equilibrium concentration of mercury between the cytoplasm and the cell membrane of a cell.

Barkay et al. (1997) also studied how DOC affected mer-lux induction, and thus light output, from the bacteria used in their experiments, and the researchers expressed their results as percent induction of a no-DOC control at two different pHs: $\mathrm{pH} 7$ and $\mathrm{pH} 5$. The researchers Barkay et al. (1997) discuss that the percent induction decreased much more at $\mathrm{pH} 7$ than at $\mathrm{pH} 5$, and state that the results of their experiments suggest that DOC reduces the bioavailability of $\mathrm{Hg}(\mathrm{II})$. Moreover, Barkay et al. (1997) state that this reduction in bioavailability is more pronounced under neutral (such as $\mathrm{pH}$ 7) than under acidic (such as $\mathrm{pH}$ 5) conditions.

Zhong and Wang (2009) conducted research on the effects of DOC and chloride on uptake of inorganic mercury ( $\mathrm{Hg}(\mathrm{II})$ ) and methylmercury $(\mathrm{MeHg}$ ) by the marine diatom Thalassiosira pseudonana. The researchers Zhong and Wang (2009) tested the effects of 
DOC by using seawater from three different sites, specifically Clearwater Bay $(\mathrm{CW})$, Tolo Harbor (TH), and Yuen Long (YL) in Hong Kong. Zhong and Wang (2009) state that, in their experiments, they found that the uptake of $\mathrm{Hg}(\mathrm{II})$ or $\mathrm{MeHg}$ was generally inhibited by the presence of DOC from each of the three types of seawater samples, especially for $\mathrm{Hg}(\mathrm{II})$, depending on the quantity of the DOC. Additionally, Zhong and Wang (2009) tested the effect of eliminating the DOC in the seawater samples by UV light, and observed that uptake of $\mathrm{Hg}(\mathrm{II})$ was greatly increased.

Zhong and Wang (2009) also carried out experiments with the diatoms Thalassiosira pseudonana in artificial seawater that contained chloride and DOC that was prepared from diatom decomposition. For these experiments by Zhong and Wang (2009), the DOC prepared from diatom decomposition was tested at concentrations of $1 \mu \mathrm{M}$ and $100 \mu \mathrm{M}$ and chloride was tested at concentrations of $0.20 \mathrm{M}$ and $0.52 \mathrm{M}$. Zhong and Wang (2009) observed that the only case where lower chloride levels $(0.2 \mu \mathrm{M})$ were associated with greater $\mathrm{Hg}(\mathrm{II})$ uptake was in the solutions with little DOC $(1 \mu \mathrm{M})$ prepared from diatom decomposition. Zhong and Wang (2009) state that this result is possibly due to the dominance of $\mathrm{Hg}(\mathrm{II})-\mathrm{Cl}$ species and to an increase of neutral $\mathrm{Hg}(\mathrm{II})$ species (such as $\mathrm{HgCl}_{2}$ ) in solution with decreasing chloride concentration, which may presumably mean that the researchers suggest passive diffusion as the mechanism for uptake of mercury, at least in these assays.

From the results of their experiments, Zhong and Wang (2009) compared the uptake rates of $\mathrm{Hg}(\mathrm{II})$ and $\mathrm{MeHg}$ and found that the uptake of $\mathrm{MeHg}$ at $1 \mu \mathrm{M}$ DOC (prepared by 
diatom decomposition) was triple that at $100 \mu \mathrm{M}$ DOC (prepared from diatom decomposition). In addition, Zhong and Wang (2009) also found that $\mathrm{Hg}(\mathrm{II})$ uptake was significantly higher for the samples with DOC prepared from diatom decomposition than with $\mathrm{DOC}$ from natural seawater when the $\mathrm{Cl}$ concentration was comparable in both samples. From these results, Zhong and Wang (2009) discuss that the origin of the DOC can affect $\mathrm{Hg}(\mathrm{II})$ uptake. As is seen in the results of Zhong and Wang (2009), increased DOC concentration in the different natural seawater samples resulted in lower internalization rates of $\mathrm{Hg}(\mathrm{II})$ by Thalassiosira pseudonana, whereas increased DOC concentration prepared from diatom decomposition in artificial seawater, at a chloride concentration of $0.52 \mathrm{M}$, resulted in faster internalization rates of $\mathrm{Hg}$ (II), but not $\mathrm{MeHg}$, by Thalassiosira pseudonana.

Benoit et al. (1999) researched mercury bioavailability with a focus on mercury sulfide species and state that they developed a model to explain observed relationships between pore water sulfide, dissolved inorganic $\mathrm{Hg}\left(\mathrm{Hg}_{\mathrm{D}}\right)$, and bulk methylmercury $(\mathrm{MeHg})$ in surficial sediments in two biogeochemically different ecosystems, the Florida Everglades and in the Patuxent River, MD.

Benoit et al. (1999) suggested that the neutral mercury sulfide species $\mathrm{HgS}^{0}$ is the dominant neutral dissolved complex in sulfidic sediments and that the concentration of this complex affected biological processes such as mercury uptake and mercury methylation by cells. Benoit et al. (1999) developed a chemical equilibrium model for mercury complexation, where equilibrium speciation calculations were carried out by the 
$\mathrm{MINEQL}^{+}$program. Benoit et al. (1999) found from their model some correlation between the concentrations of bulk methylmercury and dissolved neutral $\mathrm{Hg}$ in pore waters, with a $\mathrm{r}^{2}=0.50$ for the model applied to the Patuxent River and $\mathrm{a}^{2}=0.59$ for the model applied to the Florida Everglades. Although the model by Benoit et al. (1999) does not have a relatively high value for $\mathrm{r}^{2}$, their model does show some compelling evidence that sulfide does indeed play an important role in the uptake and methylation of mercury by cells. Of their own model, Benoit et al. (1999) state that their model was able to reproduce observed $\mathrm{Hg}_{\mathrm{D}}$ and bulk $\mathrm{MeHg}$ trends in the two ecosystems that they studied, and that their model is consistent with $\mathrm{HgS}^{0}$ as the dominant neutral complex in sulfidic pore waters. In the work of Benoit et al. (1999), the two ecosystems are biogeochemically different, as the researchers stated, and it is interesting to note that their model was able to reproduce with relative accuracy the data observed from the two ecosystems.

\section{Research Suggesting Mercury Uptake by Cells via Active/Facilitated Transport}

Schaefer and Morel (2009) conducted research with mercury uptake by the bacteria Geobacter sulfurreducens, which is known to methylate mercury. Schaefer and Morel (2009) state that their results suggest that mercury uptake and methylation by microbes are controlled more tightly by biological mechanisms than previously thought. It seems implied that, from the results of Schaefer and Morel (2009), the researchers suggest that mercury uptake may be a facilitated process, or at least that a combination of facilitated processes and passive diffusion of mercury may be mechanisms for mercury uptake by bacteria. 
Schaefer and Morel (2009) studied the effects of several inorganic compounds and organic compounds, including cysteine, on mercury methylation by the bacteria $G$. sulfurreducens and found that adding cysteine to the medium in which the bacteria were present increased the rate of mercury methylation fifty times compared to the methylation rate in control bottles.

In part of their experiments, Schaefer and Morel (2009) tested how chloride $\left(\mathrm{Cl}^{-}\right)$ concentrations and cysteine concentrations affected methylmercury production rate by cells: cysteine concentrations were tested between $1 * 10^{-6} \mathrm{M}$ and $1 * 10^{-7} \mathrm{M}$, and chloride concentrations up to $0.03 \mathrm{M}$. As the researchers Schaefer and Morel (2009) discuss, the effect of cysteine on mercury methylation is presumably caused by the formation of a $\mathrm{Hg}$ (II)-cysteine complex, and if this complex enters the cells more easily than other complexes, altering the speciation of the medium by adding a competing ligand, such as $\mathrm{Cl}^{-}$, should be able to out-compete cysteine for binding to mercury and cause the mercury methylation rate to change. From the results of the experiments by Schaefer and Morel (2009), the researchers state that, as expected, the methylation rate decreased systematically at increasing $\mathrm{Cl}^{-}$concentrations.

Schaefer and Morel (2009) also discuss the applicability of their results, and appear to suggest that facilitated processes of mercury uptake by cells, rather than passive diffusion of mercury species through cell membranes, may be the mechanisms by which $G$. sulfurreducens, and possibly other microorganisms, take up mercury from the environment. Moreover, the researchers Schaefer and Morel (2009) state that elucidating 
such processes should provide novel mechanistic insights into the factors that control the methylation of mercury in the environment.

The researchers Golding et al. (2002) conducted research on mercury uptake by the bacteria species Vibrio anguillarum and Escherichia coli. The strains of E. coli used by Golding et al. (2002) were the same used by Barkay et al. (1997), namely Escherichia coli HMS174(pRB28) and Escherichia coli HMS174(pRB27). Golding et al. (2002) state that, in order to create a bioreporter suitable for the study of mercury uptake in natural waters, the mer-lux plasmid, pRB28, and its constitutively expressed derivative, pRB27, were transferred from the bacteria species Escherichia coli HMS174 (see reference within Golding et al., 2002) to $V$. anguillarum ATCC 14181 (see reference within Golding et al., 2002), a natural aquatic species.

Golding et al. (2002) tested different assay media in which the speciation of mercury was different to verify how the speciation of mercury affected uptake by the bacteria. Five different assay media were prepared by Golding et al. (2002), and each medium had a different calculated dominant mercury species. In the research of Golding et al. (2002), the mercury species $\mathrm{Hg}(\mathrm{OH})_{2}$ and $\mathrm{Hg}\left(\mathrm{NH}_{3}\right)_{2}{ }^{2+}$ dominated the calculated speciation in their assay medium labeled "B" at percentages of $59 \%$ and $32 \%$, respectively; in addition, the mercury species $\mathrm{HgCl}_{2}$ and $\mathrm{HgOHCl}$ dominated the calculated mercury speciation in their assay medium labeled " $\mathrm{C}$ " at percentages of $60 \%$ and $28 \%$, respectively; furthermore, the mercury species $\mathrm{Hg}\left(\mathrm{NH}_{3}\right)_{2}{ }^{2+}$ dominated the speciation in their assay medium labeled "D" at a percentage of $98 \%$. 
Golding et al. (2002) discuss the results of their research and state that the $\mathrm{Hg}$ (II)-induced response was not proportional to the concentrations of neutral mercury species $\mathrm{HgCl}_{2}$ and $\mathrm{Hg}(\mathrm{OH})_{2}$ in the bulk solution, which would presumably be entering the cells through passive diffusion, and was also not proportional to the concentration of $\mathrm{Hg}\left(\mathrm{NH}_{3}\right)_{2}{ }^{2+}$. On the other hand, Golding et al. (2002) state that at high $\mathrm{Hg}$ concentrations, the bioreporter response was generally proportional to the total mercury concentration in the bulk solution and was the same in medium B and medium C. This finding by Golding et al. (2002) shows that in a medium where one of the dominant mercury species is charged (medium B), the mercury uptake is comparable to a medium where the main dominant mercury species are uncharged (medium $\mathrm{C}$ ), which may suggest that facilitated uptake of charged mercury species, such as $\mathrm{Hg}\left(\mathrm{NH}_{3}\right)_{2}{ }^{2+}$, may be a possible route of mercury uptake by cells.

Golding et al. (2002) discuss some of the limitations of their results and state that there is some uncertainty in the speciation calculations used to calculate the dominant mercury species in their media. Golding et al. (2002) discuss the possible changes in calculated mercury speciation if the stability constants are smaller, which would result in little change in $\mathrm{Hg}$ speciation, or greater, which would result in significant change in speciation. However, Golding et al. (2002) state that even if the stability constants are two orders of magnitude greater, their assay medium $\mathrm{C}$ would still have neutral mercury complexes $\left(\mathrm{HgCl}_{2}\right.$ and $\left.\mathrm{HgOHCl}\right)$ as the dominant mercury species in solution, and medium B and medium D would be dominated by charged complexes. Thus, the result discussed here by Golding et al. (2002) suggests that passive diffusion of neutral mercury 
complexes is not the only mechanism of mercury uptake by the bacteria cells used in their research. Furthermore, Golding et al. (2002) discuss that G. sulfurreducens is a gram-negative bacteria and many methylating bacteria are also gram-negative, implying that the results of their research may be applied to other bacteria.

Kelly et al. (2003) performed experiments to determine the effect of pH on mercury uptake by the bacteria strains Vibrio anguillarum (ATCC 14181) pRB28 and Vibrio anguillarum pRB27. The mer-lux bioreporter used by Kelly et al. (2003) with the bacteria Vibrio anguillarum is the same mer-lux bioreporter used in the research of Barkay et al. (1997) with the bacteria Escherichia coli and in the research of Golding et al. (2002) with both Vibrio anguillarum and Escherichia coli.

Kelly et al. (2003) found that as $\mathrm{pH}$ decreased, a large increase in bioreporter response was observed, and found that over the $\mathrm{pH}$ range tested, the bioreporter response was linearly related to the $\mathrm{H}^{+}$concentration. Kelly et al. (2003) also tested the effect of adding $\mathrm{NaCl}$ to some of their assay media at a final concentration of $1.7 \mathrm{mmol} / \mathrm{L}$, which was expected to shift the speciation of mercury in the assay media to the neutral mercury species $\mathrm{HgCl}_{2}$. In these experiments, Kelly et al. (2003) found that there was no statistical difference $(P=0.275)$ between the slopes of the regression lines for the assays that were run with adding $\mathrm{NaCl}$ and assays in which $\mathrm{NaCl}$ was not added, using a heterogeneity of slopes test. 
Kelly et al. (2003) further discuss the speciation of mercury in their different assay media and state that $\mathrm{HgCl}_{2}$ was an important species in the assays where $1.7 \mathrm{mmol} / \mathrm{L} \mathrm{NaCl}$ was added, and neutral $\mathrm{Hg}(\mathrm{OH})_{2}$ was the other important mercury species present in solution. In the experiments by Kelly et al. (2003), $\mathrm{HgCl}_{2}$ was present in an insignificant concentration in the assay media that had no added $\mathrm{NaCl}$, and $\mathrm{Hg}(\mathrm{OH})_{2}$ appeared to be a dominant species at all $\mathrm{pH}$ in these assay media. It is interesting to note that, from Mason et al. (1996), the octanol-water partition coefficient $\left(\mathrm{K}_{\mathrm{ow}}\right)$ of $\mathrm{Hg}(\mathrm{OH})_{2}$ was reported to be 0.05 , and that of $\mathrm{HgCl}_{2}$ was found to be 3.3, thus the $\mathrm{K}_{\mathrm{ow}}$ of $\mathrm{Hg}(\mathrm{OH})_{2}$ is on the order of 75 times smaller than that of $\mathrm{HgCl}_{2}$. Nonetheless, Kelly et al. (2003) still found comparable rates of mercury uptake at the two different concentrations of $\mathrm{NaCl}$, where either $\mathrm{Hg}(\mathrm{OH})_{2}$ or $\mathrm{HgCl}_{2}$ dominated the speciation, which may suggest that other mercury species, possibly including charged mercury species, are being taken up by the microorganisms in their experiments, potentially via facilitated uptake and/or passive diffusion of mercury species through the cell membranes of the microorganisms.

From their experiments, Kelly et al. (2003) discuss that it did not appear that diffusion of the relatively lipophilic mercury species $\mathrm{HgCl}_{2}$ and $\mathrm{Hg}(\mathrm{OH})_{2}$ across the cell membrane was the mechanism for $\mathrm{Hg}$ (II) uptake in the cells, nor did it appear that $\mathrm{Hg}$ (II) uptake was controlled in any obvious way by bulk solution speciation of mercury. Furthermore, Kelly et al. (2003) discuss that their work confirms the previous work of Golding et al. (2002), which showed that $\mathrm{Hg}(\mathrm{II})$ uptake by the same species of bacteria appeared to be controlled by the collective concentrations of various available charged and uncharged 
$\mathrm{Hg}$ (II) species, and Kelly et al. (2003) discuss that this is evidence that a cell-mediated process is important in determining how much $\mathrm{Hg}(\mathrm{II})$ enters the cell.

Kelly et al. (2003) also conducted experiments to test bioreporter response in DOC concentrate from L. 240 (presumably "L." stands for Lake) from the Experimental Lakes Area in northwestern Ontario at different added concentrations of mercury and different pHs. Kelly et al. (2003) also conducted experiments to test bioreporter response in whole lake water from L. 658 from the Experimental Lakes Area in northwestern Ontario at different added concentrations of mercury and different pHs. Kelly et al. (2003) discuss some of the results of their DOC experiments and found that the ratio of $\mathrm{Hg}$ to DOC was important in determining whether $\mathrm{Hg}(\mathrm{II})$ uptake was detectable, via bioreporter response, or not. Kelly et al. (2003) state that $\mathrm{Hg}$ (II) uptake was easily detectable in their experiments when $\mathrm{Hg}$ concentration was $2 \mathrm{ng} \mathrm{Hg} / \mathrm{L}$ and the DOC concentration was 85 $\mu \mathrm{mol} \mathrm{C/L}$, while the researchers found that $\mathrm{Hg}(\mathrm{II})$ uptake was barely detectable when $\mathrm{Hg}$ concentration was $3 \mathrm{ng} \mathrm{Hg} / \mathrm{L}$ and the DOC concentration was $780 \mu \mathrm{mol} \mathrm{C} / \mathrm{L}$.

From the data of Kelly et al. (2003), it appears that, for the experiments that the researchers conducted with whole lake water, specifically L. 658 water, the bioreporter response is highest at a low $\mathrm{pH}$ and at a higher $\mathrm{Hg}$ to DOC ratio. Kelly et al. (2003) discuss that they believe that, in aerobic surface waters, the $\mathrm{Hg}: \mathrm{DOC}$ ratio and the $\mathrm{pH}$ are both factors that should be considered important factors in predicting $\mathrm{Hg}$ (II) uptake by bacteria. Moreover, Kelly et al. (2003) state that a link between lake acidification and elevated concentrations of mercury in fish is well established (see references within Kelly 
et al., 2003). This link between lake acidification and elevated levels of mercury in fish appears to be further supported by the results of Kelly et al. (2003), which show that the bioreporter response to mercury uptake by the bacteria in their research was greater at lower $\mathrm{pH}$ values (higher acidity) for the same $\mathrm{Hg}$ concentration and $\mathrm{DOC}$ concentration than at higher $\mathrm{pH}$ values (lower acidity).

Najera et al. (2005) researched mercury uptake by biofilms, which are attached communities of bacteria (Najera et al., 2005, and reference therein), and planktonic cells. In their research, Najera et al. (2005) state that they used the bacteria strain Escherichia coli $\mathrm{O} 55$ as a model Gram-negative organism to study $\mathrm{Hg}(\mathrm{II})$ uptake in biofilms and planktonic cultures since many of the methylating bacteria, such as sulfate-reducing bacteria (SRB), are also Gram-negative. Najera et al. (2005) discuss that, to date (2005), all of the work concerning mercury uptake of specific $\mathrm{Hg}$ (II) species had been done with batch planktonic cultures (see references within Najera et al., 2005). Najera et al. (2005) continue to state that, however, it is now well-established that the majority of bacteria in the environment live in attached communities, or biofilms (see reference within Najera et al., 2005). Therefore, it is interesting to note that the research of Najera et al. (2005) was conducted with planktonic cultures and biofilms.

Najera et al. (2005) tested how mercury speciation affected mercury uptake by planktonic cells, and found evidence for both passive diffusion of mercury species and facilitated uptake of mercury species by planktonic cells. To study mercury uptake by cells, Najera et al. (2005) used toxicity as a surrogate for mercury uptake. Najera et al. (2005) state 
that the data from their study demonstrate that the toxicity of $\mathrm{Hg}(\mathrm{II})$ to $E$. coli is strongly influenced by the $\mathrm{Hg}$ chemical speciation in the growth medium for both planktonic and biofilm cultures.

Najera et al. (2005) state that, in planktonic cultures, a strong linear relationship between cells viability reduction (toxicity) and $\mathrm{HgCl}_{2}$ estimated uptake was reached when $\mathrm{Hg}$ chloro complexes were the dominant species, from 10 to $200 \mathrm{mM}$ chloride concentration, with a $\mathrm{R}^{2}=0.976$. Moreover, Najera et al. (2005) found that the maximum reduction in cells viability occurred at a chloride concentration range of 10 to $100 \mathrm{mM}$ chloride, a concentration range in which the dominant calculated mercury species is $\mathrm{HgCl}_{2}$. Najera et al. (2005) furthermore state that their data show a marked decrease in the toxicity of mercury at $200 \mathrm{mM}$ chloride, which the researchers calculated to be a concentration in which the calculated mercury speciation shifts such that the dominant species of mercury are the negatively charged $\mathrm{Hg}$-chloro complexes $\mathrm{HgCl}_{3}{ }^{-}$and $\mathrm{HgCl}_{4}{ }^{2-}$. Najera et al. (2005) note that the reduced observed uptake of mercury to bacteria in these experiments at high chloride concentrations may be one reason to explain why lower methylation rates and methyl- $\mathrm{Hg}$ accumulation are generally reported in estuarine and marine systems (see reference within Najera et al., 2005). Furthermore, Najera et al. (2005) state that, from some of the results of their experiments, mercury uptake at high chloride concentrations appears to have the characteristics of passive diffusion.

In addition, Najera et al. (2005) conducted a set of experiments that also showed facilitated uptake as a possible mercury uptake mechanism by bacteria. Najera et al. 
(2005) observed a significant reduction in cells viability when the charged mercury species $\mathrm{Hg}\left(\mathrm{NH}_{3}\right)_{2}{ }^{2+}$ was calculated to dominate the speciation in the assay media. Najera et al. (2005) discuss that uptake of $\mathrm{Hg}$ as a positively charged complex appears important and may indicate a facilitated uptake of this species (see reference within Najera et al., 2005).

Simple Model for Mercury Uptake and Accumulation by Bacteria

As has been described in the previous two sections, compelling evidence exists for passive diffusion of mercury to cells (Mason et al., 1996; Barkay et al. 1997; Zhong and Wang, 2009; Benoit et al., 1999) and for active/facilitated uptake of mercury by bacteria (Schaefer and Morel, 2009; Golding et al., 2002; Kelly et al., 2003; Najera et al., 2005), and possibly for a combination of both mechanisms. To model passive diffusion of neutral mercury species, a model can include the uptake of neutral species such as $\mathrm{HgCl}_{2}$ and $\mathrm{Hg}(\mathrm{OH})_{2}$, discussed above, as well as $\mathrm{HgS}^{0}$, which is discussed in the work of Benoit et al. (1999), Benoit et al. (2001a), and Benoit et al. (2001b). Also, Miller et al. (2007) discuss the hydrophobicity of multiple mercury species, including $\mathrm{Hg}(\mathrm{HS})_{2}$, so this mercury species may also possibly be taken up by bacteria via passive diffusion. To model passive diffusion, the equations used are the same as those presented by the researchers Mason et al. (1996). The work of Mason et al. (1996) is discussed in more detail in the present research in the chapter entitled Modeling Mercury Uptake by Cells.

Morel et al. (1991) conducted research to determine kinetics of trace metal uptake by phytoplankton and concentrations at which trace metals, such as $\mathrm{Fe}, \mathrm{Zn}, \mathrm{Mn}$, and $\mathrm{Ni}$, 
limit the growth of phytoplankton. Morel et al. (1991) state that it appears that the uptake of all necessary trace metals by phytoplankton occurs via binding to a surface ligand and subsequent transfer across the cell membrane. Morel et al. (1991) state that the result is the well-known Michaelis-Menten uptake kinetics, a hyperbolic rate law in which uptake rate $(\rho)$ is proportional to the reactive substrate [M] at low concentrations and reaches a maximum $\left(\rho_{\max }\right)$ at concentrations that exceed the "half-saturation constant" $K_{\rho}$. It is possible that mercury is taken up via facilitated uptake mechanisms that follow the Michaelis-Menten enzyme kinetics applied to trace metal uptake. This is an assumption in the present research. Michaelis-Menten enzyme kinetics applied to trace metal uptake, as discussed by Morel et al. (1991) and Stumm and Morgan (1996), are discussed in more detail in the present research in the chapter entitled Modeling Mercury Uptake by Cells.

To create a simple model for mercury uptake, thus, the processes of passive diffusion of neutral mercury species must be considered along with the processes of active/facilitated uptake of additional mercury species. In the present research, it is assumed that only positively-charged and neutral mercury species can be taken up via facilitated uptake, although it is possible that negatively-charged mercury species may be taken up via active/facilitated uptake processes. This simplification is discussed in more detail in the present research in Chapter V. 


\section{RESEARCH HYPOTHESES}

\section{Different Forms of Mercury}

In the present research, it was hypothesized that mercury uptake by bacteria is higher for mercury species with smaller stability constants than for mercury species with greater stability constants.

The laboratory experiments were designed to test the rate of uptake of two different forms of mercury, specifically neutral mercury chloride $\left(\mathrm{HgCl}_{2}\right)$ and mercury bound to natural organic matter ( $\mathrm{Hg}-\mathrm{NOM})$, by the same strain of sulfate-reducing bacteria, Desulfovibrio desulfuricans G20. In addition, the laboratory experiments were also designed to test how sulfide, which affects the speciation of mercury in solution, could also affect the rate of uptake of mercury by bacteria in the test solutions. This would be carried out by performing two sets of experiments: in the first set, bacteria would be in a solution with lactate and sulfate in which the bacteria could reduce sulfate to sulfide (thus sulfide would be expected to be present), and in the second set, bacteria would be in a solution with pyruvate and fumarate.

It was anticipated that the most mercury uptake by bacteria would be observed in the solutions containing pyruvate and fumarate, in which mercury had been spiked as mercury chloride $\left(\mathrm{HgCl}_{2}\right)$. In addition, some mercury uptake was expected to occur in the pyruvate/fumarate solutions spiked with $\mathrm{Hg}-\mathrm{NOM}$, though less than in the pyruvate/fumarate solutions spiked with $\mathrm{HgCl}_{2}$. Because the pyruvate/fumarate solutions 
would not contain sulfide species (such as the bisulfide ion, HS), which could bind with mercury and form relatively stable mercury sulfide complexes and/or solid mercury sulfide precipitates, more mercury uptake in these solutions was expected.

It has been assumed in the present research that $\mathrm{Hg}-\mathrm{NOM}$ complexes are relatively large because of the heterogeneity of NOM discussed by Miller et al. (2009). Because Miller et al. (2009) report a range of relatively large values for the thermodynamic equilibrium constants for the formation of different types of $\mathrm{Hg}$-NOM complexes (see Supporting Information to Miller et al., 2009, and references therein), it is also expected that $\mathrm{Hg}$ NOM complexes do not dissociate easily, and potentially would not bind as easily to the surfaces of cells or to intracellular substances. Therefore, it was also expected that less mercury uptake by bacteria would be observed in experiments with mercury spiked as Hg-NOM.

\section{Stability Constants}

In the present research, it was then anticipated that mercury uptake by bacteria would be decreased for mercury species with higher stability constants (thermodynamic equilibrium constants for their formation) than for mercury species with smaller stability constants. Whether or not a chemical species is present at a relatively high concentration in a solution depends not only on the stability constant for that species, but also on the concentration of the species in solution, the concentrations of other species in solution, the temperature, the $\mathrm{pH}$, and the ionic strength of a solution, the kinetics of the reactions occurring in the solution, and other parameters. Thus, it is apparent that many factors can 
influence which species are present in a solution, and this also affects how bacteria can take up chemical species in a solution. Nonetheless, the stability constant of a mercury species provides a measure of the stability and the relative concentration of the species in a solution at equilibrium.

\section{Possible Effects of NOM on Mercury Uptake by Bacteria}

Dong et al. (2010) researched the speciation of mercury with natural dissolved organic matter (DOM) in the contaminated East Fork Poplar Creek (EFPC) in Oak Ridge, Tennessee. Using the aqueous geochemical modeling software PHREEQC, Dong et al. (2010) found that DOM, even at low concentration $\left(\sim 3 \mathrm{mg} \mathrm{L}^{-1}\right)$, strongly complexes with mercury by forming strong $\mathrm{Hg}-\mathrm{DOM}$ and $\mathrm{CH}_{3} \mathrm{Hg}$-DOM complexes, and Dong et al. (2010) state that these complexes are formed through the reactive sulfur or thiol-like functional groups in DOM in the contaminated EFPC. However, in their modeling, Dong et al. (2010) state that they did not consider dissolved sulfide because of the relatively high levels of dissolved oxygen ( $\left.>8 \mathrm{mg} \mathrm{L}^{-1}\right)$ and redox potential $(\sim 96$ to $226 \mathrm{mV})$ in the creek, in which dissolved sulfide species would not be stable (see reference within Dong et al., 2010). Dong et al. (2010) also discuss that, in water from the East Fork Poplar Creek, the estimated concentration of $\mathrm{Hg}-\mathrm{DOM}$ complexes is at least six orders of magnitude higher than other inorganic $\mathrm{Hg}^{2+}$ complexes, such as $\mathrm{Hg}(\mathrm{OH})_{2}, \mathrm{HgOHCl}$, and $\mathrm{HgCl}_{2}$.

Miller et al. (2009) performed kinetics experiments with mercury bound to different organic compounds and NOM, and found that over time, it appeared that mercury bound 
to NOM was transferring from inorganic and reducible $\mathrm{Hg}-\mathrm{NOM}$ complexes, to stronger hydrophobic/nonreducible Hg-NOM complexes. Miller et al. (2009) also reported for their research that in solutions of $\mathrm{Hg}$ and NOM that had equilibrated for at least 24 hours, only $11 \%$ of $\mathrm{Hg}$ in solution was present as reducible $\mathrm{Hg}\left(\mathrm{Hg}_{\mathrm{R}}\right)$.

In the present research, for the purpose of testing a simple model for mercury uptake, it was assumed that only the reducible fraction of $\mathrm{Hg}$ on $\mathrm{Hg}-\mathrm{NOM}$ complexes was available for uptake by bacteria. As discussed above, Miller et al. (2009) observed in their research that in solutions of $\mathrm{Hg}$ and NOM that had equilibrated for at least 24 hours, only $11 \%$ of the $\mathrm{Hg}$ was present as reducible $\mathrm{Hg}$. Thus, because the $\mathrm{Hg}-\mathrm{NOM}$ stock solutions used in the laboratory experiments of the present research had equilibrated for at least 24 hours (before being used in the laboratory experiments to spike mercury into the test solutions containing bacteria), it is assumed that the reducible fraction of $\mathrm{Hg}$ in the $\mathrm{Hg}-\mathrm{NOM}$ stock solutions is $11 \%$. It is acknowledged that this may be an oversimplification, but this assumption is made as a first approximation. 


\section{RESEARCH OBJECTIVES}

The main objective of the present research was to determine how different forms of mercury in solution affect the uptake rate and overall uptake of mercury by a strain of sulfate-reducing bacteria. The strain of sulfate-reducing bacteria (SRB) used in this research was Desulfovibrio desulfuricans G20, which is not known to be able to produce methylmercury from mercury (Elias, personal communication, 2010). For the laboratory experiments in the present research, each test solution was spiked with one of two different forms of mercury, either mercury chloride $\left(\mathrm{HgCl}_{2}\right)$ or mercury bound to natural organic matter $(\mathrm{Hg}-\mathrm{NOM})$, to determine the uptake rate and overall uptake of mercury by bacteria in each test solution. Moreover, to determine the effect of sulfide $\left(\mathrm{S}^{2-}\right)$ in solution on uptake rate and overall uptake of mercury, some test solutions contained lactate and sulfate. Some of the sulfate in these test solutions was expected to be reduced by the bacteria to sulfide. The other test solutions contained pyruvate and fumarate, which would not contain any sulfide in solution.

A second objective of the present research was to determine if there is a possible relation between the stability constant of a mercury species and the uptake rate and overall uptake of mercury in each solution. The stability constant of each of the various mercury species that were calculated to be present in each test solution may be related to the rate of uptake and overall uptake of mercury by bacteria in each test solution. 
A third objective of the present research was to test a simple model, incorporating the theory of passive diffusion of substances through cell membranes and active/facilitated uptake of substances by cells, to be used to better understand potential processes for mercury uptake by bacteria and possibly other microorganisms. This simple model is based on the results of research by numerous researchers, discussed in more detail in the Introduction in the present research.

The strain of sulfate-reducing bacteria (SRB) Desulfovibrio desulfuricans G20 was used for the present research because mercury uptake, not methylmercury formation, was the focus, and thus the added hazard of methylmercury in test solutions was not necessary. Because different strains of Desulfovibrio desulfuricans are able to methylate mercury, such as D. desulfuricans LS (Pak and Bartha, 1998), the strain D. desulfuricans G20 may possibly be used as a representative species of SRB, and, moreover, the results of the present research may potentially apply to other similar species of SRB.

Compeau and Bartha (1985) found that sulfate-reducing bacteria are the principal methylators of mercury in anoxic estuarine sediment. It has also been discussed by Kerin et al. (2006) that dissimilatory iron-reducing bacteria can also methylate mercury, and Pak and Bartha (1998) showed that methanogens are able to catalyze mercury demethylation. With more knowledge on the factors that may affect uptake rate and overall uptake of mercury by bacteria, remediation strategies for sites that are contaminated with mercury and methylmercury can be improved. 


\section{LABORATORY EXPERIMENTS}

Experimental Plan

The focus of the laboratory experiments was to determine the rates at which two different forms of mercury; mercury bound to natural organic matter ( $\mathrm{Hg}-\mathrm{NOM})$ and mercury chloride $\left(\mathrm{HgCl}_{2}\right)$, were taken up (removed from solution) by a strain of sulfate-reducing bacteria (SRB), Desulfovibrio desulfuricans G20. The general experimental plan consisted of six main steps as follows:

1. Grow an initial culture of Desulfovibrio desulfuricans G20 for approximately 24 hours.

2. Transfer the culture of $D$. desulfuricans G20 to individual test tubes to grow the test tube cultures for 12 to 24 hours.

3. Wash the cultures with an appropriate bicarbonate buffer solution.

4. Spike either $\mathrm{HgCl}_{2}$ or $\mathrm{Hg}-\mathrm{NOM}$ to each washed cell solution.

5. Conduct mercury accumulation rate experiments, sampling washed cell solutions over time.

6. Prepare the samples for analysis.

This experimental plan is summarized into the six major steps in the flow diagram figure below: 


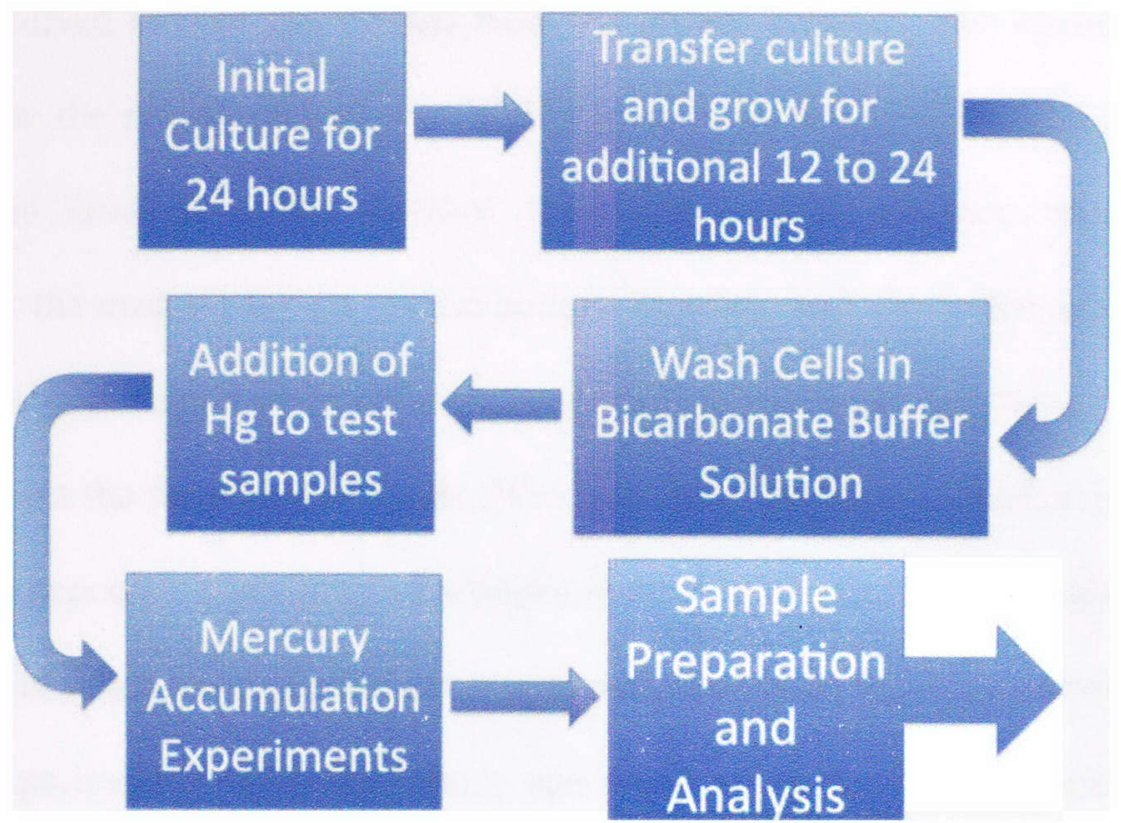

Figure 1: Experimental plan for mercury accumulation rate experiments.

The basic steps of the experimental plan are outlined in the figure above, and are discussed in more detail in the following sections of the present chapter.

Growth Media used to Grow Bacteria

The growth media used to grow sulfate-reducing bacteria (SRB) must contain a variety of substances, including an electron donor and an electron acceptor for the bacteria to be able to conduct their metabolic processes. In the laboratory experiments, two cultures of D. desulfuricans G20 were grown. The medium that was used for the first culture was Wall's Medium (see Appendix A) and the medium was amended with lactate and sulfate as the electron donor and electron acceptor, respectively. In addition, for the medium for the first culture, L-cysteine was added as the reducing agent, which would also help to 
remove dissolved oxygen gas $\left(\mathrm{O}_{2}(\mathrm{~g})\right)$ from the growth medium. The medium that was used to grow the second culture was Wall's Medium (see Appendix A) amended with pyruvate and fumarate as the electron donor and electron acceptor, respectively. In addition, for the medium for the second culture, ascorbic acid was added as the reducing agent, which would also help to remove dissolved $\mathrm{O}_{2}(\mathrm{~g})$ from the medium and would also help to prevent the formation of thiols (Wall and Elias, personal communication, 2010). Thiols are compounds containing a hydrogen ion bound to a sulfide ion, which is $\mathrm{HS}^{-}$, in their chemical structures that could react with mercury during the experiments. Thus, two different experiments, performed about one week apart, were carried out. The first experiment was carried out with the lactate/sulfate culture and the second with the pyruvate/fumarate culture. The recipe for Wall's Medium amended with either lactate and sulfate or pyruvate and fumarate can be found in Appendix A.

\section{Incubation of Bacterial Cultures}

The lactate/sulfate culture was incubated at $33{ }^{\circ} \mathrm{C}$ for approximately 24 hours while gently shaking. After the incubation period, individual $1 \mathrm{~mL}$ samples of the lactate/sulfate culture were transferred to 16 individual test tubes, each already containing $9 \mathrm{~mL}$ of the fresh lactate/sulfate medium, for a final volume of $10 \mathrm{~mL}$, in each test tube, of a culture of $D$. desulfuricans G20 in Wall's Medium amended with lactate and sulfate. The lactate/sulfate test tube cultures were incubated at $33{ }^{\circ} \mathrm{C}$ while being gently shaken for approximately 27 hours. 
The pyruvate/fumarate culture was incubated at $33^{\circ} \mathrm{C}$ for approximately 24 hours while gently shaking. After the incubation period, individual $1 \mathrm{~mL}$ samples of the pyruvate/fumarate culture were transferred to 16 individual test tubes, each already containing $9 \mathrm{~mL}$ of the fresh pyruvate/fumarate medium, for a final volume of $10 \mathrm{~mL}$, in each test tube, of a culture of $D$. desulfuricans G20 in Wall's Medium amended with pyruvate and fumarate. The pyruvate/fumarate test tube cultures were incubated at $33{ }^{\circ} \mathrm{C}$ while being gently shaken for approximately 12 hours. Due to time constraints during the experiments, the pyruvate/fumarate test tube cultures were incubated for less time than the lactate/sulfate cultures.

\section{Preparation of Bicarbonate Buffer Solutions}

Bicarbonate buffer solutions were prepared for the cell washing part of the experiments, which took place after each set of test tube cultures had incubated for the appropriate time. The reason bicarbonate buffer solutions were used, as opposed to phosphate buffer solutions, was based on research by Dong et al. (2010), who reported relatively low stability constants for mercury complexes with carbonate and bicarbonate (see reference within Dong et al., 2010). In the present research, it was expected that mercury bound to bicarbonate or carbonate would be in very low concentration in the test solutions.

Two different bicarbonate buffer solutions were prepared. For the lactate/sulfate cultures, the bicarbonate buffer solution contained 30 millimolar (mM) sodium bicarbonate $\left(\mathrm{NaHCO}_{3}\right), 60 \mathrm{mM}$ lactate, and $30 \mathrm{mM}$ sulfate. The lactate/sulfate bicarbonate buffer solution was then $\mathrm{pH}$-adjusted to a $\mathrm{pH}$ of approximately 6.8 by adding 4 normal $(4 \mathrm{~N})$ 
$\mathrm{HCl}$ drop-wise until the $\mathrm{pH}$ of the buffer solution reached $\mathrm{pH}$ 6.8. For the pyruvate/fumarate cultures, the bicarbonate buffer solution contained $28.3 \mathrm{mM} \mathrm{NaHCO}_{3}$, $56.6 \mathrm{mM}$ pyruvate, $56.6 \mathrm{mM}$ fumarate, and $0.94 \mathrm{mM}$ ascorbic acid. Ascorbic acid can be added to the bicarbonate buffer solution to prevent the formation of thiols (Wall and Elias, personal communication, 2010). The pyruvate/fumarate bicarbonate buffer solution was then $\mathrm{pH}$-adjusted to a $\mathrm{pH}$ of approximately 6.8 by adding $4 \mathrm{~N} \mathrm{HCl}$ drop-wise until the $\mathrm{pH}$ of the buffer solution reached $\mathrm{pH}$ 6.8. The reason that the concentrations of components in the pyruvate/fumarate bicarbonate buffer solution were not round numbers was because fumarate was added to the pyruvate/fumarate bicarbonate buffer solution after adjusting the volume of the pyruvate/fumarate bicarbonate buffer solution.

\section{Preparation of Mercury Stock Solutions}

Dr. Carrie Miller donated a stock solution of mercury and a stock solution of Suwannee River natural organic matter (SR NOM), both of which were used in the preparation of the mercury stock solutions in the present research. Miller (2006) states that Suwannee River natural organic matter is a freeze dried isolate collected using reverse osmosis resulting in a sample containing hydrophobic humic and fulvic acids, along with other soluble organics. Miller (2006) obtained SR NOM from the International Humic Substances Society (IHSS). A more detailed description of SR NOM is given in Miller (2006) and in the IHSS website (International Humic Substances Society, 2011). 
For all cultures, the mercury stock solutions, which were to be used for the mercury spikes in each test tube culture, were prepared at least 24 hours in advance of the mercury accumulation rate experiments. This was done to allow the mercury to equilibrate for at least 24 hours in each stock solution before using the stock solutions for the mercury spikes into the washed cell solutions.

For the lactate/sulfate test tube cultures, the $\mathrm{HgCl}_{2}$ stock solution was prepared by adding approximately $1.17 \mathrm{~mL}$ of $10 \% \mathrm{NaCl}$ stock solution to approximately $18.8 \mathrm{~mL}$ of the lactate/sulfate bicarbonate buffer solution, followed by adding $50 \mu \mathrm{L}$ of $\mathrm{Hg}$ stock solution (40 $\mu \mathrm{g} \mathrm{Hg} / \mathrm{mL}$ ). The lactate/sulfate $\mathrm{HgCl}_{2}$ stock solution contained a final $\mathrm{Cl}^{-}$ concentration of approximately $0.1 \mathrm{M}$ and a final $\mathrm{Hg}$ concentration of approximately 100 ng $\mathrm{Hg} / \mathrm{mL}$.

For the lactate/sulfate test tube cultures, the $\mathrm{Hg}-\mathrm{NOM}$ stock solution was prepared by adding approximately $1 \mathrm{~mL}$ of SR NOM stock solution to approximately $19 \mathrm{~mL}$ of the lactate/sulfate bicarbonate buffer solution, followed by adding $50 \mu \mathrm{L}$ of $\mathrm{Hg}$ stock solution (40 $\mu \mathrm{g} \mathrm{Hg} / \mathrm{mL}$ ). The lactate/sulfate $\mathrm{Hg}-\mathrm{NOM}$ stock solution contained a final NOM concentration of approximately $5 \mathrm{mg}$ of carbon per Liter of solution $(\mathrm{mg} \mathrm{C} / \mathrm{L})$ and a final $\mathrm{Hg}$ concentration of $100 \mathrm{ng} \mathrm{Hg} / \mathrm{mL}$.

For the pyruvate/fumarate test tube cultures, the $\mathrm{HgCl}_{2}$ stock solution was prepared by adding approximately $1 \mathrm{~mL}$ of $10 \% \mathrm{NaCl}$ stock solution to approximately $19 \mathrm{~mL}$ of the bicarbonate buffer solution, which had been amended with pyruvate and ascorbic acid, but not yet with fumarate, then adding $1.2 \mathrm{~mL}$ of $1 \mathrm{M}$ fumarate, followed by adding $50 \mu \mathrm{L}$ 
of $\mathrm{Hg}$ stock solution $\left(40 \mu \mathrm{g} \mathrm{Hg} / \mathrm{mL}\right.$ ). The pyruvate/fumarate $\mathrm{HgCl}_{2}$ contained a final $\mathrm{Cl}^{-}$ concentration of about $0.08 \mathrm{M}$ and a final $\mathrm{Hg}$ concentration of about $94 \mathrm{ng} \mathrm{Hg} / \mathrm{mL}$.

For the pyruvate/fumarate test tube cultures, the $\mathrm{Hg}$-NOM stock solution was prepared by adding approximately $1 \mathrm{~mL}$ of SR NOM stock solution to approximately $19 \mathrm{~mL}$ of the bicarbonate buffer solution, which had been amended with pyruvate and ascorbic acid but not yet with fumarate, then adding $1.2 \mathrm{~mL}$ of $1 \mathrm{M}$ fumarate, followed by adding $50 \mu \mathrm{L}$ of $\mathrm{Hg}$ stock solution $(40 \mu \mathrm{g} \mathrm{Hg} / \mathrm{mL}$ ). The pyruvate/fumarate $\mathrm{Hg}-\mathrm{NOM}$ stock solution contained a final NOM concentration of about $4.7 \mathrm{mg} \mathrm{C} / \mathrm{L}$ and a final $\mathrm{Hg}$ concentration of about $94 \mathrm{ng} \mathrm{Hg} / \mathrm{mL}$.

For the lactate/sulfate $\mathrm{HgCl}_{2}$ stock solution and the lactate/sulfate $\mathrm{Hg}-\mathrm{NOM}$ stock solution, the equilibration time was approximately 31 hours. For the pyruvate/fumarate $\mathrm{HgCl}_{2}$ stock solution and the $\mathrm{Hg}-\mathrm{NOM}$ stock solution, the equilibration time was approximately 24 hours.

\section{Washing Bacterial Cells and Preparing Samples for Cell Counting}

As discussed above, two sets of experiments were conducted: one set with cultures amended with pyruvate and fumarate, and the other set with cultures amended with lactate and sulfate. After the test tube cultures from each experimental set were incubated for the appropriate time, the test tubes were placed in an airlock, which is a device that facilitates transfer of items into and out of an anaerobic glovebag, and then transferred 
inside an anaerobic glovebag. Once inside the anaerobic glovebag, the cells in each test tube culture were ready to be washed.

Throughout the laboratory experiments, the anaerobic glovebag had a measured gas composition of approximately $3.0 \%$ hydrogen gas $\left(\mathrm{H}_{2}(\mathrm{~g})\right)$ and about 0 parts per million (ppm) $\mathrm{O}_{2}(\mathrm{~g})$ (both measured by the gas analyzer in the anaerobic glovebag) and $97 \%$ nitrogen gas $\left(\mathrm{N}_{2}(\mathrm{~g})\right.$ ) (calculated from the gas mix tank used to fill the anaerobic glovebag). The following photograph shows an anaerobic glovebag similar to the one used for the laboratory experiments in the present research, manufactured by COY Laboratory Products, Inc. (COY Laboratory Products, Inc., 2011).

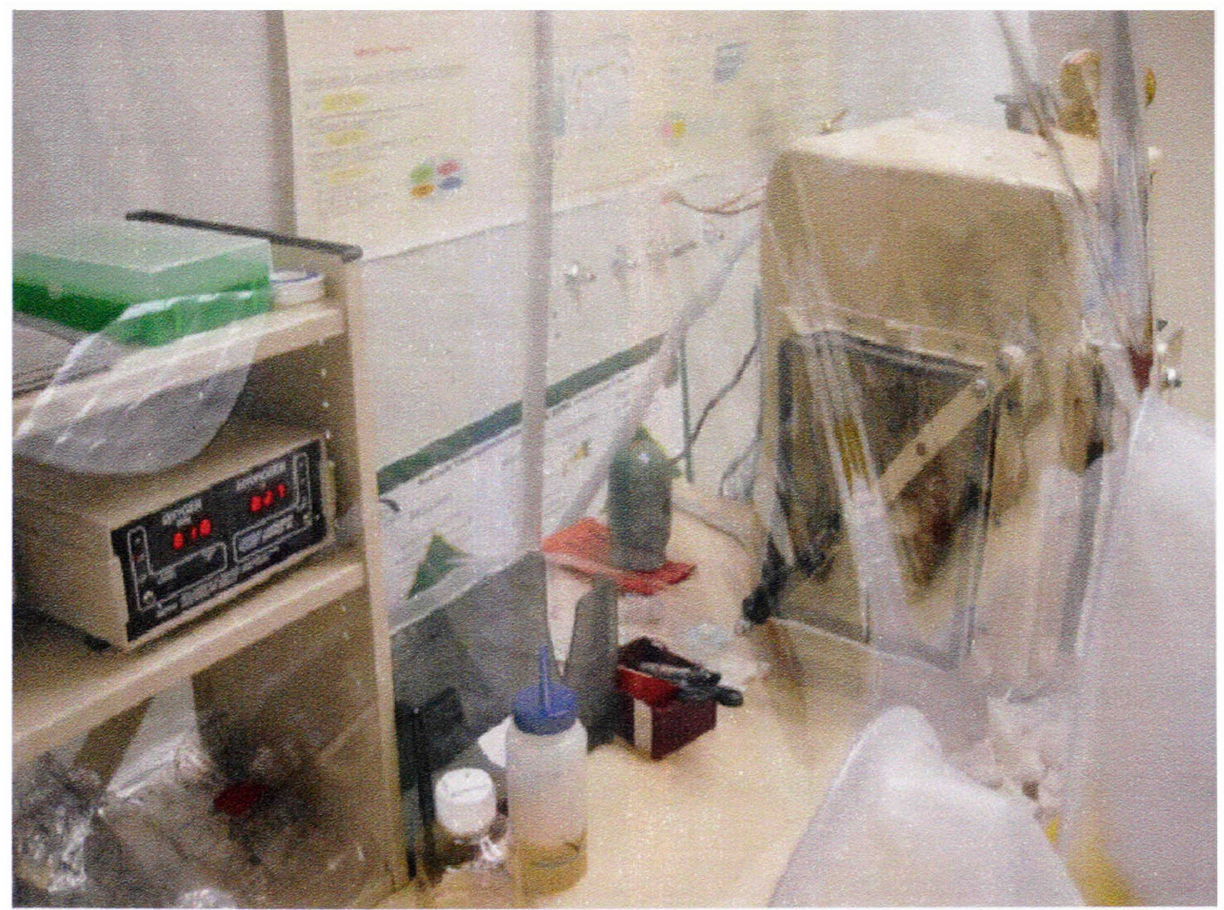

Figure 2: A photograph of an anaerobic glovebag similar to the anaerobic glovebag used in the experiments. Manufactured by COY Laboratories 
Once the test tube cultures were placed inside the glovebag, each test tube culture was opened by removing the aluminum crimp and the rubber stopper from the top of the test tube. For each test tube, the culture inside each test tube was poured into an individual sterile plastic centrifuge tube (each with a capacity of $50 \mathrm{~mL}$ ) and then each centrifuge tube was capped. Once eight of the test tube cultures were transferred to eight individual centrifuge tubes, the eight centrifuge tubes were placed in the airlock, removed from the glovebag, then centrifuged at approximately $12,000 \times$ gravity at a temperature of between 4 to $6{ }^{\circ} \mathrm{C}$. Only eight tubes were centrifuged at a time due to the space limitation of the centrifuge. For the lactate/sulfate cultures, the centrifugation time for each test tube culture was about 5 minutes. For the pyruvate/fumarate cultures, the centrifugation time was approximately 7 minutes due to the cell pellet (the hard mass of cells formed after a culture is centrifuged) in each tube consistently dissolving back into solution after being centrifuged when the tubes had only been centrifuged for 5 minutes.

After the test tubes were centrifuged for the appropriate time, they were removed from the centrifuge, placed back into the airlock and then transferred into the anaerobic glovebag. The supernatant solution in each centrifuge tube was then decanted into an Erlenmeyer flask for spent media (media that had contained bacteria and may still contain bacteria) with the cell pellet in each centrifuge still remaining. A volume of $9 \mathrm{~mL}$ of the appropriate bicarbonate buffer solution was then added to the cell pellet remaining in each centrifuge tube and the tubes were capped. The tubes were then placed inside the airlock and removed from the glovebag. Each tube was shaken to dissolve the cell pellet back into solution, and then centrifuged again under the same conditions described above. 
After centrifuging, the tubes were again transferred to the airlock and glovebag. The supernatant of each tube was decanted into the Erlenmeyer flask and $9 \mathrm{~mL}$ of the appropriate bicarbonate buffer solution was added to the cell pellet in each centrifuge tube. The tubes were capped and then placed in the airlock and removed from the glovebag. Each tube was again shaken to dissolve the cell pellet back into solution. The tubes were then centrifuged for a third time under the same conditions as described above. After centrifuging, the tubes were transferred to the airlock and glovebag. The supernatant of each tube was decanted into the Erlenmeyer flask. A volume of $9 \mathrm{~mL}$ of the appropriate bicarbonate buffer solution was added to the cell pellet in each centrifuge tube, and then each tube was shaken to dissolve the cell pellet back into solution.

For the pyruvate/fumarate cultures, a sample of 200 microliters $(\mu \mathrm{L})$ of the washed cell solution from each centrifuge tube was extracted and added to an individual small clean centrifuge tube (each with a capacity of $1.5 \mathrm{~mL}$ ) to be used for counting cells in each washed cell solution. For the lactate/sulfate cultures, the cell counting samples were extracted after the entire washing procedure, discussed below. The washed cell solution in each centrifuge tube, still inside the anaerobic glovebag, was transferred to a clean glass test tube, which was then sealed with a lubricated rubber stopper. The entire washing procedure described above was repeated for all test tube cultures. It is important to note that, for the lactate/sulfate cultures, the clean glass test tubes that contained the washed cell solutions were crimped with an aluminum cap before being removed from the glovebag. However, for the pyruvate/fumarate cultures, the clean glass test tubes that contained the washed cell solutions were crimped with an aluminum cap after being 
removed from the glovebag. This was done accidentally. However, due to the lubrication, the lubricated rubber stopper on each test tube appears to have provided a relatively secure seal for the test tubes despite them not being capped until after being removed from the glovebag.

For the lactate/sulfate cultures, once the entire washing procedure was completed, the test tubes containing the washed cell solution were placed inside a biosafety cabinet and, using a sterile technique, a $200 \mu \mathrm{L}$ sample was extracted from each test tube and placed inside an individual small clean centrifuge tube (each with a capacity of $1.5 \mathrm{~mL}$ ). Similar to the pyruvate/fumarate cultures, the small centrifuge tubes prepared for the lactate/sulfate cultures were for counting the cells in each washed cell solution. For the pyruvate/fumarate cultures, the cell counting samples were preserved in a $2 \%$ paraformaldehyde solution by adding $200 \mu \mathrm{L}$ of $4 \%$ paraformaldehyde to each small centrifuge tube, which were then placed in a refrigerator, maintained at a temperature of approximately $4{ }^{\circ} \mathrm{C}$. For the lactate/sulfate cultures, the cell counting samples were saved in the refrigerator at approximately $4{ }^{\circ} \mathrm{C}$ and, a day after the experiments, $200 \mu \mathrm{L}$ of $4 \%$ paraformaldehyde was added to each small centrifuge tube, and then the small centrifuge tubes were placed back in the refrigerator at a temperature of approximately $4^{\circ} \mathrm{C}$. After the washing procedure and preparation of cell counting samples for each culture type, the test tubes of each culture type were placed inside the mercury hood and were then ready for the mercury accumulation rate experiments. It is important to note again that the experiments with cultures containing lactate and sulfate were carried out a week before the experiments with cultures containing pyruvate and fumarate. 


\section{Mercury Spikes into Washed Cell Solutions}

The mercury timed experiments were carried out in a laboratory hood, and the temperature was assumed to be close to room temperature, approximately $76^{\circ} \mathrm{F}$. For each type of culture (i.e., either pyruvate/fumarate or lactate/sulfate), eight of the washed cell solutions were spiked with $1 \mathrm{~mL}$ of $\mathrm{HgCl}_{2}$ stock solution, while the additional eight washed cell solutions were spiked with $1 \mathrm{~mL}$ of $\mathrm{Hg}-\mathrm{NOM}$ stock solution. Therefore, each washed cell solution for the lactate/sulfate experiments contained a total volume of approximately $10 \mathrm{~mL}$ and a total mercury concentration of approximately $10 \mathrm{ng} \mathrm{Hg} / \mathrm{mL}$. In addition, each washed cell solution for the pyruvate/fumarate experiments contained a total volume of approximately $10 \mathrm{~mL}$ and a total mercury concentration of approximately $9.4 \mathrm{ng} \mathrm{Hg} / \mathrm{mL}$. Four different incubation times were then tested after spiking the washed cell solutions with mercury. For the lactate/sulfate washed cell solutions, the incubation times were 10, 20, 30, and 40 minutes after the mercury spikes, and for the pyruvate/fumarate washed cell solutions, the incubation times were 40, 50, 80, and 90 minutes. For each set of experiments with either pyruvate/fumarate or lactate/sulfate, each combination of incubation time and form of mercury spiked was run in duplicates.

Based on research by numerous researchers (Pak and Bartha, 1998; Najera et al., 2005), it was expected in the present research that the concentration of mercury used in the timed experiments would not be harmful to the bacteria. Pak and Bartha (1998) conducted research with various types of bacteria, including the strains of sulfate-reducing bacteria Desulfovibrio desulfuricans LS and Desulfovibrio desulfuricans ND-132, which are both 
known to produce methylmercury. In their experiments, Pak and Bartha (1998) tested the methylation and demethylation rates occurring in the cultures of different bacteria. For the pure cultures of Desulfovibrio desulfuricans LS in the experiments of Pak and Bartha (1998), the cultures had been spiked with either $1.0 \mu \mathrm{g}$ of $\mathrm{HgCl}_{2}$ or $0.1 \mu \mathrm{g}$ of $\mathrm{CH}_{3} \mathrm{HgI}$ per $\mathrm{mL}$. These concentrations used in the research of Pak and Bartha (1998) are significantly greater than the concentration of mercury used in the present research, and Pak and Bartha (1998) observed mercury methylation and demethylation in their research. However, it is likely that Pak and Bartha (1998) used growth media for their bacteria that was significantly different than the media used in the present research, which affects the speciation of $\mathrm{Hg}$ in solution and the uptake of $\mathrm{Hg}$ in solution.

Therefore, it is difficult to determine if the mercury concentrations spiked to the bacteria in the present research could have been toxic to the bacteria. The researchers Najera et al. (2005) conducted research on the toxicity of $\mathrm{Hg}$ (II) to planktonic cells and biofilms. Najera et al. (2005) tested how the toxicity of $\mathrm{Hg}(\mathrm{II})$ at a concentration of $250 \mathrm{ppb}$ was affected by varying the chloride concentration in their solutions. Najera et al. (2005) found that the toxicity of $\mathrm{Hg}$ (II) to planktonic cultures and biofilm cultures changed as chloride concentration changed, and thus as the speciation of mercury in solution changed, but the researchers show that the cell viability reduction due to $\mathrm{Hg}$ (II) was never greater than about $60 \%$. In the present research, the concentration of mercury used in solutions of bacteria is $10 \mathrm{ppb}(10 \mathrm{ng} / \mathrm{mL})$, which is about 25 times smaller than the concentrations used by Najera et al. (2005). Thus, it is not expected that the concentration of mercury in the solutions of bacteria in the present research was toxic to the bacteria. 
The following speciation diagram shows the concentrations of different mercury species in solution over a range of $\mathrm{pH}$ values for the pyruvate/fumarate experiments that were spiked with $\mathrm{HgCl}_{2}$ (solutions that would not contain sulfide or NOM) for a constant total chloride concentration of approximately $30 \mathrm{mM}$ in solution.

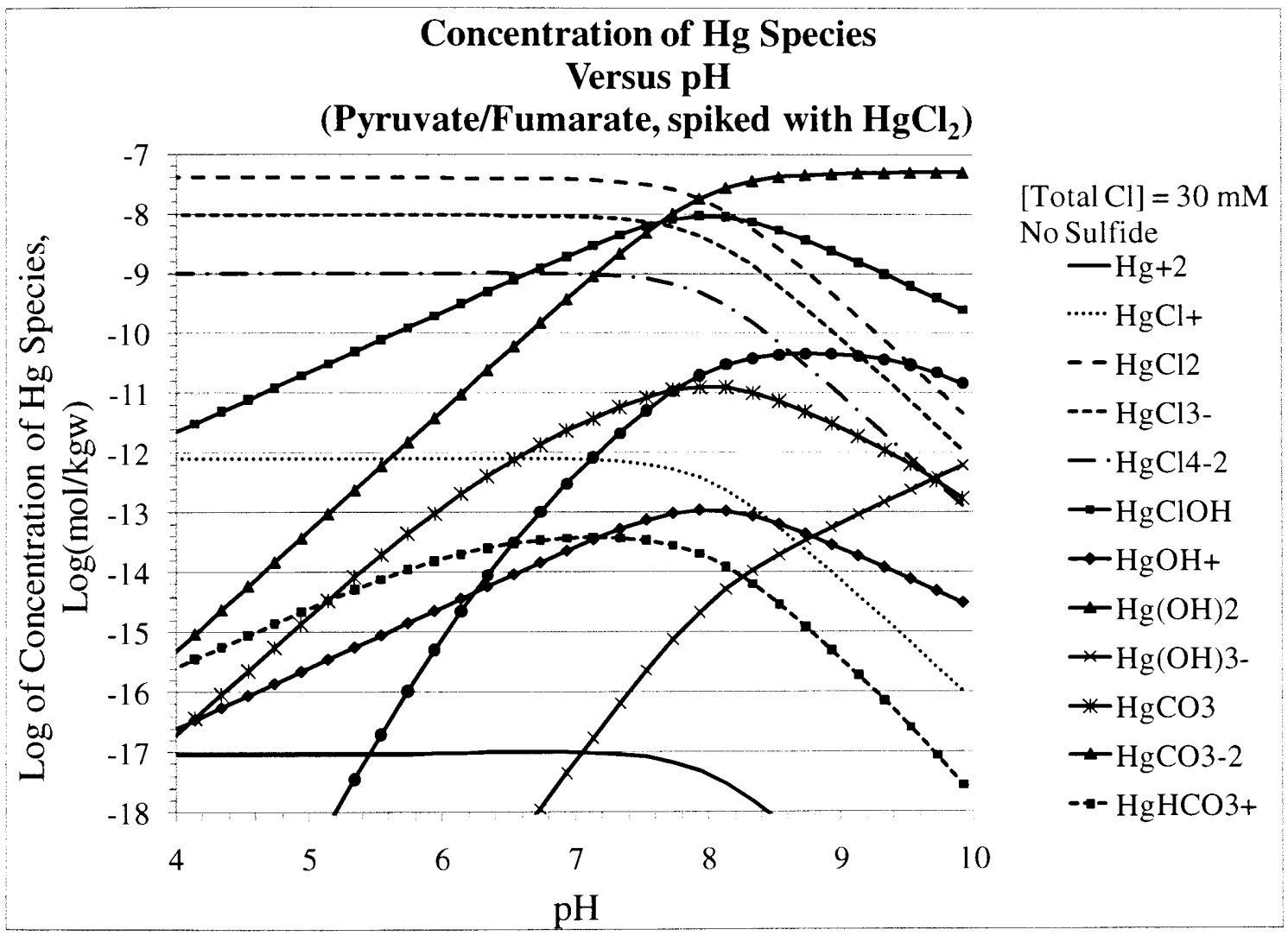

Figure 3: Estimated speciation for the pyruvate/fumarate experiments that had been spiked with $\mathrm{HgCl}_{2}$. There are no known constants between mercury and pyruvate or mercury and fumarate, though Golding et al. (2002) showed relatively high bioreporter response for mercury uptake by bacteria in the presence of fumarate. 
From the above estimated speciation diagram for the pyruvate/fumarate experiments that had been spiked with $\mathrm{HgCl}_{2}$, it appears that at $\mathrm{pH}=6.8$ the dominant form of mercury is $\mathrm{HgCl}_{2}$, followed by $\mathrm{HgCl}_{3}{ }^{-}$, and then $\mathrm{HgCl}_{4}{ }^{2-}$, thus neutral mercury chloride appears to be present in the greatest concentration, followed by negatively-charged mercury chloride species at concentrations approximately 0.6 to 1.6 orders of magnitude lower.

For the pyruvate/fumarate experiments that had been spiked with $\mathrm{Hg}-\mathrm{NOM}$, the model predicts that the speciation of mercury is dominated by $\mathrm{Hg}-\mathrm{NOM}$ in the aqueous phase. Miller et al. (2009) report a wide range of stability constants for Hg-NOM complexes, and to predict the speciation of $\mathrm{Hg}-\mathrm{NOM}$ in the present research, a value close to the average value of the range of stability constants for mercury bound to a thiol or sulfide functional group on NOM $\left(\mathrm{HgRS}^{+}\right)$reported by Miller et al. (2009) was used. Even on the low end of the range of stability constants for $\mathrm{HgRS}^{+}$complexes reported by Miller et al. (2009), the speciation of mercury in the pyruvate/fumarate experiments (that had been spiked with $\mathrm{Hg}-\mathrm{NOM}$ ) is likely to be dominated by $\mathrm{Hg}-\mathrm{NOM}$ complexes.

\section{Estimated Speciation of Mercury - Lactate/Sulfate Solutions}

For the lactate/sulfate experiments, it was assumed that the bacteria were reducing sulfate to sulfide, and thus sulfide species would be present in solution. However, the exact concentration of sulfide in each of the lactate/sulfate solutions was not measured. Because each lactate/sulfate washed cell solution had an initial sulfate concentration of $30 \mathrm{mM}$, it was assumed that after the short period of the timed experiments, the average sulfide concentration in each solution would be approximately $1 \mathrm{mM}$, and the remaining 
concentration of sulfate would be approximately $29 \mathrm{mM}$. Thus, the following speciation diagram for the lactate/sulfate experiments that had been spiked with $\mathrm{HgCl}_{2}$ shows the speciation of mercury versus $\mathrm{pH}$ for a constant total sulfide concentration of approximately $1 \mathrm{mM}$ in solution.

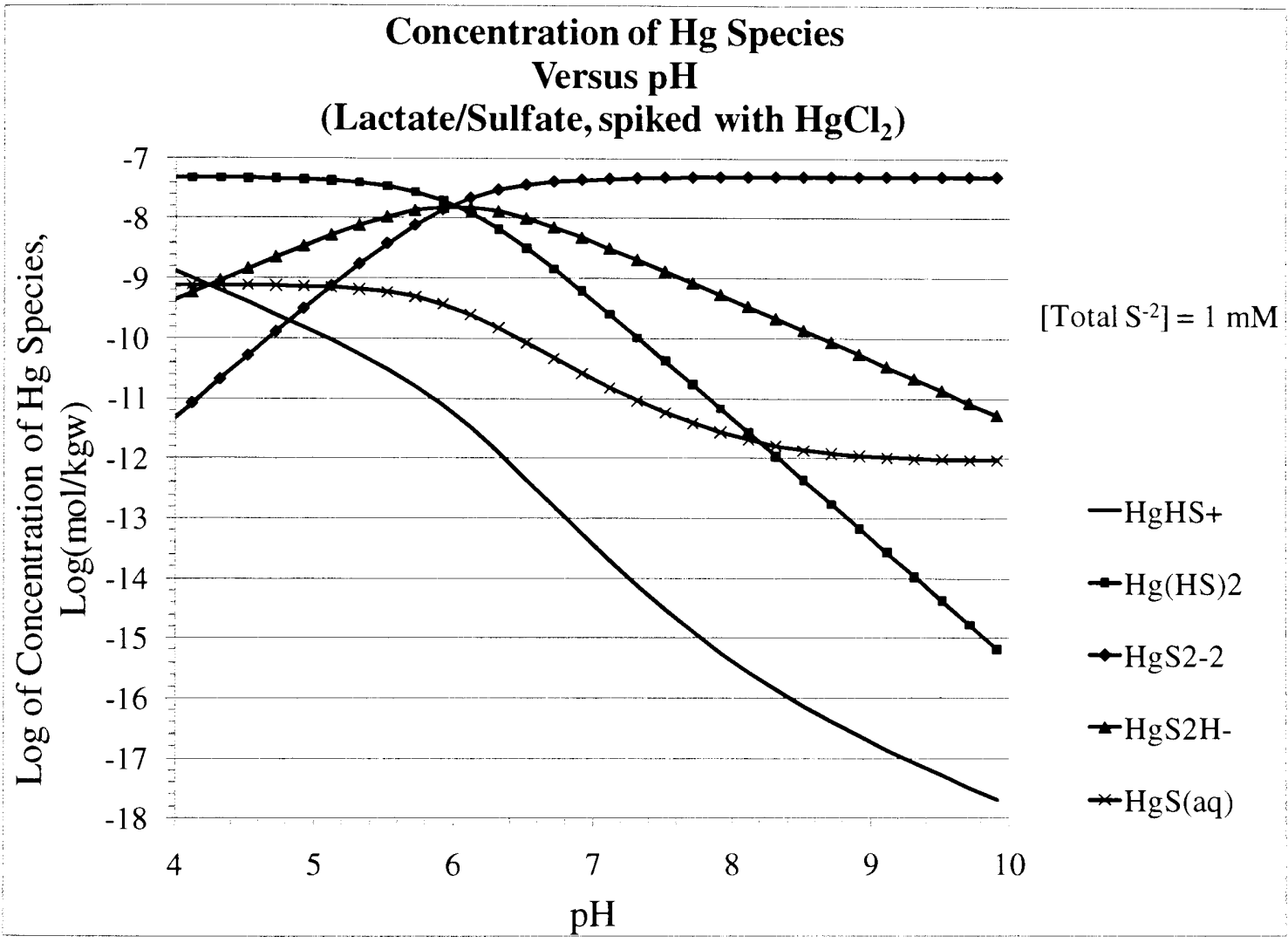

Figure 4 Estimated speciation for the lactate/sulfate experiments that had been spiked with $\mathrm{HgCl}_{2}$. There are no known constants between mercury and lactate. In addition, the dissolution/precipitation of cinnabar, which is $\mathrm{HgS}(\mathrm{s})$, was not taken into account in the speciation diagram.

From the above speciation diagram for the lactate/sulfate experiments that had been spiked with $\mathrm{HgCl}_{2}$, the simulation predicts that mercury sulfide species dominate the speciation of mercury under the conditions in the simulation and the dominant form of 
mercury predicted is the negatively-charged species $\mathrm{HgS}_{2}{ }^{2-}$. However, the dissolution/precipitation of cinnabar (solid $\mathrm{HgS}(\mathrm{s})$ ) was not taken into account in the speciation model.

\section{Uncertainty of Cinnabar Formation in Lactate/Sulfate Solutions}

When the dissolution/precipitation of cinnabar was taken into account in the speciation model, at a pH of approximately 6.8 and a concentration of total sulfide of approximately $1 \mathrm{mmol} / \mathrm{kgw}$, cinnabar was predicted by the model to dominate the speciation of mercury in the lactate/sulfate experiments that had been spiked with $\mathrm{HgCl}_{2}$, and thus little mercury would be present in solution in the aqueous (dissolved) phase compared to the mass of mercury in the solid phase. However, at a $\mathrm{pH}$ of approximately 8 or greater, the speciation model could not predict the dissolution/precipitation of cinnabar because the model was unstable. Thus, for the lactate/sulfate experiments that had been spiked with $\mathrm{HgCl}_{2}$, the extent to which cinnabar precipitated is uncertain. The results of the laboratory experiments must therefore be analyzed given the limitation that the dissolution/precipitation of cinnabar in the lactate/sulfate solutions is unknown.

\section{Uncertainty of Hg-NOM Speciation in Lactate/Sulfate Solutions}

For the lactate/sulfate experiments that had been spiked with $\mathrm{Hg}-\mathrm{NOM}$, the model predicts the speciation of mercury to be dominated by mercury sulfide species, which may or may not be the case. From the research of Miller (2006) and Miller et al. (2007), it appears that NOM competes with sulfide in solution for binding to $\mathrm{Hg}$ in solution. 
Thus, it is unlikely that the speciation predicted by the model for the lactate/sulfate experiments spiked with $\mathrm{Hg}-\mathrm{NOM}$ is accurate because the model predicts the same speciation for the lactate/sulfate experiments whether the solutions were spiked with $\mathrm{HgCl}_{2}$ or $\mathrm{Hg}-\mathrm{NOM}$. Miller (2006) found several conditional stability constants for mercury bound to both sulfide and NOM, but these were not included in the speciation diagrams in the present research because the nature of mercury bound to both sulfide and NOM is still uncertain.

\section{Preparing Experimental Samples, Controls and Cell Counting}

After each washed cell solution was spiked with mercury and incubated for the appropriate time, the aluminum crimp and rubber stopper was removed from each test tube and the washed cell solution was transferred to an individual clean sterile centrifuge tube (each with a capacity of $50 \mathrm{~mL}$ ). This was done outside the glovebag because it was assumed that, once the appropriate incubation time was reached for each test tube, the washed cell solutions could come into contact with air and this would not affect the mercury uptake by the cells or the mercury remaining in solution. Once the contents of each test tube were transferred to an individual centrifuge tube, each empty test tube was saved to be analyzed for mercury that may have attached to the test tube walls. Then, each centrifuge tube was centrifuged at a speed of approximately $12,000 \times$ gravity at a temperature between 4 to $6{ }^{\circ} \mathrm{C}$. For the lactate/sulfate test solutions, the tubes were centrifuged for about 5 minutes. For the pyruvate/fumarate test solutions, the tubes were centrifuged for about 7 minutes, and the extra time was added because the cell pellet in each tube seemed to dissolve back into solution relatively easily if the test solutions were 
centrifuged for only 5 minutes. Once each tube was centrifuged, the supernatant solution in each tube was decanted into an individual clean plastic bottle and then stored on ice. About an hour after placing the supernatant samples on ice, the supernatant samples were then stored in a freezer at $-20{ }^{\circ} \mathrm{C}$. Each centrifuge tube that still contained a cell pellet was also stored on ice. About an hour after placing the cell pellet samples on ice, the cell pellet samples were moved to a freezer at $-80^{\circ} \mathrm{C}$. The test tubes that had been saved for analysis of the test tube walls were recapped with their original rubber stoppers or with clean rubber stoppers and were stored inside the mercury hood.

The day following the experiments, the supernatant samples were removed from the refrigerator and approximately four drops of $4 \mathrm{~N}$ hydrochloric acid $(\mathrm{HCl})$ were added to each supernatant sample to preserve the samples and prevent mercury from attaching to the plastic bottle walls in each sample, and each supernatant samples was placed back in the refrigerator. In order to help remove mercury that may have been present on the walls inside of the glass test tubes that were used in the mercury accumulation rate experiments, the test tubes were uncapped and a volume of $10 \mathrm{~mL}$ of Milli-Q water and a volume $100 \mu \mathrm{L}$ of bromine chloride $(\mathrm{BrCl})$ were added to each test tube that had been saved inside the mercury hood, and each test tube was recapped with its appropriate stopper. This solution was allowed to equilibrate for approximately 24 hours before decanting the contents of each test tube into an individual clean plastic bottle. The plastic bottles containing solutions for analysis of mercury that may have attached to the test tube walls were stored in the refrigerator at a temperature of approximately $4{ }^{\circ} \mathrm{C}$. These 
samples were used as control samples to determine mercury that may have been unavailable for uptake by bacteria in the laboratory experiments.

After completing the mercury accumulation rate experiments, the bacterial cells in each cell counting sample, which had been prepared during the cell washing step, were counted using a Petroff-Hausser Counter and a light microscope. The results of the cell counts are in Appendix B. The average number of cells counted for all the samples for the pyruvate/fumarate experiments was $1.32 * 10^{8}$ cells $/ \mathrm{mL}$, with a standard deviation of $0.66 * 10^{8}$ cells $/ \mathrm{mL}$. The average number of cells for all the samples for the lactate/sulfate experiments was $1.50 * 10^{8}$ cells $/ \mathrm{mL}$, with a standard deviation of $0.85 * 10^{8}$ cells $/ \mathrm{mL}$.

Sample Analysis using Direct Mercury Analyzer 80 (DMA 80)

The supernatant samples and the samples for analysis of the test tube walls were analyzed using the Direct Mercury Analyzer 80 (DMA 80) In the Soil and Groundwater Laboratory in the Applied Research Center (ARC) at Florida International University (FIU). The DMA 80 and the determination of the Method Detection Limit (MDL) are discussed in detail in Appendix $\mathrm{C}$ in the present research. In total, there were 32 supernatant samples (16 samples each with a duplicate for a total of 32) and there were 32 samples for analysis of the test tube walls (16 samples each with a duplicate for a total of 32). For the supernatant samples, all 32 samples were run in the DMA 80 . For the samples for analysis of the test tube walls, 26 samples were run. Only 6 samples could not be run because of time constraints. 
Cell pellet samples were analyzed and supernatant samples were reanalyzed using inductively coupled plasma - mass spectrometry (ICP-MS). In addition, four of the samples for mercury on the test tube walls were reanalyzed using ICP-MS. Because the cell pellet samples were analyzed by first digesting the cell pellet samples, the difference between mercury uptake inside the cells and mercury uptake on the cell surfaces could not be determined, and thus only total mercury uptake and mercury partitioning between the cells and the aqueous supernatant solution could be determined.

\section{Assumptions for Laboratory Experiments}

The following is a list of assumptions in the laboratory experiments in the present research:

1. Because the bacteria in the present research require an electron donor and electron acceptor pair to carry out metabolic activities, the bicarbonate buffers solutions used to wash the cells contain either pyruvate and fumarate or lactate and sulfate, thus it is assumed that the bacteria are still alive after the washing step and are still carrying out metabolic processes, but are not growing or dividing at a significant rate over the time period of the experiments.

2. Sulfide is assumed to be produced in the lactate/sulfate washed cell solutions (either spiked with $\mathrm{HgCl}_{2}$ or $\mathrm{Hg}-\mathrm{NOM}$ ), but the concentration of sulfide in each washed cell solution after each time period is not known. To create the speciation diagrams discussed above, a sulfide concentration of $1 \mathrm{mM}(\sim 3.3 \%$ of original 
added amount of sulfate, with $29 \mathrm{mM}$ sulfate remaining in solution) was assumed as the average sulfide concentration in each washed cell solution after the timed experiments (after the mercury spikes in each solution).

There may be additional assumptions inherent in the plan of the laboratory experiments, which may have been discussed in the sections above.

\section{Limitations of Sample Analysis}

It is important to note some limitations of the sample analysis due to the way samples were handled prior to analysis by ICP-MS. First of all, supernatant samples and most samples for the test tube walls were analyzed using the DMA 80 in October 2010. Because these samples had been opened and closed at least once, it is possible that some mercury may have been lost due to volatilization, though this was not measured. However, this is unlikely due to the acidity of the supernatant samples and due to the bromine chloride present in the samples for analysis of the test tube walls.

The cell pellet samples had been kept frozen from when they were first created in August 2010 to November 2010, at which point the samples were slightly thawed as each sample, each contained within an individual centrifuge tube, was weighed. The short-term thawing may have resulted in some mercury loss to the tube walls and caps of the centrifuge tubes and potentially some mercury loss due to volatilization, though neither of these possible losses was measured. In addition, to weigh the centrifuge tubes containing the cell pellet samples, the centrifuge tubes were turned on their sides and some were turned upside down, which could have resulted on mercury loss to the 
centrifuge tube walls and caps. Moreover, to obtain accurate weights of the centrifuge tubes containing the cell pellet samples, some of the caps were removed momentarily to remove strands of packing material that may have gotten caught on the centrifuge tube caps. Thus, some mercury may have volatilized in the few seconds that these caps were removed on a few of the cell pellet samples. It turns out that the centrifuge tube and sample weights were not used in the present research. In addition, because cell pellet samples were eventually thawed for between 1 month and 2 months while waiting to be analyzed using ICP-MS, it is possible that some mercury may have volatilized from the samples, even though the samples were all sealed, but this potential loss was not measured.

Despite the limitations discussed above, the results of the laboratory experiments may be analyzed by keeping in mind these limitations. Potentially, some provisional conclusions from the results may be made. 


\section{MODELING MERCURY UPTAKE BY CELLS}

Conceptual Model

The following figure presents a simplified view of a cell and some of the potential processes affecting mercury uptake by the cell and mercury transport through the cell membrane.

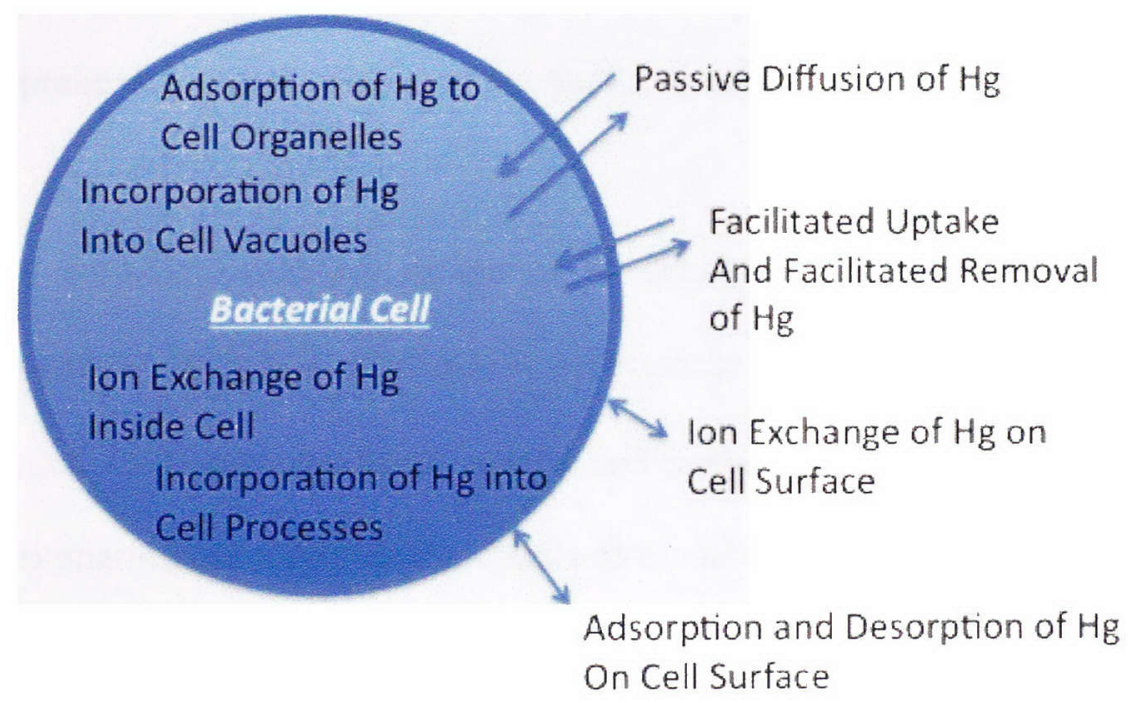

Figure 5: Some possible chemical and physical processes occurring inside a bacterial cell, as well as in and on the cell membrane of a bacterial cell.

Based on the literature review of the present research (Chapter I, Introduction), it appears that the focus of much research on mercury uptake by microorganisms is on either passive diffusion of neutral mercury species through cell membranes, facilitated uptake of mercury species by microorganisms, or a combination of both processes. It is possible 
that ion exchange is occurring on the surfaces of cells. Adsorption and desorption of mercury on the surface of a cell are physical processes, where a substance may bind to the surface of a cell because of a physical reaction, such as a slight difference in charge between the substance and the surface of a cell. On the other hand, the process of ion exchange is a chemical process, where a substance binds to a ligand on the surface of a cell because of an exchange or a sharing of electrons between the substance and the surface of a cell. These processes may be grouped with the process of facilitated uptake as the first step of the facilitated uptake process. Additional processes shown on Figure 5 may be occurring in the cells, or in or on the cell membranes, but the overall processes of facilitated uptake and passive diffusion are the focus of the present research.

The idea of modeling mercury uptake is to create a simple model combining the processes of passive diffusion of relatively hydrophobic mercury species through the cell membranes and facilitated uptake of neutral and positively-charged mercury species by cells, then comparing the model to the results of the laboratory experiments in the present research. In the present research, the mercury uptake model is intended to be used to better understand possible cellular processes involved in mercury uptake.

\section{Modeling Parameters for Mercury Uptake by Cells via Passive Diffusion}

Mason et al. (1996) discuss a relationship between $\mathrm{K}_{\mathrm{ow}}$ values and membrane permeabilities for low molecular weight neutrally charged compounds diffusing through red blood cells (see reference within Mason et al., 1996). The equation for calculating the 
corrected membrane permeability is given in Mason et al. (1996, and see reference therein) and is shown below:

$$
\mathrm{P}^{*}=\left(\mathrm{K}_{\mathrm{ow}} \mathrm{D}_{\mathrm{mem}}\right) / l
$$

where $\mathrm{P}^{*}$ is the corrected membrane permeability in $\mathrm{cm} \mathrm{s}^{-1}, \mathrm{D}_{\mathrm{mem}}$ is the molecular diffusion coefficient in the lipid bilayer in $\mathrm{cm}^{2} \mathrm{~s}^{-1}$, and $l$ is the membrane thickness in $\mathrm{cm}$ (see reference within Mason et al., 1996). Mason et al. (1996) state that an empirical relationship corrects the permeability coefficient $\mathrm{P}$ for the effects of molecular size on diffusion rate through the membrane (see reference within Mason et al., 1996):

$$
\log \mathrm{P}^{*}=\log \mathrm{P}+m v
$$

where $m$ is a proportionality constant $\left(m=0.0546 \mathrm{~mol} \mathrm{~cm}^{-3}\right)$ and $v$ is the van der Waals volume (in $\mathrm{cm}^{3} \mathrm{~mol}^{-1}$ ) of a chemical species (Mason et al., 1996, and reference therein).

Mason et al. (1996) state that, in their research, membrane permeabilities of $\mathrm{HgCl}_{2}$, $\mathrm{Hg}(\mathrm{OH})_{2}, \mathrm{CH}_{3} \mathrm{HgCl}$, and $\mathrm{CH}_{3} \mathrm{HgOH}$ were estimated from the following equation:

$$
V=4 \pi R^{2} P C
$$

where $\mathrm{V}$ is the uptake rate in mol cell ${ }^{-1} \mathrm{~s}^{-1}, \mathrm{R}$ is the cell radius in $\mathrm{cm}, \mathrm{P}$ is the membrane permeability in $\mathrm{cm} \mathrm{s}^{-1}$, and $\mathrm{C}$ is the external concentration of mercury in $\mathrm{mol} \mathrm{cm}^{-3}$, and 
from their experiments, Mason et al. (1996) state that they used short-term uptake rates measured at $\mathrm{pH}$ and chloride concentrations where each of the four species is dominant and a constant diatom cell surface area based on a cell radius of $5.6 \mu \mathrm{m}$.

Postgate (1979) discusses sulfate-reducing bacteria and presents two electron micrographs, one for the sulfate-reducing bacteria strain Desulfovibrio desulfuricans strain El Agheila, and the other for another strain of sulfate reducing bacteria, Desulfotomaculum nigrificans. Each bacterial cell appears to have a cell diameter on the order of $1 \mu \mathrm{m}$. Thus, as an initial estimate, a cell radius of approximately $0.5 \mu \mathrm{m}$ is assumed for the strain of sulfate reducing bacteria Desulfovibrio desulfuricans G20. Postgate (1979, and reference therein) discuss research on the bacteria Desulfovibrio vulgaris strain Wandle and state that the shape of cells of this bacteria strain were considered to be cylinders. However, for the present research, as a first approximation, the shape of cells of the bacteria strain Desulfovibrio desulfuricans G20 were assumed to be spheres.

Mason et al. (1996) calculated values for the membrane permeability P of different neutral mercury species. In addition, Mason et al. (1996) plotted a graph of the log $\mathrm{K}_{\text {ow }}$ versus the $\log \mathrm{P}^{*}$ of various neutral mercury species, and on this graph the researchers added an empirical relationship that relates the values of $\log \mathrm{K}_{\text {ow }}$ and $\log \mathrm{P}^{*}$, which was originally developed for organic chemicals (see reference within Mason et al., 1996) but seemed also to fit the data for mercury species studied in Mason et al. (1996). Mason et al. (1996) report van der Waals volumes of $51 \mathrm{~cm}^{3} \mathrm{~mol}^{-1}$ for $\mathrm{HgCl}_{2}$ and $43 \mathrm{~cm}^{3} \mathrm{~mol}^{-1}$ for 
$\mathrm{Hg}(\mathrm{OH})_{2}$. From the data from Mason et al. (1996) for the van der Waals volumes of $\mathrm{HgCl}_{2}$ and $\mathrm{Hg}(\mathrm{OH})_{2}$, a van der Waals volume of approximately $47 \mathrm{~cm}^{3} \mathrm{~mol}^{-1}$ for $\mathrm{HgClOH}$ was estimated in the present research.

Benoit et al. (2001b) estimated a van der Waals volume of $39 \mathrm{~cm}^{3} \mathrm{~mol}^{-1}$ for $\mathrm{HgS}^{0}$. Benoit et al. (2001b) state that it has been previously suggested by other researchers (see reference within Benoit et al., 2001b) that $\mathrm{HgS}^{0}$ may be hydrated in solution and exist possibly as $\mathrm{HgSHOH}$, and the van der Waals volume of this complex may be larger than $39 \mathrm{~cm}^{3} \mathrm{~mol}^{-1}$. Moreover, Benoit et al. (2001b) state that the permeability P of a complex is extremely sensitive to the van der Waals volume of the complex, but Benoit et al. (2001b) found that, in their research, even with a larger van der Waals volume for $\mathrm{HgS}^{0}$, the results of their research would still suggest that uptake of $\mathrm{HgS}^{0}$ by cells of Desulfovibrio propionicus (1pr3) could still be explained by passive diffusion of the neutral $\mathrm{HgS}^{0}$ complex.

From the data from Mason et al. (1996) on the van der Waals volume of $\mathrm{HgCl}_{2}$ and from the data from Benoit et al. (2001b) on the van der Waals volume of $\mathrm{HgS}^{0}$, in the present research a van der Waals volume of about $53 \mathrm{~cm}^{3} \mathrm{~mol}^{-1}$ was estimated for $\mathrm{Hg}(\mathrm{HS})_{2}$. It is also important to note that Benoit et al. (2001b) calculated a $\mathrm{K}_{\mathrm{ow}}$ for $\mathrm{HgS}^{0}$ of 25 , but Miller et al. (2007) calculated an average $\log \mathrm{K}_{\mathrm{ow}}$ of 72 for each species $\mathrm{HgS}^{0}$ and $\mathrm{Hg}(\mathrm{HS})_{2}$. For the present research, the values calculated by Miller et al. (2007) are used. 
The following table shows the values of the $\log \mathrm{K}_{\mathrm{ow}}$ (from various references, stated on the table) for various neutral mercury species and the $\log \mathrm{P}$ of each mercury species, reported by Mason et al. (1996) or calculated using the graph with the linear relationship that relates $\log \mathrm{K}_{\mathrm{ow}}$ to $\log \mathrm{P}^{*}$, plotted by Mason et al. (1996, and reference therein), and equation (10) above from Mason et al. (1996, and reference therein).

Table 1: Membrane permeabilities and octanol-water partition coefficients for different mercury species. The membrane permeability $\mathrm{P}$ for $\mathrm{HgClOH}, \mathrm{HgS}^{0}$, and $\mathrm{Hg}(\mathrm{HS})_{2}$ was calculated using the graph presented in Mason et al. (1996, and reference therein), which describes the relationship between $\log \mathbf{K}_{0 w}$ versus $\log \mathbf{P}^{*}$, and this relationship had originally been developed for organic chemicals (see reference within Mason et al., 1996), but seemed also to fit the data for four neutral mercury species studied in the research of Mason et al. (1996).

\begin{tabular}{|c|c|c|c|c|}
\hline $\begin{array}{c}\text { Mercury } \\
\text { Species }\end{array}$ & $\begin{array}{c}\text { Calculated / } \\
\text { Estimated } \\
\text { Membrane } \\
\text { Permeability (P) } \\
(\mathbf{c m} / \mathbf{s})\end{array}$ & $\begin{array}{l}\text { Octanol- } \\
\text { Water } \\
\text { Partition } \\
\text { Coefficient } \\
\left(\mathbf{K}_{\text {ow }}\right)\end{array}$ & $\begin{array}{c}\text { van der } \\
\text { Waals } \\
\text { Volume (v) } \\
\left(\mathrm{cm}^{3} \mathrm{~mol}^{-1}\right)\end{array}$ & $\begin{array}{c}\text { References (with } \\
\text { parameter referenced in } \\
\text { parentheses) }\end{array}$ \\
\hline $\mathrm{HgCl}_{2}$ & 7.4E-04 & 3.33 & 51 & Mason et al. (1996) \\
\hline $\mathrm{Hg}(\mathrm{OH})_{2}$ & $2.3 \mathrm{E}-05$ & 0.05 & 43 & Mason et al. (1996) \\
\hline $\mathrm{HgClOH}$ & $6.8 \mathrm{E}-04$ & 1.20 & 47 & $\begin{array}{l}\text { Mason et al. }(1996)\left(\mathrm{K}_{\mathrm{ow}}\right) \text {; } \\
\text { In the present research, } v \\
\text { for } \mathrm{HgClOH} \text { was } \\
\text { estimated using values of } \\
v \text { reported for } \mathrm{HgCl}_{2} \text { and } \\
\mathrm{Hg}(\mathrm{OH})_{2}\end{array}$ \\
\hline $\mathrm{HgS}^{0}$ & 3.7E-01 & 72 & 39 & $\begin{array}{l}\text { Miller et al. (2007) } \\
\text { (Kow); Benoit et al. } \\
(2001 b)(v) ;\end{array}$ \\
\hline $\mathrm{Hg}(\mathrm{HS})_{2}$ & 6.4E-02 & 72 & 53 & $\begin{array}{l}\text { Miller et al. }(2007) \\
(\mathrm{Kow}) ; \mathrm{In} \text { the present } \\
\text { research, } v \text { for } \mathrm{Hg}(\mathrm{HS})_{2} \\
\text { was estimated using } \\
\text { values of } v \text { reported for } \\
\mathrm{HgCl}_{2}, \mathrm{Hg}(\mathrm{OH})_{2} \text {, and } \\
\mathrm{HgS}^{0} \text {. }\end{array}$ \\
\hline
\end{tabular}


For modeling purposes, it is assumed that $\mathrm{Hg}-\mathrm{NOM}$ complexes are too large to enter a cell by passive diffusion, and only the reducible fraction of $\mathrm{Hg}$ on $\mathrm{Hg}-\mathrm{NOM}$ is available to a bacteria cell via facilitated uptake. This assumption is made in the present research and was not made by Miller et al. (2009), who conducted research on the kinetics of $\mathrm{Hg}$ complexation with NOM and discussed the reducible fraction of $\mathrm{Hg}$ on $\mathrm{Hg}-\mathrm{NOM}$ complexes. Furthermore, this assumption in the present research is a simplification and may be incorrect, but the assumption is made as a first approximation for uptake of $\mathrm{Hg}$ on Hg-NOM complexes.

Morel et al. (1991) discuss Fe uptake by the marine diatom Thalassiosira weissflogii. Morel et al. (1991) discuss that the dissolved concentration of Fe in the North Pacific is $\sim 5 * 10^{-11} \mathrm{M}$, and state that even with a very low $\mathrm{Fe}$ requirement, algal species with a radius of $10 \mu \mathrm{m}$ (see figure in Morel et al., 1991) require a very high concentration of uptake sites on the cell membrane, for facilitated uptake, and become almost diffusion limited if they divide once a day. Furthermore, Morel et al. (1991) state that the minimum ligand density (of facilitated uptake ligands on the cell membrane of each algal cell) of 4 pmol $\mathrm{cm}^{-2}$ required for uptake is near the maximum measured in the laboratory for Thalassiosira weissflogii $\left(10 \mathrm{pmol} \mathrm{cm}^{-2}\right)$. In addition, Morel et al. (1991) state that the ligand density is also so large that only small molecules can possibly fit in the membrane, thus reinforcing the notion that the $\mathrm{Fe}$ uptake ligands may be membrane-bound siderophores. Moreover, Morel et al. (1991) state that, clearly, the situation is not as critical for smaller algal species (see figure in Morel et al., 1991), which are at a competitive advantage at such low Fe concentrations. 
From the above discussion by Morel et al. (1991), it appears that due to the large ligand density on the cell membrane of algal species and Thalassiosira weissflogii, only small molecules can be taken up by cells through the process of passive diffusion. Moreover, from the above discussion by Morel et al. (1991) on Fe uptake by algal species, in the present research it is assumed that, if uptake of certain mercury species occurs via facilitated uptake by cells, the same mechanisms involved in facilitated uptake of essential nutrients such as $\mathrm{Fe}$ are also the same uptake mechanisms involved in the accidental uptake of $\mathrm{Hg}$ by cells, and uptake is assumed to be accidental since mercury has no known benefit to organisms. Miller et al. (2009) discuss that NOM has heterogeneity and various functional moieties, so it is possible to estimate that NOM molecules can be fairly large. Thus, it is also possible to assume that $\mathrm{Hg}-\mathrm{NOM}$ complexes are large, and may be too large to enter cells via passive diffusion.

To model mercury uptake by cells via passive diffusion in the present research, only the neutral species $\mathrm{HgCl}_{2}, \mathrm{Hg}(\mathrm{OH})_{2}, \mathrm{HgClOH}, \mathrm{HgS}^{0}$, and $\mathrm{Hg}(\mathrm{HS})_{2}$ are assumed to be able to diffuse through the cell membranes. This assumption in the present research is based on the research by several researchers, including Mason et al. (1996), Barkay et al. (1997), Zhong and Wang (2009), and Benoit et al. (1999). Barkay et al. (1997) conducted research on bacteria and mercury uptake, and state that, in their research, uncharged $\mathrm{HgCl}_{2}$ was more bioavailable than anionic forms of mercuric chloride, and the counterion associated with the uncharged $\mathrm{Hg}(\mathrm{II})$ species (i.e., either $\mathrm{HgCl}_{2}$ or $\mathrm{Hg}(\mathrm{OH})_{2}$ ) did not affect bioavailability. In addition, Barkay et al. (1997, and references therein) cite the work of numerous researchers and state that it is generally accepted that neutral forms of 
mercurials permeate biological membranes more readily than charged forms under physiological conditions. In addition, Barkay et al. (1997, and reference therein) cite the work of another researcher and state that the observation of Gutknecht (see reference within Barkay et al., 1997), that $\mathrm{Hg}(\mathrm{OH})_{2}$ and $\mathrm{HgClOH}$ did not permeate lipid bilayer membranes at significant rates is in contrast to their data (the data of Barkay et al., 1997). Barkay et al. (1997) explain that as the bacterial cell wall is composed of other components in addition to lipids, the transfer efficiency of various mercurial compounds may vary.

Modeling Parameters for Mercury Uptake by Cells via Active/Facilitated Transport

Morel et al. (1991) conducted research to determine kinetics of trace metal uptake by phytoplankton and to determine concentrations at which trace metals, such as $\mathrm{Fe}, \mathrm{Zn}, \mathrm{Mn}$, and $\mathrm{Ni}$, limit the growth of phytoplankton. Morel et al. (1991) state that it appears that the uptake of all necessary trace metal by phytoplankton occurs via binding to a surface ligand and subsequent transfer across the cell membrane. Morel et al. (1991) state that the result is the well-known Michaelis-Menten uptake kinetics, a hyperbolic rate law in which uptake rate $(\rho)$ is proportional to the concentration of the reactive substrate $[\mathrm{M}]$ at low concentrations and the uptake rate reaches a maximum $\left(\rho_{\max }\right)$ at concentrations that exceed the "half-saturation constant" $\mathrm{K}_{\mathrm{p}}$.

The following set of equations, which is for Michaelis-Menten enzyme kinetics adapted for trace metal uptake by phytoplankton, has been adapted from two references, Morel et al. (1991) and Stumm and Morgan (1996). 


$$
\begin{aligned}
& \mathrm{M}^{\prime}+\underset{k_{-}}{\stackrel{k_{L}}{\leftrightarrow} \stackrel{k_{\text {in }}}{\leftrightarrow} \mathrm{ML}} \rightarrow \mathrm{M}_{\text {cell }} \\
& \rho=(\text { Num_Cells })\left(\rho_{\max }\left[\mathrm{M}^{\prime}\right]\right) /\left(\mathrm{K}_{\mathrm{p}}+\left[\mathrm{M}^{\prime}\right]\right) \\
& \rho_{\max }=\mathrm{L}_{\mathrm{T}} k_{\text {in }} \\
& \mathrm{K}_{\rho}=\left(k_{-L}+k_{\text {in }}\right) /\left(k_{L}\right)
\end{aligned}
$$

where $\mathrm{M}^{\prime}$ is the inorganic metal species, $\mathrm{L}$ is the cell ligand, $\mathrm{ML}$ is the metal-ligand complex, $k_{L}$ is the forward rate constant with units of $\mathrm{kgw} \mathrm{mol}^{-1} \mathrm{~s}^{-1}$ (where $\mathrm{kgw}$ represents kilograms of water), $k_{-L}$ is the backward rate constant with units of $\mathrm{s}^{-1}, k_{\text {in }}$ is the internalization rate constant with units of $\mathrm{s}^{-1}, \mathrm{M}_{\text {cell }}$ is the metal species inside the cell (or for the present research, the metal species inside or bound to the surface of the cell), $\rho$ is the uptake rate with assumed units of mol $\mathrm{s}^{-1}$, Num_Cells is the total number of cells in solution, $\rho_{\max }$ is the maximum uptake rate with assumed units of mol cell ${ }^{-1} \mathrm{~s}^{-1}$ for the present research, $\mathrm{L}_{\mathrm{T}}$ is the metal transport ligand concentration with assumed units of mol $\mathrm{kgw}^{-1}$, and $\mathrm{K}_{\mathrm{\rho}}$ is the half-saturation constant in mol kgw${ }^{-1}$ (adapted from Morel et al., 1991, and Stumm and Morgan, 1996, with units adjusted to units used in the present research). The derivation of the equation for the rate of trace metal uptake ( $\rho$ ) is not discussed by Morel et al. (1991) or Stumm and Morgan (1996), and is beyond the scope of the present research. 
Morel et al. (1991) discuss the half-saturation constant $\left(\mathrm{K}_{\rho}\right)$ and the maximum uptake rate $\left(\rho_{\max }\right)$ and state that the half-saturation constant is determined by rates of metal-ligand binding and dissociation and the rate of internalization, and has been found to be invariant for a given trace metal and a given phytoplankton species (see references within Morel et al., 1991). Furthermore, Morel et al. (1991) discuss that the maximum uptake rate $\left(\rho_{\max }\right)$ can be adjusted up and down by a factor of $20-30$, depending on the degree of limitation or sufficiency of the trace metal (see references within Morel et al., 1991).

Morel et al. (1991) continue to discuss the half-saturation constant $\left(\mathrm{K}_{\rho}\right)$ and the maximum uptake rate $\left(\rho_{\max }\right)$ and state that these two properties are believed to be likely applicable to all essential trace metals and most if not all phytoplankton species but, at least at the time of the research by Morel et al. (1991), the half-saturation constant and the maximum uptake rate had only been demonstrated for $\mathrm{Fe}$ and $\mathrm{Mn}$ in experiments with merely five marine phytoplankters representing three classes (see references within Morel et al., 1991). Moreover, Morel et al. (1991) state that there is still much work to be done to quantify the kinetics of metal uptake in marine algae.

To estimate the short-term uptake rate for mercury uptake by bacteria, both $\rho_{\max }$ and $K_{\rho}$ need to be estimated. Morel et al. (1991) discuss data on short-term metal transport kinetics of $\mathrm{Fe}$ uptake by the marine diatom Thalassiosira weissflogii versus $\mathrm{Fe}$ concentration (see reference within Morel et al., 1991). From the Fe uptake by Thalassiosira weissflogii, discussed in Morel et al. (1991), an educated guess on the order of magnitude for the uptake of $\mathrm{Hg}$ by Desulfovibrio desulfuricans $\mathrm{G} 20$ may be made. 
From Morel et al. (1991), for Fe uptake by Thalassiosira weissflogii, as the Fe concentration in solution $([\mathrm{Fe}])$ approaches a value of $30 \mathrm{nM}$, the value of $\rho_{\max }$, which is assumed to be a high estimate for $\rho_{\max }$, appears to approach a value near 160 amol/cell/h $\left(160 * 10^{-18} \mathrm{~mol} \mathrm{cell}{ }^{-1} \mathrm{~h}^{-1}\right)$. In addition, from Morel et al. (1991), for Fe uptake by Thalassiosira weissflogii, as [Fe'] approaches a value of $30 \mathrm{nM}$, the value of $\rho_{\max }^{0.5}$, which is assumed to be a medium scale estimate for $\rho_{\max }$, appears to approach a value near $80 \mathrm{amol} / \mathrm{cell} / \mathrm{h}\left(80 * 10^{-18} \mathrm{~mol} \mathrm{cell}^{-1} \mathrm{~h}^{-1}\right)$. Finally, from Morel et al. (1991), for Fe uptake by Thalassiosira weissflogii, as [Fe'] approaches a value of $30 \mathrm{nM}$, the quantity " $\rho_{\max }\left[\mathrm{Fe}^{\prime}\right]_{\mathrm{ss}}=1 \mathrm{nM}$ ", which is assumed to be a low estimate for $\rho_{\max }$, appears to approach a value near $45 \mathrm{amol} / \mathrm{cell} / \mathrm{h}\left(45 * 10^{-18} \mathrm{~mol} \mathrm{cell}^{-1} \mathrm{~h}^{-1}\right)$.

As discussed above, Morel et al. (1991) conducted research on uptake of iron (Fe), an essential nutrient, by a marine diatom, Thalassiosira weissflogii. The present research is on uptake of mercury $(\mathrm{Hg})$, a metal that is usually toxic and is not known to provide any benefit to organisms, by a strain of sulfate-reducing bacteria (SRB), Desulfovibrio desulfuricans $\mathrm{G} 20$. As an initial estimate of the maximum uptake rate $\left(\rho_{\max }\right)$ of $\mathrm{Hg}$ by the sulfate-reducing bacteria strain in the present research, a value near the value of the low maximum uptake rate calculated by Morel et al. (1991) for Fe uptake by a marine diatom is used. Although this assumption is clearly a large assumption, it nevertheless provides an estimate of the possible order of magnitude of the maximum uptake rate of $\mathrm{Hg}$ by the sulfate-reducing bacteria strain Desulfovibrio desulfuricans G20. 
Morel et al. (1991) discuss that when the concentration of uptake ligands $\left(\mathrm{L}_{\mathrm{T}}\right)$ is adjusted, the short-term uptake of a trace metal follows a series of hyperbolic Michaelis-Menten kinetics whose maximum is dependent on the prior degree of trace metal stress. Morel et al. (1991) also explain that low ambient trace metal concentrations, which is the situation of interest for limiting or near-limiting conditions as may exist in the environment, is the upper limit of these uptake rate laws that obtains $\left(\mathrm{L}_{\mathrm{T}}=\mathrm{L}_{\mathrm{T}}{ }^{\mathrm{max}}\right)$. Morel et al. (1991) also state that, because the uptake system is then undersaturated $\left([M]<<K_{\rho}\right)$, the steady state uptake rate is simply proportional to [M'] and is given by the following equation:

$$
\rho^{\mathrm{ss}}=k_{\text {in }} \mathrm{L}_{\mathrm{T}}{ }^{\max }\left[\mathrm{M}^{\prime}\right] / \mathrm{K}_{\rho}
$$

where $\rho^{\text {ss }}$ is the steady state uptake rate of the trace metal (Morel et al., 1991). From the information from Morel et al. (1991) on the value of the half-saturation constant $\mathrm{K}_{\rho}$ for trace metal uptake of essential trace metals by phytoplankton when the uptake system is undersaturated (described above), an educated guess on the order of magnitude of $\mathrm{K}_{\mathrm{p}}$ for mercury uptake by bacteria can be made, and an initial estimate for the value of $\mathrm{K}_{\rho}$ can be approximately one order of magnitude greater than the value of [M].

In the present research, it is assumed that only positively charged and neutral mercury species are able to enter cells via facilitated uptake. It is acknowledged that this assumption made in the present research may not be valid, and it is possible that negatively charged mercury species may possibly enter the cells via facilitated uptake. However, based on the research of Barkay et al. (1997) and Najera et al. (2005), it 
appears that when negatively charged mercury chloride species $\left(\mathrm{HgCl}_{3}^{-}\right.$and $\mathrm{HgCl}_{4}{ }^{-2}$ ) dominate the mercury speciation, cellular uptake of mercury decreases significantly. In addition, Schaefer and Morel (2009) discuss that in their research they found a significant relationship between the calculated concentration of the complex of mercury bound to two cysteine molecules $\left(\mathrm{Hg}(\mathrm{cys})_{2}\right)$ in solution and mercury uptake by the bacteria Geobacter sulfurreducens. It is uncertain in the research of Schaefer and Morel (2009) if the species $\mathrm{Hg}$ (cys), which may also be neutral or positively-charged, was present in the solutions of their research, and Stumm and Morgan (1996) report for $\mathrm{Hg}$ (cys) a value of $\log \beta=15.3$, though it is likely that the stability constant for $\mathrm{Hg}(\mathrm{cys})_{2}$ is higher than that of $\mathrm{Hg}(\mathrm{cys})$, and thus likely that $\mathrm{Hg}$ (cys) $)_{2}$ dominated the speciation in the solutions in the experiments of Schaefer and Morel (2009).

Golding et al. (2002) showed that mercury uptake appeared to occur by facilitated uptake because the rate of mercury uptake appeared to be related to the total mercury concentration in the bulk solution, not just the concentration of neutral mercury species, which included charged mercury species such as $\mathrm{Hg}\left(\mathrm{NH}_{3}\right)^{2+}$ and uncharged mercury species such as $\mathrm{HgCl}_{2}$ and $\mathrm{Hg}(\mathrm{OH})_{2}$. Golding et al. (2002) also state that the researchers Benoit et al. (1999) suggest that a mechanism of mercury uptake is the passive diffusion of the lipophilic mercury species $\mathrm{HgS}^{0}$. Golding et al. (2002) say that an alternative mechanism may be that $\mathrm{HgS}^{0}$ is capable of ligand exchange with cell membrane ligands, similar to $\mathrm{HgCl}_{2}$ and $\mathrm{Hg}(\mathrm{OH})_{2}$ as discussed by Golding et al. (2002), which would be a facilitated uptake. However, Golding et al. (2002) state that increasing sulfide concentration in a medium would result in increased concentration of $\mathrm{HgS}_{2}{ }^{2-}$, which may 
bind the $\mathrm{Hg}(\mathrm{II})$ too tightly for it to participate in ligand exchange or be repelled from the bacterial cell because of its negative charge. Najera et al. (2005), similar to Golding et al. (2002), also showed that mercury uptake appeared to occur for the positively charged mercury species $\mathrm{Hg}\left(\mathrm{NH}_{3}\right)^{2+}$. In the present research, it is assumed that only positivelycharged and neutral mercury species can enter a cell through facilitated uptake.

\section{Summary of Model for Mercury Uptake}

As discussed in the previous three section of the current chapter, there are various possible mechanisms for mercury uptake by microorganisms. In the present research, the mercury uptake model focuses on a combination of two different mechanisms working simultaneously in bacteria, which are the mechanisms of passive diffusion of neutral relatively hydrophobic mercury complexes and facilitated uptake of positively-charged and neutral mercury species. For the passive diffusion mechanism, only passive diffusion of the mercury species $\mathrm{HgCl}_{2}, \mathrm{Hg}(\mathrm{OH})_{2}, \mathrm{HgClOH}, \mathrm{HgS}^{0}$, and $\mathrm{Hg}(\mathrm{HS})_{2}$ is taken into account in the model. For the facilitated uptake mechanism, only facilitated uptake of the mercury species $\mathrm{HgCl}_{2}, \mathrm{Hg}(\mathrm{OH})_{2}, \mathrm{HgClOH}, \mathrm{HgS}^{0}, \mathrm{Hg}(\mathrm{HS})_{2}, \mathrm{HgCl}^{+}, \mathrm{HgOH}^{+}, \mathrm{HgHS}^{+}$, as well as the possible facilitated uptake of a fraction of $\mathrm{Hg}-\mathrm{NOM}$ complexes in solution, represented by the species $\mathrm{HgRS}^{+}$, were $\mathrm{R}$ is an organic group on NOM and $\mathrm{S}$ is a sulfide group bound to an organic group on NOM. Miller et al. (2009) discuss that there is a reducible fraction of $\mathrm{Hg}$ in $\mathrm{Hg}-\mathrm{NOM}$ complexes, and this fraction has been assumed in the present research to be available to bacteria for uptake. The reducible fraction of $\mathrm{Hg}$ in Hg-NOM complexes is discussed in the following section of the current chapter in the present research. 
Miller et al. (2009) discussed that, in their work, after equilibrating a solution of $\mathrm{Hg}$ and $\mathrm{NOM}$ for at least 24 hours and then adding tin (II) chloride $\left(\mathrm{SnCl}_{2}\right)$, which is expected to reduce mercury in solution from $\mathrm{Hg}^{2+}$ or possibly $\mathrm{Hg}_{2}{ }^{2+}$ to $\mathrm{Hg}^{0}$, the fraction of reducible mercury $\left(\mathrm{Hg}_{\mathrm{R}}\right)$ in solution was only $11 \%$. For solutions with inorganic ligands that were equilibrated for at least 24 hours in the experiments of Miller et al. (2009), Miller et al. (2009) state that ionic $\mathrm{Hg}(\mathrm{II})$ complexed to inorganic ligands was completely reducible by $\mathrm{SnCl}_{2}$ under the conditions studied in their research. Miller et al. (2009) do not specifically discuss the bioavailability of mercury species, including $\mathrm{Hg}-\mathrm{NOM}$ complexes, and do not specifically discuss the difference in bioavailability of reducible mercury $\left(\mathrm{Hg}_{\mathrm{R}}\right)$ and non-reducible mercury $\left(\mathrm{Hg}_{\mathrm{NR}}\right)$. In addition, it is difficult to determine the bioavailability of $\mathrm{Hg}$ bound to NOM. As discussed previously, Zhong and Wang (2009) tested the effect of the origin of DOC on the uptake rate of mercury by microorganisms and observed different mercury uptake rates by microorganisms in solutions that each contained DOC from a different origin.

Miller et al. (2009), as discussed above, found that after a solution of $\mathrm{Hg}$ and NOM had equilibrated for at least 24 hours, only $11 \%$ of the $\mathrm{Hg}$ in solution was reducible by $\mathrm{SnCl}_{2}$. In the present research, for the purposes of modeling uptake of $\mathrm{Hg}-\mathrm{NOM}$ complexes by bacteria, only the reducible fraction of $\mathrm{Hg}$ in $\mathrm{Hg}-\mathrm{NOM}$ complexes is assumed to be available for bacteria to take up. This assumption is not discussed by Miller et al. (2009) and is made strictly for the modeling purposes in the present research. This assumption 
has been made in the present research because, in the research of Miller et al. (2009), $\mathrm{SnCl}_{2}$ was able to reduce a fraction of $\mathrm{Hg}$ in $\mathrm{Hg}-\mathrm{NOM}$ complexes, and it is therefore assumed in the present research that bacteria can also react with and possibly take up this fraction of $\mathrm{Hg}$ on $\mathrm{Hg}-\mathrm{NOM}$ complexes.

Miller et al. (2007) conducted laboratory experiments and thermodynamic equilibrium modeling research to better understand the effects of dissolved organic matter on the complexation of mercury under sulfidic conditions. Miller et al. (2007) measured and calculated individual octanol-water partition coefficient $\left(\mathrm{K}_{\mathrm{ow}}\right)$ values for two neutral dissolved mercury sulfide species, $\mathrm{HgS}^{0}$ and $\mathrm{Hg}(\mathrm{SH})_{2}{ }^{0}$, and found that both species had about the same value of $K_{\text {ow }}=72 \pm 15$ for each species. In addition, Miller et al. (2007) measured and calculated the $\mathrm{K}_{\mathrm{ow}}$ for two complexes of $\mathrm{Hg}$-DOM, each with DOM from a different origin: one was Suwannee River Natural Organic Matter (SR NOM) and the other was a hydrophilic acid DOM isolate from the Florida Everglades. For mercury bound to Suwannee River Natural Organic Matter, Miller et al. (2007) measured and calculated a $\mathrm{K}_{\mathrm{ow}}$ for $\mathrm{Hg}-\mathrm{DOM}$ of $1.7 \pm 1.1$, and for mercury bound to a hydrophilic acid DOM isolate from the Florida Everglades, Miller et al. (2007) measured and calculated a $\mathrm{K}_{\mathrm{ow}}$ for $\mathrm{Hg}$-DOM of $3.3 \pm 2.0$.

In addition, Miller et al. (2007) carried out experiments to determine the overall octanolwater partition coefficient $\left(\mathrm{D}_{\mathrm{ow}}\right)$ for various natural and laboratory-prepared solutions, and compared the measured $\mathrm{D}_{\mathrm{ow}}$ value for each solution, based on their laboratory experiments, to the predicted $D_{o w}$ value for each solution based on the results from their 
thermodynamic equilibrium modeling experiments. The calculated speciation of each of the solutions tested by Miller et al. (2007) showed that inorganic mercury sulfide species would dominate the speciation in each solution, and moreover, the $\mathrm{K}_{\mathrm{ow}}$ value for each of the neutral dissolved mercury sulfide species is much higher than that of the Hg-DOM species. Miller et al. (2007) found that the measured $\mathrm{D}_{\text {ow }}$ values from their laboratory experiments were much lower than the predicted $\mathrm{D}_{\text {ow }}$ values from their thermodynamic equilibrium modeling for each of the solutions they tested. Miller et al. (2007) concluded that their data suggests that DOM influences the complexation of $\mathrm{Hg}$ under sulfidic conditions. Moreover, Miller et al. (2007) suggest that there is a possible complex that involves $\mathrm{Hg}$, DOM, and sulfide, for which there are no known equilibrium constants, shown in the following equation from Miller et al. (2007):

$$
\mathrm{HS}-\mathrm{Hg}-\mathrm{OH}+\mathrm{HR}=\mathrm{HS}-\mathrm{Hg}-\mathrm{R}+\mathrm{H}_{2} \mathrm{O}
$$

where it is assumed that $\mathrm{HR}$ represents an organic compound, with $\mathrm{H}$ being the proton on some functional group R, such as a thiol or carboxylic acid (Miller et al., 2007). From the work of Miller (2006) and Miller et al. (2007), it appears that thermodynamic models cannot accurately predict the speciation of $\mathrm{Hg}$ with NOM in the presence of sulfide.

For the present research, only the $\mathrm{HgRS}^{+}$form of $\mathrm{Hg}$ in $\mathrm{Hg}-\mathrm{NOM}$ complexes is used in the modeling. The $\log \mathrm{K}$ of formation of $\mathrm{HgRS}^{+}$used in the modeling in the present research is close to the average value of the range of $\log \mathrm{K}$ for the formation of $\mathrm{HgRS}^{+}$ reported in the Supporting Information of Miller et al. (2009, and references therein). The 
formation of $\mathrm{Hg}(\mathrm{RS})_{2}$ (see Miller et al., 2009, and references therein) was not included in the model for the present research. This was done to simplify the modeling and represent $\mathrm{Hg}-\mathrm{NOM}$ complexes as one form of $\mathrm{Hg}-\mathrm{NOM}$.

\section{Equilibrium of Mercury Stock Solutions}

In the laboratory experiments, the $\mathrm{HgCl}_{2}$ solution and the $\mathrm{Hg}-\mathrm{NOM}$ solution were each allowed to equilibrate for at least 24 hours prior to being spiked into the washed cell solutions. The $\mathrm{HgCl}_{2}$ solution is assumed to have been at thermodynamic equilibrium by 24 hours. As discussed previously in the Introduction in the present research, the researchers Tebes-Stevens et al. (1998, and reference therein) discuss that, with the exception of aqueous redox reactions, most aqueous speciation reactions, including complexation and acid-base reactions, occur rapidly in comparison with the rate of flow of groundwater, and it is usually valid in groundwater modeling to treat aqueous speciation reactions as if they proceed instantaneously to thermodynamic equilibrium.

As for the $\mathrm{Hg}-\mathrm{NOM}$ stock solutions, it is difficult to assess whether the stock solutions can be considered to be at thermodynamic equilibrium after each had an equilibration period of at least 24 hours. Miller et al. (2009) discuss that, for aquatic systems receiving input of inorganic $\mathrm{Hg}$, equilibrium conditions cannot be assumed in such systems due to the heterogeneity of NOM and the competitive interactions among various functional moieties of NOM for binding with Hg. In their research, Miller et al. (2009) found that only $11 \%$ of $\mathrm{Hg}$ in a solution of $\mathrm{Hg}$ and $\mathrm{NOM}$ was reducible after at least a 24 hour

equilibration period. Moreover, Miller et al. (2009) state that greater than $85 \%$ of the $\mathrm{Hg}$ 
in solution with the NOM is anticipated to be present as nonreducible $\mathrm{Hg}-\mathrm{NOM}$ complexes under equilibrium conditions. Miller et al. (2009) then discuss that, from their kinetics experiments, it appears that $\mathrm{Hg}$ is being transferred from inorganic complexes or reducible $\mathrm{Hg}-\mathrm{NOM}$ to stronger nonreducible/hydrophobic Hg-NOM complexes. From the results that are discussed above from Miller et al. (2009), it appears that, although a solution of $\mathrm{Hg}$ and $\mathrm{SR}$ NOM equilibrated for at least 24 hours may not be at thermodynamic equilibrium, it may be close to thermodynamic equilibrium. Thus, in the present research, the $\mathrm{Hg}-\mathrm{NOM}$ stock solutions prepared in this research are assumed to be at thermodynamic equilibrium, which means it is assumed that $\mathrm{Hg}$ was added as equilibrated $\mathrm{Hg}$-NOM for modeling purposes.

\section{PHREEQC Version 2}

PHREEQC is a computer modeling software that is available by the United States Geological Survey (USGS). According to the PHREEQC (Version 2) User's Guide, written by David L. Parkhurst and C. A. J. Appelo (Parkhurst and Appelo, 1999), PHREEQC has many capabilities for modeling geochemical reactions for a system that include mixing of waters, ion-exchange equilibria, surface-complexation equilibria, kinetically controlled reactions, one-dimensional (1D) transport coupled with diffusion into stagnant zones, and many more capabilities, and of specific interest to this research is the ability of PHREEQC to model kinetic reactions. PHREEQC can be used to model kinetic reactions, and the rate of mercury uptake and accumulation by bacteria can be modeled as a relatively simple kinetic model. 
The PHREEQC (Version 2) User's Manual (Parkhurst and Appelo, 1999) also discusses 18 different example simulations that explain how the PHREEQC code can be used in different types of simulations. One of the examples discussed in the PHREEQC (Version 2) User's Manual (Parkhurst and Appelo, 1999) is Example 15, and this example is based on the work of Tebes-Stevens et al. (1998). Tebes-Stevens et al. (1998) created a reactive transport code called FEREACT, and they state this code was developed to examine the coupled effects of two-dimensional steady-state groundwater flow, equilibrium speciation reactions, and kinetically-controlled interphase reactions. Example 15 in the PHREEQC (Version 2) User's Guide (Parkhurst and Appelo, 1999) is a simulation, using the model PHREEQC, of the research that was conducted by Tebes-Stevens et al. (1998) who developed the code FEREACT. Parkhurst and Appelo (1999) obtained very similar results using PHREEQC to the results Tebes-Stevens et al. (1998) using FEREACT.

In Example 15 from the PHREEQC (Version 2) User's Guide (Parkhurst and Appelo, 1999), multiple simultaneous thermodynamic equilibrium and kinetic reactions are occurring in a system, including biomass growth, metal sorption, and biodegradation of an organic compound. Example 15 from the PHREEQC (Version 2) User's Guide (Parkhurst and Appelo, 1999) may be used as a template, with additional changes, for modeling mercury uptake by cells.

Assumptions for Modeling Mercury Uptake by Bacteria

The following is a list of assumptions for the modeling of mercury uptake by bacteria in the present research: 
1. The two mechanisms of mercury uptake, which are passive diffusion of neutral relatively hydrophobic mercury species and facilitated uptake of neutral and positively-charged mercury species, are combined and are assumed to work simultaneously in bacterial cells for the model

2. The concentration of sulfide in the lactate/sulfate solutions in the laboratory experiments was not measured, and for the purposes of modeling has been assumed to be approximately $1 \mathrm{mM}$ (which is approximately $3.3 \%$ of the total initial added sulfate in each lactate/sulfate solution in the laboratory experiments.

There may be more assumptions inherent in the modeling, and some may be discussed above in the present chapter. 


\section{RESULTS FROM LABORATORY EXPERIMENTS}

Analysis of Supernatant Samples and Test Tube Walls Samples by using the Direct Mercury Analyzer 80 (DMA 80)

A significant effort was made to initially conduct the sample analysis using the Direct Mercury Analyzer 80 (DMA 80) for the supernatant samples and the samples of the test tube walls. However, from the results of these analyses, most of the samples had a calculated concentration of mercury that was below the method detection limit (MDL) of the DMA 80. The results of the MDL determination for the DMA 80, as well as the sample analysis using the DMA 80, are shown in Appendices C and D, respectively. Cell pellet samples from the laboratory experiments were analyzed using inductively coupled plasma - mass spectrometry (ICP-MS), and supernatant samples were reanalyzed using ICP-MS. Due to the high expense of analyzing samples using ICP-MS, only four samples of the test tube walls were reanalyzed using ICP-MS. These samples can be used to obtain an estimate of the average mass of mercury on the test tube walls of each sample.

Analysis of Cell Pellet Samples and Supernatant Samples by using Inductively Coupled Plasma-Mass Spectrometry (ICP-MS)

All of the cell pellet samples and supernatant samples were analyzed using inductively coupled plasma - mass spectrometry (ICP-MS). Only four samples of the test tube walls were analyzed using ICP-MS due to the high expense of analyzing samples using this procedure. These four samples can be used to obtain an estimate of the average mass of 
mercury on the test tube walls of the samples. The following table shows the results of the analysis of the cell pellet samples, the aqueous supernatant samples, and two samples of the test tube walls for the lactate/sulfate experiments, analyzed using ICP-MS.

Table 2: Results of the cell pellet samples, aqueous supernatant samples, and two samples of the test tube walls that were analyzed for the lactate/sulfate experiments, analyzed using ICP-MS. The initial volume of each washed cell solution was approximately $10 \mathrm{~mL}$. (N/A = Not Available).

\begin{tabular}{|c|c|c|c|c|}
\hline Sample Identification & $\begin{array}{c}\text { Measured } \\
\text { Hg mass } \\
\text { in cell } \\
\text { pellet } \\
\text { sample } \\
\text { (ng) }\end{array}$ & $\begin{array}{c}\text { Measured } \mathrm{Hg} \\
\text { concentration } \\
\text { in aqueous } \\
\text { supernatant } \\
\text { sample } \\
(\mathrm{ng} / \mathrm{mL})\end{array}$ & $\begin{array}{c}\text { Measured } \mathrm{Hg} \\
\text { concentration } \\
\text { in samples of } \\
\text { test tube } \\
\text { walls } \\
(\mathrm{ng} / \mathrm{mL})\end{array}$ & $\begin{array}{c}\text { Estimated } \\
\text { number } \\
\text { of cells in } \\
\text { solution } \\
\text { (cells) }\end{array}$ \\
\hline $\begin{array}{l}\text { G20, Lac-Sulf, } 10 \mathrm{~min} \text {, } \\
\mathrm{HgCl}_{2}, \# 1\end{array}$ & 5.7 & $<0.01$ & N/A & $2.20 \mathrm{E}+09$ \\
\hline $\begin{array}{l}\text { G20, Lac-Sulf, } 10 \mathrm{~min} \text {, } \\
\mathrm{HgCl}_{2}, \# 2\end{array}$ & 3.9 & $<0.01$ & N/A & $2.14 \mathrm{E}+09$ \\
\hline $\begin{array}{l}\text { G20, Lac-Sulf, } 20 \mathrm{~min} \text {, } \\
\mathrm{HgCl}_{2} \text {, \#1 }\end{array}$ & 5.3 & $<0.01$ & 0.070 & $7.20 \mathrm{E}+08$ \\
\hline $\begin{array}{l}\text { G20, Lac-Sulf, } 20 \text { min, } \\
\mathrm{HgCl}_{2}, \# 2\end{array}$ & 6.5 & $<0.01$ & N/A & $8.46 \mathrm{E}+08$ \\
\hline $\begin{array}{l}\text { G20, Lac-Sulf, } 30 \mathrm{~min} \text {, } \\
\mathrm{HgCl}_{2}, \# 1\end{array}$ & 8.3 & $<0.01$ & N/A & $2.21 E+09$ \\
\hline $\begin{array}{l}\text { G20, Lac-Sulf, } 30 \mathrm{~min} \text {, } \\
\mathrm{HgCl}_{2} \text {, \#2 }\end{array}$ & 5.7 & $<0.01$ & N/A & $7.20 \mathrm{E}+08$ \\
\hline $\begin{array}{l}\text { G20, Lac-Sulf, } 40 \mathrm{~min} \text {, } \\
\mathrm{HgCl}_{2}, \# 1\end{array}$ & 4.4 & $<0.01$ & N/A & $2.56 \mathrm{E}+09$ \\
\hline $\begin{array}{l}\text { G20, Lac-Sulf, } 40 \text { min, } \\
\mathrm{HgCl}_{2}, \# 2\end{array}$ & 5.2 & $<0.01$ & N/A & $4.86 \mathrm{E}+08$ \\
\hline $\begin{array}{l}\text { G20, Lac-Sulf, } 10 \text { min, } \\
\text { Hg-NOM, } \# 1\end{array}$ & 10.3 & 0.154 & N/A & $7.20 \mathrm{E}+08$ \\
\hline $\begin{array}{l}\text { G20, Lac-Sulf, } 10 \text { min, } \\
\mathrm{Hg} \text {-NOM, \#2 }\end{array}$ & 11.9 & 0.279 & N/A & $2.14 \mathrm{E}+09$ \\
\hline $\begin{array}{l}\text { G20, Lac-Sulf, } 20 \text { min, } \\
\text { Hg-NOM, } \# 1\end{array}$ & 10.4 & 0.115 & 0.087 & $1.60 \mathrm{E}+09$ \\
\hline $\begin{array}{l}\text { G20, Lac-Sulf, } 20 \text { min, } \\
\text { Hg-NOM, \#2 }\end{array}$ & 9.4 & 0.017 & N/A & $1.62 \mathrm{E}+08$ \\
\hline
\end{tabular}




\begin{tabular}{|l|c|c|c|c|}
\hline & $\begin{array}{c}\text { Measured } \\
\text { Hg mass } \\
\text { in cell } \\
\text { pellet } \\
\text { sample } \\
\text { (ng) }\end{array}$ & $\begin{array}{c}\text { Measured Hg } \\
\text { concentration } \\
\text { in aqueous } \\
\text { supernatant } \\
\text { sample } \\
\text { (ng/mL) }\end{array}$ & $\begin{array}{c}\text { Measured Hg } \\
\text { concentration } \\
\text { in samples of } \\
\text { test tube } \\
\text { walls } \\
\text { (ng/mL) }\end{array}$ & $\begin{array}{c}\text { Estimated } \\
\text { number } \\
\text { of cells in } \\
\text { solution } \\
\text { (cells) }\end{array}$ \\
\hline $\begin{array}{l}\text { G20, Lac-Sulf, 30 min, } \\
\text { Hg-NOM, \#1 }\end{array}$ & 3.3 & 0.067 & N/A & $5.04 \mathrm{E}+08$ \\
\hline $\begin{array}{l}\text { G20, Lac-Sulf, } 30 \mathrm{~min}, \\
\text { Hg-NOM, \#2 }\end{array}$ & 6.1 & 0.097 & N/A & $1.57 \mathrm{E}+09$ \\
\hline $\begin{array}{l}\text { G20, Lac-Sulf, } 40 \mathrm{~min}, \\
\text { Hg-NOM, \#1 }\end{array}$ & 8.4 & 0.083 & N/A & $1.35 \mathrm{E}+09$ \\
\hline $\begin{array}{l}\text { G20, Lac-Sulf, } 40 \mathrm{~min}, \\
\text { Hg-NOM, \#2 }\end{array}$ & 5.8 & 0.015 & N/A & $1.64 \mathrm{E}+09$ \\
\hline
\end{tabular}

From the above table for the lactate/sulfate experiments, Table 2, it appears that for the washed cell solutions that had been spiked with $\mathrm{HgCl}_{2}$, the mercury concentration in each of the supernatant samples was below the method detection limit, or at least below the limit of quantitation (LOQ), of the ICP-MS. It is possible that, because sulfide was likely present in these solutions, most of the mercury may have precipitated out of solution as $\mathrm{HgS}(\mathrm{s})$. When the speciation model for these solutions is allowed to include the formation of $\mathrm{HgS}(\mathrm{s})$, under certain conditions, $\mathrm{HgS}(\mathrm{s})$ dominates the speciation of mercury. This is discussed in Chapter IV of the present research in the section entitled Uncertainty of Cinnabar Formation in the Lactate/Sulfate Solutions. Therefore, mercury in the cell pellet samples for these solutions may have precipitated as $\mathrm{HgS}(\mathrm{s})$ and may not have been taken up by bacteria. For the washed cell solutions from the lactate/sulfate experiments that had been spiked with $\mathrm{Hg}-\mathrm{NOM}$, the mercury concentration in each of the supernatant samples was detectable. From Table 2, it can be seen that for the two samples of the test tube walls that were analyzed, the concentration of mercury was 
significant and comparable to the concentration of mercury in the respective supernatant samples. It is also important to note that the range of the estimated number of cells in each of the washed cell solutions, between all of the washed cell solutions for the lactate/sulfate experiments, was approximately one order of magnitude, from $1.62 * 10^{8}$ cells to $2.56 * 10^{9}$ cells. The following table compares the measured mass of mercury in each cell pellet sample to the calculated mass of mercury in each respective supernatant sample for the lactate/sulfate experiments. In addition, for the two samples of the test tube walls that were analyzed for the lactate/sulfate experiments, the calculated mass of mercury in each of these samples is also shown.

Table 3: Measured and calculated masses of mercury for the samples from the lactate/sulfate experiments, analyzed using ICP-MS, and the ratio of the mass of mercury in the cell pellet sample to the mass of mercury in the aqueous supernatant sample. See notes on the bottom of the table for more details. (N/A = Not Available).

\begin{tabular}{|c|c|c|c|c|}
\hline Sample Identification & $\begin{array}{c}\text { Measured } \\
\text { Hg mass } \\
\text { in cell } \\
\text { pellet } \\
\text { sample } \\
\text { (ng) }\end{array}$ & $\begin{array}{l}\text { Calculated } \\
\text { mass of } \mathrm{Hg} \\
\text { in aqueous } \\
\text { supernatant } \\
\text { sample (ng) }\end{array}$ & $\begin{array}{c}\text { Calculated } \\
\text { mass of } \mathrm{Hg} \\
\text { in sample } \\
\text { of the test } \\
\text { tube walls } \\
\text { (ng) }\end{array}$ & $\begin{array}{c}\text { Calculated ratio } \\
\text { of } \mathrm{Hg} \text { mass in } \\
\text { cell pellet } \\
\text { sample to } \mathrm{Hg} \\
\text { mass in } \\
\text { supernatant } \\
\text { sample (ng/ng) }\end{array}$ \\
\hline $\begin{array}{l}\text { G20, Lac-Sulf, } 10 \text { min, } \\
\mathrm{HgCl} 2, \# 1\end{array}$ & 5.7 & $<0.1$ & N/A & 57 \\
\hline $\begin{array}{l}\text { G20, Lac-Sulf, } 10 \mathrm{~min} \text {, } \\
\mathrm{HgCl} 2 \text {, \#2 }\end{array}$ & 3.9 & $<0.1$ & N/A & 39 \\
\hline $\begin{array}{l}\text { G20, Lac-Sulf, } 20 \mathrm{~min} \text {, } \\
\mathrm{HgCl} 2 \text {, \#1 }\end{array}$ & 5.3 & $<0.1$ & 0.70 & 53 \\
\hline $\begin{array}{l}\text { G20, Lac-Sulf, } 20 \mathrm{~min} \text {, } \\
\mathrm{HgCl} 2 \text {, \#2 }\end{array}$ & 6.5 & $<0.1$ & N/A & 65 \\
\hline $\begin{array}{l}\text { G20, Lac-Sulf, } 30 \mathrm{~min} \text {, } \\
\mathrm{HgCl} 2 \text {, \#1 }\end{array}$ & 8.3 & $<0.1$ & N/A & 83 \\
\hline $\begin{array}{l}\text { G20, Lac-Sulf, } 30 \mathrm{~min} \text {, } \\
\mathrm{HgCl} 2 \text {, \#2 }\end{array}$ & 5.7 & $<0.1$ & N/A & 57 \\
\hline
\end{tabular}




\begin{tabular}{|l|c|c|c|c|}
\hline & $\begin{array}{c}\text { Measured } \\
\text { Hg mass } \\
\text { in cell } \\
\text { pellet } \\
\text { sample } \\
\text { (ng) }\end{array}$ & $\begin{array}{c}\text { Calculated } \\
\text { mass of Hg } \\
\text { in aqueous } \\
\text { supernatant } \\
\text { sample (ng) }\end{array}$ & $\begin{array}{c}\text { Calculated } \\
\text { mass of Hg } \\
\text { in sample } \\
\text { of the test } \\
\text { tube walls } \\
\text { (ng) }\end{array}$ & $\begin{array}{c}\text { Calculated ratio } \\
\text { of Hg mass in } \\
\text { cell pellet } \\
\text { sample to Hg } \\
\text { mass in } \\
\text { supernatant } \\
\text { sample (ng/ng) }\end{array}$ \\
\hline $\begin{array}{l}\text { G20, Lac-Sulf, } 40 \text { min, } \\
\text { HgCl2, \#1 }\end{array}$ & 4.4 & $<0.1$ & N/A & 44 \\
\hline $\begin{array}{l}\text { G20, Lac-Sulf, } 40 \text { min, } \\
\text { HgCl2, \#2 }\end{array}$ & 5.2 & $<0.1$ & N/A & 52 \\
\hline $\begin{array}{l}\text { G20, Lac-Sulf, 10 min, } \\
\text { Hg-NOM, \#1 }\end{array}$ & 10.3 & 1.54 & N/A & 7 \\
\hline $\begin{array}{l}\text { G20, Lac-Sulf, 10 min, } \\
\text { Hg-NOM, \#2 }\end{array}$ & 11.9 & 2.79 & N/A & 4 \\
\hline $\begin{array}{l}\text { G20, Lac-Sulf, 20 min, } \\
\text { Hg-NOM, \#1 }\end{array}$ & 10.4 & 1.15 & 0.87 & 9 \\
\hline $\begin{array}{l}\text { G20, Lac-Sulf, } 20 \text { min, } \\
\text { Hg-NOM, \#2 }\end{array}$ & 9.4 & 0.17 & N/A & 55 \\
\hline $\begin{array}{l}\text { G20, Lac-Sulf, 30 min, } \\
\text { Hg-NOM, \#1 }\end{array}$ & 3.3 & 0.67 & N/A & 5 \\
\hline $\begin{array}{l}\text { G20, Lac-Sulf, 30 min, } \\
\text { Hg-NOM, \#2 }\end{array}$ & 6.1 & 0.97 & N/A & 6 \\
\hline $\begin{array}{l}\text { G20, Lac-Sulf, 40 min, } \\
\text { Hg-NOM, \#1 }\end{array}$ & 8.4 & 0.83 & N/A & 10 \\
\hline $\begin{array}{l}\text { G20, Lac-Sulf, 40 min, } \\
\text { Hg-NOM, \#2 }\end{array}$ & 5.8 & 0.15 & N/A & 38 \\
\hline
\end{tabular}

Notes: For each supernatant sample that had a concentration below the detection limit of the ICP-MS, a value of $0.1 \mathrm{ng} \mathrm{Hg}$ was assumed to calculate the ratio of the mass of mercury in the cell pellet to the mass of mercury in the supernatant. In addition, the initial volume of each washed cell solution was approximately $10 \mathrm{~mL}$, which was used to calculate the mass of $\mathrm{Hg}$ in each supernatant sample and in each sample of the test tube walls.

From Table 3 above, for each incubation time for the lactate/sulfate experiments, the ratio of the mass of mercury in the cell pellet sample to the mass of mercury in the supernatant sample was generally higher for the washed cell solutions that had been spiked with $\mathrm{HgCl}_{2}$ than for the washed cell solutions that had been spiked with $\mathrm{Hg}-\mathrm{NOM}$. Two of the eight total washed cell solutions that had been spiked with $\mathrm{Hg}-\mathrm{NOM}$ show a relatively 
high ratio of the mass of mercury in the cell pellet to the mass of mercury in the supernatant, but the duplicate of each of these washed cell solutions has a lower ratio. The following figure compares the measured mass of mercury in the cell pellet sample to the calculated mass of mercury in the supernatant sample for each washed cell solution in the lactate/sulfate experiments that had been spiked with $\mathrm{HgCl}_{2}$.

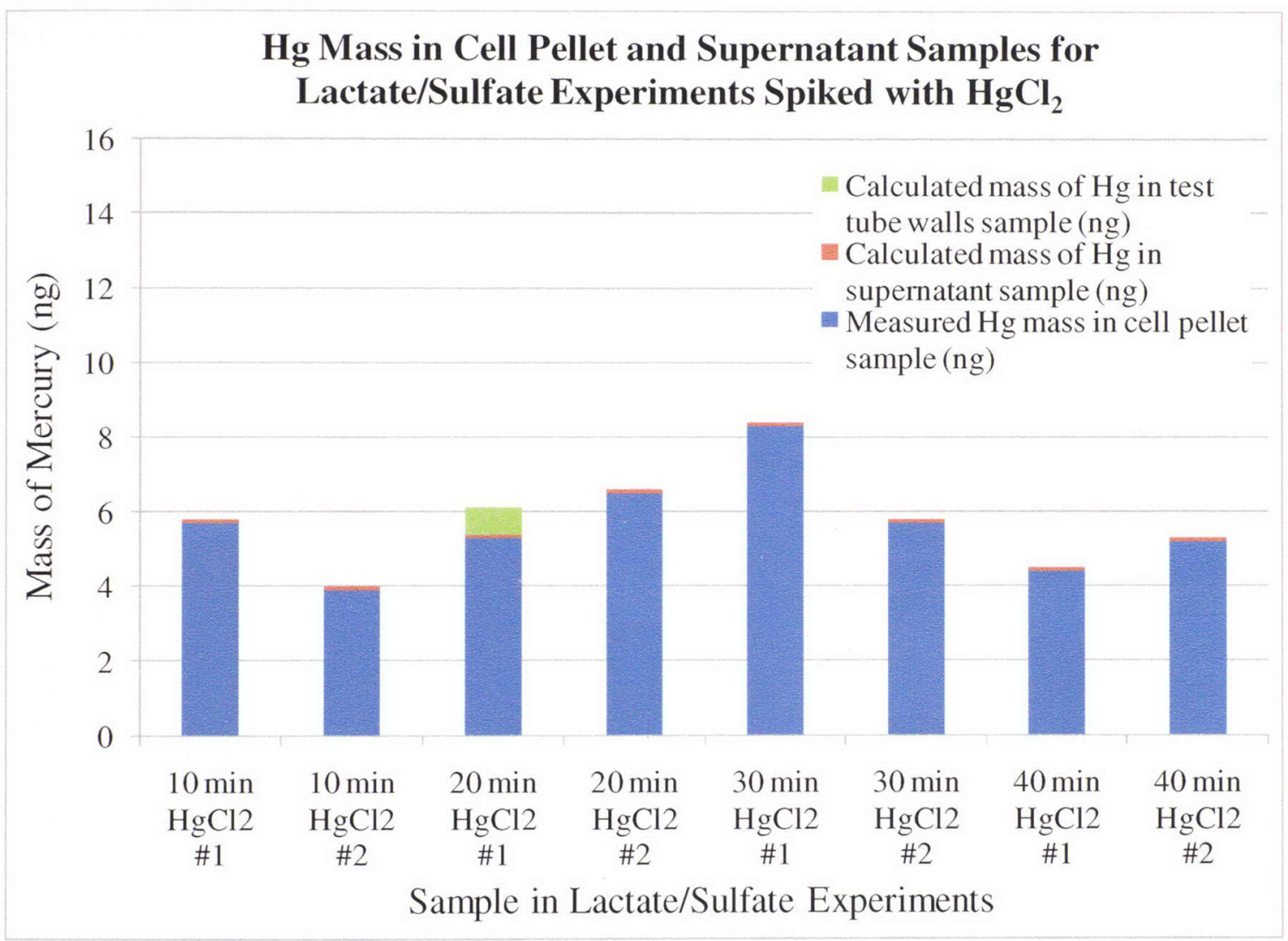

Figure 6: Mass of mercury in the cell pellet sample and the supernatant sample, for each washed cell solution in the lactate/sulfate experiments that had been spiked with $\mathrm{HgCl}_{2}$. One sample of the test tube walls was analyzed.

From Figure 6, for the washed cell solutions from the lactate/sulfate experiments that had been spiked with $\mathrm{HgCl}_{2}$, the measured mass of mercury in each cell pellet sample was 
much higher than the calculated mass of mercury in each supernatant sample. It is possible that the supernatant concentration of mercury in these experiments could have been due to the formation of $\mathrm{HgS}(\mathrm{s})$ in solution, though this could not be measured in the laboratory experiments. The test tube walls sample that was analyzed had a detectable mass of mercury that was greater than the mass of mercury in the respective supernatant sample. The following figure compares the measured mass of mercury in the cell pellet sample to the calculated mass of mercury in the supernatant sample for each washed cell solution in the lactate/sulfate experiments that had been spiked with $\mathrm{Hg}-\mathrm{NOM}$.

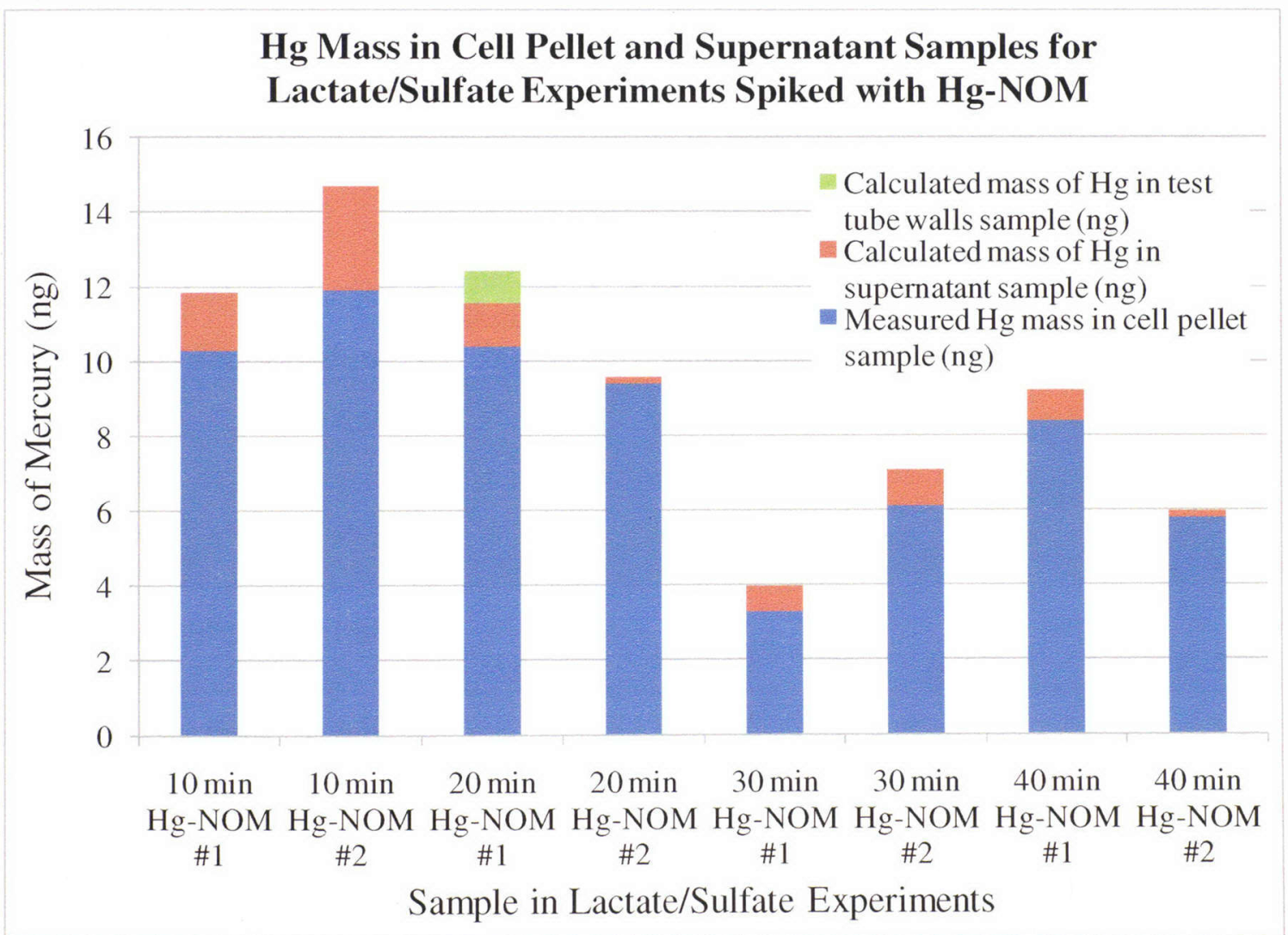

Figure 7: Mass of mercury in the cell pellet sample and the supernatant sample for each washed cell solution in the lactate/sulfate experiments that had been spiked with $\mathrm{Hg}-\mathrm{NOM}$. One sample of the test tube walls was analyzed. 
From Figure 7, for the washed cell solutions from the lactate/sulfate experiments that had been spiked with $\mathrm{Hg}-\mathrm{NOM}$, the mass of mercury in each cell pellet sample was higher than the mass of mercury in each supernatant sample. The test tube walls sample that had been analyzed had a detectable mass of mercury that was comparable to the mass of mercury in the respective supernatant sample. The following table show the results of the analysis of the cell pellet samples, supernatant samples, and test tube walls samples for the pyruvate/fumarate experiments, analyzed using ICP-MS.

Table 4: Results of the cell pellet samples, aqueous supernatant samples, and two samples of the test tube walls that were analyzed for the pyruvate/fumarate experiments, analyzed using ICP-MS. The initial volume of each washed cell solution was approximately $10 \mathrm{~mL}$. (N/A = Not Available).

\begin{tabular}{|c|c|c|c|c|}
\hline Sample Identification & $\begin{array}{c}\text { Measured } \\
\text { mass of } \\
\mathrm{Hg} \text { in cell } \\
\text { pellet } \\
\text { sample } \\
\text { (ng) }\end{array}$ & $\begin{array}{c}\text { Measured Hg } \\
\text { concentration } \\
\text { in aqueous } \\
\text { supernatant } \\
\text { sample } \\
(\mathrm{ng} / \mathrm{mL}) \\
\end{array}$ & $\begin{array}{c}\text { Measured Hg } \\
\text { concentration } \\
\text { in samples of } \\
\text { test tube } \\
\text { walls } \\
(\mathrm{ng} / \mathrm{mL}) \\
\end{array}$ & $\begin{array}{c}\text { Estimated } \\
\text { number } \\
\text { of cells in } \\
\text { solution } \\
\text { (cells) }\end{array}$ \\
\hline $\begin{array}{l}\text { G20, Pyruv-Fum, } 40 \mathrm{~min} \text {, } \\
\mathrm{HgCl}_{2}, \# 1\end{array}$ & 10.9 & 0.21 & N/A & $1.03 \mathrm{E}+09$ \\
\hline $\begin{array}{l}\text { G20, Pyruv-Fum, } 40 \text { min, } \\
\mathrm{HgCl}_{2}, \# 2\end{array}$ & 3.9 & 0.12 & N/A & $5.22 \mathrm{E}+08$ \\
\hline $\begin{array}{l}\text { G20, Pyruv-Fum, } 50 \text { min, } \\
\mathrm{HgCl}_{2}, \# 1\end{array}$ & 4.6 & 0.17 & 0.078 & $1.17 \mathrm{E}+09$ \\
\hline $\begin{array}{l}\text { G20, Pyruv-Fum, } 50 \mathrm{~min} \text {, } \\
\mathrm{HgCl}_{2}, \# 2\end{array}$ & 6.4 & 0.13 & N/A & $5.94 \mathrm{E}+08$ \\
\hline $\begin{array}{l}\text { G20, Pyruv-Fum, } 80 \mathrm{~min} \text {, } \\
\mathrm{HgCl}_{2}, \# 1\end{array}$ & 6.2 & 0.06 & N/A & $8.10 \mathrm{E}+08$ \\
\hline $\begin{array}{l}\text { G20, Pyruv-Fum, } 80 \mathrm{~min} \text {, } \\
\mathrm{HgCl}_{2}, \# 2\end{array}$ & 6.6 & $<0.01$ & N/A & $2.05 \mathrm{E}+09$ \\
\hline $\begin{array}{l}\text { G20, Pyruv-Fum, } 90 \mathrm{~min} \text {, } \\
\mathrm{HgCl}_{2}, \# 1\end{array}$ & 4.2 & 0.03 & N/A & $1.60 \mathrm{E}+09$ \\
\hline
\end{tabular}




\begin{tabular}{|c|c|c|c|c|}
\hline Sample Identification & $\begin{array}{l}\text { Measured } \\
\text { mass of } \\
\mathrm{Hg} \text { in cell } \\
\text { pellet } \\
\text { sample } \\
\text { (ng) }\end{array}$ & $\begin{array}{c}\text { Measured } \mathrm{Hg} \\
\text { concentration } \\
\text { in aqueous } \\
\text { supernatant } \\
\text { sample } \\
(\mathrm{ng} / \mathrm{mL}) \\
\end{array}$ & $\begin{array}{c}\text { Measured Hg } \\
\text { concentration } \\
\text { in samples of } \\
\text { test tube } \\
\text { walls } \\
(\mathrm{ng} / \mathrm{mL})\end{array}$ & $\begin{array}{c}\text { Estimated } \\
\text { number } \\
\text { of cells in } \\
\text { solution } \\
\text { (cells) }\end{array}$ \\
\hline $\begin{array}{l}\text { G20, Pyruv-Fum, } 90 \mathrm{~min} \text {, } \\
\mathrm{HgCl}_{2}, \# 2\end{array}$ & 5.2 & 0.16 & N/A & $1.21 \mathrm{E}+09$ \\
\hline $\begin{array}{l}\text { G20, Pyruv-Fum, } 40 \mathrm{~min} \text {, } \\
\text { Hg-NOM, \#1 }\end{array}$ & 4.5 & 0.12 & N/A & $1.70 \mathrm{E}+08$ \\
\hline $\begin{array}{l}\text { G20, Pyruv-Fum, } 40 \mathrm{~min} \text {, } \\
\text { Hg-NOM, \#2 }\end{array}$ & 3.2 & 0.26 & N/A & $5.58 \mathrm{E}+08$ \\
\hline $\begin{array}{l}\text { G20, Pyruv-Fum, } 50 \mathrm{~min} \text {, } \\
\text { Hg-NOM, \#1 }\end{array}$ & 3.4 & 0.17 & 0.175 & $1.06 \mathrm{E}+09$ \\
\hline $\begin{array}{l}\text { G20, Pyruv-Fum, } 50 \mathrm{~min} \text {, } \\
\text { Hg-NOM, \#2 }\end{array}$ & 4.2 & 0.02 & N/A & $6.84 \mathrm{E}+08$ \\
\hline $\begin{array}{l}\text { G20, Pyruv-Fum, } 80 \mathrm{~min} \text {, } \\
\text { Hg-NOM, \#1 }\end{array}$ & 2.7 & 0.04 & N/A & $1.73 \mathrm{E}+09$ \\
\hline $\begin{array}{l}\text { G20, Pyruv-Fum, } 80 \mathrm{~min} \text {, } \\
\text { Hg-NOM, \#2 }\end{array}$ & 3 & 0.17 & N/A & $2.36 \mathrm{E}+09$ \\
\hline $\begin{array}{l}\text { G20, Pyruv-Fum, } 90 \mathrm{~min} \text {, } \\
\text { Hg-NOM, \#1 }\end{array}$ & 4.3 & 0.2 & N/A & $6.12 \mathrm{E}+08$ \\
\hline $\begin{array}{l}\text { G20, Pyruv-Fum, } 90 \mathrm{~min} \text {, } \\
\mathrm{Hg}-\mathrm{NOM}, \# 2\end{array}$ & 3.6 & 0.17 & N/A & $1.44 \mathrm{E}+09$ \\
\hline
\end{tabular}

From Table 4 above for the pyruvate/fumarate experiments, the measured concentrations of mercury in the supernatant samples were detectable for almost all of the samples spiked with either $\mathrm{HgCl}_{2}$ or $\mathrm{Hg}-\mathrm{NOM}$, which is in contrast to the results from the lactate/sulfate experiments that had been spiked with $\mathrm{HgCl}_{2}$. For the pyruvate/fumarate experiments, the measured masses of mercury in the cell pellet samples were comparable between washed cell solutions that had been spiked with either $\mathrm{HgCl}_{2}$ or $\mathrm{Hg}-\mathrm{NOM}$. In addition, the measured concentration of mercury in each of the two test tube walls samples that had been analyzed is significant and comparable to the measured 
concentration of mercury in each respective supernatant sample. It is also important to note that the range of the estimated number of cells in each of the washed cell solutions, between all of the washed cell solutions for the pyruvate/fumarate experiments, was approximately one order of magnitude, from $1.70 * 10^{8}$ cells to $2.36 * 10^{9}$ cells.

The following table compares the measured mass of mercury in each cell pellet sample to the calculated mass of mercury in each respective aqueous supernatant sample for the pyruvate/fumarate experiments. In addition, for the two samples of the test tube walls that were analyzed for the pyruvate/fumarate experiments, the calculated mass of mercury in each of these samples is shown.

Table 5: Measured and calculated masses of mercury for the samples from the pyruvate/fumarate experiments, analyzed using ICP-MS, and the ratio of the mass of mercury in the cell pellet sample to the mass of mercury in the aqueous supernatant sample. See notes at the bottom for more details. (N/A = Not Available).

\begin{tabular}{|c|c|c|c|c|}
\hline $\begin{array}{c}\text { Sample } \\
\text { Identification }\end{array}$ & $\begin{array}{c}\text { Measured } \\
\text { mass of } \\
\text { Hg in cell } \\
\text { pellet } \\
\text { sample } \\
(\mathrm{ng}) \\
\end{array}$ & $\begin{array}{c}\text { Calculated } \\
\text { mass of } \mathrm{Hg} \\
\text { in aqueous } \\
\text { supernatant } \\
\text { sample (ng) }\end{array}$ & $\begin{array}{c}\text { Calculated } \\
\text { mass of } \mathrm{Hg} \\
\text { in sample } \\
\text { of the test } \\
\text { tube walls } \\
\text { (ng) }\end{array}$ & $\begin{array}{c}\text { Calculated ratio } \\
\text { of } \mathrm{Hg} \text { mass in } \\
\text { cell pellet } \\
\text { sample to } \mathrm{Hg} \\
\text { mass in } \\
\text { supernatant } \\
\text { sample (ng/ng) } \\
\end{array}$ \\
\hline $\begin{array}{l}\text { G20, Pyruv-Fum, } \\
40 \text { min, } \mathrm{HgCl}_{2}, \# 1\end{array}$ & 10.9 & 2.1 & N/A & 5 \\
\hline $\begin{array}{l}\text { G20, Pyruv-Fum, } \\
40 \text { min, } \mathrm{HgCl}_{2}, \# 2\end{array}$ & 3.9 & 1.2 & N/A & 3 \\
\hline $\begin{array}{l}\text { G20, Pyruv-Fum, } \\
50 \mathrm{~min}, \mathrm{HgCl}_{2}, \# 1\end{array}$ & 4.6 & 1.7 & 0.78 & 3 \\
\hline $\begin{array}{l}\text { G20, Pyruv-Fum, } \\
50 \mathrm{~min}, \mathrm{HgCl}_{2}, \# 2\end{array}$ & 6.4 & 1.3 & N/A & 5 \\
\hline $\begin{array}{l}\text { G20, Pyruv-Fum, } \\
80 \text { min, } \mathrm{HgCl}_{2}, \# 1\end{array}$ & 6.2 & 0.6 & N/A & 10 \\
\hline
\end{tabular}




\begin{tabular}{|c|c|c|c|c|}
\hline $\begin{array}{c}\text { Sample } \\
\text { Identification } \\
\end{array}$ & $\begin{array}{l}\text { Measured } \\
\text { mass of } \\
\text { Hg in cell } \\
\text { pellet } \\
\text { sample } \\
(\mathrm{ng})\end{array}$ & $\begin{array}{c}\text { Calculated } \\
\text { mass of } \mathrm{Hg} \\
\text { in aqueous } \\
\text { supernatant } \\
\text { sample (ng) }\end{array}$ & $\begin{array}{c}\text { Calculated } \\
\text { mass of } \mathrm{Hg} \\
\text { in sample } \\
\text { of the test } \\
\text { tube walls } \\
\text { (ng) }\end{array}$ & $\begin{array}{c}\text { Calculated ratio } \\
\text { of } \mathrm{Hg} \text { mass in } \\
\text { cell pellet } \\
\text { sample to } \mathrm{Hg} \\
\text { mass in } \\
\text { supernatant } \\
\text { sample (ng/ng) }\end{array}$ \\
\hline $\begin{array}{l}\mathrm{G} 20, \text { Pyruv-Fum, } \\
80 \mathrm{~min}, \mathrm{HgCl}_{2}, \# 2\end{array}$ & 6.6 & $<0.1$ & N/A & 66 \\
\hline $\begin{array}{l}\text { G20, Pyruv-Fum, } \\
90 \text { min, } \mathrm{HgCl}_{2}, \# 1\end{array}$ & 4.2 & 0.3 & N/A & 13 \\
\hline $\begin{array}{l}\text { G20, Pyruv-Fum, } \\
90 \mathrm{~min}, \mathrm{HgCl}_{2}, \# 2\end{array}$ & 5.2 & 1.6 & N/A & 3 \\
\hline $\begin{array}{l}\text { G20, Pyruv-Fum, } \\
40 \text { min, Hg-NOM, } \# 1\end{array}$ & 4.5 & 1.2 & N/A & 4 \\
\hline $\begin{array}{l}\text { G20, Pyruv-Fum, } \\
40 \text { min, } \mathrm{Hg}-\mathrm{NOM}, \# 2\end{array}$ & 3.2 & 2.6 & N/A & 1 \\
\hline $\begin{array}{l}\text { G20, Pyruv-Fum, } \\
50 \text { min, Hg-NOM, } \# 1\end{array}$ & 3.4 & 1.7 & 1.75 & 2 \\
\hline $\begin{array}{l}\text { G20, Pyruv-Fum, } \\
50 \text { min, Hg-NOM, \#2 }\end{array}$ & 4.2 & 0.2 & N/A & 17 \\
\hline $\begin{array}{l}\text { G20, Pyruv-Fum, } \\
80 \text { min, Hg-NOM, \#1 }\end{array}$ & 2.7 & 0.4 & N/A & 7 \\
\hline $\begin{array}{l}\text { G20, Pyruv-Fum, } \\
80 \text { min, Hg-NOM, \#2 }\end{array}$ & 3 & 1.7 & N/A & 2 \\
\hline $\begin{array}{l}\text { G20, Pyruv-Fum, } \\
90 \text { min, Hg-NOM, \#1 }\end{array}$ & 4.3 & 2 & N/A & 2 \\
\hline $\begin{array}{l}\text { G20, Pyruv-Fum, } \\
90 \text { min, Hg-NOM, \#2 }\end{array}$ & 3.6 & 1.7 & N/A & 2 \\
\hline
\end{tabular}

Notes: For the supernatant sample that had a concentration below the detection limit of the ICP-MS, a value of $0.1 \mathrm{ng} \mathrm{Hg}$ was assumed to calculate the ratio of the mass of mercury in the cell pellet to the mass of mercury in the supernatant. In addition, the initial volume of each washed cell solution was approximately $10 \mathrm{~mL}$, which was used to calculate the mass of mercury in each supernatant sample and in each sample of the test tube walls.

From Table 5, for the pyruvate/fumarate experiments, the measured mass of mercury in each cell pellet sample was greater than the calculated mass of mercury in each respective supernatant sample. In addition, the ratio of the measured mass of mercury in the cell 
pellet sample to the calculated mass of mercury in the supernatant sample was higher for most of the washed cell solutions that had been spiked with $\mathrm{HgCl}_{2}$ than those spiked with Hg-NOM. The following figure compares the measured mass of mercury in the cell pellet sample to the calculated mass of mercury in the supernatant sample for each washed cell solution in the pyruvate/fumarate experiments that had been spiked with $\mathrm{HgCl}_{2}$.

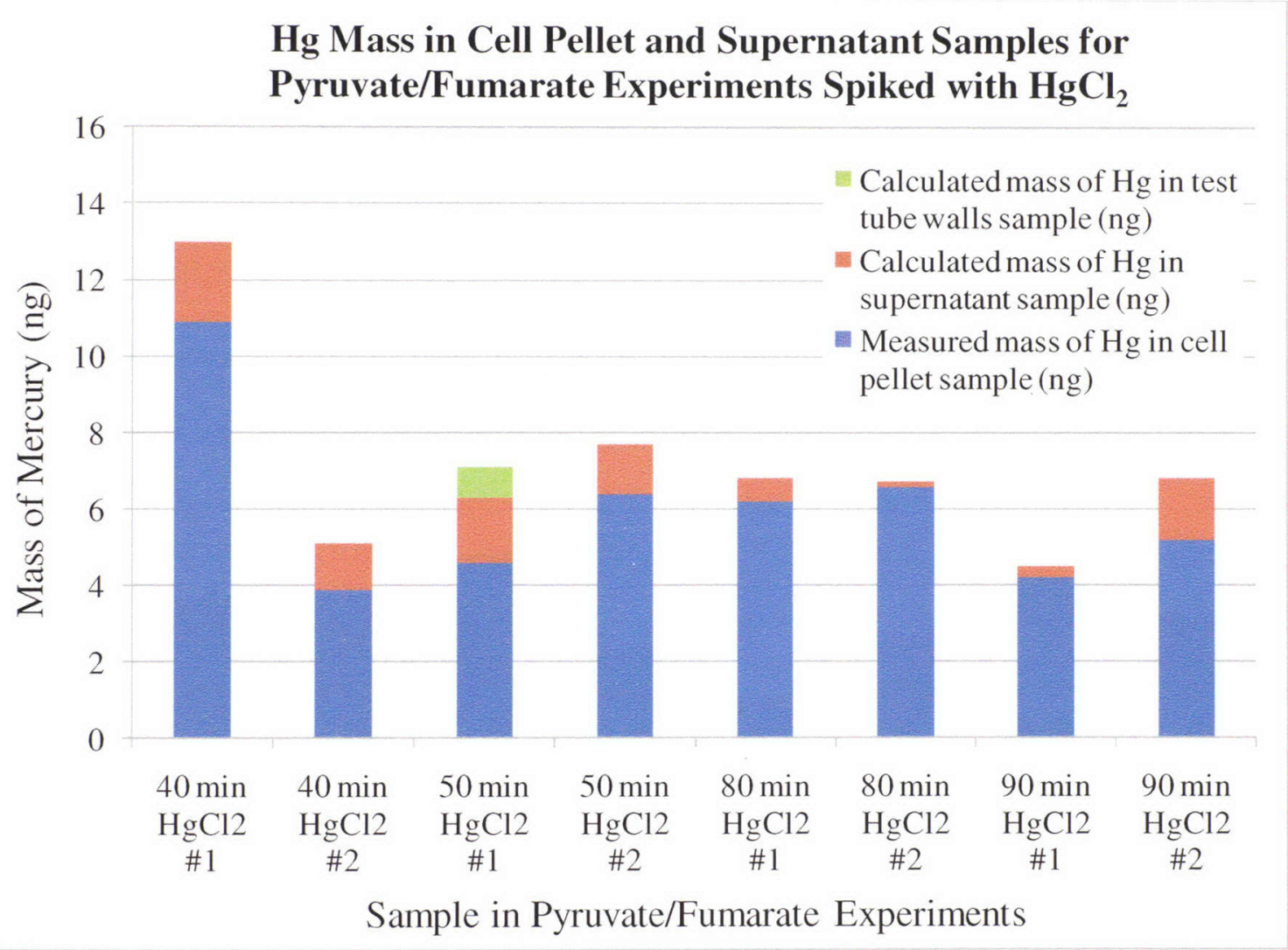

Figure 8: Mass of mercury in the cell pellet sample and the supernatant sample for each washed cell solution in the pyruvate/fumarate experiments that had been spiked with $\mathrm{HgCl}_{2}$. One sample of the test tube walls was analyzed.

From Figure 8, for the washed cell solutions from the pyruvate/fumarate experiments that had been spiked with $\mathrm{HgCl}_{2}$, the measured mass of mercury in each cell pellet sample 
was greater than the calculated mass of mercury in each supernatant sample. In addition, the calculated mass of mercury in the sample of the test tube walls that was analyzed was comparable to the calculated mass of mercury in the respective supernatant sample. The following figure compares the measured mass of mercury in the cell pellet sample to the calculated mass of mercury in the supernatant sample for each washed cell solution in the pyruvate/fumarate experiments that had been spiked with $\mathrm{Hg}-\mathrm{NOM}$.

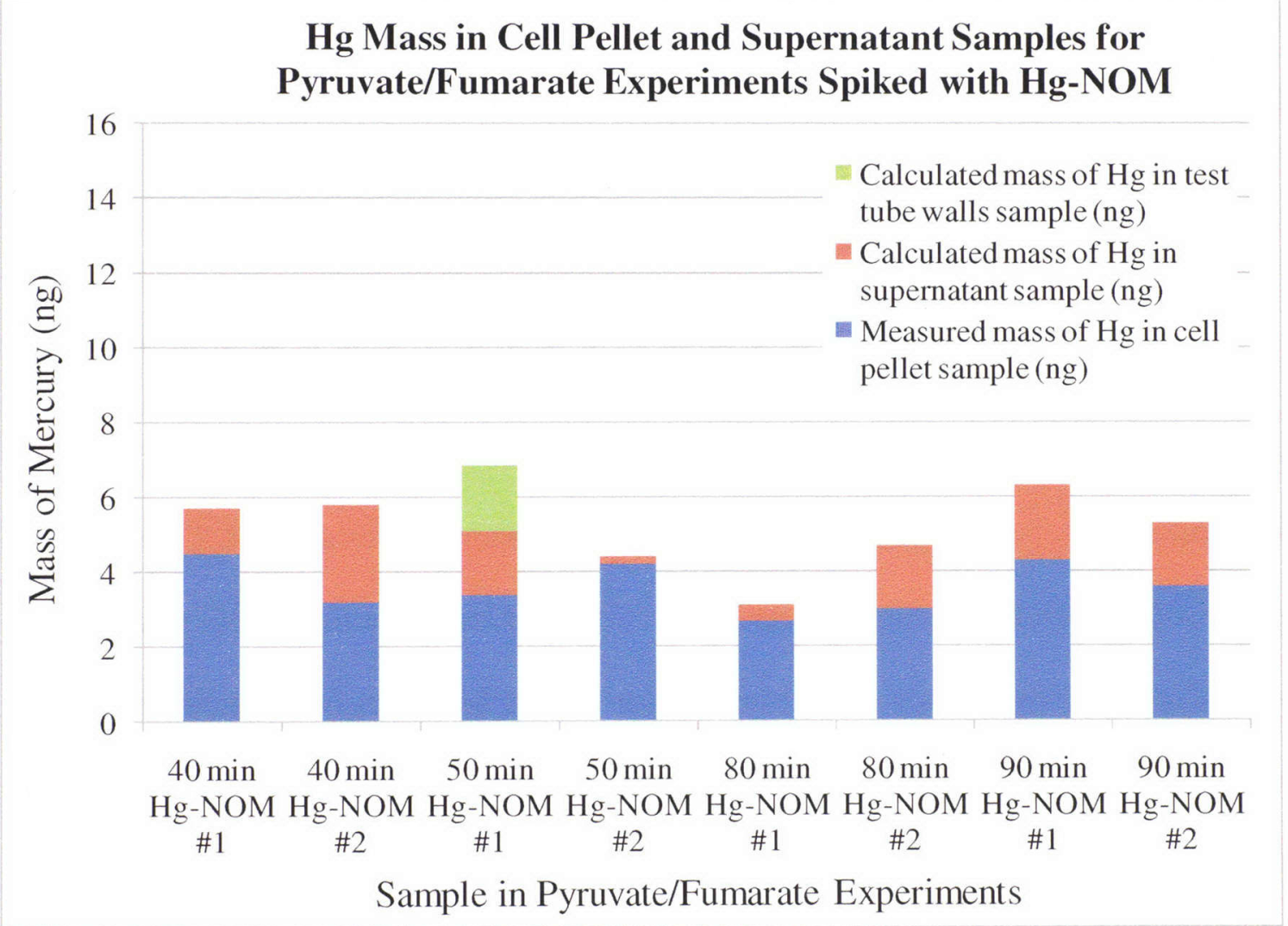

Figure 9: Mass of mercury in the cell pellet sample and in the supernatant sample for each washed cell solution in the pyruvate/fumarate experiments that had been spiked with Hg-NOM. One sample of the test tube walls was analyzed. 
From Figure 9, for most of the washed cell solutions from the pyruvate/fumarate experiments that had been spiked with $\mathrm{Hg}-\mathrm{NOM}$, the measured mass of mercury in each cell pellet sample is comparable to the calculated mass of mercury in each respective supernatant sample. For the one sample of the test tube walls that was analyzed, the calculated mass of mercury in the sample is comparable to the calculated mass of mercury in the respective supernatant sample and cell pellet sample. For the pyruvate/fumarate experiments, the masses of mercury in the cell pellet samples for the washed cell solutions that had been spiked with $\mathrm{Hg}-\mathrm{NOM}$ are, for most of the washed cell solutions, lower than the masses of mercury in the cell pellet samples for the washed cell solutions that had been spiked with $\mathrm{HgCl}_{2}$.

\section{Difference in Results from the DMA 80 and Results from ICP-MS}

The DMA 80 analysis was conducted by the present researcher and completed in October 2010. The ICP-MS analysis was conducted by professional chemists in the Department of Chemistry in Florida International University (FIU) and completed in February 2011. The supernatant samples from the laboratory experiments were initially analyzed using the DMA 80 , but the results of the analysis showed that most of the supernatant samples and samples of the test tube walls had mercury concentrations that were below the method detection limit (MDL) of the DMA 80. Therefore, all of the supernatant samples and four of the samples of the test tube walls were reanalyzed using ICP-MS. There were only a few supernatant samples that had been analyzed by the DMA 80 that had mercury concentrations above the limit of quantitation (LOQ) of the DMA 80. The limit of quantitation is the lowest concentration at which quantitative measurements can be made 
(Skoog, Holler, and Nieman, 1998). The mercury concentrations of these samples from the results of the DMA 80 analysis were about one order of magnitude higher than the mercury concentrations of the same samples from the results of the ICP-MS analysis. The results of these samples from the DMA 80 analysis are shown in Table 25 of Appendix D. The concentration of mercury in each of these samples analyzed using the DMA 80 can be compared to the concentration of mercury in each of the same samples analyzed using ICP-MS, shown in Table 2 above.

During DMA 80 analysis of the samples, each sample was left uncapped for approximately 20 seconds while a sample volume was extracted with a clean pipette tip. Thus, it is unlikely that this short time interval of samples being uncapped could have resulted in any volatilization or significant decrease in concentration of mercury. The mercury reference standard solution that was used to calculate the method detection limit (MDL) and create the calibration curve for the DMA 80, which had a concentration of 1000 parts per million $(\mathrm{ppm}) \pm 1 \%$ mercury in $1.8 \%$ nitric acid solution, had been expired by approximately two weeks when it was used for the MDL calculation and calibration curve creation for the DMA 80. However, Katsenovich et al. (2009) calculated a MDL and created a calibration curve similar to the calculated MDL and calibration curve in the present research for the same exact DMA 80 in the Soil and Groundwater Laboratory at the Applied Research Center (ARC) in Florida International University (FIU).

Thus, it is difficult to ascertain where an error in the analysis of the samples could have occurred. Because the ICP-MS procedure was likely carried out with higher quality 
control than the DMA 80 procedure, the results from the ICP-MS are likely more reliable than the results from the DMA 80 . Therefore, the results and discussion are presented given the limitations described above.

\section{Mass Balance Discrepancy for Results of ICP-MS Analysis}

For each washed cell solution in the laboratory experiments, the sum of the mass of mercury in the cell pellet, supernatant, and test tube walls samples should equal approximately $100 \mathrm{ng}$ of $\mathrm{Hg}$. This is because the initial concentration of mercury in each washed cell solution was $10 \mathrm{ng} \mathrm{Hg} / \mathrm{mL}$, and the total volume of each washed cell solution was $10 \mathrm{~mL}$. However, as is clear from the above results analyzed using ICP-MS, the mercury mass balance is approximately one order of magnitude lower than expected for each washed cell solution. One possible reason for this discrepancy in the mass balance could be that mercury may have volatilized from the solutions during the laboratory experiments, though this was not predicted in the speciation modeling and could not be measured during the laboratory experiments. In addition, the test tubes containing the washed cell solutions were sealed with rubber stoppers and aluminum crimps throughout the laboratory experiments, therefore it is unlikely that volatilization occurred. If volatilization did occur, mercury may have bound to the rubber stoppers on the test tubes, though this could not be measured in the laboratory experiments.

All the cell pellet samples had originally been stored in a freezer at a temperature of approximately $-80^{\circ} \mathrm{C}$. The cell pellet samples, which were inside plastic centrifuge tubes that each had a capacity of $50 \mathrm{~mL}$, had been weighed prior to ICP-MS analysis. During 
weighing, the samples were slightly thawed and turned on their sides, which may have caused mercury to attach to the upper walls and/or caps of some of the plastic tubes. However, this could not be measured in the laboratory experiments. Furthermore, while the cell pellet samples were waiting to be analyzed using ICP-MS, the cell pellet samples had been thawed and kept out of the freezer for a period of approximately one month, which may have resulted in mercury volatilization.

From the data above for the test tube walls samples that had been analyzed, a concentration of mercury that was comparable to that of each respective supernatant sample was detected. It is also possible that mercury may have become attached to the bottle walls of the stock solutions, which would have possibly reduced the concentration of the aqueous mercury in the stock solutions, though this could not be measured. Nevertheless, each of the above possible explanations alone would not account for the $\sim 90 \%$ loss of mercury in the mass balance for each test solution. It is a possibility that these proposed explanations, in combination, may account for the loss of mercury in the mass balance. Despite the mass balance discrepancy, the results of the laboratory experiments can still yield some potentially useful information, which is discussed in the following section of the present chapter.

\section{Usefulness of Laboratory Experiment Results}

The results of the laboratory experiments must be analyzed from the perspective of the limitations described above, which are the differences in measured concentrations of the supernatant samples between the DMA 80 and ICP-MS, as well as the discrepancy of the 
expected mass balance for the results of the samples analyzed using ICP-MS. Despite these limitations, some useful information may be obtained from the results of the laboratory experiments, especially when analyzing the ratio of the measured mass of mercury in each cell pellet sample to the calculated mass of mercury in each supernatant sample for each of the washed cell solutions, which is described above.

The following section in the present chapter shows estimates for the initial uptake rates of mercury in each set of laboratory experiments based on the differences between the initial mercury concentration and the concentration of mercury after the available first time interval for each set of laboratory experiments.

\section{Estimates for Initial Mercury Uptake Rates}

The estimate of the initial mercury uptake rate in each set of laboratory experiments was calculated by the difference between the initial concentration of mercury in each washed cell solution and the concentration of mercury remaining in the supernatant after the available first time interval, divided by the available first time interval of sampling. The

following figure shows the gross estimate of the initial uptake rate of mercury for the washed cell solutions in the lactate/sulfate experiments. 

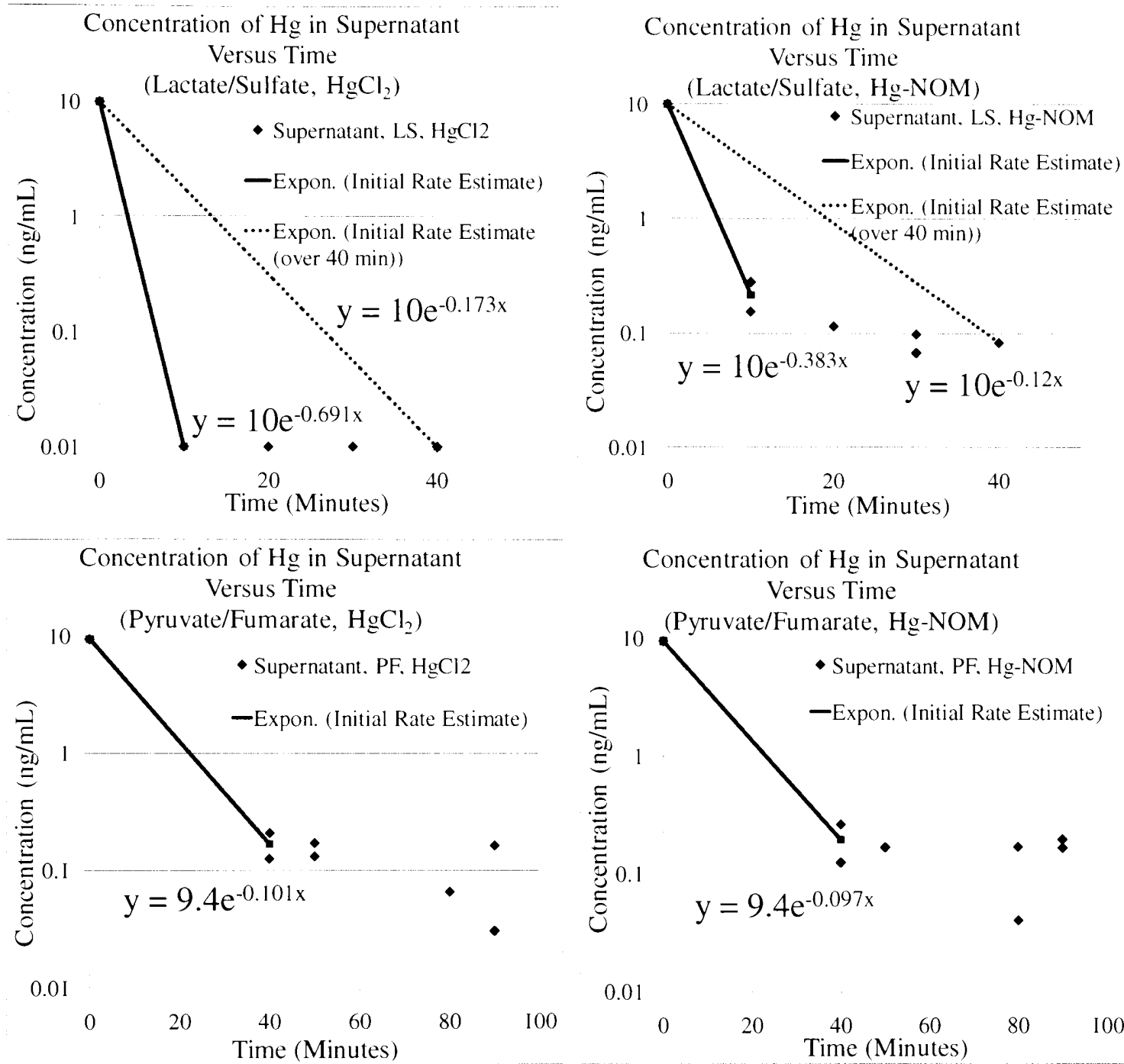

Figure 10: Supernatant concentrations of mercury versus time, with calculated initial uptake rates of mercury. For all laboratory experiments, the uptake rate is approximated as a first order exponential decay function. The detection limit of the ICP-MS was assumed to be approximately $0.01 \mathrm{ng} \mathrm{Hg} / \mathrm{mL}$, therefore any data points that were $0.02 \mathrm{ng} \mathrm{Hg} / \mathrm{mL}$ or less were removed from the plots because they were relatively close to the detection limit of the ICP-MS. For the lactate/sulfate experiments, the estimated initial rates were each plotted over a 40 minute period to compare to the estimated initial rates in the pyruvate/fumarate experiments.

From Figure 10 for all the laboratory experiments, the estimated initial uptake rate of mercury for each set of laboratory experiments was approximated as a first-order 
exponential decay function, where the rate constant $k$, with units of $\min ^{-1}$, is the number in the exponent of each equation on the figure. The estimated initial mercury uptake rates appeared to be higher for the washed cell solutions in the lactate/sulfate experiments than the solutions in the pyruvate/fumarate experiments. For the pyruvate/fumarate experiments, the estimated initial uptake rate of mercury for the washed cell solutions that had been spiked with $\mathrm{HgCl}_{2}$ was comparable to that of the solutions that had been spiked with Hg-NOM. The following table compares the estimated initial rate constants, shown in Figure 10, with the stability constant of each mercury species that was calculated or estimated to be the dominant form of mercury in each set of experiments.

Table 6: Calculated initial mercury uptake rate constants compared to stability constants for dominant mercury species (calculated or estimated) in each solution.

\begin{tabular}{|c|c|c|c|c|c|}
\hline Solution & $\begin{array}{c}\text { Calculated } \\
\text { or } \\
\text { Estimated } \\
\text { dominant } \\
\text { mercury } \\
\text { species }\end{array}$ & $\begin{array}{c}\text { Average } \\
\text { Estimate } \\
\text { of } \log K \\
\text { of } \\
\text { formation }\end{array}$ & $\begin{array}{c}\text { Refer- } \\
\text { ences } \\
\text { for log } \\
\mathbf{K}\end{array}$ & $\begin{array}{c}\text { Calculated } \\
\text { initial rate } \\
\text { constant } \\
(1 / \mathrm{min})\end{array}$ & $\begin{array}{c}\text { Calculated } \\
\text { initial rate } \\
\text { constant } \\
\text { (over } 40 \\
\text { minutes) } \\
(1 / \mathrm{min})\end{array}$ \\
\hline $\begin{array}{l}\text { Lactate/Sulfate } \\
\mathrm{HgCl}_{2}\end{array}$ & $\mathrm{HgS}_{2}{ }^{2-}$ & 24.3 & 1,5 & 0.691 & 0.173 \\
\hline $\begin{array}{l}\text { Lactate/Sulfate } \\
\text { Hg-NOM }\end{array}$ & $\begin{array}{c}\text { Possibly } \\
\text { Hg-S-NOM } \\
\text { (see ref. 2) }\end{array}$ & 28.95 & 2 & 0.383 & 0.120 \\
\hline $\begin{array}{l}\text { Pyruvate/Fumarate } \\
\mathrm{HgCl}_{2}\end{array}$ & $\mathrm{HgCl}_{2}$ & 13.61 & 3,6 & 0.101 & 0.101 \\
\hline $\begin{array}{l}\text { Pyruvate/Fumarate } \\
\text { Hg-NOM }\end{array}$ & $\mathrm{Hg}-\mathrm{NOM}$ & 34.65 & 4 & 0.097 & 0.097 \\
\hline
\end{tabular}

References: 1. Benoit et al. (1999), 2. Miller (2006), 3. Smith and Martell (1993), 4. Miller et al. (2009, and references therein), 5. MINTEQ Database, available through PHREEQC (Parkhurst and Appelo, 1999), 6. Dong et al. (2010, and reference therein). 
The cell walls of strains of Desulfovibrio vulgaris and Desulfovibrio desulfuricans are described by Postgate (1979, and referenes therein) to contain numerous amino acids, including diaminopimelic acid, and glucosamine. No thermodynamic information for mercury bound to either diaminopimelic acid or glucosamine have been found. However, if an amino acid such as cysteine is present in the cell walls, the amino acid may bind strongly to mercury and allow mercury to be taken up by cells. As discussed in Chapter I of the present research, in the section entitled Research Suggesting Mercury Uptake by Cells via Active/Facilitated Transport, Schaefer and Morel (2009) found increased mercury uptake by Geobacter sulfurreducens in the presence of cysteine, and found a significant correlation between mercury uptake and the calculated concentration of the bis mercury cysteine complex, which can be written as $\mathrm{Hg}(\text { cys })_{2}$. For the complex of mercury bound to one cysteine molecule, which can be written as $\mathrm{Hg}$ (cys), Stumm and Morgan (1996) report a stability constant of $\log \beta=15.3$, but the stability constant for $\mathrm{Hg}$ (cys) $)_{2}$ is likely higher. If cysteine is present on the cell walls of Desulfovibrio desulfuricans $\mathrm{G} 20$, the portions of the cell walls with cysteine present may have stability constants as high as that of the complex of mercury bound to one cysteine molecule, $\mathrm{Hg}(\mathrm{cys})$, and possibly higher. These stability constants would be comparable to those of mercury chloride species, therefore binding of mercury to the cell surfaces would be competitive with binding of mercury to chloride and other inorganic substances in solution.

The following figure shows the plot of the thermodynamic equilibrium constant (log $\mathrm{K}$ ) of formation of each of the estimated dominant mercury species versus the estimated 
initial mercury uptake rate constant for the washed cell solution from each set of laboratory experiments.

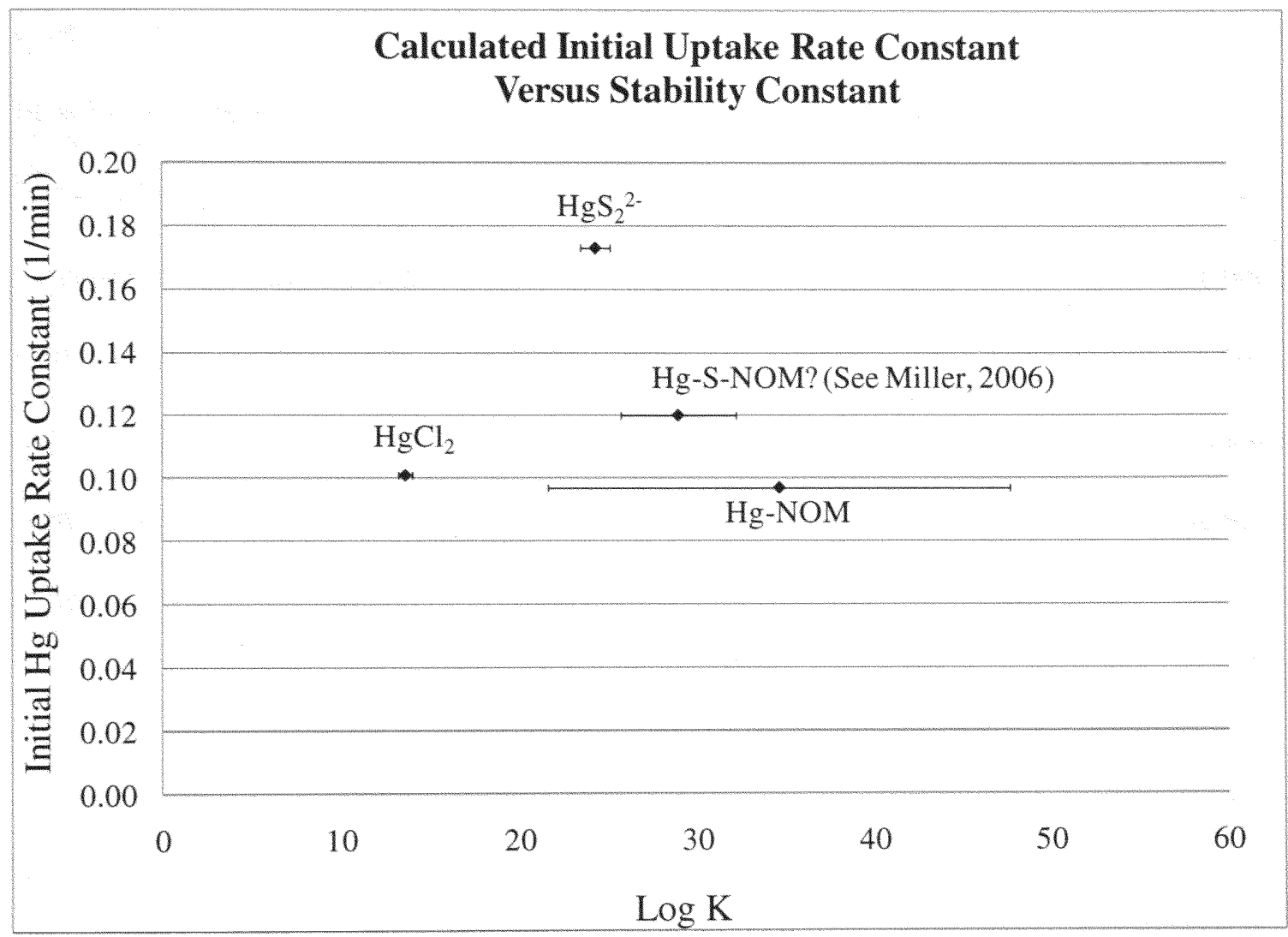

Figure 11: Initial uptake rate constants versus stability constants for each set of experimental conditions.

From Figure 11, despite the significantly different stability constants for $\mathrm{Hg}-\mathrm{NOM}$ and $\mathrm{HgCl}_{2}$, the calculated initial rate constants for mercury uptake for these two complexes appeared to be comparable. The speciation modeling discussed in Chapter IV of the present research shows that inorganic mercury sulfide species dominate the speciation of mercury whether or not $\mathrm{Hg}-\mathrm{NOM}$ was spiked into the lactate/sulfate solutions. Based on the research of Miller (2006) and Miller et al. (2007), it is likely that complexes of $\mathrm{Hg}$, 
sulfide, and NOM exist in the solution, and the estimated $\log \mathrm{K}$ values for the $\mathrm{Hg}-\mathrm{S}$ NOM complexes are from Miller (2006). In addition, it is important to note that due to the low concentrations of mercury in the supernatant samples in the lactate/sulfate experiments that had been spiked with $\mathrm{HgCl}_{2}$, it is possible that $\mathrm{HgS}(\mathrm{s})$ precipitated out of solution, and thus mercury uptake by cells in these solutions may not have occurred. However, $\mathrm{HgS}(\mathrm{s})$ formation could not be measured in the laboratory experiments. Nevertheless, for the pyruvate/fumarate experiments, no $\mathrm{HgS}(\mathrm{s})$ could have possibly been in the washed cell solutions because no sulfide was present in these solutions. Therefore, the estimated initial mercury uptake rates measured in the pyruvate/fumarate experiments were likely due to mercury uptake by cells, and not to formation of precipitates in solution, such as $\mathrm{HgS}(\mathrm{s})$. 


\section{RESULTS FROM MODELING EXPERIMENTS}

Initial Assumed Parameters for Models

The source code for the model for the lactate/sulfate washed cell solutions that had been spiked with $\mathrm{Hg}-\mathrm{NOM}$ is in Appendix E, and this source code can be edited to model all the experiments because it includes information for the mercury sulfide species and the complex of mercury bound to natural organic matter. In addition, a sample part of the output file for the model for the lactate/sulfate washed cell solutions that had been spiked with $\mathrm{Hg}-\mathrm{NOM}$ is shown in Appendix F. The following table shows the initial assumed parameters that were used in creating the models for mercury uptake by cells via passive diffusion and facilitated uptake.

Table 7: Initial estimated parameters for passive diffusion and facilitated uptake model.

\begin{tabular}{|c|c|c|c|}
\hline $\begin{array}{r}\text { Parameter } \\
\text { Passive Diffusion }\end{array}$ & Description & Value & Units \\
\hline $\mathrm{R}$ & Cell Radius & 5.E-05 & $\begin{array}{l}\mathrm{cm} \text { for one } \\
\text { cell }\end{array}$ \\
\hline Cells_per_mL & $\begin{array}{l}\text { Number of Cells per mL of } \\
\text { initial washed cell solution }\end{array}$ & $1 . \mathrm{E}+08$ & cells $\mathrm{mL}^{-1}$ \\
\hline$\overline{\mathrm{P}_{\mathrm{HgCl} 2}}$ & $\begin{array}{c}\text { Membrane Permeability of } \\
\mathrm{HgCl}_{2}\end{array}$ & $7.4 \mathrm{E}-04$ & $\mathrm{~cm} \mathrm{~s}^{-1}$ \\
\hline $\mathrm{P}_{\mathrm{Hg}(\mathrm{OH}) 2}$ & $\begin{array}{c}\text { Membrane Permeability of } \\
\qquad \mathrm{Hg}(\mathrm{OH})_{2}\end{array}$ & $2.3 \mathrm{E}-05$ & $\mathrm{~cm} \mathrm{~s}^{-1}$ \\
\hline$\overline{\mathrm{P}_{\mathrm{HgS}}}$ & $\begin{array}{l}\text { Membrane Permeability of } \\
\qquad \mathrm{HgS}^{0}\end{array}$ & $3.7 \mathrm{E}-01$ & $\mathrm{~cm} \mathrm{~s}^{-1}$ \\
\hline $\mathrm{P}_{\mathrm{Hg}(\mathrm{HS}) 2}$ & $\begin{array}{c}\text { Membrane Permeability of } \\
\operatorname{Hg}(\mathrm{HS})_{2}\end{array}$ & $6.4 \mathrm{E}-02$ & $\mathrm{~cm} \mathrm{~s}^{-1}$ \\
\hline
\end{tabular}




\begin{tabular}{|c|c|c|c|}
\hline $\begin{array}{c}\text { Parameter } \\
\text { Facilitated Diffusion }\end{array}$ & Description & Value & Units \\
\hline$\rho_{\max }$ & $\begin{array}{c}\text { Maximum Uptake Rate of a } \\
\text { Metal }\end{array}$ & $6.125 \mathrm{E}-21$ & $\mathrm{~mol} \mathrm{cell}^{-1} \mathrm{~s}$ \\
\hline$\overline{\mathrm{K}_{\rho}}$ & $\begin{array}{c}\text { Half-Saturation Constant of a } \\
\text { Metal }\end{array}$ & 5.E-07 & $\mathrm{mol} \mathrm{kgw}^{-1}$ \\
\hline Cells_per_mL & $\begin{array}{l}\text { Number of cells per mL of } \\
\text { initial washed cell solution }\end{array}$ & $1 . \mathrm{E}+08$ & cells $\mathrm{mL}^{-1}$ \\
\hline Reducible_Fraction_Hg & $\begin{array}{c}\text { Reducible Fraction of } \mathrm{Hg} \\
\text { bound to NOM }\end{array}$ & 0.11 & No Units \\
\hline
\end{tabular}

Most of the above parameters have been estimated from the research of other researchers as discussed previously. The concentration of cells in each solution (Cells_per_mL) used in the model is close to the average number of cells counted for the pyruvate/fumarate experiments and the average number of cells counted for the lactate/sulfate experiments.

\section{Additional Thermodynamic Equilibrium Reaction Data Added to Model}

The PHREEQC model has several built-in thermodynamic equilibrium databases with thermodynamic equilibrium constants for many chemical reactions, and the model also allows the ability to create a thermodynamic equilibrium database to use in the model. For all simulations in the present research, which include the pyruvate/fumarate experiments spiked with either $\mathrm{HgCl}_{2}$ or $\mathrm{Hg}-\mathrm{NOM}$ and the lactate/sulfate experiments spiked with either $\mathrm{HgCl}_{2}$ or $\mathrm{Hg}-\mathrm{NOM}$, the MINTEQ database (see Parkhurst and Appelo, 1999) was used. Some additional reactions, which were obtained from various references, including Miller et al. (2007) and Martell and Smith (1993), were added to the model. Because reactions of aqueous mercury species are written in terms of neutral $\mathrm{Hg}(\mathrm{OH})_{2}$ as 
the reactant, reactions from the following table have been rewritten from their original reference source in terms of $\mathrm{Hg}(\mathrm{OH})_{2}$ as the reactant by using the formation reaction of $\mathrm{Hg}(\mathrm{OH})_{2}$ from the MINTEQ database.

Table 8: Chemical reactions and thermodynamic equilibrium constants added to the model for mercury sulfide species and mercury bound to NOM.

\begin{tabular}{|lll|}
\hline \multicolumn{1}{|c|}{ Reaction } & Log K & \multicolumn{1}{c|}{ Reference } \\
\hline $\mathrm{Hg}(\mathrm{OH})_{2}+\mathrm{H}^{+}+\mathrm{HS}^{-}=\mathrm{HgS}(\mathrm{aq})+2 \mathrm{H}_{2} \mathrm{O}$ & 32.097 & Miller et al. (2007) \\
\hline $\mathrm{Hg}(\mathrm{OH})_{2}+\mathrm{HS}^{-}+2 \mathrm{H}^{+}=\mathrm{HgHS}^{+}+2 \mathrm{H}_{2} \mathrm{O}$ & 36.297 & Miller et al. (2007) \\
\hline $\mathrm{Hg}(\mathrm{OH})_{2}+2 \mathrm{HS}^{-}+\mathrm{H}^{+}=\mathrm{HgS}_{2} \mathrm{H}^{-}+2 \mathrm{H}_{2} \mathrm{O}$ & 37.597 & Miller et al. (2007) \\
\hline $\mathrm{Hg}(\mathrm{OH})_{2}+2 \mathrm{H}^{+}+\mathrm{RS}^{-}=\mathrm{HgRS}^{+}+2 \mathrm{H}_{2} \mathrm{O}$ & 34.097 & $\begin{array}{l}\text { Miller et al. (2009, and } \\
\text { references therein). } \\
\text { Value used in present } \\
\text { research is near average } \\
\text { value of range of values } \\
\text { reported in Miller et al. } \\
\text { (2009). }\end{array}$ \\
\hline $\mathrm{Hg}(\mathrm{OH})_{2}+2 \mathrm{H}^{+}+\mathrm{CO}^{2-}=\mathrm{HgCO}_{3}+2 \mathrm{H}_{2} \mathrm{O}$ & 16.797 & $\begin{array}{l}\text { Martell and Smith } \\
\text { (1993) }\end{array}$ \\
\hline $\mathrm{Hg}(\mathrm{OH})_{2}+2 \mathrm{CO}_{3}{ }^{2-}+2 \mathrm{H}^{+}=\mathrm{Hg}^{2-}\left(\mathrm{CO}_{3}\right)^{2-}+2 \mathrm{H}_{2} \mathrm{O}$ & 20.597 & $\begin{array}{l}\text { Martell and Smith } \\
\text { (1993) }\end{array}$ \\
\hline $\mathrm{Hg}(\mathrm{OH})_{2}+2 \mathrm{H}^{+}+\mathrm{HCO}_{3}{ }^{-}=\mathrm{HgHCO}_{3}{ }^{+}+2 \mathrm{H}_{2} \mathrm{O}$ & 11.587 & $\begin{array}{l}\text { Martell and Smith } \\
\text { (1993) }\end{array}$ \\
\hline $\mathrm{Hg}(\mathrm{OH})_{2}+2 \mathrm{H}^{+}+2 \mathrm{SO}_{4}{ }^{2-}=\mathrm{Hg}^{-}\left(\mathrm{SO}_{4}\right)^{2-}+2 \mathrm{H}_{2} \mathrm{O}$ & 8.497 & $\begin{array}{l}\text { Martell and Smith } \\
\text { (1993) }\end{array}$ \\
\hline
\end{tabular}

Notes: Each reaction has been taken from the source listed above and has been rewritten in terms of $\mathrm{Hg}(\mathrm{OH})_{2}$ being the reactant to be consistent with the form of the MINTEQ database within PHREEQC (Parkhurst and Appelo, 1999, and reference therein). Thus, each reaction combines the reaction $\mathrm{Hg}(\mathrm{OH})_{2}+2 \mathrm{H}^{+}=\mathrm{Hg}^{+2}+2 \mathrm{H}_{2} \mathrm{O}(\log \mathrm{K}=6.097)$, with the reaction found in each reference listed above, and the $\log \mathrm{K}$ value of each reaction was added to calculated the $\log \mathrm{K}$ value for each reaction listed in the table. For the reaction $\mathrm{Hg}(\mathrm{OH})_{2}+2 \mathrm{H}^{+}+\mathrm{RS}^{-}=\mathrm{HgRS}^{+}+2 \mathrm{H}_{2} \mathrm{O}$, the reactant $\mathrm{RS}^{-}$represents a sulfide group $\mathrm{S}^{2-}$ bound to an organic group $\mathrm{R}^{+}$, where $\mathrm{RS}^{-}$is within NOM, and for this reaction, a value for the thermodynamic equilibrium constant was chosen near the middle of the range of values reported in the Supporting Information to Miller et al. (2009). 
During the laboratory experiments, the initial concentration of mercury in each solution was volumetrically measured to be $10 \mathrm{ng} \mathrm{Hg} / \mathrm{mL}$. The following table shows the initial concentrations of elements input into the model for the washed cell solutions from the pyruvate/fumarate experiments spiked with $\mathrm{HgCl}_{2}$.

Table 9: Initial input concentrations of elements for the model for the pyruvate/fumarate experiments that were spiked with $\mathrm{HgCl}_{2}$.

\begin{tabular}{|lccc|}
\hline Variable or Element & $\begin{array}{c}\text { Primary Master } \\
\text { Species }\end{array}$ & Value & Units \\
\hline $\mathrm{pH}$ & - & 6.8 & - \\
\hline temperature & - & 25 & ${ }^{\circ} \mathrm{C}$ \\
\hline $\mathrm{C}(+4)$ & $\mathrm{CO}_{3}^{-2}$ & 30 & $\mathrm{mmol} / \mathrm{kgw}$ \\
\hline $\mathrm{Na}$ & $\mathrm{Na}^{+}$ & 30 & $\mathrm{mmol} / \mathrm{kgw}$ \\
\hline $\mathrm{Hg}(2)$ & $\mathrm{Hg}(\mathrm{OH})_{2}$ & $4.69 \mathrm{E}-05$ & $\mathrm{mmol} / \mathrm{kgw}$ \\
\hline $\mathrm{Cl}$ & $\mathrm{Cl}^{-}$ & 30 & $\mathrm{mmol} / \mathrm{kgw}$ \\
\hline water & - & 0.010 & $\mathrm{kgw}$ \\
\hline
\end{tabular}

Notes: No thermodynamic information between Pyruvate or fumarate and mercury was found. Golding et al. (2002) showed that mercury uptake increased in the presence of fumarate. This effect of fumarate was not taken into account in the model. Actual Na concentration is much higher in solution because pyruvate and fumarate were added as $\mathrm{Na}$ pyruvate and Na-fumarate, but this is not expected to shift the speciation of mercury in the solution. The variable $\mathrm{C}(+4)$ is carbon with a valence state +4 and $\mathrm{Hg}(2)$ is mercury with a valence state +2 . The units $\mathrm{kgw}$ are kilograms of water.

The following table shows the initial concentrations of elements input into the model for the washed cell solutions in the pyruvate/fumarate experiments that had been spiked with Hg-NOM. 
Table 10: Initial input concentrations of elements for the model for the pyruvate/fumarate experiments that were spiked with Hg-NOM.

\begin{tabular}{|lccc|}
\hline Variable or Element & Primary Master Species & Value & Units \\
\hline $\mathrm{pH}$ & - & 6.8 & - \\
\hline temperature & - & 25 & ${ }^{\circ} \mathrm{C}$ \\
\hline $\mathrm{C}(+4)$ & $\mathrm{CO}_{3}{ }^{-2}$ & 30 & $\mathrm{mmol} / \mathrm{kgw}$ \\
\hline $\mathrm{Na}$ & $\mathrm{Na}^{+}$ & 30 & $\mathrm{mmol} / \mathrm{kgw}$ \\
\hline $\mathrm{Hg}(2)$ & $\mathrm{Hg}(\mathrm{OH})_{2}$ & $4.69 \mathrm{E}-05$ & $\mathrm{mmol} / \mathrm{kgw}$ \\
\hline $\mathrm{Rs}(\mathrm{NOM})$ & $\mathrm{Rs}^{-}$ & $2 \mathrm{E}-02$ & $\mathrm{mmol} / \mathrm{kgw}$ \\
\hline $\mathrm{Cl}$ & $\mathrm{Cl}^{-}$ & 30 & $\mathrm{mmol} / \mathrm{kgw}$ \\
\hline water & - & 0.010 & $\mathrm{kgw}$ \\
\hline
\end{tabular}

Notes: The concentration of NOM, which is represented by Rs, is an estimate based on the milligrams of carbon per milliliter of solution in the Hg-NOM stock solution, which may be an underestimate because there are likely other substances in NOM. No thermodynamic information between Pyruvate or fumarate and mercury was found. Golding et al. (2002) showed that mercury uptake increased in the presence of fumarate. This effect of fumarate was not taken into account in the model. Actual $\mathrm{Na}$ concentration is much higher in solution because pyruvate and fumarate were added as Na-pyruvate and Na-fumarate, but this is not expected to shift the speciation of mercury in the solution. The variable $\mathrm{C}(+4)$ is carbon with a valence state +4 and $\mathrm{Hg}(2)$ is mercury with a valence state +2 . The units $\mathrm{kgw}$ are kilograms of water.

Initial Conditions for the Lactate/Sulfate Models

The following table shows the initial conditions and concentrations input into the model for the washed cell solutions in the lactate/sulfate experiments that had been with $\mathrm{HgCl}_{2}$. It is important to note that the sulfide concentration in each of the lactate/sulfate experiments was not known and was estimated to be approximately $1 \mathrm{mmol} / \mathrm{kgw}$, which is based on the initial concentration of sulfate in each solution prior to washing the cells in the laboratory experiments. 
Table 11: Initial input concentrations of elements for the model for the lactate/sulfate experiments that were spiked with $\mathrm{HgCl}_{2}$.

\begin{tabular}{|lccc|}
\hline Variable or Element & Primary Master Species & Value & Units \\
\hline $\mathrm{pH}$ & - & 6.8 & - \\
\hline temperature & - & 25 & ${ }^{\circ} \mathrm{C}$ \\
\hline $\mathrm{C}(+4)$ & $\mathrm{CO}^{-2}$ & 30 & $\mathrm{mmol} / \mathrm{kgw}$ \\
\hline $\mathrm{Na}$ & $\mathrm{Na}^{+}$ & 30 & $\mathrm{mmol} / \mathrm{kgw}$ \\
\hline $\mathrm{Hg}(2)$ & $\mathrm{Hg}(\mathrm{OH})_{2}$ & $4.69 \mathrm{E}-05$ & $\mathrm{mmol} / \mathrm{kgw}$ \\
\hline $\mathrm{Cl}$ & $\mathrm{Cl}^{-}$ & 30 & $\mathrm{mmol} / \mathrm{kgw}$ \\
\hline $\mathrm{S}(6)$ & $\mathrm{SO}_{4}^{-2}$ & 29 & $\mathrm{mmol} / \mathrm{kgw}$ \\
\hline $\mathrm{S}(-2)$ & $\mathrm{HS}^{-}$ & 1 & $\mathrm{mmol} / \mathrm{kgw}$ \\
\hline water & - & 0.010 & $\mathrm{kgw}$ \\
\hline
\end{tabular}

Notes: The concentration of $S(-2)$ is not known and was estimated, and the sum of the concentrations of $S(6)$ and $S(-2)$ must equal about $30 \mathrm{mmol} / \mathrm{kgw}$ because sulfate was initially added at a concentration of about $30 \mathrm{mmol} / \mathrm{kgw}$. No thermodynamic information between lactate and mercury was found. Actual Na concentration in solution is much higher because lactate and sulfate were added as Na-lactate and Na-sulfate, but this is not expected to shift the speciation of mercury. The variable $S(6)$ is sulfur with a valence state +6 (sulfate) and the variable $S(-2)$ is sulfur with a valence state -2 (sulfide). The units $\mathbf{k g w}$ are kilograms of water.

The following table shows the initial conditions and concentrations input into the model for the washed cell solutions in the lactate/sulfate experiments that had been spiked with Hg-NOM. It is important to note that the sulfide concentration in each solution was not known and was estimated to be approximately $1 \mathrm{mmol} / \mathrm{kgw}$, which is based on the initial concentration of sulfate in solution prior to washing the cells in the laboratory experiments.

Table 12: Initial input concentrations of elements for the model for the lactate/sulfate experiments that were spiked with Hg-NOM.

\begin{tabular}{|lccc|}
\hline \multicolumn{1}{|c}{ Variable or Element } & Primary Master Species & Value & Units \\
\hline $\mathrm{pH}$ & - & 6.8 & - \\
\hline temperature & - & 25 & ${ }^{\circ} \mathrm{C}$ \\
\hline
\end{tabular}




\begin{tabular}{|lccc|}
\hline \multicolumn{1}{c}{ Variable or Element } & Primary Master Species & Value & Units \\
\hline $\mathrm{C}(+4)$ & $\mathrm{CO}_{3}^{-2}$ & 30 & $\mathrm{mmol} / \mathrm{kgw}$ \\
\hline $\mathrm{Na}$ & $\mathrm{Na}^{+}$ & 30 & $\mathrm{mmol} / \mathrm{kgw}$ \\
\hline $\mathrm{Hg}(2)$ & $\mathrm{Hg}(\mathrm{OH})_{2}$ & $4.69 \mathrm{E}-05$ & $\mathrm{mmol} / \mathrm{kgw}$ \\
\hline $\mathrm{Cl}$ & $\mathrm{Cl}^{-}$ & 30 & $\mathrm{mmol} / \mathrm{kgw}$ \\
\hline $\mathrm{S}(6)$ & $\mathrm{SO}_{4}^{-2}$ & 29 & $\mathrm{mmol} / \mathrm{kgw}$ \\
\hline $\mathrm{S}(-2)$ & $\mathrm{HS}^{-}$ & 1 & $\mathrm{mmol} / \mathrm{kgw}$ \\
\hline Rs $(\mathrm{NOM})$ & $\mathrm{Rs}^{-}$ & $2 . \mathrm{E}-02$ & $\mathrm{mmol} / \mathrm{kgw}$ \\
\hline water & - & 0.010 & $\mathrm{kgw}$ \\
\hline
\end{tabular}

Notes: The concentration of NOM, which is represented by Rs, in solution is an estimate based on the milligrams of carbon per milliliter of solution in the Hg-NOM stock solution, which may be an underestimate because there are likely other substances in NOM. The concentration of $S(-2)$ is not known and was estimated, and the sum of the concentrations of $S(6)$ and $S(-2)$ must equal about $30 \mathrm{mmol} / \mathrm{kgw}$ because sulfate was initially added at a concentration of about $30 \mathrm{mmol} / \mathrm{kgw}$. No thermodynamic information between lactate and mercury was found. Actual Na concentration in solution is much higher because lactate and sulfate were added as Na-lactate and $\mathrm{Na}$-sulfate, but this is not expected to shift the speciation of mercury. The variable $S(6)$ is sulfur with a valence state +6 (sulfate) and the variable $S(-2)$ is sulfur with a valence state -2 (sulfide). The units kgw represent kilograms of water.

The initial conditions and concentrations of elements input into the model are based on the laboratory experiments. The model PHREEQC calculates the equilibrium concentrations of all species in solution based on the initial conditions and concentrations of elements, such as $\mathrm{pH}$, temperature, initial concentration of bicarbonate species, etcetera.

Model for the Pyruvate/F umarate Experiments spiked with $\mathrm{HgCl}_{2}$

The following table shows the initial speciation of mercury, calculated using PHREEQC, for the washed cell solutions in the pyruvate/fumarate experiments spiked with $\mathrm{HgCl}_{2}$. 
Table 13: Calculated initial speciation of mercury for the washed cell solutions in the pyruvate/fumarate experiments that had been spiked with $\mathrm{HgCl}_{2}$. Mercury speciation was calculated using PHREEQC.

\begin{tabular}{|c|c|}
\hline Species & $\begin{array}{l}\text { Calculated Molality } \\
\text { (mol/kg solution) }\end{array}$ \\
\hline Hg(II) & $4.69 \mathrm{E}-08$ \\
\hline $\mathrm{HgCl}_{2}$ & $3.60 \mathrm{E}-08$ \\
\hline $\mathrm{HgCl}_{3}^{-}$ & $8.60 \mathrm{E}-09$ \\
\hline $\mathrm{HgClOH}$ & $1.15 \mathrm{E}-09$ \\
\hline $\mathrm{HgCl}_{4}{ }^{2-}$ & $9.47 \mathrm{E}-10$ \\
\hline$\overline{\mathrm{Hg}(\mathrm{OH})_{2}}$ & $1.42 \mathrm{E}-10$ \\
\hline $\mathrm{HgCO}_{3}$ & $1.27 \mathrm{E}-12$ \\
\hline $\mathrm{HgCl}^{+}$ & $7.56 \mathrm{E}-13$ \\
\hline $\mathrm{Hg}\left(\mathrm{CO}_{3}\right)_{2}{ }^{2-}$ & $9.62 \mathrm{E}-14$ \\
\hline $\mathrm{HgHCO}_{3}{ }^{+}$ & $3.23 \mathrm{E}-14$ \\
\hline $\mathrm{HgOH}^{+}$ & $1.36 \mathrm{E}-14$ \\
\hline $\mathrm{Hg}^{2+}$ & $9.41 \mathrm{E}-18$ \\
\hline $\mathrm{Hg}(\mathrm{OH})_{3}^{-}$ & $1.07 \mathrm{E}-18$ \\
\hline
\end{tabular}

For the washed cell solutions from the pyruvate/fumarate experiments that had been spiked with $\mathrm{HgCl}_{2}$, the calculated dominant mercury species in solution was $\mathrm{HgCl}_{2}$.

The following figure shows the results of the model for passive diffusion and facilitated uptake of mercury by cells for the washed cell solutions in the pyruvate/fumarate experiments that had been spiked with $\mathrm{HgCl}_{2}$. The model was tested with the original estimated parameters and some varied parameters. 


\section{Model Results and Experimental Data for Pyruvate/Fumarate}

Experiments Spiked with $\mathrm{HgCl}_{2}$

2

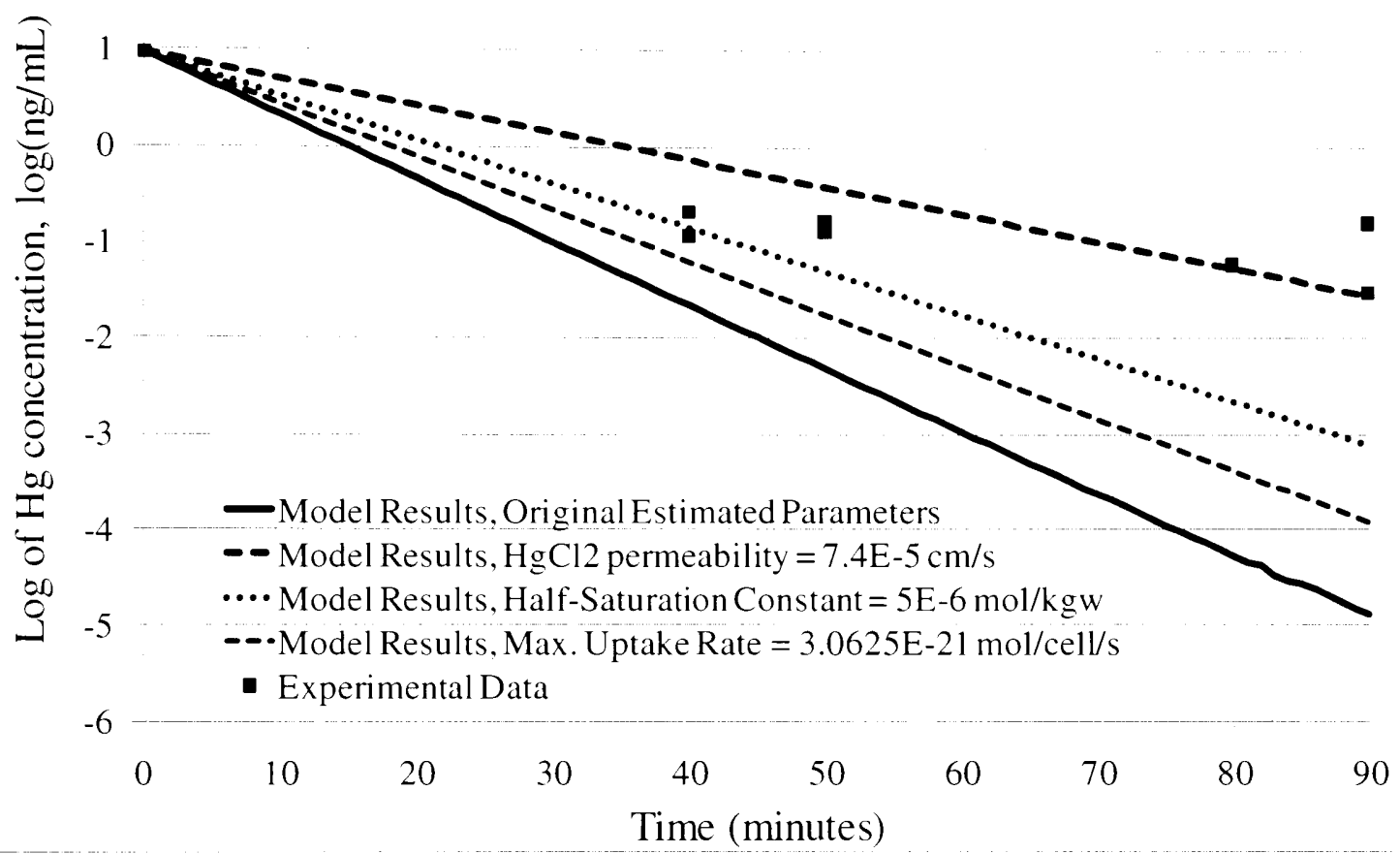

Figure 12: Model results and experimental data for the washed cell solutions from the pyruvate/fumarate experiments that had been spiked with $\mathrm{HgCl}_{2}$. The initial concentration of mercury in the washed cell solutions was measured volumetrically during the laboratory experiments, not measured using ICP-MS. Experimental data points that were $0.02 \mathrm{ng} \mathrm{Hg} / \mathrm{mL}$ or less, which is close to the detection limit of the ICP-MS of $0.01 \mathrm{ng} \mathrm{Hg} / \mathrm{mL}$, were removed from the experimental data.

From the above figure, Figure 12, for the washed cell solutions from the pyruvate/fumarate experiments that had been spiked with $\mathrm{HgCl}_{2}$, the model results with the original estimated parameters predict a faster rate of mercury uptake than the experimental data suggest. When only the half-saturation constant $K_{\rho}$ is changed and increased to $5 \mathrm{E}-06 \mathrm{~mol} \mathrm{kgw}^{-1}$, which is one order of magnitude greater than the original estimated $\mathrm{K}_{\rho}$, the model appears to provide a better fit for the initial estimated uptake rate of mercury over the first 40 minutes of the laboratory experiments. When only the 
membrane permeability of $\mathrm{HgCl}_{2}$ is changed and decreased to $7.4 \mathrm{E}-05 \mathrm{~cm} \mathrm{~s}^{-1}$, which is one order of magnitude smaller than the original estimated membrane permeability of $\mathrm{HgCl}_{2}$, the model appears to provide a better fit to the uptake rate of mercury over the 90 minutes of the pyruvate/fumarate experiments spiked with $\mathrm{HgCl}_{2}$. The adjustment of the half-saturation constant, which is a parameter used only in the rate equation for facilitated uptake, and the adjustment of the membrane permeability of $\mathrm{HgCl}_{2}$, which is a parameter used only in the rate equation for passive diffusion, show that the model is sensitive to both parameters. From the model results, the processes of both facilitated uptake and passive diffusion appear to be important in the uptake of mercury by cells in the washed cell solutions in the pyruvate/fumarate experiments that had been spiked with $\mathrm{HgCl}_{2}$.

Model for the Pyruvate/Fumarate Experiments spiked with Hg-NOM

The following table shows the initial speciation of mercury, calculated using PHREEQC, for the washed cell solutions in the pyruvate/fumarate experiments spiked with $\mathrm{Hg}-\mathrm{NOM}$.

Table 14: Calculated initial speciation of mercury for the washed cell solutions in the pyruvate/fumarate experiments that had been spiked with Hg-NOM. Mercury speciation was calculated using PHREEQC.

\begin{tabular}{|lc|}
\multicolumn{1}{|c|}{ Species } & $\begin{array}{c}\text { Calculated Molality } \\
\text { (mol/kg solution) }\end{array}$ \\
\hline $\mathbf{H g}(\mathbf{I I})$ & $4.69 \mathrm{E}-08$ \\
\hline $\mathbf{H g R S}^{+}$ & $4.69 \mathrm{E}-08$ \\
\hline $\mathbf{H g C l}_{\mathbf{2}}$ & $1.80 \mathrm{E}-21$ \\
\hline $\mathbf{H g C l}_{\mathbf{3}}{ }^{-}$ & $4.30 \mathrm{E}-22$ \\
\hline $\mathbf{H g C l O H}^{-}$ & $5.76 \mathrm{E}-23$ \\
\hline $\mathbf{H g C l}_{\mathbf{4}}{ }^{2-}$ & $4.74 \mathrm{E}-23$ \\
\hline $\mathbf{H g}(\mathbf{O H})_{\mathbf{2}}$ & $7.10 \mathrm{E}-24$ \\
\hline
\end{tabular}




\begin{tabular}{|lc|}
\multicolumn{1}{|c|}{ Species } & $\begin{array}{c}\text { Calculated Molality } \\
\text { (mol/kg solution) }\end{array}$ \\
\hline $\mathbf{H g C O}_{3}$ & $6.37 \mathrm{E}-26$ \\
\hline $\mathbf{H g C l}^{+}$ & $3.78 \mathrm{E}-26$ \\
\hline $\left.\mathbf{H g}^{+} \mathbf{C O}_{3}\right)_{2}{ }^{2-}$ & $4.81 \mathrm{E}-27$ \\
\hline $\mathbf{H g H C O}_{3}{ }^{+}$ & $1.61 \mathrm{E}-27$ \\
\hline $\mathbf{H g O H}^{+}$ & $6.81 \mathrm{E}-28$ \\
\hline $\mathbf{H g}^{2+}$ & $4.71 \mathrm{E}-31$ \\
\hline $\mathbf{H g}(\mathbf{O H})_{3}{ }^{-}$ & $5.37 \mathrm{E}-32$ \\
\hline
\end{tabular}

For the washed cell solutions in the pyruvate/fumarate experiments that had been spiked with $\mathrm{Hg}-\mathrm{NOM}$, the only species present at a significant concentration was $\mathrm{HgRS}^{+}$, which represents $\mathrm{Hg}-\mathrm{NOM}$. One of the more stable forms of $\mathrm{Hg}$ in $\mathrm{Hg}-\mathrm{NOM}$ complexes, $\mathrm{Hg}(\mathrm{RS})_{2}$, was not included in the model to simplify the modeling and represent $\mathrm{Hg}-\mathrm{NOM}$ complexes as one form of $\mathrm{Hg}-\mathrm{NOM}$. Only a fraction of $\mathrm{Hg}$ in $\mathrm{Hg}-\mathrm{NOM}$ complexes was assumed to be available for bacteria to take up. Miller et al. (2009) discuss the reducible fraction of $\mathrm{Hg}$ in $\mathrm{Hg}-\mathrm{NOM}$ complexes, but do not make assumptions on the bioavailability of this fraction of $\mathrm{Hg}$. In the present research, it is assumed that the reducible fraction of $\mathrm{Hg}$ in $\mathrm{Hg}-\mathrm{NOM}$ complexes is available for bacteria to take up, and this assumption is made only in the present research. To model the uptake of $\mathrm{Hg}-\mathrm{NOM}$ by bacteria, in the rate equation for facilitated uptake of $\mathrm{Hg}-\mathrm{NOM}$, the concentration of $\mathrm{Hg}-\mathrm{NOM}$ complexes was multiplied by the reducible fraction of $\mathrm{Hg}$ on $\mathrm{Hg}-\mathrm{NOM}$ complexes. The following figure shows the results of the model for passive diffusion and facilitated uptake of mercury by cells for the washed cell solutions in the pyruvate/fumarate experiments that had been spiked with $\mathrm{Hg}$-NOM. The model was tested with the original estimated parameters and some varied parameters. 


\section{Model Results and Experimental Data for Pyruvate/Fumarate}

Experiments Spiked with $\mathrm{Hg}$-NOM

2

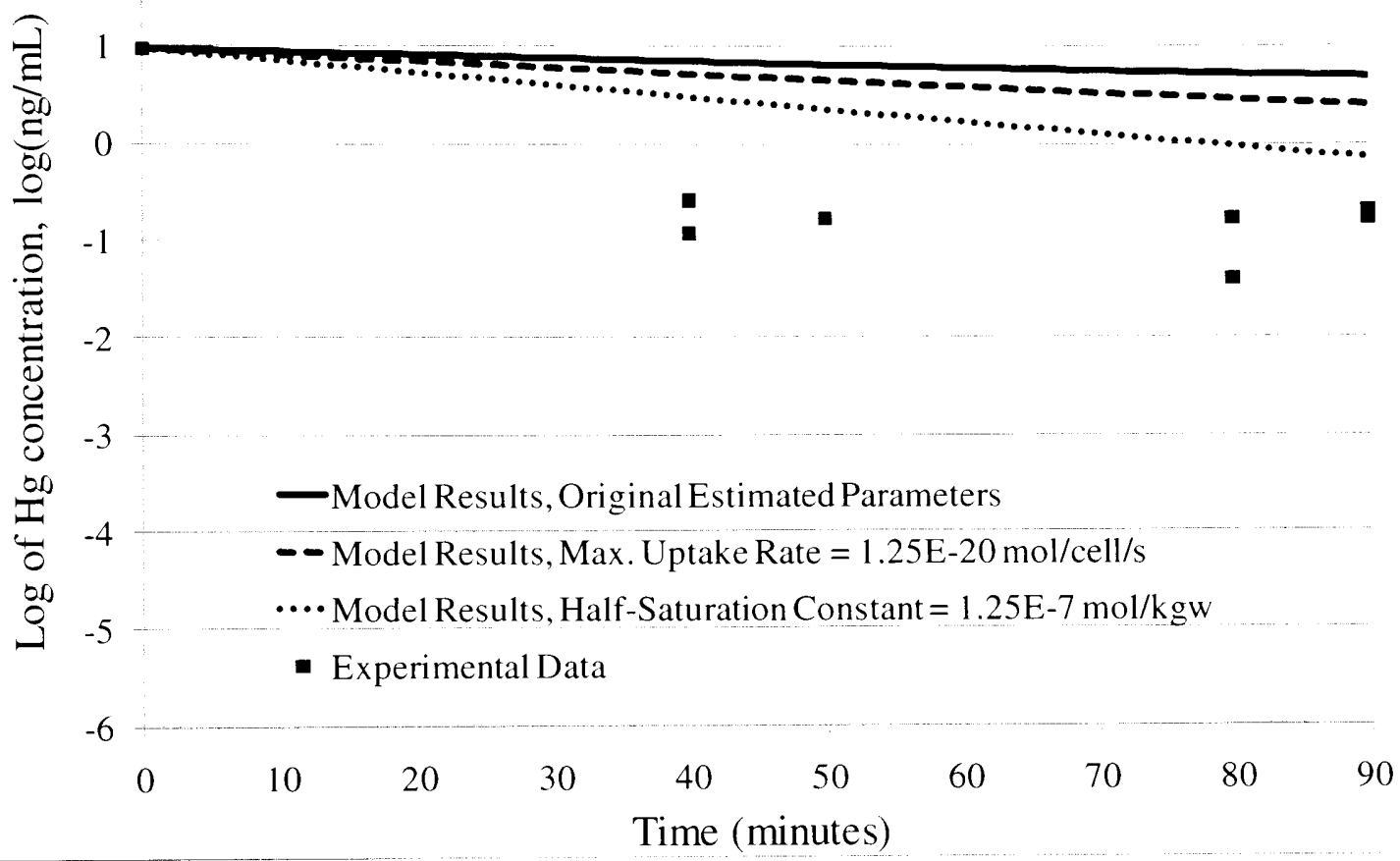

Figure 13: Model results and experimental data for the washed cell solutions from the pyruvate/fumarate experiments that had been spiked with Hg-NOM. The initial concentration of mercury in the washed cell solutions was measured volumetrically during the laboratory experiments, not measured using ICP-MS. Experimental data points that were $0.02 \mathrm{ng} \mathrm{Hg} / \mathrm{mL}$ or less, which is close to the detection limit of the ICP-MS of $0.01 \mathrm{ng} \mathrm{Hg} / \mathrm{mL}$, were removed from the experimental data.

From the above figure, Figure 13, for the washed cell solutions from the pyruvate/fumarate experiments that had been spiked with $\mathrm{Hg}-\mathrm{NOM}$, it appears that the model could not accurately fit the experimental data. The model results show an uptake rate of mercury that is slower than the uptake rate suggested in the experimental data. 
The following table shows the initial speciation of mercury, calculated by PHREEQC, for the washed cell solutions in the lactate/sulfate experiments spiked with $\mathrm{HgCl}_{2}$.

Table 15: Calculated initial speciation of mercury for the washed cell solutions in the lactate/sulfate experiments that had been spiked with $\mathrm{HgCl}_{2}$. Mercury speciation was calculated using PHREEQC.

\begin{tabular}{|c|c|}
\hline Species & $\begin{array}{c}\text { Calculated Molality } \\
(\mathrm{mol} / \mathrm{kg})\end{array}$ \\
\hline Hg(II) & $5.00 \mathrm{E}-08$ \\
\hline $\mathrm{HgS}_{2}{ }^{2-}$ & $4.13 \mathrm{E}-08$ \\
\hline $\mathrm{HgS}_{2} \mathrm{H}^{-}$ & $7.16 \mathrm{E}-09$ \\
\hline $\mathrm{Hg}(\mathrm{HS})_{2}$ & 1.45E-09 \\
\hline $\mathrm{HgS}^{0}$ & $4.70 \mathrm{E}-11$ \\
\hline $\mathrm{HgHS}^{+}$ & $1.54 \mathrm{E}-13$ \\
\hline $\mathrm{HgCl}_{2}$ & $1.39 \mathrm{E}-30$ \\
\hline $\mathrm{HgCl}_{3}{ }^{-}$ & $3.29 E-31$ \\
\hline $\mathrm{HgClOH}$ & $4.80 \mathrm{E}-32$ \\
\hline $\mathrm{HgCl}_{4}{ }^{-2}$ & $4.02 \mathrm{E}-32$ \\
\hline$\overline{\mathrm{Hg}(\mathrm{OH})_{2}}$ & $6.40 \mathrm{E}-33$ \\
\hline $\mathrm{HgCO}_{3}$ & $5.51 \mathrm{E}-35$ \\
\hline $\mathrm{HgCl}+$ & $3.39 \mathrm{E}-35$ \\
\hline $\mathrm{Hg}\left(\mathrm{CO}_{3}\right)_{2}{ }^{2-}$ & $5.15 \mathrm{E}-36$ \\
\hline $\mathrm{HgHCO}_{3}{ }^{+}$ & $1.50 \mathrm{E}-36$ \\
\hline $\mathrm{HgOH}^{+}$ & $6.61 \mathrm{E}-37$ \\
\hline $\mathrm{Hg}^{+2}$ & $5.48 \mathrm{E}-40$ \\
\hline $\mathrm{Hg}(\mathrm{OH})_{3}^{-}$ & $0.00 \mathrm{E}+00$ \\
\hline $\mathrm{HgSO}_{4}$ & $0.00 \mathrm{E}+00$ \\
\hline $\mathrm{Hg}\left(\mathrm{SO}_{4}\right)_{2}{ }^{2-}$ & $0.00 \mathrm{E}+00$ \\
\hline
\end{tabular}

For modeling the washed cell solutions from the lactate/sulfate experiments that had been spiked with $\mathrm{HgCl}_{2}$, the estimated total concentration of sulfide was $1 \mathrm{mmol} / \mathrm{kgw}$. The 
speciation of mercury in these solutions is dominated by mercury sulfide species and the calculated dominant mercury species is $\mathrm{HgS}_{2}{ }^{2-}$. The following figure shows the change in speciation versus total sulfide concentration for the mercury sulfide species in the washed cell solutions in the lactate/sulfate experiments that had been spiked with $\mathrm{HgCl}_{2}$.

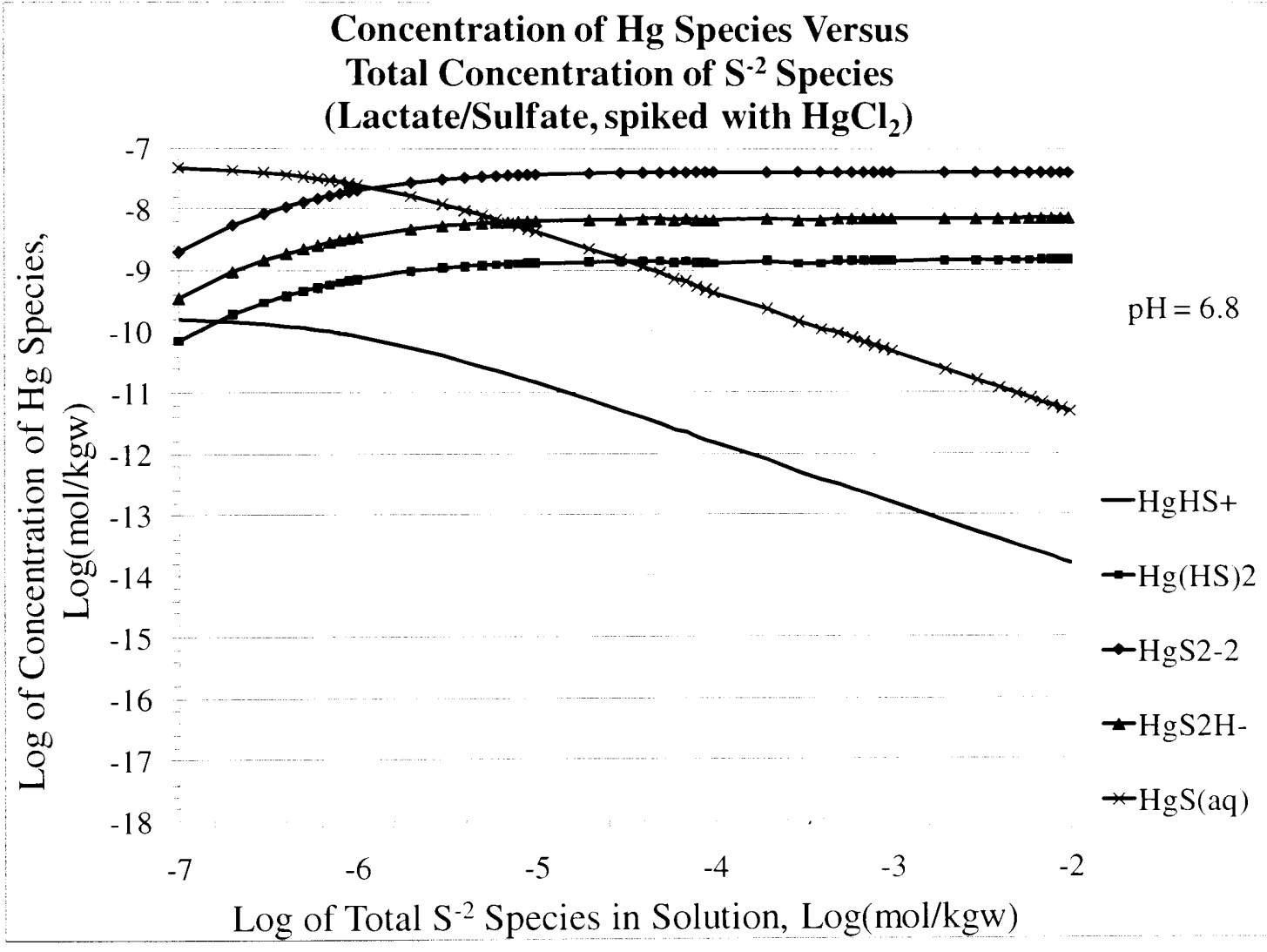

Figure 14: Concentration of different mercury sulfide species versus the estimated total concentration of sulfide in solution for the washed cell solutions in the lactate/sulfate experiments that had been spiked with $\mathbf{H g C l}_{2}$.

For the washed cell solutions in the lactate/sulfate experiments spiked with $\mathrm{HgCl}_{2}$, the calculated speciation of mercury shifts from $\mathrm{HgS}^{0}$ to $\mathrm{HgS}_{2}{ }^{2-}$ being the dominant form of mercury in solution as total sulfide concentration increases from $10^{-7} \mathrm{~mol} / \mathrm{kgw}$ to $10^{-1}$ 
$\mathrm{mol} / \mathrm{kgw}$. For the modeling, the estimated total sulfide concentration in each of the washed cell solutions in the lactate/sulfate experiments was $10^{-3} \mathrm{~mol} / \mathrm{kgw}$, or 1 $\mathrm{mmol} / \mathrm{kgw}$. The following figure shows the results of the model for the washed cell solutions in the lactate/sulfate experiments spiked with $\mathrm{HgCl}_{2}$. The model was tested with the original estimated parameters and varying total sulfide concentration. The graph is not presented in logarithmic scale because the mercury concentration in each supernatant sample was below the detection limit of the ICP-MS.

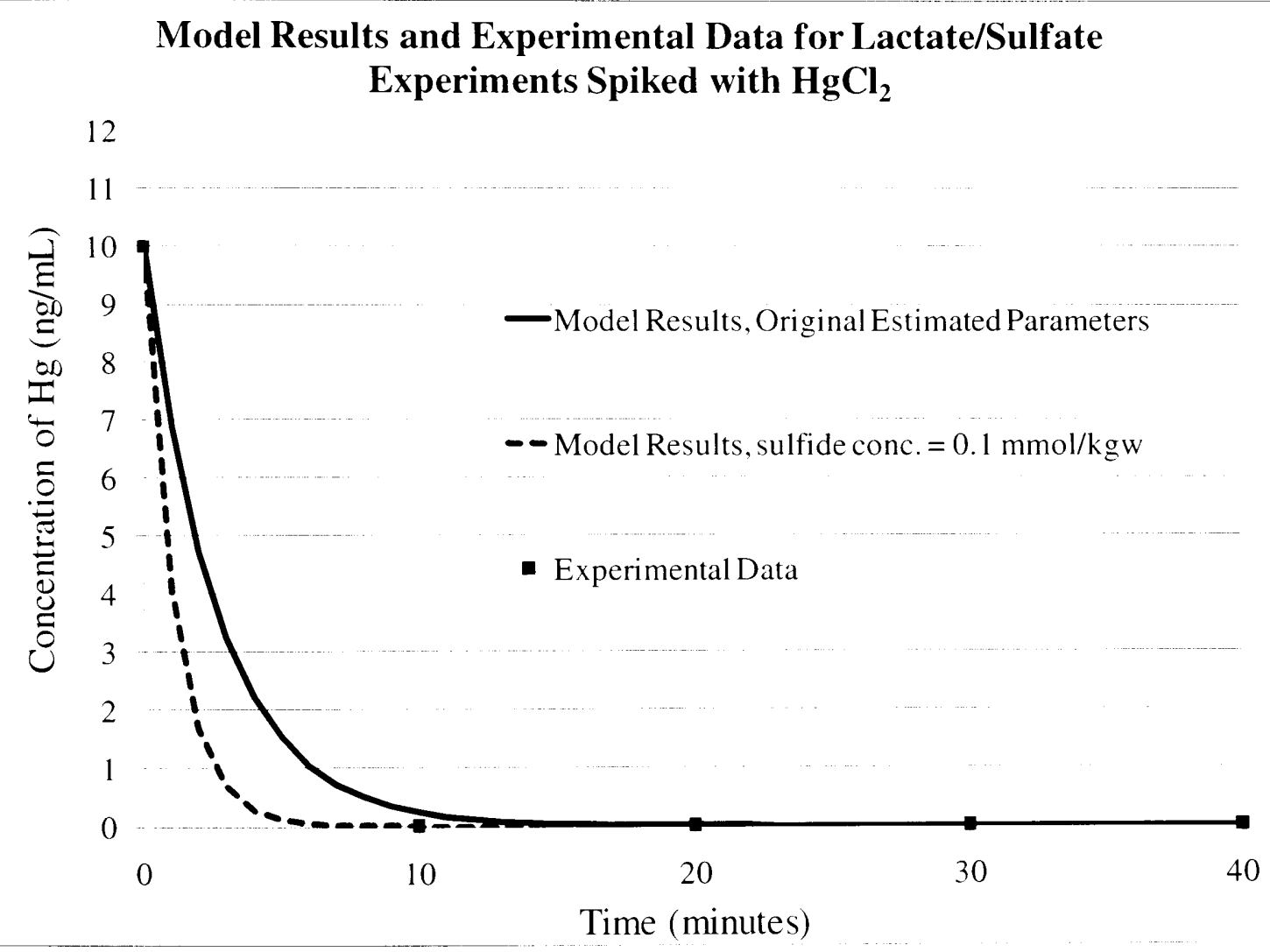

Figure 15: Model results and experimental data for the washed cell solutions from the lactate/sulfate experiments spiked with $\mathrm{HgCl}_{2}$. The initial concentration of $\mathrm{Hg}$ in the washed cell solutions was measured volumetrically during the experiments, not measured using ICP-MS. Experimental data points that were $0.02 \mathrm{ng} \mathrm{Hg} / \mathrm{mL}$ or less, close to the detection limit of the ICP-MS of $0.01 \mathrm{ng} \mathrm{Hg} / \mathrm{mL}$, were not included. 
From the above figure, Figure 15, for the model of the washed cell solutions in the lactate/sulfate experiments that had been spiked with $\mathrm{HgCl}_{2}$, decreasing the concentration of total sulfide in solution by one order of magnitude results in an increase in the mercury uptake rate. This is likely due to the increase in the concentration of $\mathrm{HgS}^{0}$ at lower concentrations of total sulfide in solution since this mercury species is assumed to be able to be taken up by passive diffusion and facilitated uptake. The mercury species $\mathrm{HgS}_{2}{ }^{2-}$ is assumed to not be able to be taken up by either passive diffusion or facilitated uptake. The models for the washed cell solutions in the lactate/sulfate experiments do not include the possibility of formation of the solid mercury species $\mathrm{HgS}(\mathrm{s})$, which can significantly affect the speciation and uptake of mercury in these solutions. When $\mathrm{HgS}(\mathrm{s})$ is allowed to form in the model simulations, $\mathrm{HgS}(\mathrm{s})$ dominates the speciation of mercury. This has been discussed in Chapter IV of the present research in the section entitled Uncertainty of Cinnabar Formation in the Lactate/Sulfate Solutions. It is possible that $\mathrm{HgS}(\mathrm{s})$ formed in washed cell solutions from the lactate/sulfate experiments that had been spiked with $\mathrm{HgCl}_{2}$, which may explain the very low (below the detection limit of the ICP-MS) concentrations of $\mathrm{Hg}$ in the supernatant samples from these solutions.

Model for the Lactate/Sulfate Experiments spiked with Hg-NOM

The following table shows the initial mercury speciation, calculated by PHREEQC, for the washed cell solutions for the lactate/sulfate experiments that had been spiked with Hg-NOM. 
Table 16: Calculated initial speciation of mercury for the washed cell solutions in the lactate/sulfate experiments that had been spiked with Hg-NOM. Mercury speciation was calculated using PHREEQC.

\begin{tabular}{|c|c|}
\hline Species & $\begin{array}{c}\text { Calculated Molality } \\
\text { (mol/kg solution) }\end{array}$ \\
\hline $\mathrm{Hg}(\mathrm{II})$ & $5.00 \mathrm{E}-08$ \\
\hline $\mathrm{HgS}_{2}{ }^{2-}$ & $4.13 E-08$ \\
\hline $\mathrm{HgS}_{2} \mathrm{H}^{-}$ & $7.16 \mathrm{E}-09$ \\
\hline $\mathrm{Hg}(\mathrm{HS})_{2}$ & $1.45 \mathrm{E}-09$ \\
\hline $\mathrm{HgS}^{0}$ & $4.70 \mathrm{E}-11$ \\
\hline $\mathrm{HgHS}^{+}$ & $1.54 \mathrm{E}-13$ \\
\hline $\mathrm{HgRS}^{+}$ & $4.29 \mathrm{E}-17$ \\
\hline $\mathrm{HgCl}_{2}$ & $1.39 \mathrm{E}-30$ \\
\hline $\mathrm{HgCl}_{3}^{-}$ & $3.29 \mathrm{E}-31$ \\
\hline $\mathrm{HgClOH}$ & $4.80 \mathrm{E}-32$ \\
\hline $\mathrm{HgCl}_{4}{ }^{-2}$ & $4.02 \mathrm{E}-32$ \\
\hline$\overline{\mathrm{Hg}(\mathrm{OH})_{2}}$ & $6.40 \mathrm{E}-33$ \\
\hline $\mathrm{HgCO}_{3}$ & $5.51 \mathrm{E}-35$ \\
\hline $\mathrm{HgCl}+$ & $3.39 \mathrm{E}-35$ \\
\hline $\mathrm{Hg}\left(\mathrm{CO}_{3}\right)_{2}{ }^{2-}$ & $5.15 \mathrm{E}-36$ \\
\hline $\mathrm{HgHCO}_{3}{ }^{+}$ & $1.50 \mathrm{E}-36$ \\
\hline $\mathrm{HgOH}^{+}$ & $6.61 \mathrm{E}-37$ \\
\hline $\mathrm{Hg}^{+2}$ & $5.48 \mathrm{E}-40$ \\
\hline $\mathrm{Hg}(\mathrm{OH})_{3}^{-}$ & $0.00 \mathrm{E}+00$ \\
\hline $\mathrm{HgSO}_{4}$ & $0.00 \mathrm{E}+00$ \\
\hline $\mathrm{Hg}\left(\mathrm{SO}_{4}\right)_{2}{ }^{2-}$ & $0.00 \mathrm{E}+00$ \\
\hline
\end{tabular}

For the washed cell solutions in the lactate/sulfate experiments that had been spiked with Hg-NOM, the calculated speciation is almost identical to the calculated speciation of the lactate/sulfate experiments spiked with $\mathrm{HgCl}_{2}$. Miller (2006) and Miller et al. (2007) have discussed the possibility that complexes of mercury, sulfide, and NOM, may exist and are not predicted by thermodynamic models. For example, Miller et al. (2007) propose that there may be a mercury species HS-Hg- $\mathrm{R}$ in solutions containing $\mathrm{Hg}$, sulfide, and NOM. 
However, there are no known thermodynamic equilibrium constants of formation for this species. Miller (2006) calculated conditional stability constants for some possible complexes of mercury, sulfide, and NOM, but these constants were not added to the model in the present research. The following figure shows the results of the model for the washed cell solutions in the lactate/sulfate experiments that had been spiked with $\mathrm{Hg}$ NOM. The original estimated parameters were tested and some parameters were varied.

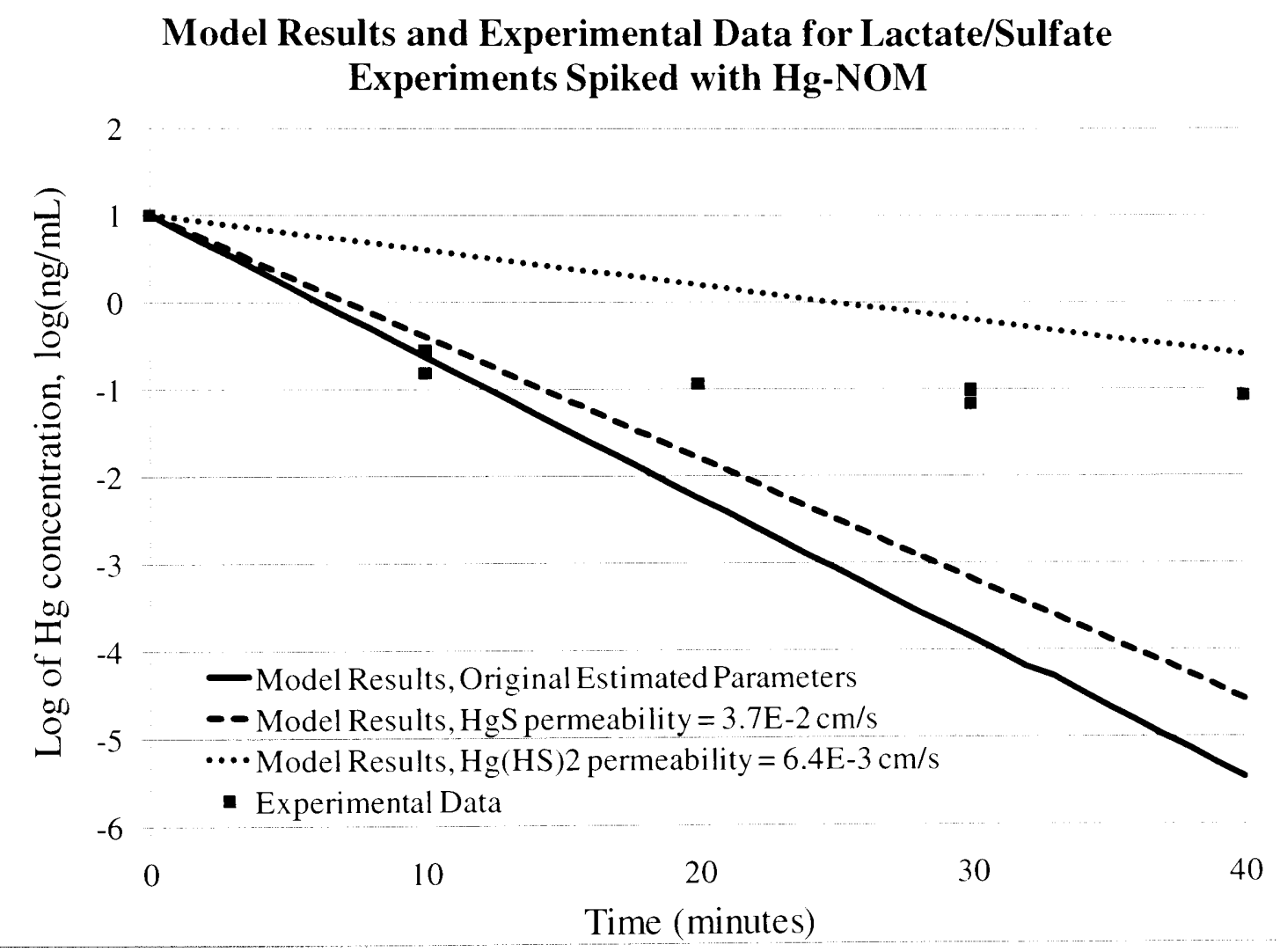

Figure 16: Model results and experimental data for washed cell solutions from the lactate/sulfate experiments spiked with $\mathrm{Hg}$-NOM. The initial concentration of $\mathrm{Hg}$ in the washed cell solutions was measured volumetrically during the experiments, not measured using ICP-MS. Experimental data points that were $0.02 \mathrm{ng} \mathrm{Hg} / \mathrm{mL}$ or less, close to the detection limit of the ICP-MS of $0.01 \mathrm{ng} \mathrm{Hg} / \mathrm{mL}$, were not included. 
For the model results for the washed cell solutions in the lactate/sulfate experiments that had been spiked with $\mathrm{Hg}-\mathrm{NOM}$, the model does not predict that $\mathrm{Hg}-\mathrm{NOM}$ complexes are present at any significant concentration. Thus, the model results from Figure 16 do not predict any significant uptake of $\mathrm{Hg}-\mathrm{NOM}$ complexes. The possible interaction between $\mathrm{Hg}$, sulfide, and NOM is discussed by numerous researchers, including Miller (2006) and Miller et al. (2007). In the present research, from Figure 16, the model for the lactate/sulfate experiments that had been spiked with $\mathrm{Hg}-\mathrm{NOM}$ appears to predict the estimated initial uptake rate of mercury over the first 40 minutes of the experiments. Nevertheless, the model does not take into account the possible interactions between $\mathrm{Hg}$, sulfide, and NOM, therefore the model results for this set of experiments are similar to the model results for the lactate/sulfate experiments that had been spiked with $\mathrm{HgCl}_{2}$, which is most likely not correct. The models in the present research do not include thermodynamic equilibrium information for complexes of mercury, sulfide, and NOM. Therefore, it is difficult to accurately predict the speciation of mercury, and the uptake of mercury by cells, in the solutions that contain mercury, sulfide, and NOM. 


\section{DISCUSSION}

Limitations in the Results of the Laboratory Experiments

From the results of the laboratory experiments, there was a large discrepancy in the mass balance of mercury for each of the washed cell solutions, where approximately $90 \%$ of the added mercury in each washed cell solution could not be accounted for. Some plausible explanations for this mass balance discrepancy have been discussed in Chapter VI of the present research in the section entitled Mass Balance Discrepancy for Results of ICP-MS Analysis. Despite the discrepancy in the mass balance, some potentially useful information was obtained from each set of experiments by comparing the measured mass of mercury in each cell pellet sample to the calculated mass of mercury in each respective supernatant sample, as well as taking into account the calculated mass of mercury in the control samples of the test tube walls.

Most of the supernatant samples analyzed using the DMA 80 had mercury concentrations that were below the limit of quantitation (LOQ) of the DMA 80. However, for the few supernatant samples that had mercury concentrations above the LOQ of the DMA 80, the results of the DMA 80 analysis of these samples and the results of the ICP-MS analysis of the same samples were significantly different. Some possible explanations for this difference have been discussed in Chapter VI of the present research in the section entitled Difference in Results from the DMA 80 and Results from ICP-MS. Because of the likely higher quality control of the ICP-MS analysis, the results of the ICP-MS 
analysis were used in the present research and the procedure and results of the DMA 80 analysis are presented in Appendices $\mathrm{C}$ and $\mathrm{D}$.

\section{Mercury Uptake by Bacteria in the Pyruvate/Fumarate Experiments}

For the washed cell solutions in the pyruvate/fumarate experiments that had been spiked with $\mathrm{HgCl}_{2}$, the measured mass of mercury in the cell pellet samples was significantly greater than the calculated mass of mercury in the respective supernatant samples, and the mass of mercury in the sample of the test tube walls that was analyzed for this set of experiments contained a mercury concentration comparable to that of the respective supernatant sample (Tables 4 and 5, Figure 8). Due to the relatively high mass of mercury in the cell pellet samples for this set of experiments, it is likely that mercury uptake by bacteria occurred. In addition, because the calculated mass of mercury in the test tube walls sample was comparable to the calculated mass of mercury in the respective supernatant sample, it appears that a significant amount of mercury binds to the glass walls of the test tubes.

For the washed cell solutions in the pyruvate/fumarate experiments that had been spiked with $\mathrm{Hg}-\mathrm{NOM}$, the measured mass of mercury in the cell pellet samples was greater than the calculated mass of mercury in the respective supernatant samples, though the mass of mercury in the cell pellet samples was, in general, not much greater than the mass of mercury in the supernatant samples (Tables 4 and 5, Figure 9). In addition, the mass of mercury in the sample of the test tube walls that was analyzed for this set of experiments contained a mercury concentration that was approximately equal to the mercury 
concentration in the respective supernatant sample. This suggests significant binding of mercury to the glass walls of the test tubes in the pyruvate/fumarate experiments.

From the results of the pyruvate/fumarate experiments, it appears that mercury uptake was occurring in the washed cell solutions because of the higher mass of mercury in each cell pellet sample than in each respective supernatant sample. In general, for the pyruvate/fumarate experiments, the ratio between the mass of mercury in the cell pellet sample to the mass of mercury in the supernatant sample was higher for the washed cell solutions that had been spiked with $\mathrm{HgCl}_{2}$ than for the washed cell solutions that had been spiked with $\mathrm{Hg}-\mathrm{NOM}$. In addition, due to the relatively constant but slightly fluctuating mass of mercury for all the cell pellet and supernatant samples in the pyruvate/fumarate experiments, it appears that most of the mercury uptake occurred before the first 40 minutes after the mercury spikes. Therefore, from the laboratory experiments for the pyruvate/fumarate solutions, it is difficult to obtain an accurate estimate of the short-term (prior to 40 minutes) rates of mercury uptake by bacteria.

\section{Mercury Uptake by Bacteria in the Lactate/Sulfate Experiments}

For the washed cell solutions in the lactate/sulfate experiments that had been spiked with $\mathrm{HgCl}_{2}$, the concentration of mercury in all the supernatant samples was below the detection limit of the ICP-MS (Tables 2 and 3, Figure 6). These results suggest that in these solutions, because sulfide was expected to be present, mercury may have precipitated and formed $\mathrm{HgS}(\mathrm{s})$. Because $\mathrm{HgS}(\mathrm{s})$ is a solid, it is probably not available for bacteria to take up. If $\mathrm{HgS}(\mathrm{s})$ formed in the washed cell solutions in the lactate/sulfate 
experiments that had been spiked with $\mathrm{HgCl}_{2}$, any mass of mercury that was detected in the cell pellet samples was probably $\operatorname{HgS}(\mathrm{s})$. For the washed cell solutions in the lactate/sulfate experiments that had been spiked with $\mathrm{HgCl}_{2}$, the speciation modeling predicted that, if $\mathrm{HgS}(\mathrm{s})$ was allowed to form in the model simulations, $\mathrm{HgS}(\mathrm{s})$ would dominate the mercury speciation at $\mathrm{pH} 6.8$. However, at $\mathrm{pH}$ approximately greater than or equal to 8, the model became unstable. Therefore, it is uncertain if $\mathrm{HgS}(\mathrm{s})$ formed in these solutions, and more importantly, measurements of the mercury uptake rate by bacteria in these solutions may be inaccurate if $\mathrm{HgS}(\mathrm{s})$ did form in this set of experiments.

For the washed cell solutions in the lactate/sulfate experiments that had been spiked with Hg-NOM, the concentration of mercury in each of the supernatant samples was detectable (Tables 2 and 3, Figure 7). Sulfide was also expected to be in these solutions, potentially making it uncertain if the mass of mercury in each cell pellet sample was due to mercury uptake by bacteria or to the formation of $\mathrm{HgS}(\mathrm{s})$. But more importantly, the presence of NOM in these solutions appears to decrease either mercury uptake by bacteria or formation of $\mathrm{HgS}(\mathrm{s})$, or possibly both.

Stability Constants of Mercury Species and Mercury Uptake Rates

From the speciation modeling and the laboratory experiments, the thermodynamic equilibrium constants of formation of various mercury species were compared to the estimated initial mercury uptake rate constant for each set of experiments (Table 6, Figures 10 and 11). Because the laboratory experiments had limited data, no obvious 
correlation between the thermodynamic equilibrium constant of formation for the calculated dominant mercury species in each solution and the estimated initial mercury uptake rate constant in each solution was observed.

\section{Model of Mercury Uptake by Bacteria}

The model of mercury uptake in the present research combined two possible mechanisms for mercury uptake by bacteria, which include the processes of passive diffusion of neutral mercury species and facilitated uptake of neutral and positively-charged mercury species. From the results of the model for the pyruvate/fumarate experiments that had been spiked with $\mathrm{HgCl}_{2}$, the model appeared to simulate some of the experimental data when some of the original estimated parameters of the model were varied. For this set of experiments, moreover, the model predicted that both passive diffusion and facilitated uptake of mercury species are important in the uptake of mercury by bacteria.

The model for the washed cell solutions in the pyruvate/fumarate experiments that had been spiked with $\mathrm{Hg}-\mathrm{NOM}$ did not accurately simulate the experimental data. This is likely due to the complex chemistry of Hg-NOM. As discussed by Miller et al. (2009), NOM is heterogeneous. Improvement in the understanding of the characteristics of NOM and of the thermodynamic equilibrium constants for the formation of different forms of $\mathrm{Hg}$-NOM complexes would be helpful for the purposes of modeling the speciation of $\mathrm{Hg}$ in the presence of NOM. 
For the model of the lactate/sulfate experiments that had been spiked with either $\mathrm{HgCl}_{2}$ or Hg-NOM, improvements to the model created in the present research must be made to accurately predict the formation of $\mathrm{HgS}(\mathrm{s})$. In addition, the speciation of mercury in the presence of NOM and sulfide is complicated and requires further investigation. From the experimental data for the washed cell solutions in the lactate/sulfate experiments that had been spiked with $\mathrm{Hg}-\mathrm{NOM}$, it is evident that NOM decreases the ability of bacteria to take up mercury and/or decreases the ability of sulfide to react with $\mathrm{Hg}$ to form $\mathrm{HgS}$ (s). The model simulations were not able to capture the complex chemistry between $\mathrm{Hg}$, sulfide, and NOM. 


\section{CONCLUSIONS}

Some useful information was obtained from the results of the experiments and some preliminary conclusions may be made, despite the mass balance discrepancy. Analyzing the ratio between mercury in cell pellet samples to mercury in the supernatant samples provides information on the relative uptake of $\mathrm{Hg}$ by the bacteria.

In the present research, the main hypothesis was that mercury uptake by bacteria would be higher for mercury species with smaller stability constants than for mercury species with greater stability constants.

The original hypothesis that mercury uptake by bacteria is greater for mercury species with smaller stability constants than for mercury species with larger stability constants could neither be accepted nor rejected. The results of the pyruvate/fumarate experiments suggest that mercury uptake by bacteria occurred whether $\mathrm{HgCl}_{2}$ or $\mathrm{Hg}-\mathrm{NOM}$ had been spiked into the washed cell solutions. The species $\mathrm{HgCl}_{2}$ has a smaller stability constant ( $\log \mathrm{K} \sim 14$, see Dong et al., 2010, and reference therein) than the reported range of stability constants for Hg-NOM (log K between 21 and 47, see Supporting Information to Miller et al., 2009, and references therein). In the present research, mercury uptake by cells in the pyruvate/fumarate experiments appeared to be greater for the solutions that had been spiked with $\mathrm{HgCl}_{2}$, which has a smaller stability constant than $\mathrm{Hg}-\mathrm{NOM}$. It is worth noting that $\mathrm{Hg}$-NOM complexes are estimated to be much larger than $\mathrm{HgCl}_{2}$ 
complexes, due to the heterogeneity of NOM discussed by Miller et al. (2009). This difference in size is expected to have a significant effect on mercury uptake by bacteria.

The anticipation that mercury uptake would occur in pyruvate/fumarate solutions that had been spiked with $\mathrm{Hg}$-NOM was correct. For the pyruvate/fumarate experiments, mercury uptake appeared to be greater for the solutions that had been spiked with $\mathrm{HgCl}_{2}$, which was expected, and the results suggest that significant mercury uptake occurred in the solutions that also had been spiked with Hg-NOM. For the washed cell solutions in the pyruvate/fumarate experiments that had been spiked with $\mathrm{Hg}-\mathrm{NOM}$, the dominant form of mercury was calculated to be $\mathrm{Hg}$-NOM. Because of the expected large size of $\mathrm{Hg}$ NOM complexes, it is unlikely that these complexes are taken up by bacteria through passive diffusion.

One possible mechanism for the observed uptake of $\mathrm{Hg}$-NOM by bacteria is that some of the $\mathrm{Hg}$ bound to NOM may bind to ligands on the surface of a cell, and if the bond between $\mathrm{Hg}$ and the cell surface ligand is stronger than the bond between $\mathrm{Hg}$ and $\mathrm{NOM}$, the latter may break and allow $\mathrm{Hg}$ to be transported through the cell membrane and into the cell. This mechanism falls under the category of facilitated uptake.

For the lactate/sulfate solutions spiked with $\mathrm{HgCl}_{2}$, the very low concentrations of $\mathrm{Hg}$ remaining in the supernatant samples (all concentrations were below the detection limit of the ICP-MS) suggest that $\mathrm{HgS}(\mathrm{s})$ may have formed. Therefore, mercury may not have been available for bacteria to take up. On the other hand, in the lactate/sulfate solutions 
spiked with Hg-NOM, mercury was detectable in all the supernatant samples. This suggests that NOM slows down or prevents the formation of $\mathrm{HgS}(\mathrm{s})$, or even that NOM may slow down or prevent mercury uptake by bacteria.

The theoretical model that was created in the present research combined the processes of passive diffusion of neutral mercury species through cell membranes and facilitated uptake of neutral and positively-charged mercury species. The key assumption of the model is that these two mechanisms of mercury uptake are occurring simultaneously in bacteria. The results showed that the model appeared to simulate the experimental data from the pyruvate/fumarate solutions spiked with $\mathrm{HgCl}_{2}$. Because these solutions lacked NOM or sulfide, the chemistry was relatively simple.

In the pyruvate/fumarate solutions, acetate was not included because it was expected to have a relatively small concentration, resulting from the oxidation of pyruvate. In addition, the modeling became complicated for solutions that contained either sulfide, NOM, or both. From the model created in the present research, the formation of $\mathrm{HgS}(\mathrm{s})$ was omitted, and as discussed above, it is possible that $\mathrm{HgS}(\mathrm{s})$ formed in the washed cell solutions in the lactate/sulfate experiments that had been spiked with $\mathrm{HgCl}_{2}$.

In summary, though only one strain of sulfate-reducing bacteria was used in the present research, Desulfovibrio desulfuricans G20, it is likely that the results of the laboratory experiments, which are preliminary, may be applied to similar bacteria. From the results of the pyruvate/fumarate experiments, it appears that $D$. desulfuricans G20 was able to 
take up both $\mathrm{HgCl}_{2}$ and $\mathrm{Hg}-\mathrm{NOM}$. It is possible that a fraction of $\mathrm{Hg}$ bound to NOM, such as the reducible fraction of $\mathrm{Hg}$ in $\mathrm{Hg}-\mathrm{NOM}$ complexes discussed by Miller et al. (2009), may be available for uptake by bacteria. Natural organic matter from different origins may yield different results (see discussion on the origin of dissolved organic carbon, or DOC, in the experiments of Zhong and Wang, 2010). Further research on how the form of mercury affects the uptake of mercury by bacteria can yield valuable information to help design bioremediation strategies for contaminated environments and to possibly slow down the methylation of mercury by bacteria in contaminated environments. 


\section{RECOMMENDATIONS FOR FUTURE WORK}

For future research on mercury uptake by bacteria, an improved experimental plan would include several elements. First of all, it would be important to determine and optimize the experimental amounts of mercury that can bind to the cell membranes, how much mercury is inside cells over a certain time after a mercury spike and the mercury left in solution, to ranges that allow an effective measurement of the various mercury fractions. A solution containing a strong ligand for mercury, such as ethylenediaminetetraacetic acid (EDTA), can be added to the washed cell solution after incubating for a certain time after a mercury spike. The washed cell solutions can then be centrifuged. It is expected that mercury bound to the surfaces of cells would come into contact with EDTA and EDTA would bind to the mercury and remove the mercury from the cell membranes but not the mercury inside the cells (Katsenovich, personal communication, 2011). It is assumed that, for bacteria to produce methylmercury, mercury must be inside the cells. Thus, it is important to ascertain how much mercury is bound to the cell membranes, and how much mercury is inside cells after a certain time period in order to predict the rate of methylmercury production. This will allow a better estimate of the stability constant of mercury bound to a cell surface, which can be helpful in understanding the relationship between the estimated initial uptake rate and the stability constant of a mercury species.

A second improvement to the laboratory experiments in the present research would be to maintain better controls, including the measured concentration of mercury in a solution without cells. This would give a better estimate of the concentration of mercury added 
initially in each washed cell solution. A second type of control would be to determine the background concentration of mercury in a washed cell solution with no added mercury. This would provide a better estimate of the background mercury concentration in the solutions.

A third improvement to the laboratory experiments in the present research would be to maintain a relatively constant number of cells in each solution. This can be accomplished by washing only one large culture of cells, then distributing equal volumes of the washed cell solution to individual test tubes. The number of cells between each set of experiments can also be varied to obtain information on the mercury uptake rate per cell. Varying the initial concentration of mercury and the number of cells in each solution, for the mercury accumulation rate experiments, could yield interesting information about the mercury uptake rate and overall mercury uptake by bacteria

A fourth improvement to the laboratory experiments can be made in the method in which mercury remaining in solution was separated from mercury taken up by cells. In the present research, mercury remaining in solution was separated from solid phase mercury (mercury bound to cells or potentially $\mathrm{HgS}(\mathrm{s})$ ) by centrifuging the centrifuge tubes that contained the washed cell solutions. After centrifuging, the supernatant had to be decanted, and it was difficult to decant all of the supernatant from each centrifuge tube. It is possible to use filter paper instead of centrifuge tubes to separate mercury remaining in solution from mercury in the solid phase. Once a washed cell solution has been spiked with mercury and has incubated for the appropriate time, the washed cell solution can be 
decanted onto filter paper. Aqueous species should pass through the filter, but bacteria would remain on the filter. Therefore, any mercury bound to the bacteria would remain on the filter, and the filter could be rinsed and analyzed, then the rinse solution could be saved for analysis of mercury that was bound to bacteria.

Another improvement to the laboratory experiments would be to incubate washed cell solutions for time intervals that are shorter and closer to the time of mercury spikes. This would allow for data to be obtained on the short-term uptake rates of mercury. In addition, more mercury species can be tested to obtain a better relationship between the estimated initial uptake rate and the stability constant of a mercury species.

As for the modeling, the inclusion of the formation of $\mathrm{HgS}(\mathrm{s})$ and acetate could provide different results. Also, further experimenting with the negative logarithm of the electron activity of the experimental solutions, the $\mathrm{p} \varepsilon$, could give alternate results for the model. 


\section{REFERENCES}

Barkay, Tamar, Mark Gillman, and Ralph R. Turner. "Effects of Dissolved Organic Carbon and Salinity on Bioavailability of Mercury". November 1997. Applied and Environmental Microbiology.Vol. 63, No. 11, Pages 4267 - 4271.

Benoit, Janina M., Cynthia C. Gilmour, Robert P. Mason, and Andrew Heyes. "Sulfide Controls on Mercury Speciation and Bioavailability to Methylating Bacteria in Sediment Pore Water". 1999. Environmental Science and Technology. Vol. 33, No. 6.

Benoit, J. M., C. C. Gilmour, and R. P. Mason. "Aspects of Bioavailability of Mercury for Methylation in Pure Cultures of Desulfobulbus propionicus (1pr3)". January 2001a. Applied and Environmental Microbiology. Vol. 67, No. 1, Pages 51 - 58.

Benoit, J. M., C. C. Gilmour, and R. P. Mason. "The Influence of Sulfide on Solid-Phase Mercury Bioavailability for Methylation by Pure Cultures of Desulfobulbus propionicus (1pr3)". 2001b. Environmental Science and Technology. Vol. 35, No. 1, Pages $127-132$.

Compeau, G. C. and R. Bartha. "Sulfate-Reducing Bacteria: Principal Methylators of Mercury in Anoxic Estuarine Sediment". August 1985. Applied and Environmental Microbiology. Vol. 50, No. 2, pages 498 - 502.

Coy Laboratory Products, Inc. <http://www.coylab.com>. Accessed March 25, 2011.

de Duve, Christian. A Guided Tour of the Living Cell. 1984. Scientific American Books, Inc., Scientific American, Inc.: New York, New York. Printed in the United States of America.

Dong, Wenming, Liyuan Liang, Scott Brooks, George Southworth, and BaohuaGu. "Roles of dissolved organic matter in the speciation of mercury and methylmercury in a contaminated ecosystem in Oak Ridge, Tennessee". 2010. Environmental Chemistry. Volume 7, Issue 1, Pages $94-102$.

Electronic Code of Federal Regulations (e-CFR). "Definition and Procedure for Determination of the Method Detection Limit (MDL)". Revision 1.11. 1986. Title 40: Protection of Environment, Code of Federal Regulations. Part 136, Appendix B. Accessed on October 12, 2010. <http://www.gpoaccess.gov/ecfr>

Elias, Dwayne A. Personal Communications throughout Summer 2010. 
Golding, George R., Carol A. Kelly, Richard Sparling, Peter C. Loewen, John W. M. Rudd, and Tamar Barkay. "Evidence for facilitated uptake of $\mathrm{Hg}(\mathrm{II})$ by Vibrio anguillarum and Escherichia coli under anaerobic and aerobic conditions". July 2002. Limnology and Oceanography. Volume 47, Issue 4, Pages 967 - 975.

International Humic Substances Society (IHSS) website. <http://www.ihss.gatech.edu/>. 2008. Accessed April 18, 2011.

Katsenovich, Yelena, Prof. H. Fuentes, and Georgio Tachiev. "Appendix T6-003, Experimental Studies of the Transport Parameters of Mercury (II) in Oak Ridge Reservation (ORR) Soil".August 6, 2009. Task 6 Modeling of Mercury Distribution in Soil and Groundwater in Support of the Oak Ridge Mercury Remediation Strategies of Remediation and Treatment Technology Development and Support. Progress Report, Version 2. Prepared for U.S. Department of Energy, Oak Ridge Operations Office, Oak Ridge Reservation.

Katsenovich, Yelena. Personal Communications. Fall 2010 through Spring 2011.

Kelly, C. A., John W. M. Rudd, and M. H. Holoka. "Effect of pH on Mercury Uptake by an Aquatic Bacterium: Implications for $\mathrm{Hg}$ Cycling". 2003. Environmental Science and Technology. Vol. 37, No. 13, Pages 2941 - 2946.

Kerin, E. J., C. C. Gilmour, E. Roden, M. T. Suzuki, J. D. Coates, and R. P. Mason. "Mercury Methylation by Dissimilatory Iron-Reducing Bacteria". December 2006. Applied and Environmental Microbiology. Vol. 72, No. 12, Pages 7919 7921.

Martell, Arthur E., and Robert M. Smith. National Institute of Standards and Technology (NIST) Critical Stability Constants of Metal Complexes Database. Database Software Developed By Ramunas J. Motekaitis. 1993. NIST Standard Reference Database 46. Department of Commerce on behalf of the United States. Gaithersburg, MD.

Mason, R. P., W. F. Fitzgerald, and F. M. M. Morel. "The biogeochemical cycling of elemental mercury: Anthropogenic influences". 1994. Geochimica et Cosmochimica Acta. Vol. 58, No. 15, Pages 3191-3198.

Mason, Robert P., John R. Reinfelder, and François M. M. Morel. "Uptake, Toxicity, and Trophic Transfer of Mercury in a Coastal Diatom". 1996. Environmental Science and Technology. Vol. 30, No. 6, Pages 1835-1845.

Milestone Microwave Laboratory Systems.DMA 80 User Manual. Revision 3. 2004. 
Miller, Carrie Lynn. The Role of Organic Matter in the Dissolved Phase Speciation and Solid Phase Partitioning of Mercury. 2006. Dissertation for the degree of Doctor of Philosophy. University of Maryland, College Park.

Miller, Carrie L., Robert P. Mason, Cynthia C. Gilmour, and Andrew Heyes. "Influence of Dissolved Organic Matter on the Complexation of Mercury Under Sulfidic Conditions." 2007. Environmental Toxicology and Chemistry. Vol. 26, No. 4, Pages $624-633$.

Miller, Carrie L., George Southworth, Scott Brooks, Liyuan Liang, and Baohua Gu. "Kinetic Controls on the Complexation between Mercury and Dissolved Organic Matter in a Contaminated Environment". Paper includes Supporting Information (SI). 2009. Environmental Science and Technology. Vol 43, No. 22, Pages 8548 8553.

Morel, François M. M., Robert J. M. Hudson, and Neil M. Price. "Limitation of Productivity by Trace Metals in the Sea". December 1991. Limnology and Oceanography. Volume 36, Issue 8, Pages $1742-1755$.

Najera, Isaac, Chu-Ching Lin, Golenaz Adeli Kohbodi, and Jennifer A. Jay. "Effect of Chemical Speciation on Toxicity of Mercury to Escherichia coli Biofilms and Planktonic Cells". 2005. Environmental Science and Technology. Volume 39, No. 9, Pages $3116-3120$.

Pak, K.-R. and R. Bartha. "Mercury Methylation and Demethylation in Anoxic Lake Sediments and by Strictly Anaerobic Bacteria". March 1998. Applied and Environmental Microbiology. Vol. 64, No.3, Pages 1013 - 1017.

Parkhurst, David L. and C. A. J. Appelo. "User's Guide to PHREEQC (Version 2) - A Computer Program for Speciation, Batch-Reaction, One-Dimensional Transport, and Inverse Geochemical Calculations". 1999. United States Department of the Interior, United States Geological Survey. Water-Resources Investigations Report 99-4259. Denver, Colorado.

Pollack, Andrew."The End of a Tragedy in Pictures". August 3, 1997. The New York Times.<http://www.nytimes.com/1997/08/03/weekinreview/the-end-of-a-tragedyin-pictures.html>. Accessed May 6, 2010.

Postgate, John Raymond. The sulphate-reducing bacteria. 1979. $1^{\text {st }}$ Edition. Cambridge University Press, Printed in Great Britain.

Postgate, John R. and L. Leon Campbell. "Classification of Desulfovibrio Species, the Nonsporulating Sulfate-reducing Bacteria". December 1966. Bacteriological Reviews. Volume 30, No. 4, Pages $732-738$. 
Raven, Peter H., George P. Johnson, Jonathan B. Losos, Kenneth A. Mason, and Susan R. Singer. Biology. $8^{\text {th }}$ Edition. 2008. McGraw-Hill, The McGraw-Hill Companies, Inc.: New York, New York.

Schaefer, Jeffra K. and François M. M. Morel. "High methylation rates of mercury bound to cysteine by Geobacter sulfurreducens". February 2009. Nature Geoscience. Vol. 2.

Skoog, Douglas A., F. James Holler, and Timothy A. Nieman. Principles of Instrumental Analysis. $5^{\text {th }}$ Edition. 1998. Saunders College Publishing. Harcourt Brace College Publishers. Printed in the United States of America.

Stumm, Werner and James J. Morgan. Aquatic Chemistry: Chemical Equilibria and Rates in Natural Waters. 1996. $3^{\text {rd }}$ Edition. A Wiley-Interscience Publication, John Wiley and Sons, Inc.: New York, New York. Printed in the United States of America.

Tebes-Stevens, Caroline, Albert J. Valocchi, Jeanne M. VanBriesen, Bruce E. Rittmann. "Multicomponent transport with coupled geochemical and microbiological reactions: model description and example simulations". 1998. Journal of Hydrology. Volume 209, Issues 1 - 4, Pages 8 - 26.

Voordouw, Gerrit. "The Genus Desulfovibrio: The Centennial". August 1995. Applied and Environmental Microbiology. Vol. 61, No. 8, Pages 2813-2819.

Wall, Judy and Dwayne Elias. Personal electronic mail (e-mail) communication between Dr. Judy Wall and Dr. Dwayne Elias, forwarded to Amaury Betancourt. 2010. 
Table 17: Wall's Medium (or Wall Media) by Judy Wall and Dwayne Elias. Edited by Amaury Betancourt on 08/01/2010. Wall Media was used as the growth medium for growing the bacterial cells. Total Volume of Media $=1000 \mathrm{~mL}$.

\begin{tabular}{|c|c|c|}
\hline Wall Media by Judy Wall and Dwayn & Elias. & \\
\hline Edited by Amaury Betancourt on 08/ & $/ 2010$. & \\
\hline Total Volume of Media: $1000 \mathrm{~mL}$ & & \\
\hline Component & Amount & Units \\
\hline Deionized Water & 900.306 & $\mathrm{~mL}$ \\
\hline $\mathrm{MgCl}_{2} * 6 \mathrm{H}_{2} \mathrm{O}(1.35 \mathrm{M})$ & 5.926 & $\mathrm{~mL}$ \\
\hline $\mathrm{NH}_{4} \mathrm{Cl}(3.74 \mathrm{M})$ & 5.348 & $\mathrm{~mL}$ \\
\hline $\mathrm{CaCl}_{2} * 2 \mathrm{H}_{2} \mathrm{O}(0.95 \mathrm{M})$ & 0.632 & $\mathrm{~mL}$ \\
\hline $\mathrm{K}_{2} \mathrm{HPO}_{4}-\mathrm{NaH}_{2} \mathrm{PO}_{4}(1 \mathrm{M})$ & 2 & $\mathrm{~mL}$ \\
\hline $\begin{array}{l}\text { Trace Elements } \\
\left(\text { Trace Minerals - No NTA, No } \mathrm{FeCl}_{2} \text { ) }\right.\end{array}$ & 1 & $\mathrm{~mL}$ \\
\hline Tris- $\mathrm{HCl}(2 \mathrm{M}), \mathrm{pH} 7.4$ & 15 & $\mathrm{~mL}$ \\
\hline Yeast Extract & 1 & $g$ \\
\hline Thauers Vitamins $(10 \mathrm{X})$ & 1 & $\mathrm{~mL}$ \\
\hline Resazurin $(0.1 \%)$ & 0.8 & $\mathrm{~mL}$ \\
\hline Add the following components post-a & oclave: & \\
\hline $\begin{array}{l}\text { For media amended with Lactate and } S \\
\text { electron acceptor, respectively, add the }\end{array}$ & $\begin{array}{l}\text { ate as the electro } \\
\text { llowing compon }\end{array}$ & nts: \\
\hline
\end{tabular}




\begin{tabular}{|l|r|l|}
\hline Component & Amount & Units \\
\hline Lactate (2 M) & 60 & $\mathrm{~mL}$ \\
\hline Sulfate (2 M) & 30 & $\mathrm{~mL}$ \\
\hline L-Cysteine HCl (0.14 M) & 7.1 & $\mathrm{~mL}$ \\
\hline For media amended with Pyruvate and Fumarate as the electron donor \\
and electron acceptor, respectively, add the following components: \\
\hline Pyruvate (2 M) & 30 & $\mathrm{~mL}$ \\
\hline Fumarate (1 M) & 60 & $\mathrm{~mL}$ \\
\hline Ascorbic Acid (0.14 M) & 7.1 & $\mathrm{~mL}$ \\
\hline Media should be labeled as Wall Medium and then designated with \\
the electron donor/acceptor. For example, if you are using Lactate and \\
Sulfate - the medium would be Wall Lac/Sulf. \\
\hline
\end{tabular}




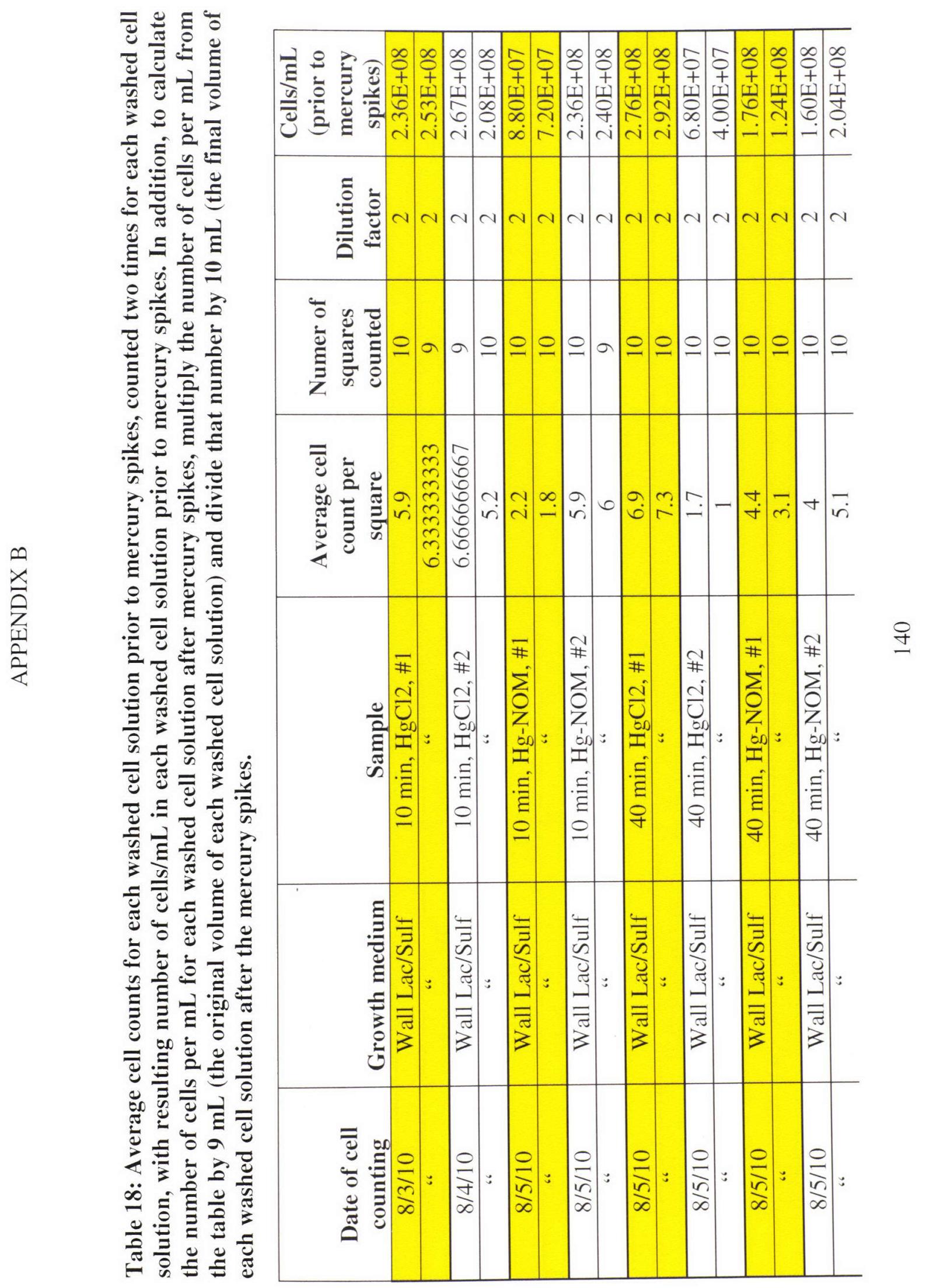




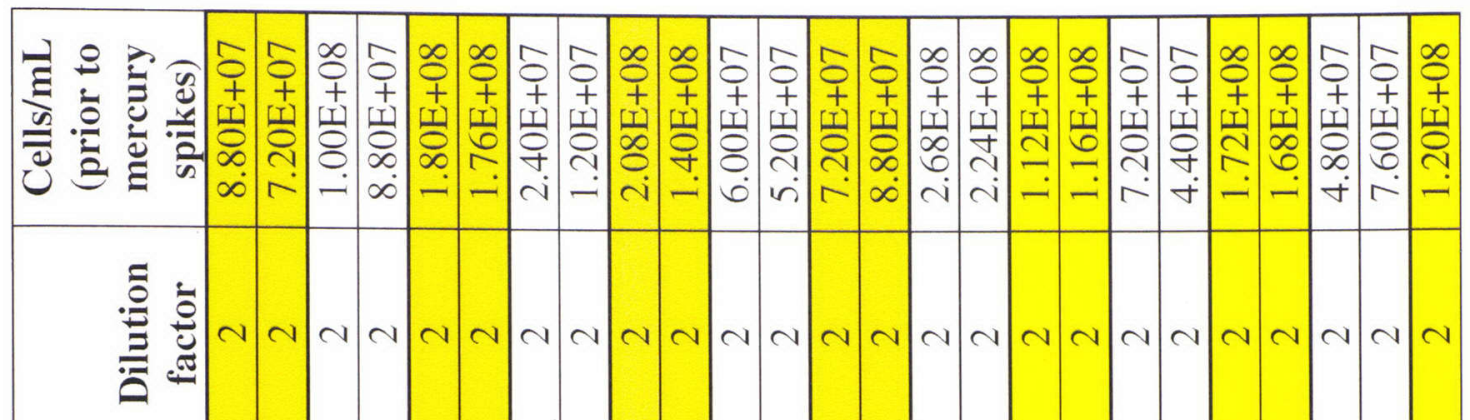

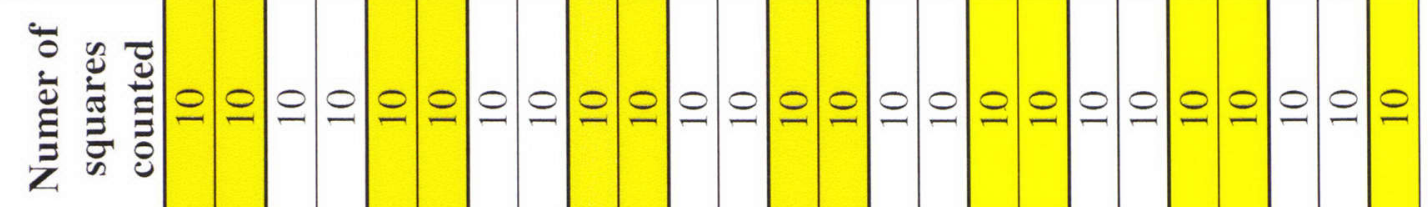

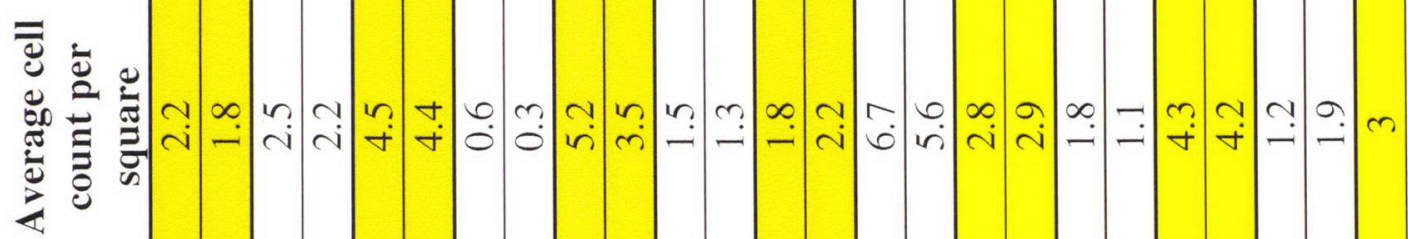

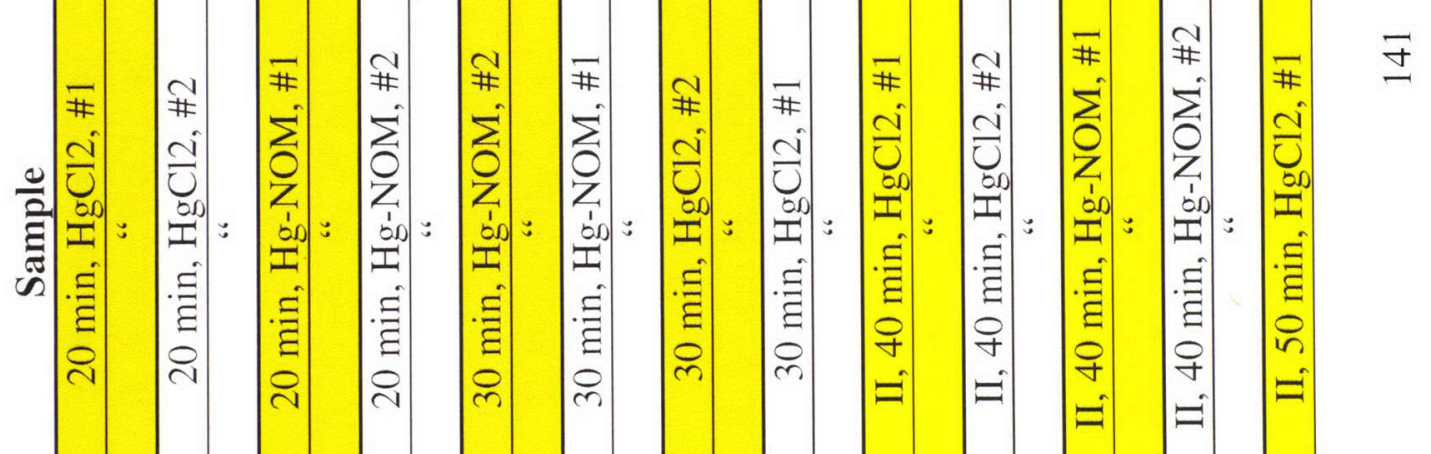

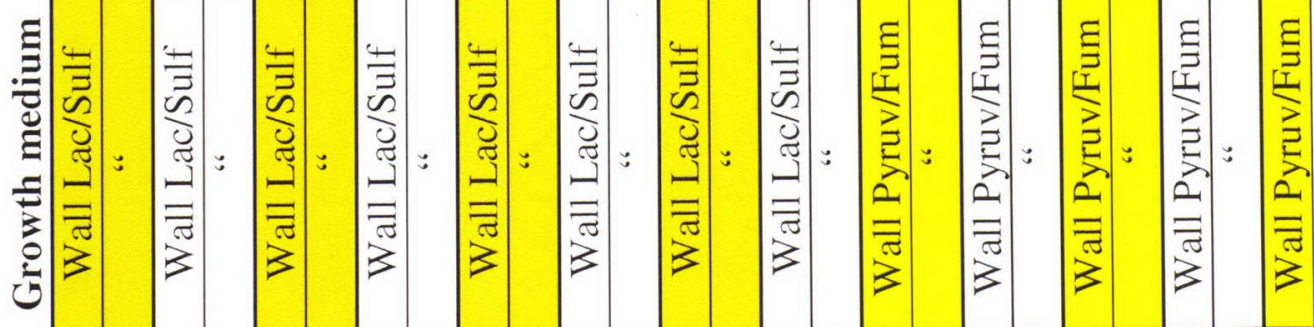

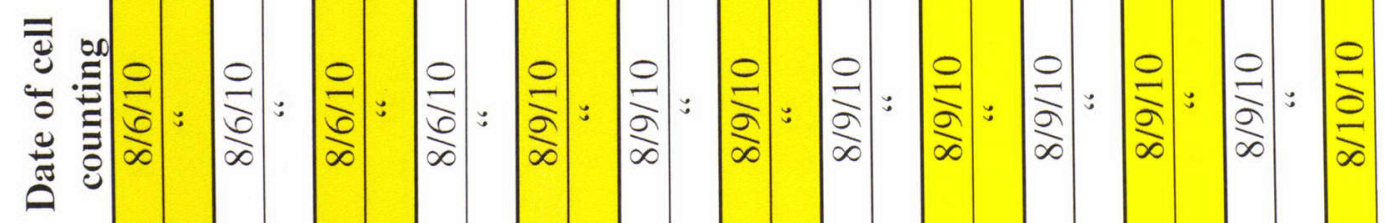




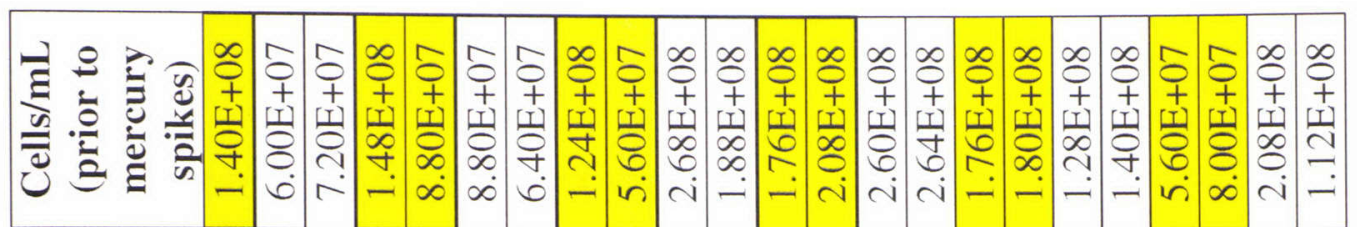

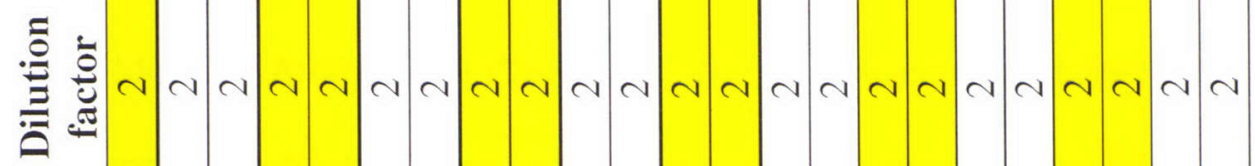

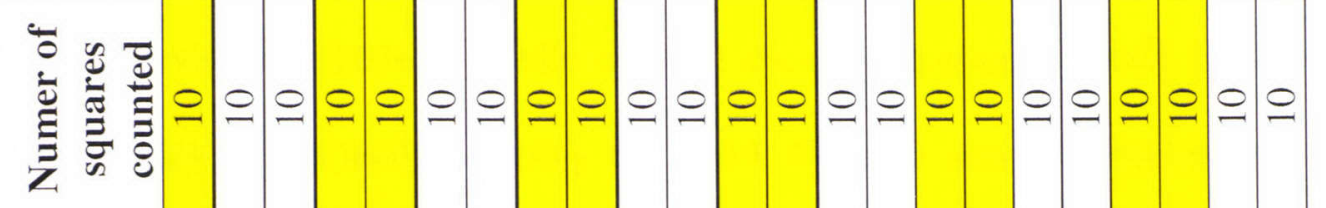

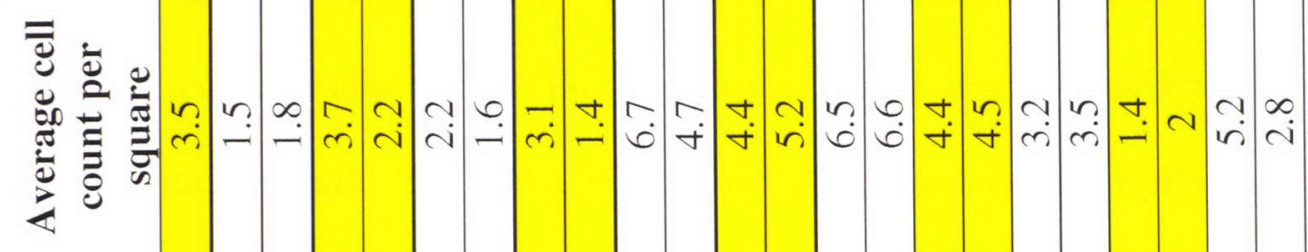

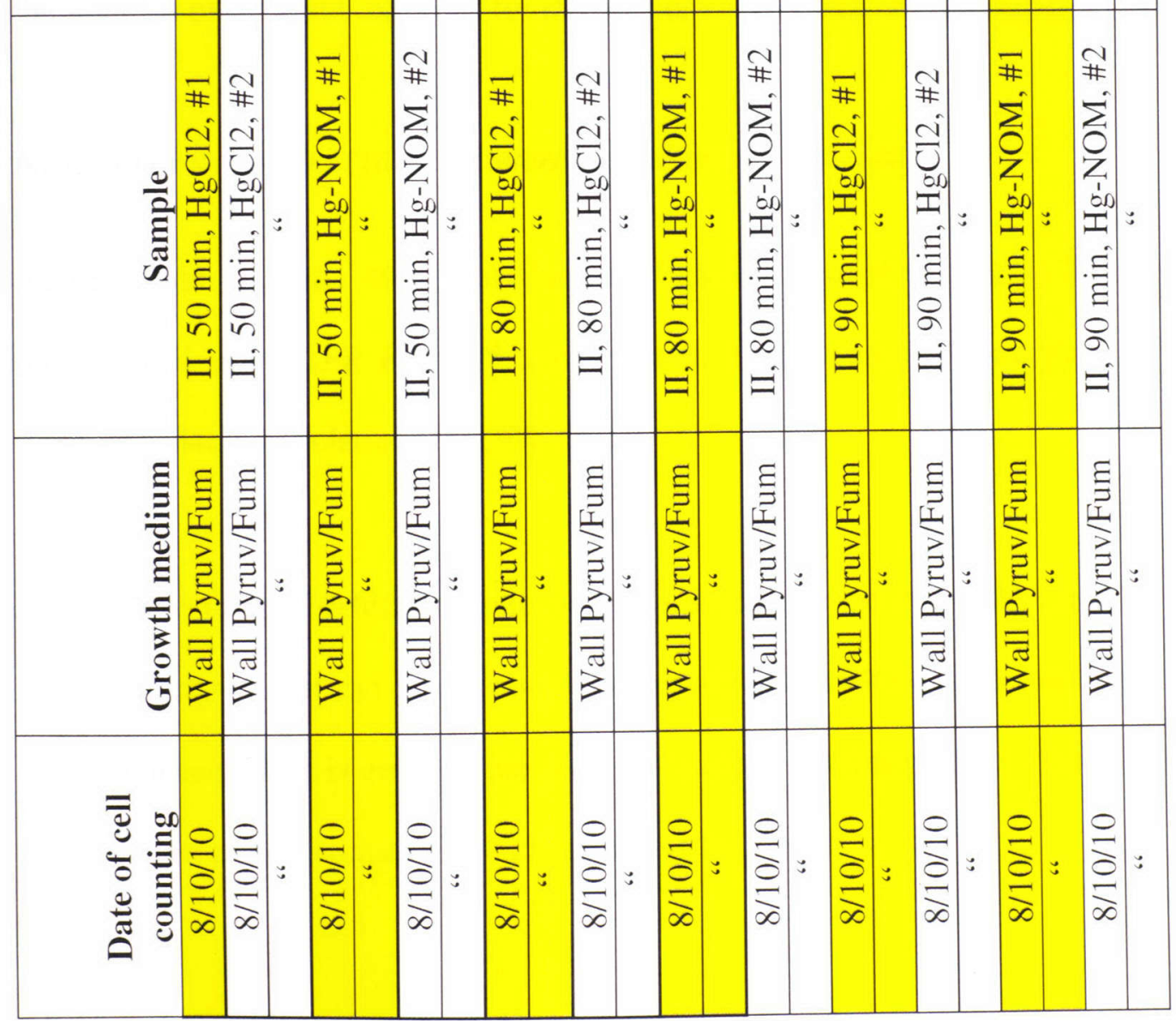




\section{APPENDIX C}

Direct Mercury Analyzer 80 (DMA 80)

The Direct Mercury Analyzer 80 (DMA 80, Milestone Microwave Laboratory Systems) runs on the principle of atomic absorption spectrometry, according to the DMA 80 User Manual, Revision 3 (Milestone Microwave Laboratory Systems, 2004). Both liquid and solid samples can be analyzed using the DMA 80. Each sample, once analyzed, has an absorbance height that is detected by the DMA 80 . Using a calibration curve for the appropriate concentration range, the absorbance height can be converted to mass of mercury in each sample. The DMA 80 was used to analyze the supernatant samples and the samples of the test tube walls for the mercury accumulation rate experiments.

Method Detection Limit (MDL) Determination for the DMA 80

According to the Title 40 of the Code of Federal Regulations, Part 136, Appendix B (abbreviated as 40 CFR Part 136, Appendix B, 1986), accessed through the Electronic Code of Federal Regulations (e-CFR, 2010),

"The method detection limit (MDL) is defined as the minimum concentration of a substance that can be measured and reported with $99 \%$ confidence that the analyte concentration is greater than zero and is determined from analysis of a sample in a given matrix containing the analyte (e-CFR, 2010)." 
The method detection limit (MDL)for the DMA 80 was calculated using the general method for determining the MDL (for any instrument) in 40 CFR Part 136, Appendix B, 1986 (e-CFR, 2010). The first step in determining the MDL for the DMA 80 is to make an initial estimate of the MDL. Several acceptable methods may be used to estimate the MDL. To make an initial estimate of the MDL, a calibration curve giving the relationship between absorbance height and mass of mercury detected was needed. Thus, the MDL determination and the calibration curve were done simultaneously. The initial estimate for the MDL for the DMA 80 was $0.2 \mathrm{ng}$ of $\mathrm{Hg}$. This initial estimate was based on discussions with Dr. Yelena Katsenovich (Katsenovich, 2010), Research Scientist at Florida International University (FIU) Applied Research Center (ARC), and on the research by Katsenovich et al. (2009).

DOE Fellow and FIU student Alexander Henao was very helpful in preparing the mercury standards to determine the MDL for the DMA 80. Once the initial estimate of the MDL was made, a solution of $2 \%$ nitric acid $\left(\mathrm{HNO}_{3}\right)$ and two mercury standard solutions were prepared. The first mercury standard solution was prepared at a concentration of 1 part per million (ppm) mercury, and was prepared by first adding approximately $20 \mathrm{~mL}$ of the $2 \%$ nitric acid solution to a $100 \mathrm{~mL}$ volumetric flask, then adding 100 microliters $(\mu \mathrm{L})$ of a mercury reference standard solution (Fisher Scientific), which has a concentration of $1000 \mathrm{ppm}+/-1 \%$ mercury in $1.8 \%$ nitric acid solution, to the volumetric flask, gently mixing the solution, and then adding $2 \%$ nitric acid solution to the volumetric flask up to the $100 \mathrm{~mL}$ mark on the volumetric flask. The second mercury standard solution was prepared at a concentration of 10 parts per billion (ppb) of 
mercury, and was prepared by first adding approximately $20 \mathrm{~mL}$ of the $2 \%$ nitric acid solution to a $50 \mathrm{~mL}$ volumetric flask, then adding $500 \mu \mathrm{L}$ of the $1 \mathrm{ppm}$ mercury standard solution to the volumetric flask, and then adding $2 \%$ nitric acid solution to the volumetric flask up to the $50 \mathrm{~mL}$ mark on the volumetric flask.

It is important to note that, for the MDL determination of the DMA 80 , during the preparation of the mercury standards from the mercury stock solution (Fisher Scientific), the mercury stock solution (Fisher Scientific) was used approximately two weeks after its expiration date, but this was assumed not to be a significant factor when determining the MDL for the DMA 80 . As can be seen from the results of the runs to determine the MDL and calibration curve for the DMA 80 discussed below, the expiration of the mercury stock solution (Fisher Scientific) does not appear to have had an effect on the MDL of the DMA 80.

The DMA 80 can be used to analyze liquid samples or solid samples, and is equipped with quartz sample boats and metal sample boats. From discussions with Dr. Yelena Katsenovich (Katsenovich, 2010), quartz sample boats are more accurate to use for liquid samples. The MDL determination was therefore done using only quartz sample boats. For the first MDL run, seven replicate samples of the $2 \%$ nitric acid solution were run as blanks, followed by seven replicate samples of the $10 \mathrm{ppb}$ mercury standard solution, each with a volume of $20 \mu \mathrm{L}$ of the $10 \mathrm{ppb}$ mercury standard solution, which gave a mercury mass of $0.2 \mathrm{ng}$ of $\mathrm{Hg}$ in each replicate sample. For the MDL calculations, masses of mercury of $0.5 \mathrm{ng}, 0.8 \mathrm{ng}$, and $1.0 \mathrm{ng}$ of $\mathrm{Hg}$ were also tested, each test with 
seven replicate samples. In addition, for the calibration curve, masses of mercury of 1.5 $\mathrm{ng}, 2.0 \mathrm{ng}, 3.0 \mathrm{ng}$, and $5.0 \mathrm{ng}$ of $\mathrm{Hg}$ were also tested, each test with three replicate samples.

Before using the DMA 80 to determine the MDL and create the calibration curve, the DMA 80 went through multiple cleaning runs, in which sample boats were washed with a $5 \%$ to $10 \%$ solution of nitric acid, and then the DMA 80 was run with empty sample boats. Once absorbance heights for all the sample boats in a cleaning run were less than approximately 0.0030 , the sample boat was assumed to be clean. The results of the MDL and calibration curve runs are shown in the following table.

Table 19: Calculations and Measurements for the Method Detection Limit (MDL) determination for the Direct Mercury Analyzer 80 (DMA 80).

\begin{tabular}{|c|c|c|c|c|c|}
\hline Sample ID & $\begin{array}{c}\text { Weight } \\
(\mathbf{g})\end{array}$ & $\begin{array}{c}\text { Absorbance } \\
\text { Height }\end{array}$ & $\begin{array}{c}\text { Calculated } \\
\text { Mass of } \\
\text { Mercury } \\
\text { Added } \\
(\mathbf{n g})\end{array}$ & $\begin{array}{c}\text { Calculated } \\
\text { Mass of } \\
\text { Mercury } \\
\text { Detected } \\
(\mathbf{n g})\end{array}$ & $\begin{array}{c}\text { Mean } \\
\text { Recovery } \\
\text { \% of Mass } \\
\text { of } \\
\text { Mercury }\end{array}$ \\
\hline Blank & 0.1032 & 0.0024 & 0.00 & N/A & N/A \\
\hline Blank & 0.1020 & 0.0019 & 0.00 & N/A & N/A \\
\hline Blank & 0.1016 & 0.0013 & 0.00 & N/A & N/A \\
\hline Blank & 0.1011 & 0.0009 & 0.00 & N/A & N/A \\
\hline Blank & 0.1020 & 0.0004 & 0.00 & N/A & N/A \\
\hline Blank & 0.1025 & 0.0011 & 0.00 & N/A & N/A \\
\hline Blank & 0.1022 & 0.0025 & 0.00 & N/A & N/A \\
\hline $\mathbf{0 . 2} \mathbf{n g}$ & 0.0210 & 0.0027 & 0.21 & 0.12 & 55.32 \\
\hline $\mathbf{0 . 2} \mathbf{n g}$ & 0.0212 & 0.0025 & 0.21 & 0.11 & 50.73 \\
\hline $\mathbf{0 . 2} \mathbf{~ n g}$ & 0.0200 & 0.0011 & 0.20 & 0.05 & 23.60 \\
\hline $\mathbf{0 . 2} \mathbf{~ n g}$ & 0.0209 & 0.0026 & 0.21 & 0.11 & 53.52 \\
\hline $\mathbf{0 . 2} \mathbf{~ n g}$ & 0.0213 & 0.0017 & 0.21 & 0.07 & 34.30 \\
\hline $\mathbf{0 . 2} \mathbf{~ n g}$ & 0.0214 & 0.0041 & 0.21 & 0.18 & 82.48 \\
\hline $\mathbf{0 . 2} \mathbf{~ n g}$ & 0.0212 & 0.0030 & 0.21 & 0.13 & 60.89 \\
\hline
\end{tabular}




\begin{tabular}{|c|c|c|c|c|c|}
\hline Sample ID & $\begin{array}{l}\text { Weight } \\
\text { (g) }\end{array}$ & $\begin{array}{c}\text { Absorbance } \\
\text { Height }\end{array}$ & $\begin{array}{l}\text { Calculated } \\
\text { Mass of } \\
\text { Mercury } \\
\text { Added } \\
\text { (ng) }\end{array}$ & $\begin{array}{l}\text { Calculated } \\
\text { Mass of } \\
\text { Mercury } \\
\text { Detected } \\
\text { (ng) }\end{array}$ & $\begin{array}{c}\text { Mean } \\
\text { Recovery } \\
\% \text { of Mass } \\
\text { of } \\
\text { Mercury }\end{array}$ \\
\hline $0.5 \mathrm{ng}$ & 0.0514 & 0.0117 & 0.51 & 0.50 & 98.07 \\
\hline $0.5 \mathrm{ng}$ & 0.0510 & 0.0116 & 0.51 & 0.50 & 98.00 \\
\hline $0.5 \mathrm{ng}$ & 0.0516 & 0.0126 & 0.52 & 0.54 & 105.21 \\
\hline $0.5 \mathrm{ng}$ & 0.0514 & 0.0094 & 0.51 & 0.40 & 78.79 \\
\hline $0.5 \mathrm{ng}$ & 0.0508 & 0.0117 & 0.51 & 0.50 & 99.23 \\
\hline $0.5 \mathrm{ng}$ & 0.0514 & 0.0120 & 0.51 & 0.52 & 100.59 \\
\hline $0.5 \mathrm{ng}$ & 0.0514 & 0.0141 & 0.51 & 0.61 & 118.20 \\
\hline $0.8 \mathrm{ng}$ & 0.0810 & 0.0197 & 0.81 & 0.85 & 104.81 \\
\hline $0.8 \mathrm{ng}$ & 0.0809 & 0.0208 & 0.81 & 0.90 & 110.80 \\
\hline $0.8 \mathrm{ng}$ & 0.0811 & 0.0172 & 0.81 & 0.74 & 91.39 \\
\hline $0.8 \mathrm{ng}$ & 0.0817 & 0.0167 & 0.82 & 0.72 & 88.08 \\
\hline $0.8 \mathrm{ng}$ & 0.0810 & 0.0191 & 0.81 & 0.82 & 101.61 \\
\hline $0.8 \mathrm{ng}$ & 0.0808 & 0.0173 & 0.81 & 0.75 & 92.26 \\
\hline $0.8 \mathrm{ng}$ & 0.0811 & 0.0137 & 0.81 & 0.59 & 72.79 \\
\hline $1.0 \mathrm{ng}$ & 0.1021 & 0.0238 & 1.02 & 1.03 & 100.46 \\
\hline $1.0 \mathrm{ng}$ & 0.1021 & 0.0253 & 1.02 & 1.09 & 106.79 \\
\hline $1.0 \mathrm{ng}$ & 0.1026 & 0.0232 & 1.03 & 1.00 & 97.44 \\
\hline $1.0 \mathrm{ng}$ & 0.0996 & 0.0227 & 1.00 & 0.98 & 98.22 \\
\hline $1.0 \mathrm{ng}$ & 0.1015 & 0.0238 & 1.02 & 1.03 & 101.05 \\
\hline $1.0 \mathrm{ng}$ & 0.1014 & 0.0243 & 1.01 & 1.05 & 103.27 \\
\hline $1.0 \mathrm{ng}$ & 0.1015 & 0.0251 & 1.02 & 1.08 & 106.57 \\
\hline $1.5 \mathrm{ng}$ & 0.1517 & 0.0384 & 1.52 & 1.65 & 109.09 \\
\hline $1.5 \mathrm{ng}$ & 0.1522 & 0.0391 & 1.52 & 1.69 & 110.72 \\
\hline $1.5 \mathrm{ng}$ & 0.1522 & 0.0384 & 1.52 & 1.65 & 108.74 \\
\hline $2.0 \mathrm{ng}$ & 0.2042 & 0.0485 & 2.04 & 2.09 & 102.37 \\
\hline $2.0 \mathrm{ng}$ & 0.2030 & 0.0455 & 2.03 & 1.96 & 96.60 \\
\hline $2.0 \mathrm{ng}$ & 0.2010 & 0.0435 & 2.01 & 1.87 & 93.27 \\
\hline $3.0 \mathrm{ng}$ & 0.3027 & 0.0756 & 3.03 & 3.26 & 107.64 \\
\hline $3.0 \mathrm{ng}$ & 0.3012 & 0.0726 & 3.01 & 3.13 & 103.89 \\
\hline $3.0 \mathrm{ng}$ & 0.2996 & 0.0728 & 3.00 & 3.14 & 104.73 \\
\hline $5.0 \mathrm{ng}$ & 0.5032 & 0.1168 & 5.03 & 5.03 & 100.05 \\
\hline $5.0 \mathrm{ng}$ & 0.5011 & 0.1122 & 5.01 & 4.84 & 96.51 \\
\hline $5.0 \mathrm{ng}$ & 0.4990 & 0.1130 & 4.99 & 4.87 & 97.60 \\
\hline
\end{tabular}


The following figure shows the calibration curve determined for the DMA 80, using only quartz sample boats, for the mass of mercury range of $0.5 \mathrm{ng}$ of $\mathrm{Hg}$ to $5.0 \mathrm{ng}$ of $\mathrm{Hg}$.

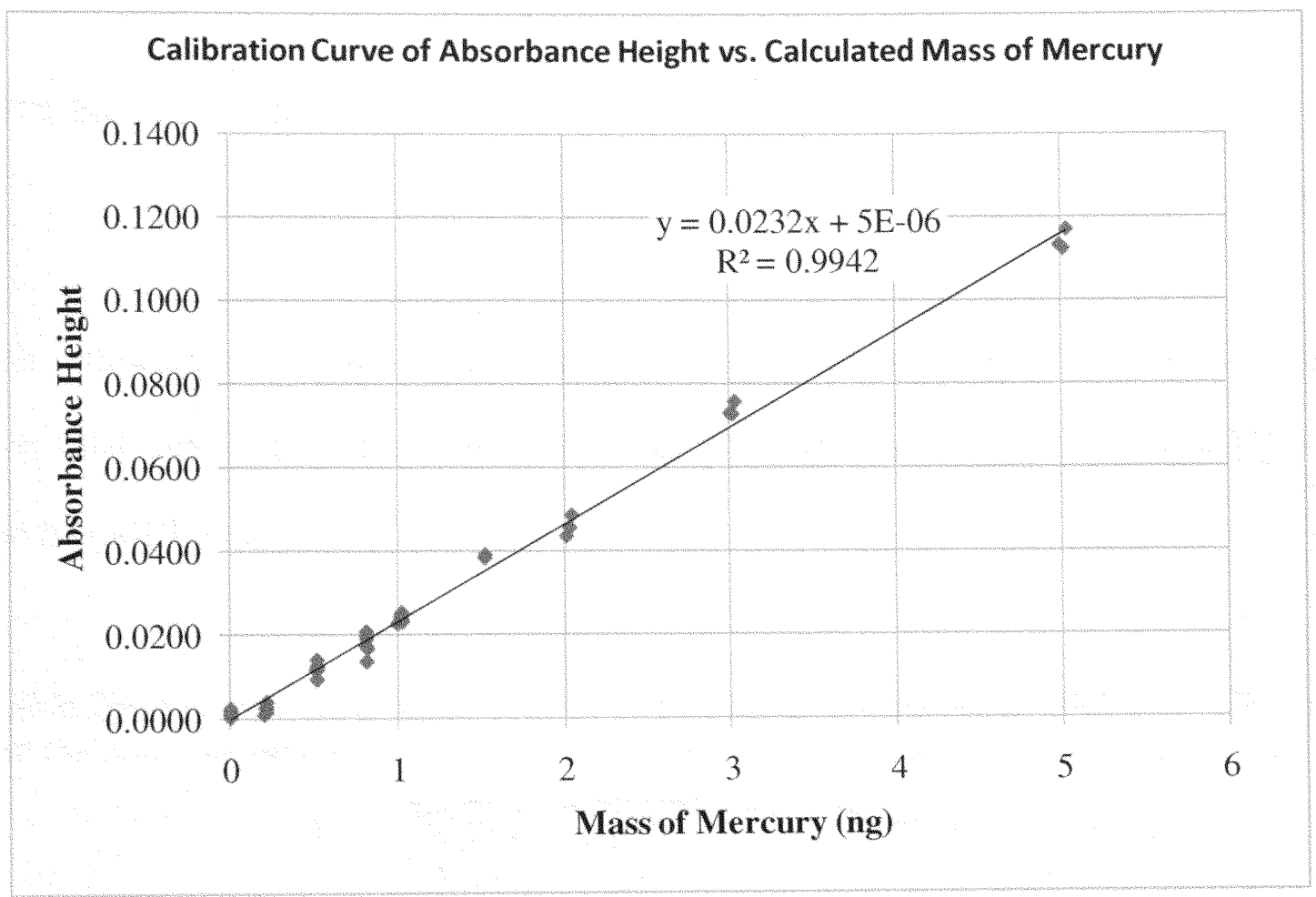

Figure 17: Calibration curve for the DMA 80, using only quartz sample boats, for the mass of mercury range of $0.2 \mathrm{ng}$ of $\mathrm{Hg}$ to $5.0 \mathrm{ng}$ of $\mathrm{Hg}$. In the equation for the calibration curve, the variable $y$ is equal to the absorbance height and the variable $x$ is equal to the mass of mercury in ng.

From 40 CFR Part 136, Appendix B, 1986 (e-CFR, 2010), the equation for the calculated MDL is the following:

$$
\mathrm{MDL}=\mathrm{t}(\mathrm{n}-1,1-\alpha=0.99) * \mathrm{~S}
$$

where the quantity $\mathrm{t}(\mathrm{n}-1,1-\alpha=0.99)$ is the students' $\mathrm{t}$ value appropriate for a $99 \%$ confidence level and a standard deviation estimate with $\mathrm{n}-1$ degrees of freedom, and $\mathrm{S}$ is 
the standard deviation of replicate analyses (e-CFR, 2010). For the present research, there are 6 degrees of freedom because there are 7 replicate analyses. From the "Tables of Students' t Values at the 99\% Confidence Level" in 40 CFR Part 136, Appendix B, 1986 (e-CFR, 2010), the $t$ value for 6 degrees of freedom is 3.143 . Then, the equation for the MDL becomes the following:

$$
\mathrm{MDL}=3.143 * \mathrm{~S}
$$

The following table shows the average absorbance height and standard deviation in the first MDL run for the blank boats and the sample boats that contained $0.2 \mathrm{ng}$ of $\mathrm{Hg}$ for the first MDL run.

Table 20: Average absorbance height and standard deviation in the first MDL run for the blank sample boats and the sample boats that contained $0.2 \mathrm{ng}$ of $\mathrm{Hg}$

\begin{tabular}{|ll|}
\hline Blank Boats: & \\
\hline Average Height & 0.0015 \\
\hline $\begin{array}{l}\text { Standard } \\
\text { Deviation }\end{array}$ & 0.0008 \\
\hline 0.2 ng Hg Boats: & \\
\hline Average Height & 0.0025 \\
\hline $\begin{array}{l}\text { Standard } \\
\text { Deviation }\end{array}$ & 0.0010 \\
\hline
\end{tabular}

From Table 20, it can be seen that the average absorbance height of the samples containing $0.2 \mathrm{ng}$ of $\mathrm{Hg}$ was higher but relatively close to that of the blank boats. In addition, it can be seen that because there is an absorbance for the blank boats, the equation for the MDL can include the average absorbance height of a blank sample boat as the $y$-axis intercept, so that when zero mercury concentration is present in a sample, 
the zero reading of the instrument is expected to be near the average absorbance height for a blank sample boat. For this research, the MDL equation was modified to include the average absorbance height of a blank, shown in the following equation:

$$
\mathrm{MDL}=(\text { Avg. Blank Reading })+3.143 *(\text { Std. Dev. of the } 0.2 \mathrm{ng} \text { Samples })
$$

Using this equation and the data for the $0.2 \mathrm{ng}$ of $\mathrm{Hg}$ samples in Table 20, the MDL for the DMA 80 , using only quartz sample boats, was calculated to be:

Calculated MDL for DMA 80 (quartz sample boats) $=0.19375 \mathrm{ng}$ of $\mathrm{Hg}$

The calculated MDL meets the criteria in 40 CFR Part 136, Appendix B, 1986 (e-CFR, 2010), which are the following:

1. The signal/noise ratio should be in the range of 2.5 to 5 . According to Skoog, Holler, and Nieman (1998), the authors state that, for a dc signal, the magnitude of the noise is conveniently defined as the standard deviation $s$ of numerous measurements of the signal strength, and the signal is given by the mean $\mathrm{x}$ of the measurements. For this research, the average absorbance height can be interpreted as the signal and the standard deviation can be interpreted as the noise. In the case of the samples containing $0.2 \mathrm{ng}$ of $\mathrm{Hg}$, the average absorbance height was 0.0025 and the standard deviation was 0.0010 . Thus, the signal/noise ratio is 2.5 . 
2. The calculated MDL must be less than the spike level. From Appendix $\mathrm{C}$, the lowest spike level in the samples of $0.2 \mathrm{ng}$ of $\mathrm{Hg}$ was $0.20 \mathrm{ng}$ of $\mathrm{Hg}$. The calculated MDL, $0.19375 \mathrm{ng}$ of $\mathrm{Hg}$, is less than 0.20ng of $\mathrm{Hg}$.

3. The spike level must be less than ten times the calculated MDL. Table 19 shows the highest spike level in the samples of $0.2 \mathrm{ng}$ of $\mathrm{Hg}$ was $0.21 \mathrm{ng}$ of $\mathrm{Hg}$. The spike level, $0.21 \mathrm{ng}$ of $\mathrm{Hg}$, is less than ten times the calculated MDL.

For the samples containing $0.2 \mathrm{ng}$ of $\mathrm{Hg}$, the percent recovery of the mass of mercury was relatively low, as can be seen in Table 19. The mean recovery for the samples containing $0.2 \mathrm{ng}$ of $\mathrm{Hg}$ was only about $51.55 \%$. For the samples containing $0.5 \mathrm{ng}$ of $\mathrm{Hg}$, the mean recovery was much higher, about $99.73 \%$. The recovery for the higher masses of mercury was also much higher than the mean recovery for the samples containing $0.2 \mathrm{ng}$ of $\mathrm{Hg}$.

In addition to the MDL, another quantity that is important when analyzing data from an instrument is the limit of quantitation (LOQ) of the instrument. Skoog, Holler, and Nieman (1998) state that the LOQ is the lowest concentration at which quantitative measurements can be made. Skoog, Holler, and Nieman (1998) state that the lower limit of quantitative measurements is generally taken to be equal to ten times the standard deviation of repetitive measurements on a blank, or $10 s_{\mathrm{b}}$. For the present research, because there is an average reading on the blank measurements that is greater than zero, the lower LOQ will be equal to the sum of the average blank reading plus ten times the standard deviation of repetitive measurements on a blank. It is believed that this estimate 
gives a more conservative estimate for the LOQ. The equation for the LOQ, adapted from Skoog, Holler, and Nieman (1998) and modified for the present research to include the average reading of a blank sample boat in the DMA 80 , is the following:

$$
\text { LOQ }=\text { Average Blank Reading }+10 * \text { Standard Deviation of Blanks }
$$

From Table 20, which contains information on the blank sample runs and the sample runs for the samples containing $0.2 \mathrm{ng}$ of $\mathrm{Hg}$, the average absorbance height for the blanks is 0.0015 and the standard deviation of the blanks is 0.0008 . Therefore, the LOQ for the DMA 80, in terms of absorbance height, is calculated as 0.0095 . Figure 17, which is the calibration curve for the DMA 80 , using only quartz sample boats, for the range of mass of mercury in a sample between $0.2 \mathrm{ng}$ to $5.0 \mathrm{ng}$ of $\mathrm{Hg}$, can be used to calculate the LOQ in units of $\mathrm{ng}$ of $\mathrm{Hg}$. The LOQ of the DMA 80, using only quartz sample boats, is calculated to be $0.41 \mathrm{ng}$ of $\mathrm{Hg}$, and is shown in the following equation:

LOQ (DMA 80, quartz sample boats) $=0.41 \mathrm{ng}$ of $\mathrm{Hg}$

This estimate for the LOQ may be different from past and future determinations of the LOQ for the DMA 80 in the Soil and Groundwater Laboratory at the Applied Research Center, but it is used in the present research and is estimated to be relatively accurate. 
The following data table shows the results for the analysis of the supernatant samples for different incubation times for the pyruvate/fumarate experiments. The results are assumed to be the mass of mercury, in each washed cell solution, that was not taken up by bacteria.

Table 21: Results for the analysis of the supernatant samples from the pyruvate/fumarate experiments, analyzed using the DMA 80. The results are assumed to be the mass of mercury that remained in solution, in each sample, and was not taken up by bacteria. Using the calculated mercury concentration in each mercury stock solution, the initial mercury concentration of each washed cell solution was calculated, not measured, to be 10 parts per billion (ppb) $\mathbf{H g}$.

\begin{tabular}{|c|c|c|c|c|c|c|}
\hline $\begin{array}{c}\text { Sample } \\
\text { ID }\end{array}$ & $\begin{array}{c}\text { Weight } \\
(\mathrm{g})\end{array}$ & Height & $\begin{array}{l}\text { Calculated } \\
\text { Mass of } \\
\text { Mercury } \\
(\mathrm{ng})\end{array}$ & $\begin{array}{c}\text { Calculated } \\
\text { Mass } \\
\text { Above or } \\
\text { Below } \\
\text { MDL }\end{array}$ & $\begin{array}{c}\text { Calculated } \\
\text { Mass } \\
\text { Above or } \\
\text { Below } \\
\text { LOQ } \\
\end{array}$ & $\begin{array}{c}\text { Calculated } \\
\text { Concen- } \\
\text { tration of } \\
\text { Mercury } \\
\text { ( } \mathrm{ng} / \mathrm{g} \text { of } \\
\text { sample) } \\
\text { or (ppb) }\end{array}$ \\
\hline $\begin{array}{l}40 \\
\min , \\
\mathrm{HgCl} 2, \\
\mathrm{PF}, \# 1\end{array}$ & 0.1964 & 0.0024 & 0.10 & below & below & 0.53 \\
\hline $\begin{array}{l}40 \\
\min , \\
\mathrm{HgCl}_{2}, \\
\mathrm{PF}, \# 2\end{array}$ & 0.1944 & 0.0043 & 0.19 & below & below & 0.95 \\
\hline $\begin{array}{l}40 \\
\text { min, } \\
\text { Hg- } \\
\text { NOM, } \\
\text { PF, \#1 }\end{array}$ & 0.1957 & 0.0010 & 0.04 & below & below & 0.22 \\
\hline $\begin{array}{l}40 \\
\text { min, } \\
\text { Hg- } \\
\text { NOM, } \\
\text { PF, \#2 }\end{array}$ & 0.2044 & 0.0015 & 0.06 & below & below & 0.32 \\
\hline
\end{tabular}




\begin{tabular}{|c|c|c|c|c|c|c|}
\hline $\begin{array}{c}\text { Sample } \\
\text { ID }\end{array}$ & $\begin{array}{c}\text { Weight } \\
\text { (g) }\end{array}$ & Height & $\begin{array}{l}\text { Calculated } \\
\text { Mass of } \\
\text { Mercury } \\
\text { (ng) }\end{array}$ & $\begin{array}{c}\text { Calculated } \\
\text { Mass } \\
\text { Above or } \\
\text { Below } \\
\text { MDL }\end{array}$ & $\begin{array}{c}\text { Calculated } \\
\text { Mass } \\
\text { Above or } \\
\text { Below } \\
\text { LOQ }\end{array}$ & $\begin{array}{l}\text { Calculated } \\
\text { Concen- } \\
\text { tration of } \\
\text { Mercury } \\
\text { (ng/g of } \\
\text { sample) } \\
\text { or (ppb) }\end{array}$ \\
\hline $\begin{array}{l}50 \\
\min , \\
\mathrm{HgCl} 2, \\
\mathrm{PF}, \# 1\end{array}$ & 0.1965 & 0.0040 & 0.17 & below & below & 0.88 \\
\hline $\begin{array}{l}50 \\
\min , \\
\mathrm{HgCl}_{2}, \\
\mathrm{PF}, \# 2\end{array}$ & 0.1948 & 0.0024 & 0.10 & below & below & 0.53 \\
\hline $\begin{array}{l}50 \\
\text { min, } \\
\text { Hg- } \\
\text { NOM, } \\
\text { PF, \#1 }\end{array}$ & 0.2011 & 0.0089 & 0.38 & above & below & 1.91 \\
\hline $\begin{array}{l}50 \\
\text { min, } \\
\text { Hg- } \\
\text { NOM, } \\
\text { PF, \#2 }\end{array}$ & 0.2006 & 0.0043 & 0.19 & below & below & 0.92 \\
\hline $\begin{array}{l}80 \\
\min , \\
\mathrm{HgCl} 2, \\
P F, \# 1\end{array}$ & 0.1972 & 0.0047 & 0.20 & above & below & 1.03 \\
\hline $\begin{array}{l}80 \\
\text { min, } \\
\mathrm{HgCl}_{2}, \\
\mathrm{PF}, \# 2\end{array}$ & 0.2003 & 0.0039 & 0.17 & below & below & 0.84 \\
\hline $\begin{array}{l}80 \\
\text { min, } \\
\text { Hg- } \\
\text { NOM, } \\
\text { PF, \#1 }\end{array}$ & 0.1972 & 0.0030 & 0.13 & below & below & 0.65 \\
\hline $\begin{array}{l}80 \\
\text { min, } \\
\text { Hg- } \\
\text { NOM, } \\
\text { PF, \#2 }\end{array}$ & 0.1963 & 0.0032 & 0.14 & below & below & 0.70 \\
\hline $\begin{array}{l}90 \\
\text { min, } \\
\mathrm{HgCl}_{2}, \\
\mathrm{PF}, \# 1\end{array}$ & 0.2016 & 0.0026 & 0.11 & below & below & 0.55 \\
\hline $\begin{array}{l}90 \\
\text { min, } \\
\mathrm{HgCl}_{2}, \\
\mathrm{PF}, \# 2\end{array}$ & 0.2006 & 0.0019 & 0.08 & below & below & 0.41 \\
\hline
\end{tabular}




\begin{tabular}{|l|c|c|c|c|c|c|}
\hline & & $\begin{array}{c}\text { Calculated } \\
\text { Mass of } \\
\text { Mercury } \\
\text { (ng) }\end{array}$ & $\begin{array}{c}\text { Calculated } \\
\text { Mass } \\
\text { Above or } \\
\text { Below } \\
\text { ID }\end{array}$ & $\begin{array}{c}\text { MDL } \\
\text { (g) }\end{array}$ & $\begin{array}{c}\text { Calculated } \\
\text { Mass } \\
\text { Above or } \\
\text { Below } \\
\text { LoQ }\end{array}$ & $\begin{array}{c}\text { Concen- } \\
\text { tration of } \\
\text { Mercury } \\
\text { (ng/g of } \\
\text { sample) } \\
\text { or (ppb) }\end{array}$ \\
\hline $\begin{array}{l}\mathbf{9 0} \\
\text { min, } \\
\text { Hg- } \\
\text { NOM, } \\
\text { PF, \# 1 }\end{array}$ & 0.2003 & 0.0024 & 0.10 & below & below & 0.52 \\
\hline $\begin{array}{l}\mathbf{9 0} \\
\text { min, } \\
\text { Hg- } \\
\text { NOM, } \\
\text { PF, \#2 }\end{array}$ & 0.1920 & 0.0040 & 0.17 & below & below & \\
\hline
\end{tabular}

The above table shows that, for the supernatant samples of the pyruvate/fumarate experiments, only two of the total sixteen supernatant samples had an individual absorbance height above the calculated MDL for the DMA 80, and all of the total sixteen samples had an individual absorbance height below the calculated LOQ for the DMA 80.

The following table shows the results for the analysis of the samples of the test tube walls for different incubation times for the pyruvate/fumarate experiments. The results are assumed to be the mass of mercury, in each washed cell solution, that was not available for uptake by bacteria. 
Table 22: Results for the analysis of the samples of the test tube walls from the pyruvate/fumarate experiments, analyzed using the DMA 80 . The results are assumed to be the mass of mercury in each sample that was not available for uptake by bacteria. Using the calculated concentration of mercury in each mercury stock solution, the initial mercury concentration of each washed cell solution was calculated, not measured, to be $\mathbf{1 0}$ parts per billion (ppb) $\mathbf{H g}$.

\begin{tabular}{|c|c|c|c|c|c|c|}
\hline $\begin{array}{c}\text { Sample } \\
\text { ID }\end{array}$ & $\begin{array}{l}\text { Weight } \\
\text { (g) }\end{array}$ & Height & $\begin{array}{l}\text { Calculated } \\
\text { Mass of } \\
\text { Mercury } \\
\text { (ng) }\end{array}$ & $\begin{array}{c}\text { Calculated } \\
\text { Mass } \\
\text { Above or } \\
\text { Below } \\
\text { MDL }\end{array}$ & $\begin{array}{c}\text { Calculated } \\
\text { Mass } \\
\text { Above or } \\
\text { Below } \\
\text { LOQ }\end{array}$ & $\begin{array}{c}\text { Calculated } \\
\text { Concen- } \\
\text { tration of } \\
\text { Mercury } \\
\text { ( } \mathrm{ng} / \mathrm{g} \text { of } \\
\text { sample) } \\
\text { or }(\mathrm{ppb})\end{array}$ \\
\hline $\begin{array}{l}\mathrm{BW}, 40 \\
\mathrm{~min}, \\
\mathrm{HgCl} 2 \\
\mathrm{PF}, 1\end{array}$ & 0.3978 & 0.0026 & 0.11 & below & below & 0.28 \\
\hline $\begin{array}{l}\mathrm{BW}, 40 \\
\mathrm{~min}, \\
\mathrm{HgCl} 2 \\
\mathrm{PF}, 2\end{array}$ & 0.3987 & 0.0010 & 0.04 & below & below & 0.11 \\
\hline $\begin{array}{l}\text { BW, } 40 \\
\text { min, } \\
\text { Hg- } \\
\text { NOM, } \\
\text { PF, } 1\end{array}$ & 0.3995 & 0.0021 & 0.09 & below & below & 0.23 \\
\hline $\begin{array}{l}\text { BW, } 40 \\
\text { min, } \\
\text { Hg- } \\
\text { NOM, } \\
\text { PF, } 2\end{array}$ & 0.3994 & 0.0020 & 0.09 & below & below & 0.22 \\
\hline $\begin{array}{l}\mathrm{BW}, 50 \\
\min , \\
\mathrm{HgCl}_{2} \\
\mathrm{PF}, 1\end{array}$ & 0.3966 & 0.0021 & 0.09 & below & below & 0.23 \\
\hline $\begin{array}{l}\mathrm{BW}, 50 \\
\min , \\
\mathrm{HgCl} 2 \\
\mathrm{PF}, 2\end{array}$ & 0.3988 & 0.0021 & 0.09 & below & below & 0.23 \\
\hline $\begin{array}{l}\text { BW, } 50 \\
\text { min, } \\
\text { Hg- } \\
\text { NOM, } \\
\text { PF, } 1\end{array}$ & 0.3889 & 0.0029 & 0.12 & below & below & 0.32 \\
\hline $\begin{array}{l}\text { BW, } 50 \\
\text { min, } \\
\text { Hg- } \\
\text { NOM, } \\
\text { PF, } 2\end{array}$ & 0.3990 & 0.0011 & 0.05 & below & below & 0.12 \\
\hline
\end{tabular}




\begin{tabular}{|c|c|c|c|c|c|c|}
\hline $\begin{array}{c}\text { Sample } \\
\text { ID }\end{array}$ & $\begin{array}{c}\text { Weight } \\
\text { (g) }\end{array}$ & Height & $\begin{array}{l}\text { Calculated } \\
\text { Mass of } \\
\text { Mercury } \\
\text { (ng) }\end{array}$ & $\begin{array}{c}\text { Calculated } \\
\text { Mass } \\
\text { Above or } \\
\text { Below } \\
\text { MDL }\end{array}$ & $\begin{array}{c}\text { Calculated } \\
\text { Mass } \\
\text { Above or } \\
\text { Below } \\
\text { LOQ }\end{array}$ & $\begin{array}{l}\text { Calculated } \\
\text { Concen- } \\
\text { tration of } \\
\text { Mercury } \\
\text { (ng/g of } \\
\text { sample) } \\
\text { or (ppb) }\end{array}$ \\
\hline $\begin{array}{l}\mathrm{BW}, 80 \\
\min , \\
\mathrm{HgCl} \text {, } \\
\mathrm{PF}, 1\end{array}$ & 0.3984 & 0.0028 & 0.12 & below & below & 0.30 \\
\hline $\begin{array}{l}\mathrm{BW}, 80 \\
\min , \\
\mathrm{HgCl} 2 \\
\mathrm{PF}, 2\end{array}$ & 0.3970 & 0.0015 & 0.06 & below & below & 0.16 \\
\hline $\begin{array}{l}\text { BW, } 80 \\
\text { min, } \\
\text { Hg- } \\
\text { NOM, } \\
\text { PF, 1 }\end{array}$ & 0.3977 & 0.0054 & 0.23 & above & below & 0.58 \\
\hline $\begin{array}{l}\text { BW, } 80 \\
\text { min, } \\
\text { Hg- } \\
\text { NOM, } \\
\text { PF, } 2\end{array}$ & 0.3970 & 0.0020 & 0.09 & below & below & 0.22 \\
\hline $\begin{array}{l}\mathrm{BW}, 90 \\
\min , \\
\mathrm{HgCl} 2 \\
\mathrm{PF}, 1\end{array}$ & 0.3968 & 0.0020 & 0.09 & below & below & 0.22 \\
\hline $\begin{array}{l}\mathrm{BW}, 90 \\
\mathrm{~min}, \\
\mathrm{HgCl} 2 \\
\mathrm{PF}, 2\end{array}$ & 0.3894 & 0.0005 & 0.02 & below & below & 0.05 \\
\hline $\begin{array}{l}\text { BW, } 90 \\
\text { min, } \\
\text { Hg- } \\
\text { NOM, } \\
\text { PF, } 1\end{array}$ & 0.3991 & 0.0021 & 0.09 & below & below & 0.23 \\
\hline $\begin{array}{l}\text { BW, } 90 \\
\text { min, } \\
\text { Hg- } \\
\text { NOM, } \\
\text { PF, } 2\end{array}$ & 0.3994 & 0.0011 & 0.05 & below & below & 0.12 \\
\hline
\end{tabular}

From the above table, it can be seen that, for the samples of the test tube walls for the pyruvate/fumarate experiments, only one of the total sixteen samples had an individual 
absorbance height above the calculated MDL for the DMA 80, and all of the total sixteen samples had an individual absorbance height below the calculated LOQ for the DMA 80.

The following table shows the results for the analysis of the supernatant samples for different incubation times for the lactate/sulfate experiments. The results are assumed to be the mass of mercury, in each washed cell solution, that was not taken up by bacteria.

Table 23: Results for the analysis of the supernatant samples from the pyruvate/fumarate experiments, analyzed using the DMA 80. The results are assumed to be the mass of mercury that remained in solution, in each sample, and was not taken up by bacteria. Using the calculated mercury concentration in each mercury stock solution, the initial concentration of mercury in each washed cell solution was calculated, not measured, to be 10 parts per billion (ppb) $\mathbf{H g}$.

\begin{tabular}{|c|c|c|c|c|c|c|}
\hline $\begin{array}{c}\text { Sample } \\
\text { ID }\end{array}$ & $\begin{array}{c}\text { Weight } \\
(\mathrm{g})\end{array}$ & Height & $\begin{array}{c}\text { Calculated } \\
\text { Mass of } \\
\text { Mercury } \\
\text { (ng) }\end{array}$ & $\begin{array}{c}\text { Calculated } \\
\text { Mass } \\
\text { Above or } \\
\text { Below } \\
\text { MDL }\end{array}$ & $\begin{array}{c}\text { Calculated } \\
\text { Mass } \\
\text { Above or } \\
\text { Below } \\
\text { LOQ }\end{array}$ & $\begin{array}{l}\text { Calculated } \\
\text { Concen- } \\
\text { tration of } \\
\text { Mercury } \\
\text { (ng/g of } \\
\text { sample) } \\
\text { or (ppb) }\end{array}$ \\
\hline $\begin{array}{l}10 \\
\min , \\
\mathrm{HgCl} 2 \\
\mathrm{LS}, 1\end{array}$ & 0.3941 & 0.0020 & 0.09 & below & below & 0.22 \\
\hline $\begin{array}{l}10 \\
\min , \\
\mathrm{HgCl} 2, \\
\mathrm{LS}, 2\end{array}$ & 0.3907 & 0.0023 & 0.10 & below & below & 0.25 \\
\hline $\begin{array}{l}10 \\
\text { min, } \\
\text { Hg- } \\
\text { NOM, } \\
\text { LS, } 1\end{array}$ & 0.4019 & 0.0176 & 0.76 & above & above & 1.89 \\
\hline $\begin{array}{l}10 \\
\text { min, } \\
\mathrm{Hg}^{-} \\
\text {NOM, } \\
\text { LS, } 2\end{array}$ & 0.3936 & 0.0095 & 0.41 & above & above & 1.04 \\
\hline
\end{tabular}




\begin{tabular}{|c|c|c|c|c|c|c|}
\hline $\begin{array}{c}\text { Sample } \\
\text { ID }\end{array}$ & $\begin{array}{c}\text { Weight } \\
\text { (g) }\end{array}$ & Height & $\begin{array}{c}\text { Calculated } \\
\text { Mass of } \\
\text { Mercury } \\
(\mathrm{ng})\end{array}$ & $\begin{array}{c}\text { Calculated } \\
\text { Mass } \\
\text { Above or } \\
\text { Below } \\
\text { MDL }\end{array}$ & $\begin{array}{c}\text { Calculated } \\
\text { Mass } \\
\text { Above or } \\
\text { Below } \\
\text { LOQ }\end{array}$ & $\begin{array}{c}\text { Calculated } \\
\text { Concen- } \\
\text { tration of } \\
\text { Mercury } \\
\text { ( } \mathrm{ng} / \mathrm{g} \text { of } \\
\text { sample) } \\
\text { or (ppb) }\end{array}$ \\
\hline $\begin{array}{l}20 \\
\min , \\
\mathrm{HgCl} 2 \\
\mathrm{LS}, 1\end{array}$ & 0.4002 & 0.0035 & 0.15 & below & below & 0.38 \\
\hline $\begin{array}{l}20 \\
\min , \\
\mathrm{HgCl} 2 \\
\mathrm{LS}, 2\end{array}$ & 0.4042 & 0.0030 & 0.13 & below & below & 0.32 \\
\hline $\begin{array}{l}20 \\
\min , \\
\mathrm{Hg}- \\
\text { NOM, } \\
\text { LS, } 1\end{array}$ & 0.4003 & 0.0117 & 0.50 & above & above & 1.26 \\
\hline $\begin{array}{l}20 \\
\text { min, } \\
\text { Hg- } \\
\text { NOM, } \\
\text { LS, } 2 \\
\end{array}$ & 0.3920 & 0.0035 & 0.15 & below & below & 0.38 \\
\hline $\begin{array}{l}30 \\
\text { min, } \\
\mathrm{HgCl} 2 \\
\mathrm{LS}, 1\end{array}$ & 0.3940 & 0.0029 & 0.12 & below & below & 0.32 \\
\hline $\begin{array}{l}30 \\
\text { min, } \\
\mathrm{HgCl} 2, \\
\mathrm{LS}, 2\end{array}$ & 0.3979 & 0.0015 & 0.06 & below & below & 0.16 \\
\hline $\begin{array}{l}30 \\
\min , \\
\text { Hg- } \\
\text { NOM, } \\
\text { LS, } 1\end{array}$ & 0.3960 & 0.0220 & 0.95 & above & above & 2.39 \\
\hline $\begin{array}{l}30 \\
\text { min, } \\
\text { Hg- } \\
\text { NOM, } \\
\text { LS, } 2\end{array}$ & 0.4004 & 0.0116 & 0.50 & above & above & 1.25 \\
\hline
\end{tabular}




\begin{tabular}{|c|c|c|c|c|c|c|}
\hline $\begin{array}{c}\text { Sample } \\
\text { ID }\end{array}$ & $\begin{array}{c}\text { Weight } \\
\text { (g) }\end{array}$ & Height & $\begin{array}{l}\text { Calculated } \\
\text { Mass of } \\
\text { Mercury } \\
\text { (ng) }\end{array}$ & $\begin{array}{c}\text { Calculated } \\
\text { Mass } \\
\text { Above or } \\
\text { Below } \\
\text { MDL }\end{array}$ & $\begin{array}{c}\text { Calculated } \\
\text { Mass } \\
\text { Above or } \\
\text { Below } \\
\text { LOQ }\end{array}$ & $\begin{array}{c}\text { Calculated } \\
\text { Concen- } \\
\text { tration of } \\
\text { Mercury } \\
\text { ( } \mathrm{ng} / \mathrm{g} \text { of } \\
\text { sample) } \\
\text { or (ppb) }\end{array}$ \\
\hline $\begin{array}{l}40 \\
\min , \\
\mathrm{HgCl} 2 \\
\mathrm{LS}, 1\end{array}$ & 0.4063 & 0.0035 & 0.15 & below & below & 0.37 \\
\hline $\begin{array}{l}40 \\
\min , \\
\mathrm{HgCl} 2, \\
\mathrm{LS}, 2\end{array}$ & 0.3987 & 0.0033 & 0.14 & below & below & 0.36 \\
\hline $\begin{array}{l}40 \\
\text { min, } \\
\text { Hg- } \\
\text { NOM, } \\
\text { LS, } 1\end{array}$ & 0.4041 & 0.0094 & 0.40 & above & below & 1.00 \\
\hline $\begin{array}{l}40 \\
\text { min, } \\
\text { Hg- } \\
\text { NOM, } \\
\text { LS, } 2\end{array}$ & 0.4022 & 0.0098 & 0.42 & above & above & 1.05 \\
\hline
\end{tabular}

From the above table, it can be seen that, for the supernatant samples for the lactate/sulfate experiments, seven of the total eight solutions that had been spiked with Hg-NOM had an individual absorbance height that was above the MDL for the DMA 80, and six of the total eight solutions that had been spiked with $\mathrm{Hg}-\mathrm{NOM}$ had an individual absorbance height above the calculated LOQ for the DMA 80. In addition, for the supernatant samples for the lactate/sulfate experiments, all of the total eight solutions that had been spiked with $\mathrm{HgCl}_{2}$ had an individual absorbance height that was below the calculated MDL and below the calculated LOQ for the DMA 80. 
The following table shows the results for the analysis of the samples of the test tube walls for different incubation times for the lactate/sulfate experiments. The results are assumed to be the mass of mercury, in each washed cell solution, that was not available for uptake by bacteria. The was originally a total of thirty-two samples, but only twenty-six samples were tested due to time constraints in using the DMA 80.

Table 24: Results for the analysis of the samples of the test tube walls for the lactate/sulfate experiments, analyzed using the DMA 80. The results are assumed to be the mass of mercury, in each sample, that was not available for uptake by bacteria. Using the calculated concentration of mercury in each mercury stock solution, the initial concentration of mercury in each washed cell solution was calculated, not measured, to be 10 parts per billion ( $\mathrm{ppb}$ ) $\mathrm{Hg}$. In addition, there was a total originally of thirty-two samples of the test tube walls for the lactate/sulfate experiments, but only twenty six samples were analyzed because of time constraints in using the DMA 80.

\begin{tabular}{|l|l|l|l|l|l|c|}
\hline $\begin{array}{l}\text { Sample } \\
\text { ID }\end{array}$ & $\begin{array}{c}\text { Weight } \\
\text { (g) }\end{array}$ & Height & $\begin{array}{c}\text { Calculated } \\
\text { Mass of } \\
\text { Mercury } \\
\text { (ng) }\end{array}$ & $\begin{array}{c}\text { Calculated } \\
\text { Mass } \\
\text { Above or } \\
\text { Below } \\
\text { MDL }\end{array}$ & $\begin{array}{c}\text { Calculated } \\
\text { Mass } \\
\text { Above or } \\
\text { Below } \\
\text { LOQ }\end{array}$ & $\begin{array}{c}\text { Calculated } \\
\text { Concen- } \\
\text { tration of } \\
\text { Mercury } \\
\text { (ng/g or } \\
\text { ppb) }\end{array}$ \\
\hline $\begin{array}{l}\text { BW, 10 } \\
\text { min, } \\
\mathbf{H g C l 2 ,} \\
\text { LS, 1 }\end{array}$ & 0.4011 & 0.0018 & 0.08 & below & below & 0.19 \\
\hline $\begin{array}{l}\text { BW, 10 } \\
\text { min, } \\
\text { HgCI2, } \\
\text { LS, 2 }\end{array}$ & 0.3990 & 0.0010 & 0.04 & below & below & 0.11 \\
\hline $\begin{array}{l}\text { BW, 10 } \\
\text { min, } \\
\text { Hg- } \\
\text { NOM, } \\
\text { LS, 1 }\end{array}$ & 0.4002 & 0.0029 & 0.12 & below & below & \\
\hline $\begin{array}{l}\text { BW, 10 } \\
\text { min, } \\
\text { Hg- } \\
\text { NOM, } \\
\text { LS, 2 }\end{array}$ & 0.3980 & 0.0025 & 0.11 & below & below & 0.31 \\
\hline
\end{tabular}




\begin{tabular}{|c|c|c|c|c|c|c|}
\hline $\begin{array}{c}\text { Sample } \\
\text { ID }\end{array}$ & $\begin{array}{c}\text { Weight } \\
\text { (g) }\end{array}$ & Height & $\begin{array}{c}\text { Calculated } \\
\text { Mass of } \\
\text { Mercury } \\
(\mathbf{n g})\end{array}$ & $\begin{array}{c}\text { Calculated } \\
\text { Mass } \\
\text { Above or } \\
\text { Below } \\
\text { MDL }\end{array}$ & $\begin{array}{c}\text { Calculated } \\
\text { Mass } \\
\text { Above or } \\
\text { Below } \\
\text { LOQ }\end{array}$ & $\begin{array}{c}\text { Calculated } \\
\text { Concen- } \\
\text { tration of } \\
\text { Mercury } \\
(\mathrm{ng} / \mathrm{g} \text { or } \\
\mathrm{ppb})\end{array}$ \\
\hline $\begin{array}{l}\text { BW, } 20 \\
\text { min, } \\
\mathrm{HgCl}, \\
\mathrm{LS}, 1\end{array}$ & 0.4003 & 0.0034 & 0.15 & below & below & 0.37 \\
\hline $\begin{array}{l}\mathrm{BW}, \\
20 \mathrm{~min}, \\
\mathrm{HgCl} 2 \text {, } \\
\mathrm{LS}, 2\end{array}$ & 0.3964 & 0.0038 & 0.16 & below & below & 0.41 \\
\hline $\begin{array}{l}\text { BW, } 20 \\
\text { min, } \\
\text { Hg- } \\
\text { NOM, } \\
\text { LS, } 1\end{array}$ & 0.4006 & 0.0019 & 0.08 & below & below & 0.20 \\
\hline $\begin{array}{l}\text { BW, } 20 \\
\text { min, } \\
\text { Hg- } \\
\text { NOM, } \\
\text { LS, } 2\end{array}$ & 0.3916 & 0.0029 & 0.12 & below & below & 0.32 \\
\hline $\begin{array}{l}\mathrm{BW}, 30 \\
\mathrm{~min}, \\
\mathrm{HgCl} 2 \\
\mathrm{LS}, 1\end{array}$ & 0.3996 & 0.0081 & 0.35 & above & below & 0.87 \\
\hline $\begin{array}{l}\mathrm{BW}, 30 \\
\text { min, } \\
\mathrm{HgCl} 2 \text {, } \\
\mathrm{LS}, 2\end{array}$ & 0.3920 & 0.0012 & 0.05 & below & below & 0.13 \\
\hline
\end{tabular}

From the above table, it can be seen that, for the samples of the test tube walls for the lactate/sulfate experiments, only one of the total sixteen samples had an individual absorbance height above the calculated MDL for the DMA 80, and all of the total sixteen samples had an individual absorbance height below the calculated LOQ for the DMA 80. 


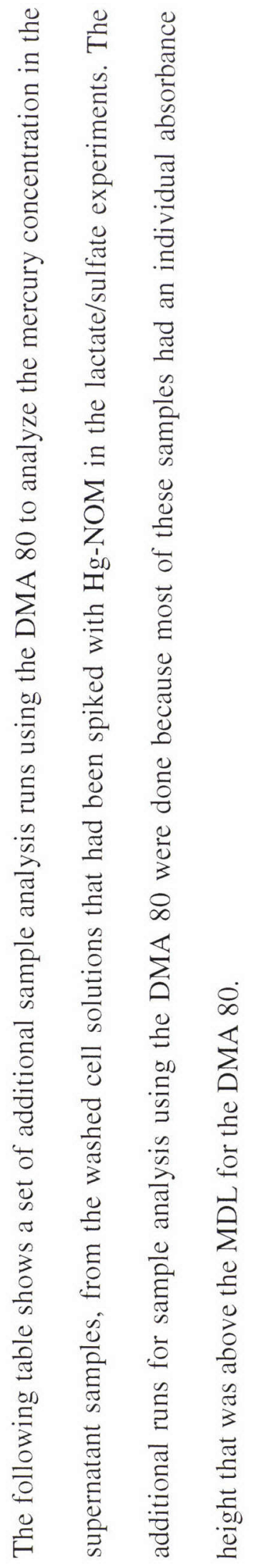

殸

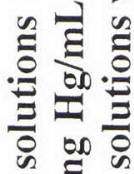

音 $\equiv \overline{\mathrm{g}}$

किष

ล

然

可

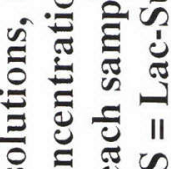

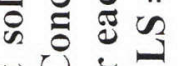

ह0

这

这

을

ज.

ㄴ.

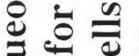

궁

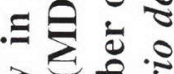

范范

范

$\div \cdot \frac{0}{0}$

呟

政

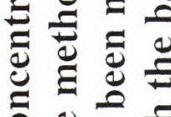

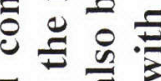

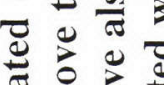

跣宽

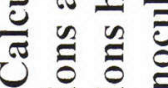

舫

글

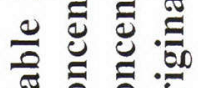

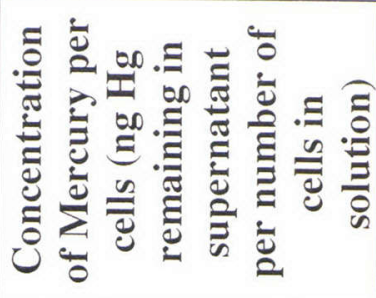

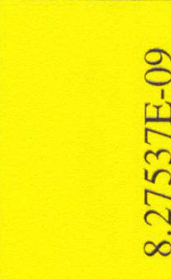

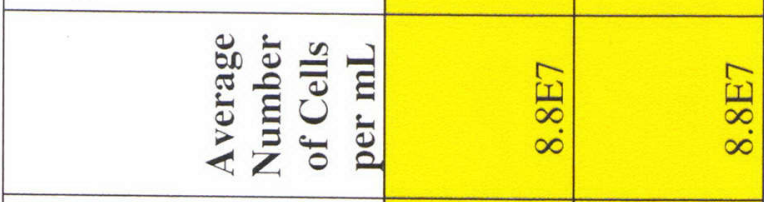

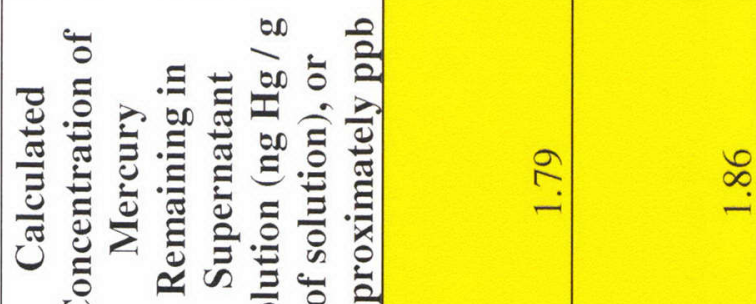

ช 2 音

$\stackrel{8}{9}$
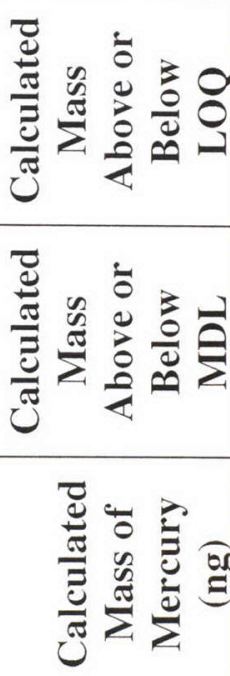


\begin{tabular}{|c|c|c|c|c|c|}
\hline 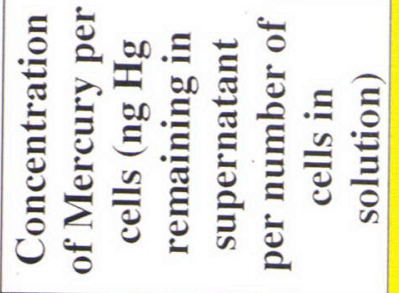 & 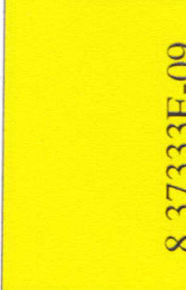 & 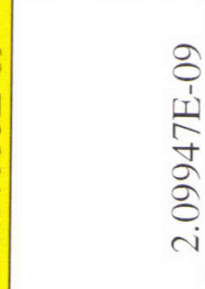 & 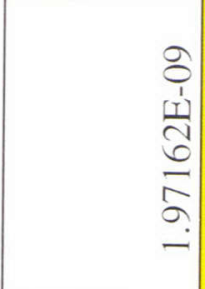 & 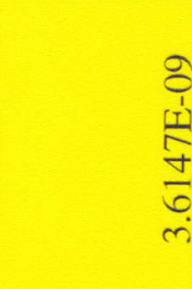 & 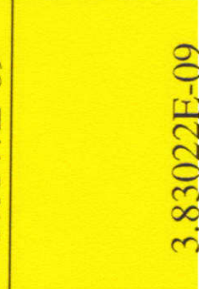 \\
\hline 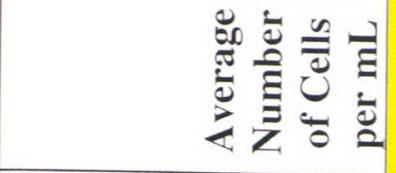 & $\begin{array}{l}\tilde{T} \\
\alpha \\
\alpha\end{array}$ & 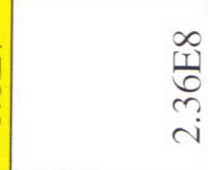 & 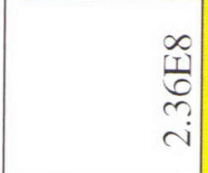 & $\begin{array}{l}\infty \\
1 \\
\infty \\
\infty\end{array}$ & $\begin{array}{l}\infty \\
\propto \\
\infty \\
\end{array}$ \\
\hline 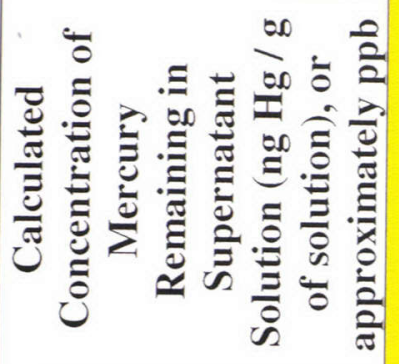 & 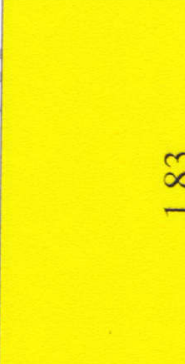 & $\stackrel{\text { rn }}{-}$ & $\stackrel{0}{=}$ & $\underline{\sigma}$ & $\stackrel{ }{I}$ \\
\hline 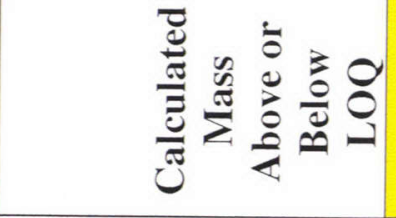 & $\frac{5}{6}$ & $\begin{array}{l}0 \\
\frac{8}{\pi} \\
\frac{8}{\pi}\end{array}$ & $\begin{array}{l}0 \\
0 \\
0 \\
\frac{0}{\sigma 0}\end{array}$ & $\begin{array}{l}\text { ह } \\
\text { ह }\end{array}$ & \\
\hline 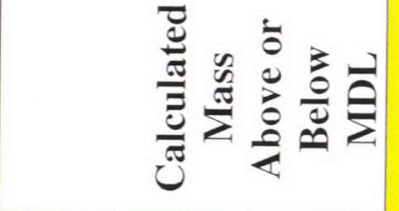 & a & $\begin{array}{l}0 \\
0 \\
0 \\
0\end{array}$ & $\begin{array}{l}0 \\
0 \\
0 \\
0 \\
\text { है }\end{array}$ & & \\
\hline 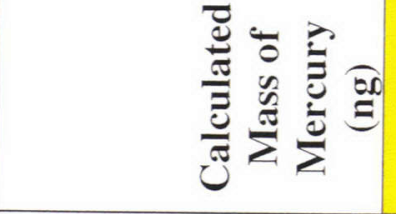 & $\frac{\pi}{2}$ & $\stackrel{n}{0}$ & $\stackrel{\overbrace{}}{\ominus}$ & $\stackrel{n}{6}$ & $\stackrel{b}{0}$ \\
\hline$\stackrel{\frac{7}{600}}{\frac{00}{2}}$ & $\overline{0}$ & $\begin{array}{l}n \\
\overline{0} \\
0 \\
0\end{array}$ & $\begin{array}{l}\infty \\
\stackrel{0}{0} \\
\stackrel{0}{0}\end{array}$ & $\frac{\pi}{0}$ & 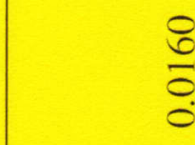 \\
\hline$\frac{\vec{E}}{3} \frac{000}{200}$ & $\overbrace{0}^{\infty}$ & $\begin{array}{l}\frac{0}{0} \\
\dot{0} \\
\dot{0}\end{array}$ & $\begin{array}{l}\mathfrak{v} \\
\vdots \\
\dot{y} \\
0\end{array}$ & \begin{tabular}{l}
0 \\
ปิ \\
\multirow{2}{+}{} \\
0
\end{tabular} & 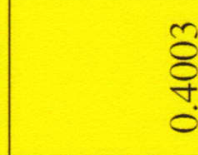 \\
\hline 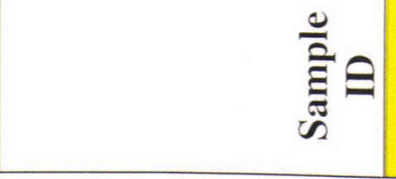 & 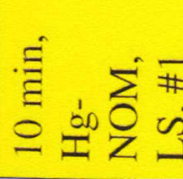 & 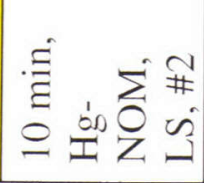 & 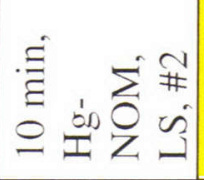 & 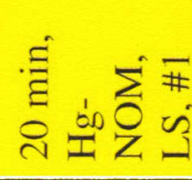 & 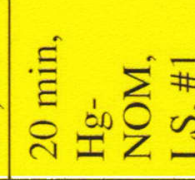 \\
\hline
\end{tabular}




\begin{tabular}{|c|c|c|c|c|c|}
\hline 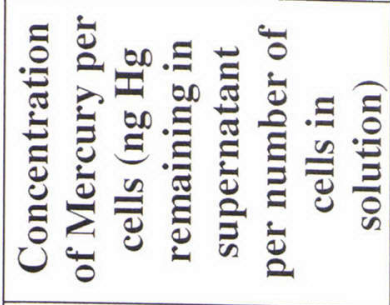 & 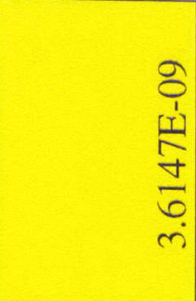 & 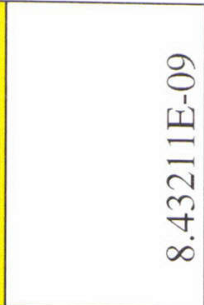 & 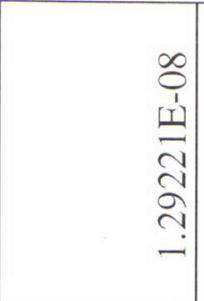 & 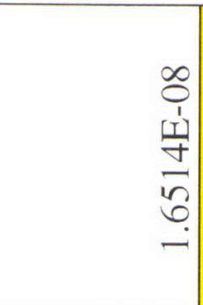 & 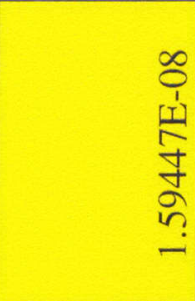 \\
\hline 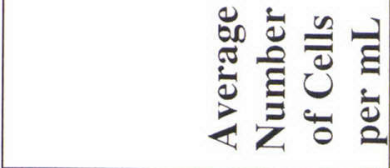 & $\begin{array}{l}\infty \\
1 \\
0 \\
\infty \\
-\end{array}$ & $\stackrel{\text { Î }}{\text { i }}$ & 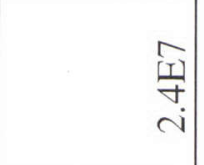 & $\begin{array}{l}\hat{y} \\
\text { ì } \\
\text { ¿ }\end{array}$ & త్త్ర \\
\hline 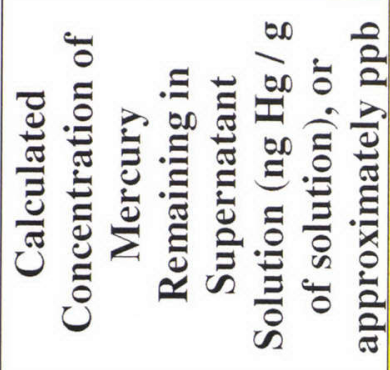 & $\stackrel{d}{t}$ & $\tilde{n}$ & \begin{tabular}{l}
$\infty$ \\
\hdashline \\
0
\end{tabular} & $\underset{-}{8}$ & $\underset{\mathrm{i}}{\mathrm{i}}$ \\
\hline 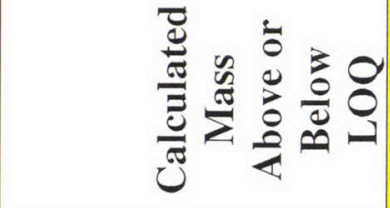 & हे & $\frac{3}{0}$ & $\begin{array}{c}3 \\
0 \\
\frac{0}{0} \\
0\end{array}$ & $\begin{array}{l}3 \\
\frac{3}{2} \\
0\end{array}$ & $\begin{array}{l}\text { हे } \\
\text { है }\end{array}$ \\
\hline 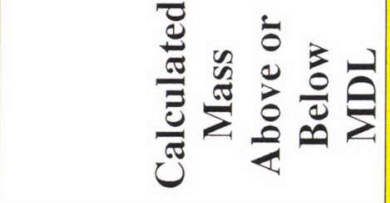 & $\begin{array}{l}0 \\
\text { हे } \\
\text { के }\end{array}$ & $\begin{array}{l}0 \\
\text { ठ } \\
\text { ते }\end{array}$ & $\begin{array}{l}0 \\
0 \\
0 \\
0 \\
\pi\end{array}$ & $\begin{array}{l}0 \\
0 \\
0 \\
0 \\
0\end{array}$ & $\begin{array}{l}\text { है } \\
\text { है }\end{array}$ \\
\hline 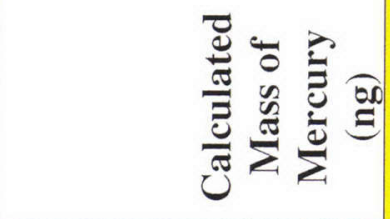 & $\begin{array}{l}n \\
0\end{array}$ & ஸి & $\vec{\jmath}$ & $\stackrel{f}{+}$ & 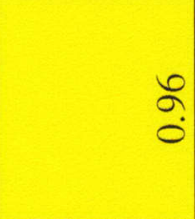 \\
\hline 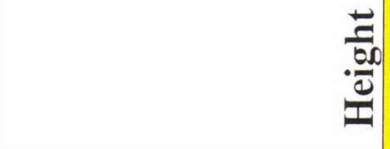 & $\begin{array}{l}\bar{n} \\
\vdots \\
0\end{array}$ & $\begin{array}{l}\text { f. } \\
8 \\
0 \\
0\end{array}$ & 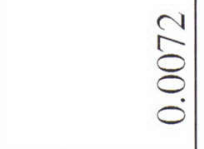 & $\begin{array}{l}1 \\
\hat{8} \\
0 \\
0\end{array}$ & $\begin{array}{l}\text { ते } \\
0 \\
0\end{array}$ \\
\hline$\sum_{3}^{\overrightarrow{5}}$ & $\begin{array}{l}\tilde{n} \\
\tilde{n} \\
0\end{array}$ & $\begin{array}{l}\bar{n} \\
\tilde{n} \\
0\end{array}$ & 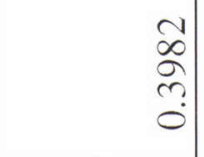 & 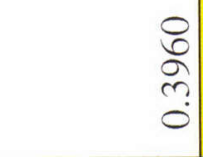 & 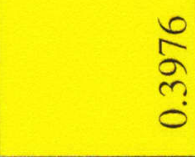 \\
\hline 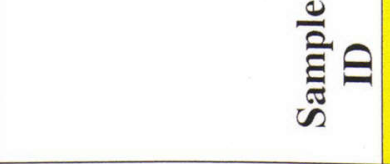 & 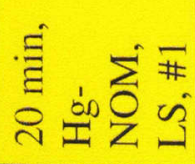 & 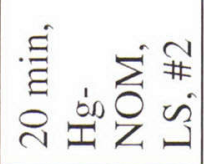 & 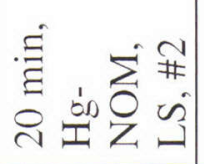 & 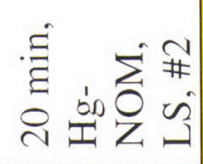 & 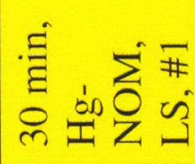 \\
\hline
\end{tabular}




\begin{tabular}{|c|c|c|c|c|c|}
\hline 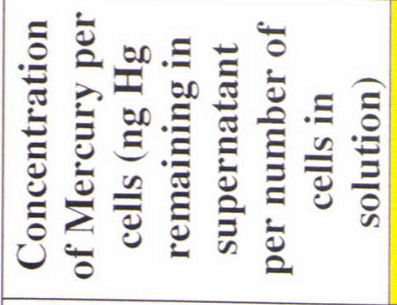 & 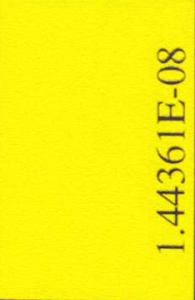 & 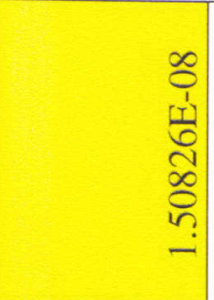 & 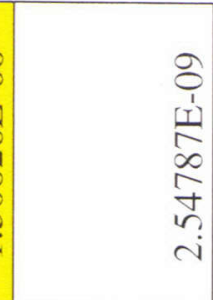 & 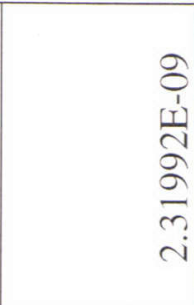 & 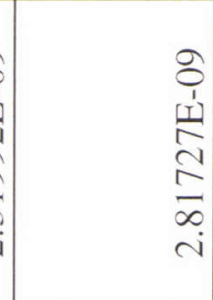 \\
\hline 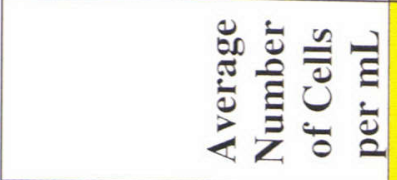 & त्रㅇ & 종 & $\begin{array}{l}\infty \\
1 \\
0 \\
0 \\
i \\
i\end{array}$ & $\begin{array}{l}\infty \\
11 \\
\infty \\
0 \\
i\end{array}$ & $\begin{array}{l}\infty \\
\text { II } \\
\infty \\
0 \\
i\end{array}$ \\
\hline 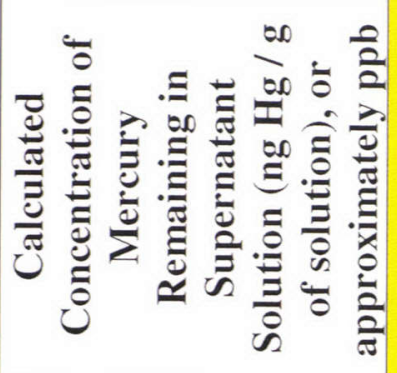 & $\stackrel{\bar{i}}{-}$ & ल) & $\stackrel{m}{m}$ & 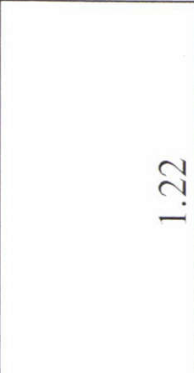 & f \\
\hline 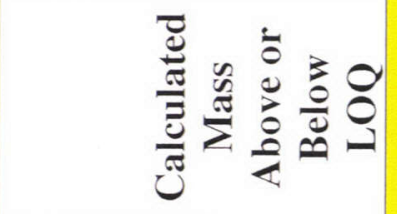 & $\begin{array}{c}\stackrel{0}{0} \\
\frac{0}{\sigma}\end{array}$ & $\begin{array}{l}\text { Dे } \\
\frac{0}{\sigma}\end{array}$ & $\begin{array}{l}0 \\
\frac{0}{\sigma} \\
\frac{\delta}{\sigma}\end{array}$ & 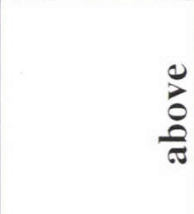 & $\begin{array}{l}0 \\
\text { हे }\end{array}$ \\
\hline 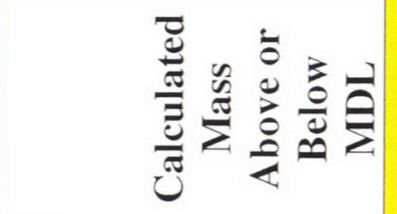 & 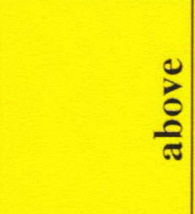 & $\begin{array}{l}\text { हे } \\
\text { के }\end{array}$ & $\begin{array}{l}\overrightarrow{0} \\
\frac{8}{\sigma}\end{array}$ & 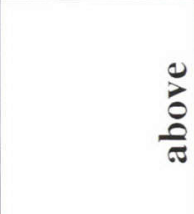 & $\begin{array}{l}0 \\
\text { हे }\end{array}$ \\
\hline 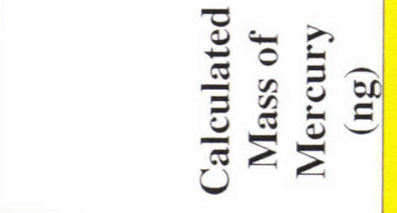 & \begin{tabular}{l}
$\infty$ \\
\hdashline \\
\hdashline
\end{tabular} & $\stackrel{1}{8}$ & ?ै? & $\stackrel{\infty}{+}$ & है \\
\hline 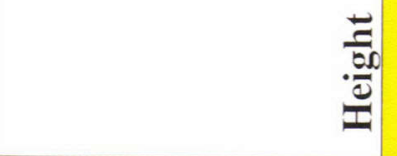 & $\begin{array}{l}\overline{0} \\
\vdots \\
0 \\
0\end{array}$ & $\begin{array}{l}0 \\
\frac{0}{0} \\
0\end{array}$ & 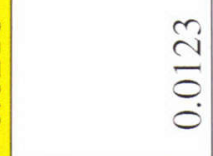 & 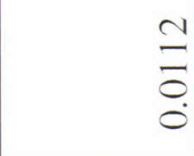 & $\stackrel{\substack{m \\
0}}{0}$ \\
\hline$\frac{\overrightarrow{6}}{300}$ & $\begin{array}{l}\infty \\
\infty \\
\vdots \\
\vdots \\
0\end{array}$ & $\begin{array}{l}\text { } \\
\text { ले } \\
\text { ?े }\end{array}$ & ले & 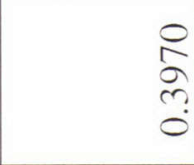 & $\stackrel{\circ}{\infty}$ \\
\hline 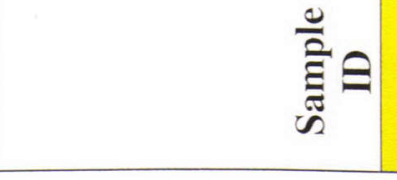 & 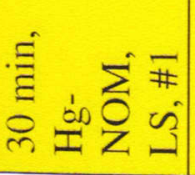 & 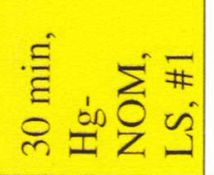 & 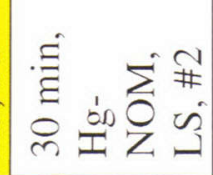 & 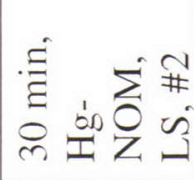 & 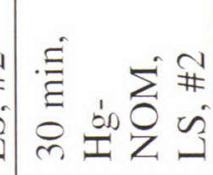 \\
\hline
\end{tabular}




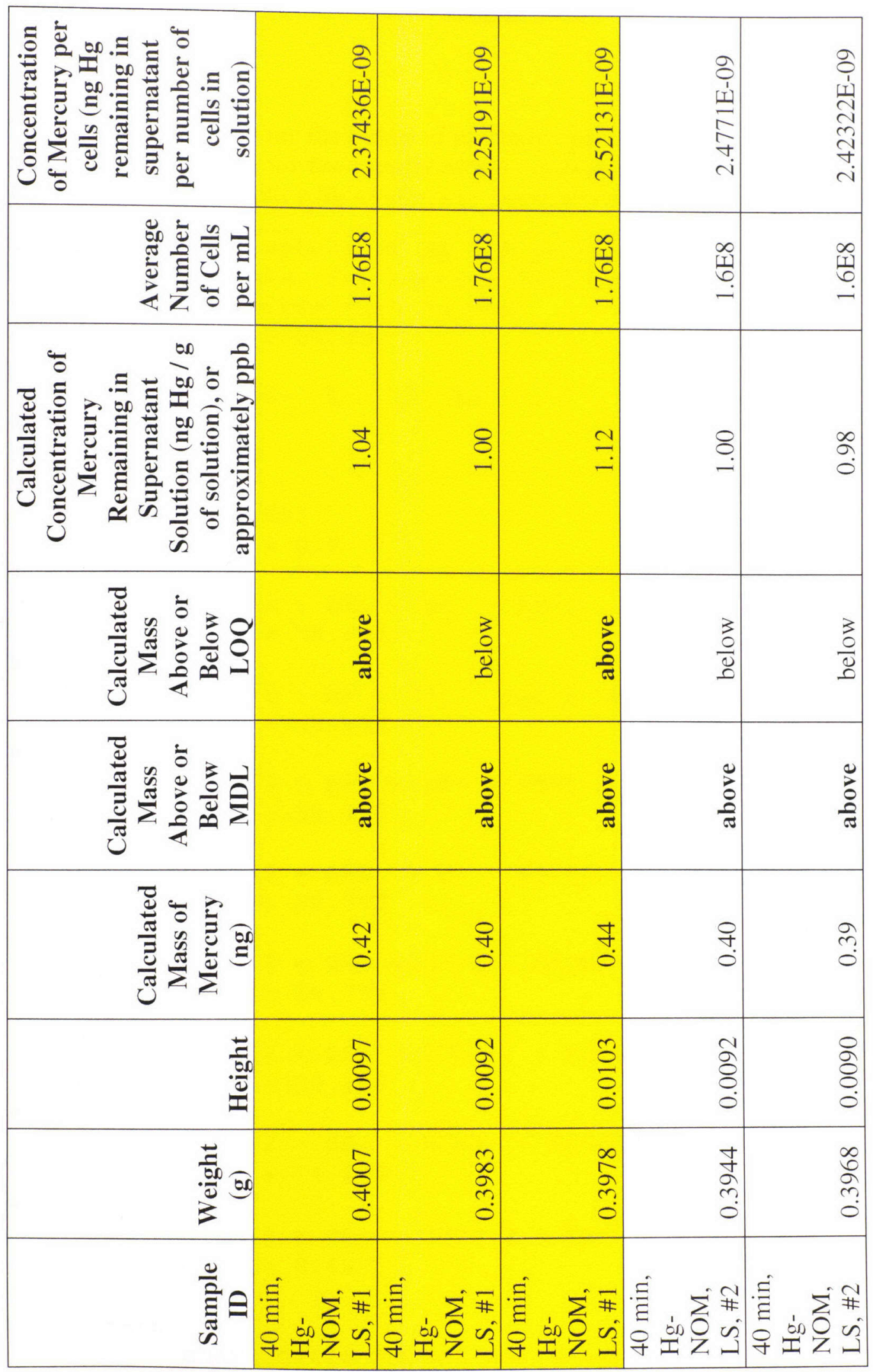




\section{APPENDIX E}

Table 26: Source code for the model of mercury uptake by cells via passive diffusion and facilitated uptake for the lactate/sulfate experiments that had been spiked with Hg-NOM. Lines are split with a $\backslash$ sign and comments begin with a \# sign.

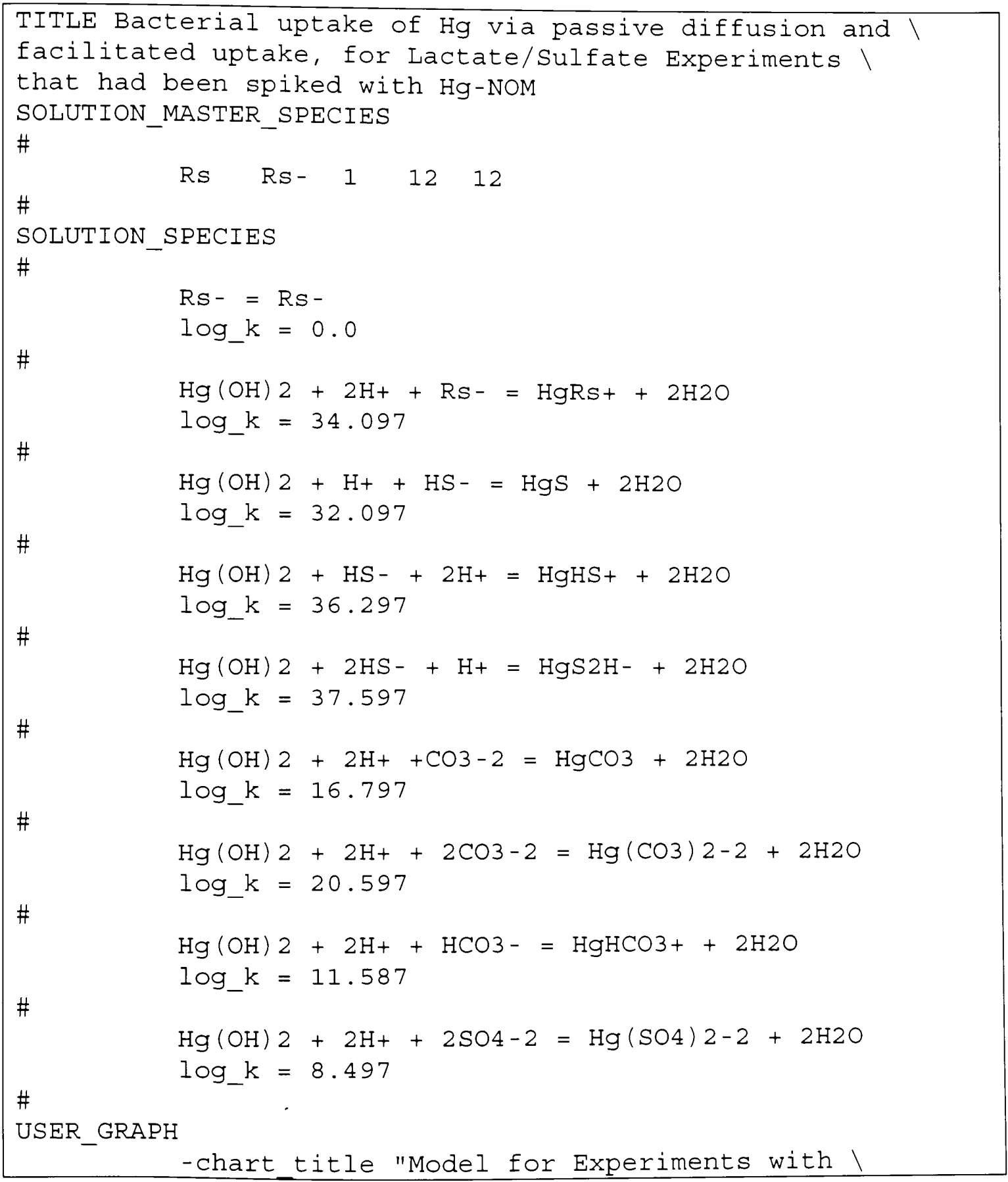




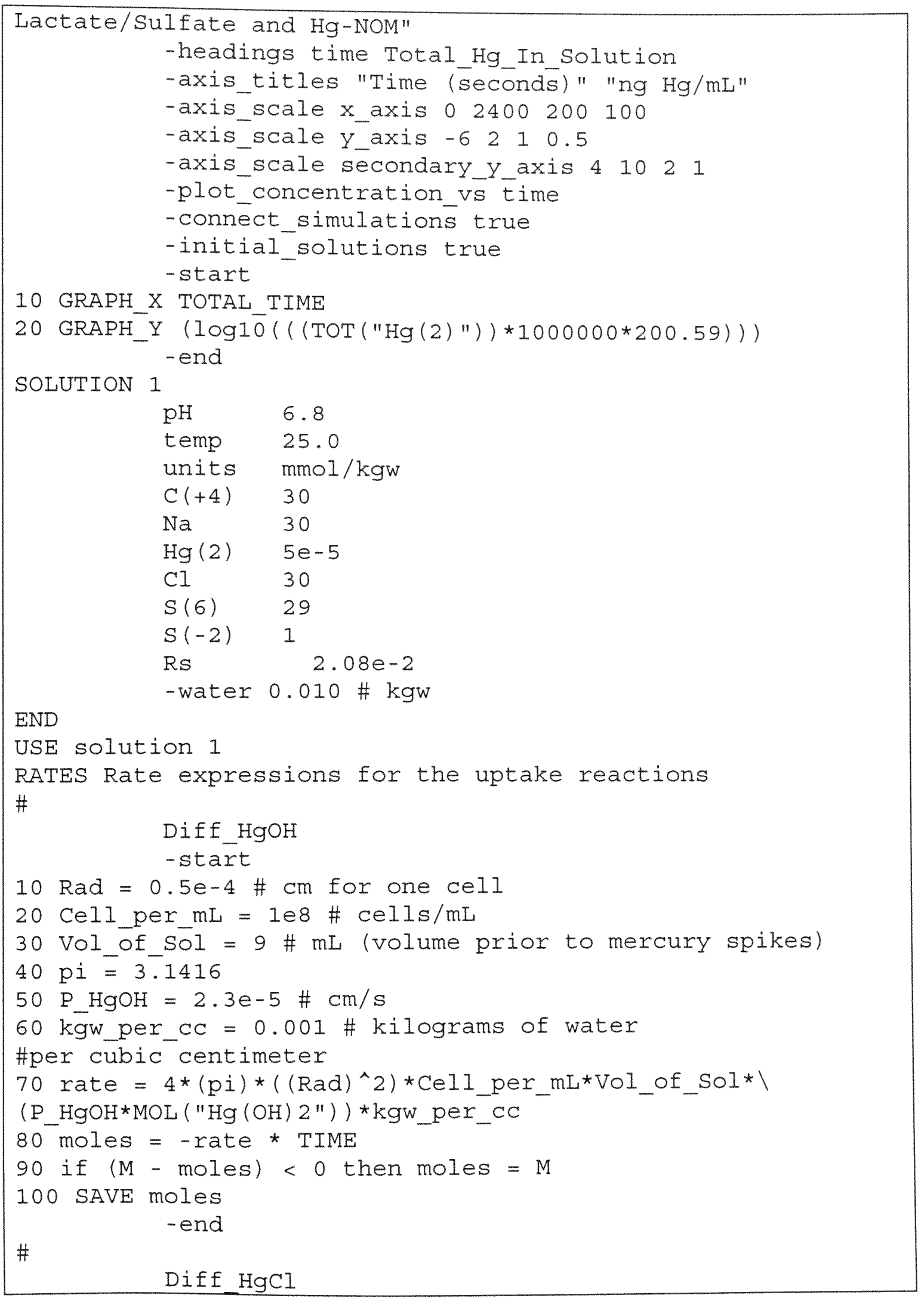


$10 \mathrm{Rad}=0.5 e-4$

20 Cel1 per $\mathrm{mL}=1$ e8

30 Vol_of SOL $=9$

$40 \mathrm{pi}=3.1416$

$50 \mathrm{P}$ HgCl $=7.4 \mathrm{e}-4 \# \mathrm{~cm} / \mathrm{s}$

$60 \mathrm{kgw}$ per_cc $=0.001$

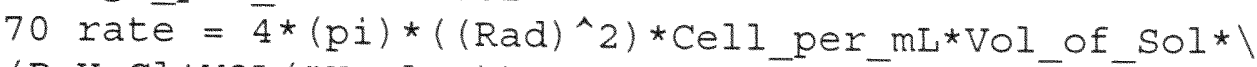

(P_HgCl*MOL ("HgCl2"))*kgw_per_C

80 moles $=$-rate * TIME

90 if $(M-$ moles $)<0$ then moles $=M$

100 SAVE moles

$$
\text { -end }
$$

$\#$

\section{Diff_HgClOH}

- start

$10 \mathrm{Rad}=0.5 e-4$

20 Cell_per $m L=1 e 8$

30 Vol_of_Sol $=9$

$40 \mathrm{pi}=3.1416$

$50 \mathrm{P} H \mathrm{HgClOH}=6.8 \mathrm{e}-4 \# \mathrm{~cm} / \mathrm{s}$

$60 \mathrm{kgw}$ _per_cC $=0.001$

70 rate $=\overline{4} *(\mathrm{pi}) *\left((\mathrm{Rad})^{\wedge} 2\right) *$ Cel1_per_mL*Vol_of_SoI ${ }^{*} \backslash$

(P_HgClOH*MOL ("HgClOH")) *kgw_per_CC

80 moles $=$-rate * TIME

90 if $(\mathrm{M}$ - moles) < 0 then moles $=\mathrm{M}$

100 SAVE moles

$$
\text { -end }
$$

\#

$$
\begin{aligned}
& \text { Diff_HgS } \\
& \text {-start }
\end{aligned}
$$

$10 \mathrm{Rad}=0.5 e-4$

$20 \mathrm{Cel}$ per $\mathrm{mL}=1$ es

30 Vol_of SOI $=9$

$40 \mathrm{pi}=3.1416$

$50 \mathrm{P}$ _HgS $=3.7 e-1 \# \mathrm{~cm} / \mathrm{s}$

$60 \mathrm{kgw}$ per_cc $=0.001$

70 rate $\bar{e}=\overline{4} *(\mathrm{pi}) *\left((\operatorname{Rad})^{\wedge} 2\right) *$ Cell_per_mL*Vol_of_Sol $*$

( $P$ _HgS*MOL ("HgS"))*kgw_per_CC

80 moles $=$-rate * TIME

90 if (M - moles) < 0 then moles $=M$

100 SAVE moles

$$
\text { -end }
$$

$\#$

\section{Diff_HgHS}

-start 


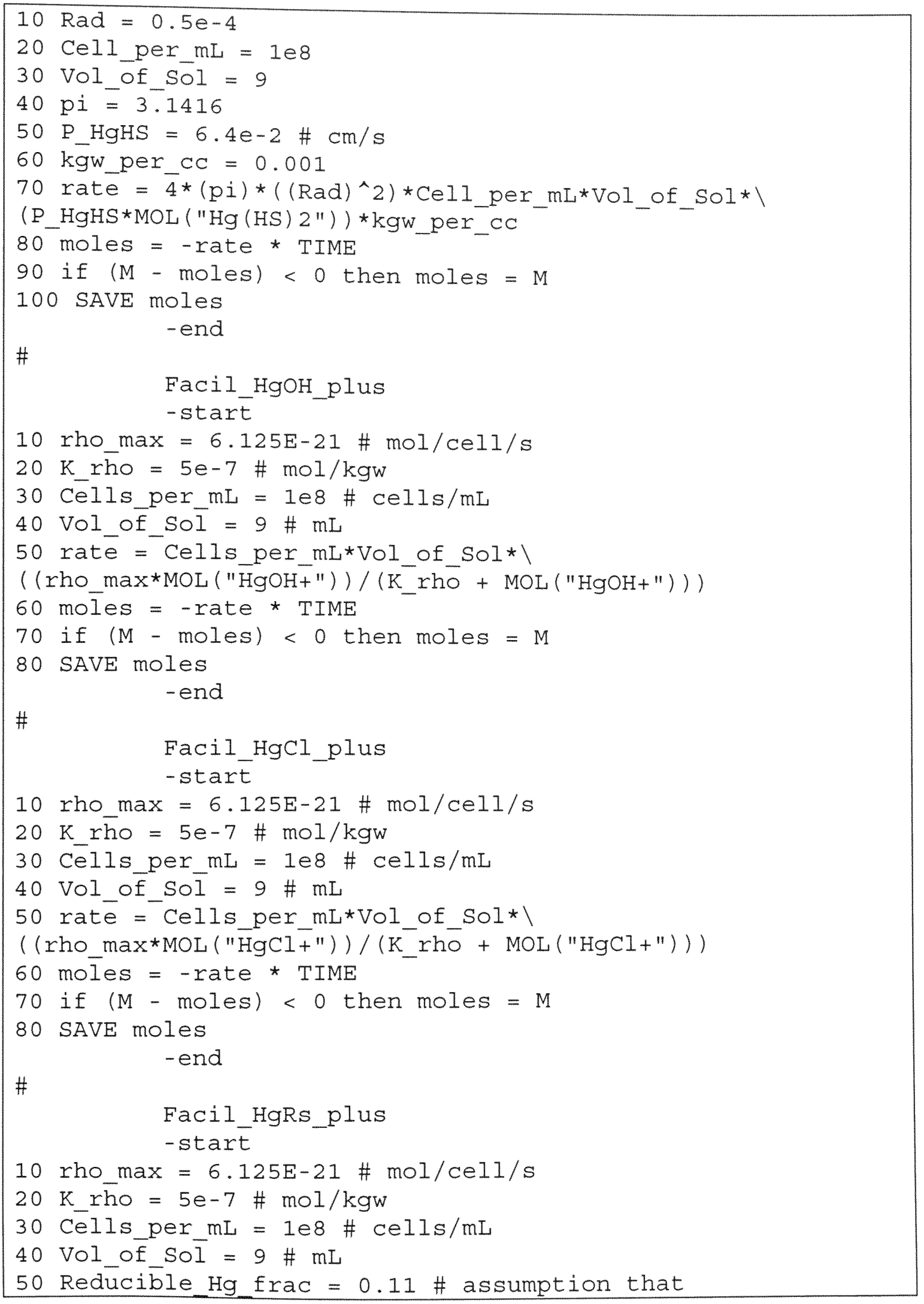




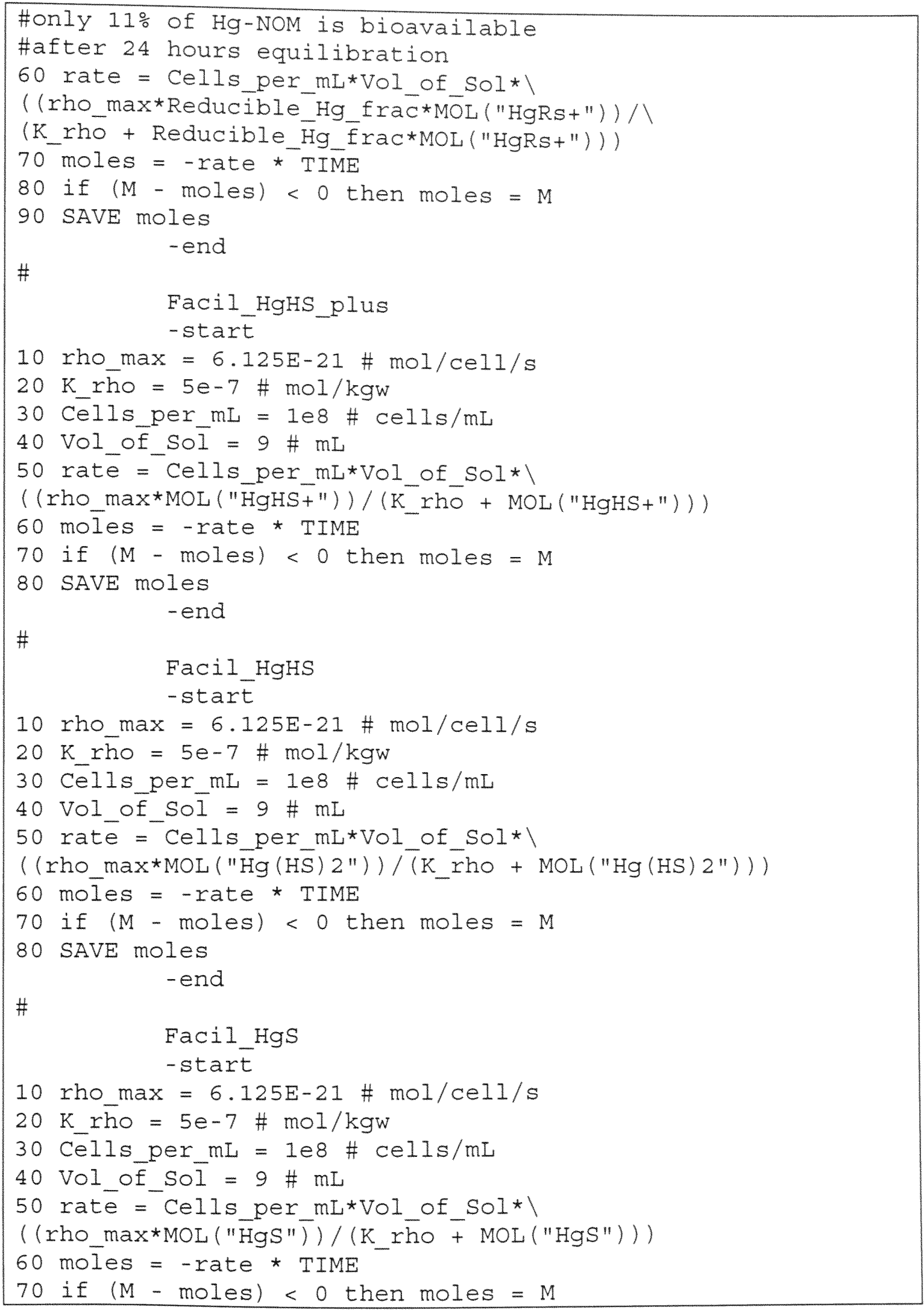




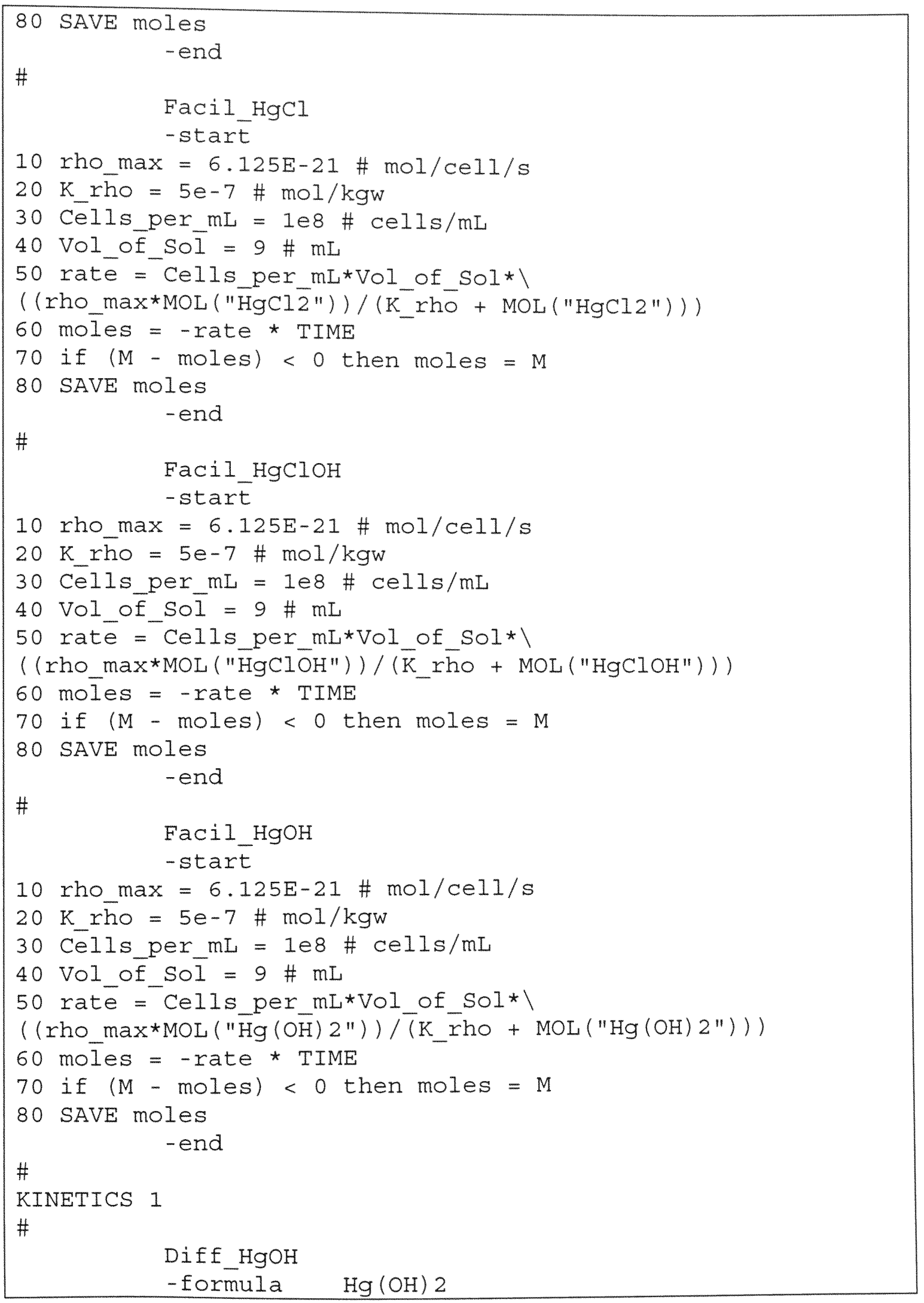




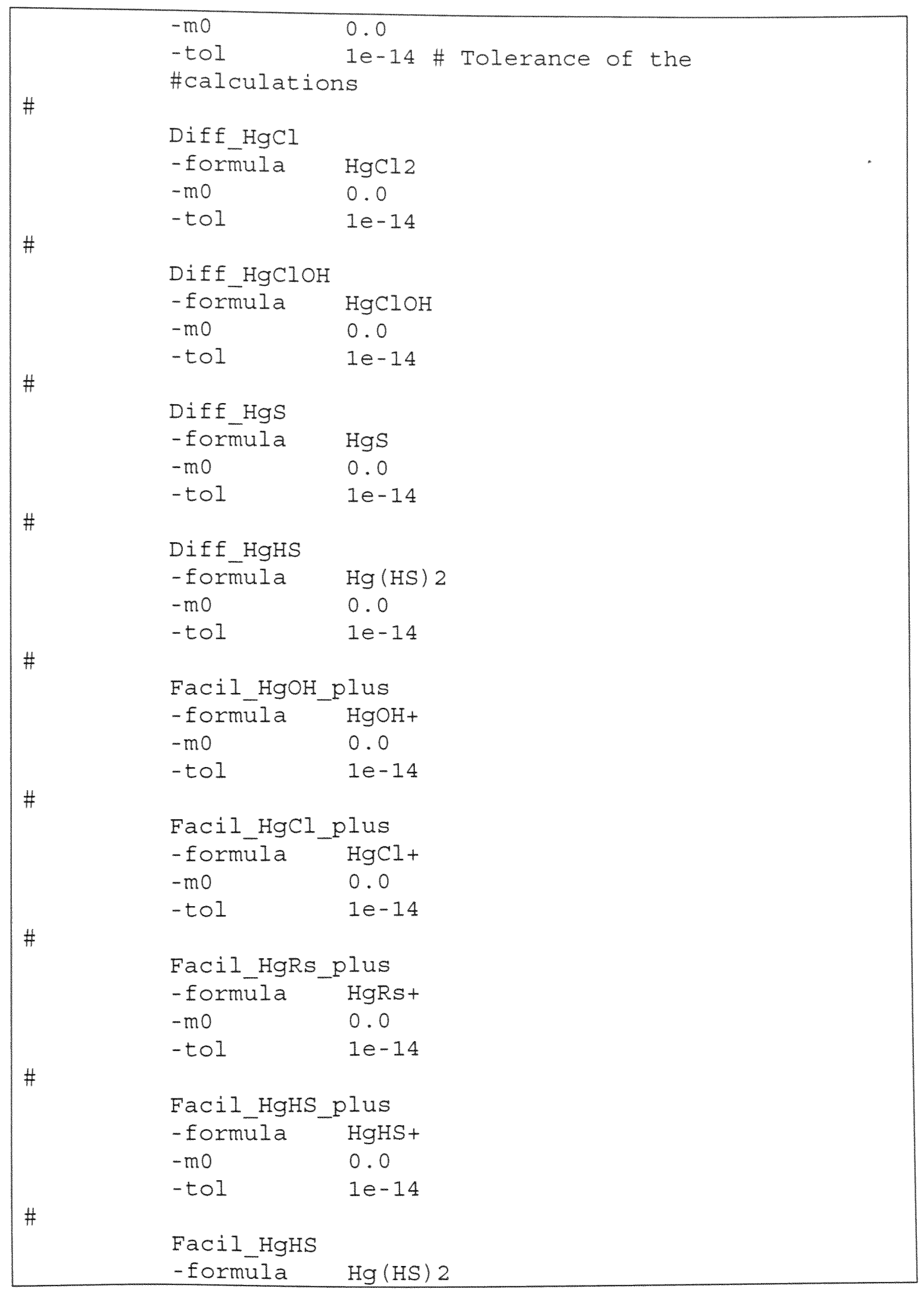




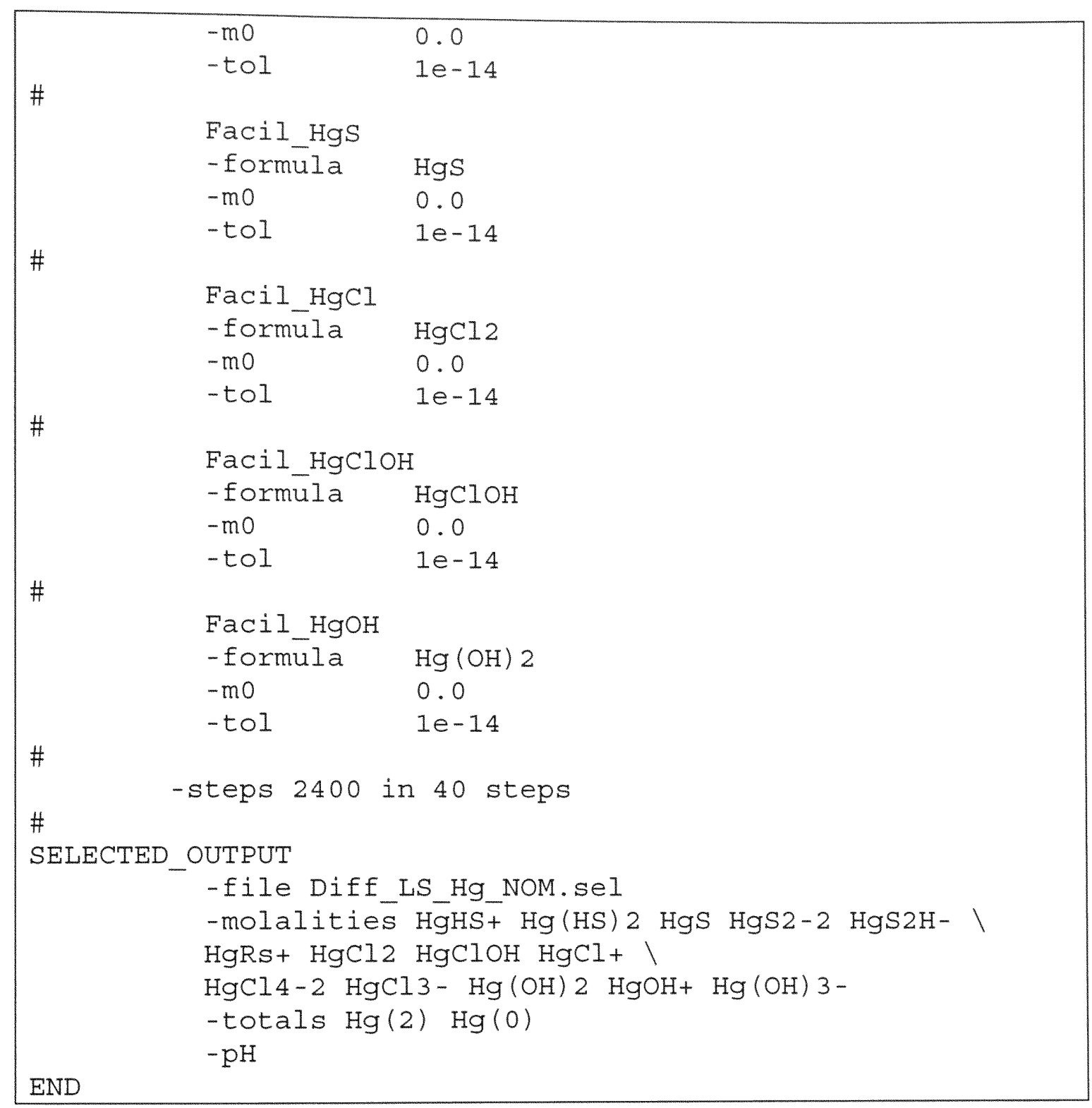




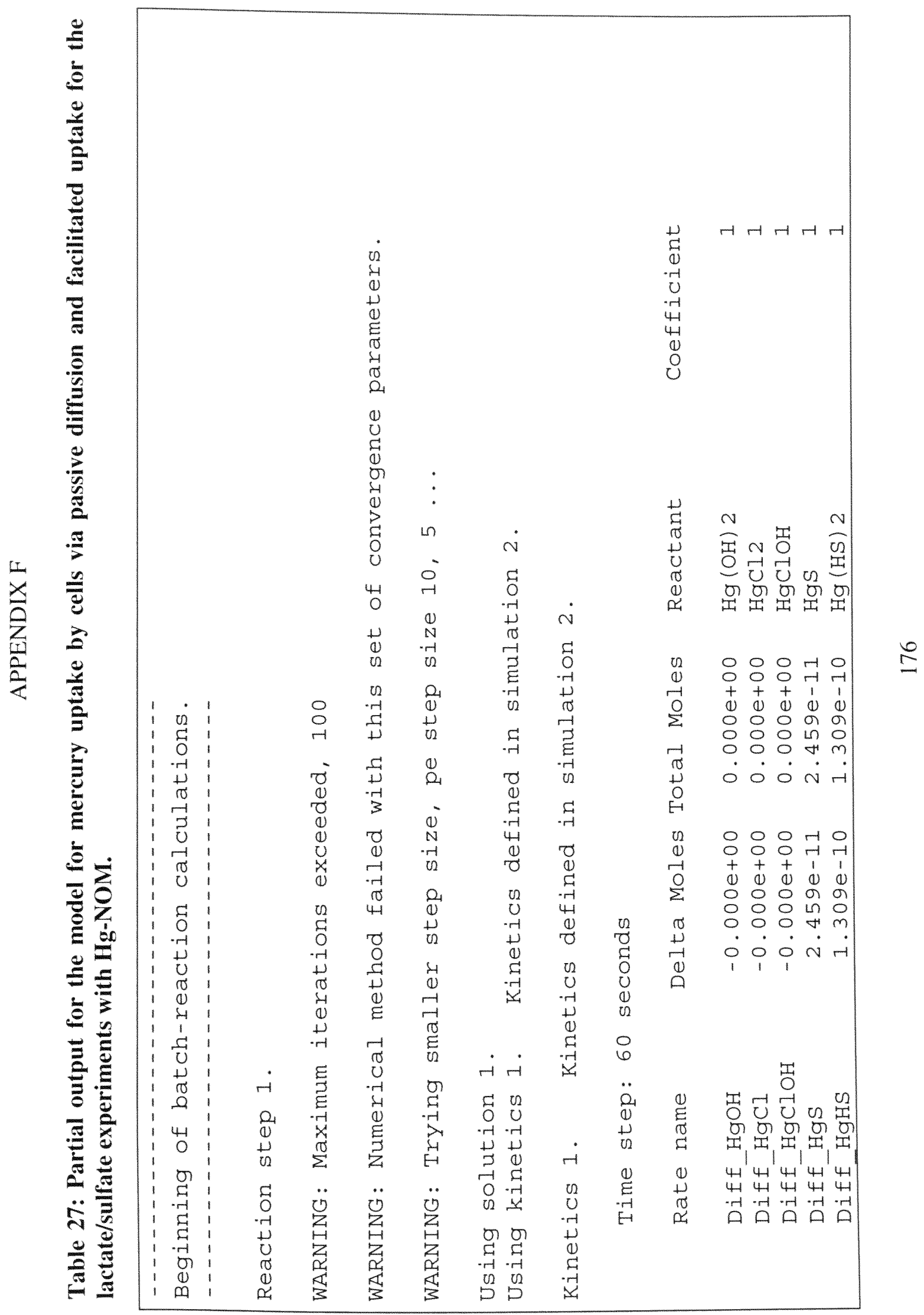


A 40 ar h

$\begin{array}{llllll}+ & 1 \\ 0 & 0 & 1 & 1 & + \\ 0 & 4 & 4\end{array}$

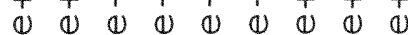
$00 \mathrm{mom} / 000$ $\begin{array}{lllllllll}0 & 0 & 0 & 0 & \text { in } & \text { 月 } & 0 & 0 & 0 \\ 0 & 0 & 6 & \text { n } & \text { \% } & \text { in } & 0 & 0 & 0\end{array}$ - $\dot{0} \dot{0} \dot{0} \dot{0} \dot{0} 0$

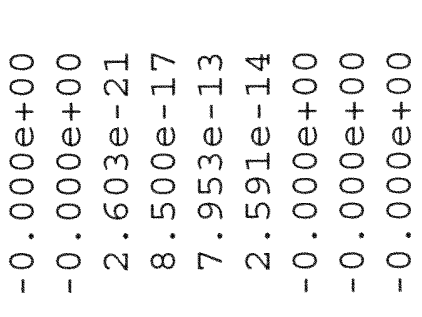
$\begin{array}{llllll}1 & 1 & 1 & 1 & 1 & 1\end{array}$ (1) ब1 (1) \& 110 $\begin{array}{llllll}0 & 0 & 0 & 0 & 0 & 0 \\ 0 & 0 & m & 0 & 0 & 0\end{array}$ $\begin{array}{llllll}0 & 0 & m & 0 & 0 & 0 \\ 0 & 0 & 4 & 0 & 0 & 0\end{array}$ $m m m n m$

$\begin{array}{lllllll}-4 & 1 & 1 & 1 & 1 & 1 & 1\end{array}$ 4 (1) 0 (1) 00 (1) r 000000 r $00 \%$ 0
2 $m m m m n$

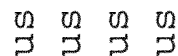

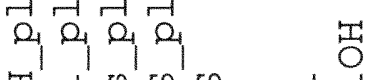

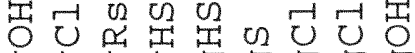
का का का का का का का का

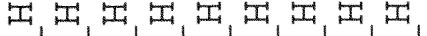

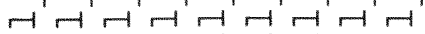

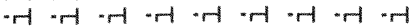

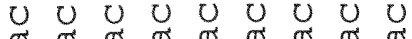

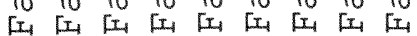

$$
\begin{aligned}
& \begin{array}{r}
5 \\
5 \\
-4 \\
4 \\
0 \\
-7 \\
-1 \\
-7 \\
3 \\
0 \\
0
\end{array} \\
& \text { } \\
& 0 \text { \& }
\end{aligned}
$$

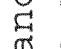

$$
\begin{aligned}
& -1+ \\
& \text { त) } \\
& \text { a } \\
& \text { (1) } \\
& \text { or } 0 \\
& \text { म } 3 \\
& \text { 范 }
\end{aligned}
$$

ज्ञ ति के कि

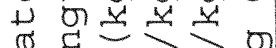

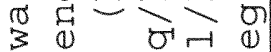
4 is $\begin{array}{llll}4 & 4 & 0 & -E \\ 0 & 0 & + & 0\end{array}$ $\rightarrow 03 \perp N$ 4
$-\pi$ $\rightarrow 000.40$ - $H$ थ

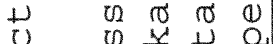
U $\quad$ 足 +1
0
0
0
0

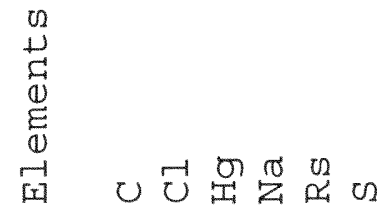




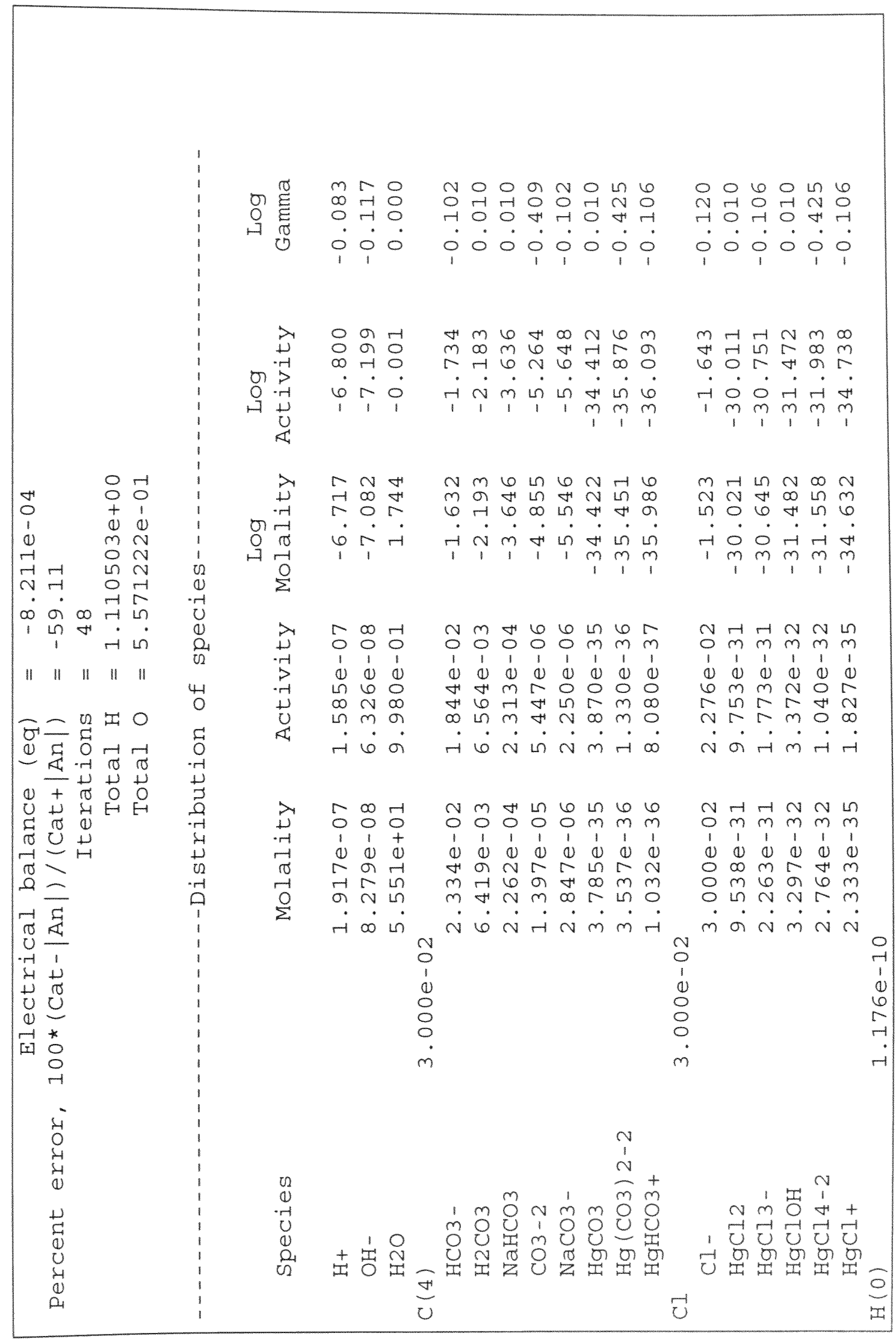


$\begin{array}{ccc}0 & 0 & 0 \\ -1 & 7 & \text { in } \\ 0 & 0 & 4 \\ 0 & 0 & 0\end{array}$

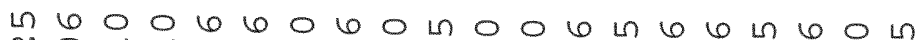

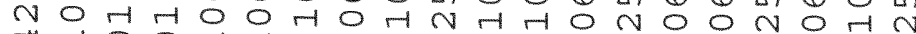

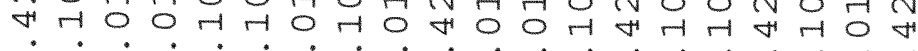

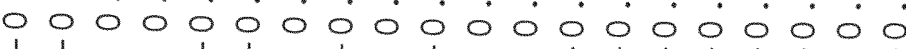

L $\mathrm{N} O \mathrm{O}$ $\begin{array}{llll}4 & 4 & 0 & -1 \\ 0 & 0 & 0\end{array}$ 0000

$\begin{array}{ccc}r & r & n \\ N & \sigma & r \\ N & \sigma & m \\ 0 & 0 & \dot{N} \\ \dot{H} & -1 & +\end{array}$

H $m$ H

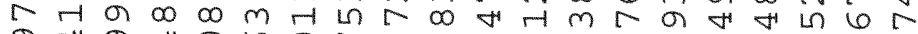

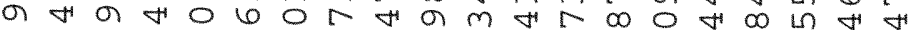
م $\dot{\infty} \dot{0} \dot{0} \dot{0} \dot{0} \dot{0} \dot{0} \dot{0} \dot{0} \dot{0} \dot{0} \dot{0} \dot{0} \dot{0}$

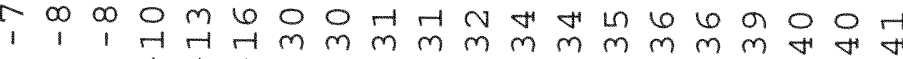

L 6 \% 66 तi $\dot{\mathrm{N}} \dot{\mathrm{L}}$

H H

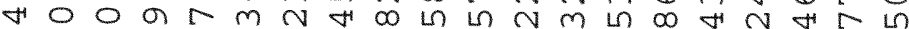

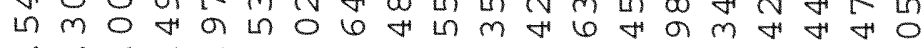

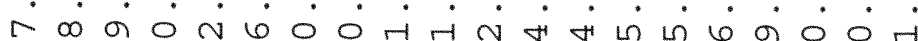

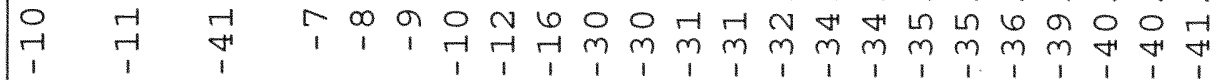

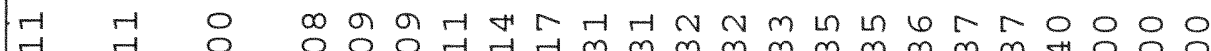
$1,1,1,1, m m m m m m m i, 1++$

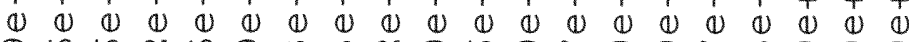

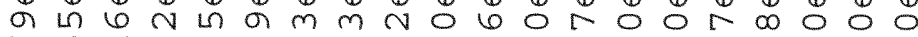

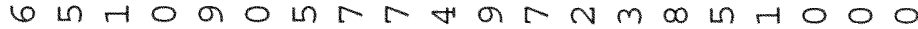

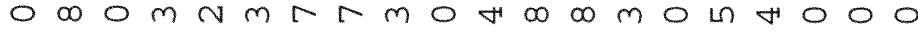

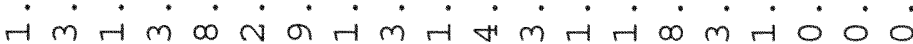

H $\mathrm{H}$ - 0 \%

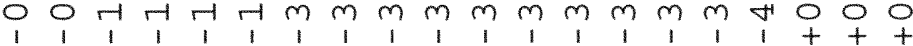

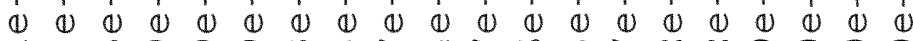
HmL

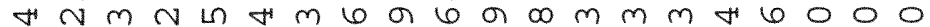

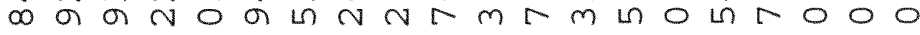

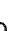
N N

$\sim m 66$ A 6 \& in $\infty 6 \mathrm{~L}$ - $\dot{1} \dot{\mathrm{m}} \mathrm{i}$ 1111

ก 0000

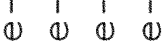
$\infty$ it $m o$

$N \infty$ H NOMN $\mathrm{N} \sim \mathrm{N}$

c $m$ J 6 0000 (1) 1$) \quad 0 \quad 0$ ON N N \$1 6 $\infty m \sim \infty$ $\mathrm{N} N \mathrm{~N}$ $\begin{array}{lll}N & \circ & \infty \\ 7 & 0 & 0 \\ 1 & + & 1\end{array}$ (1) +1 1 $\begin{array}{lll}0 & 0 & 6\end{array}$ \% ? 
$\begin{array}{lll}0 & 6 & 6 \\ 4 & 0 & 0 \\ 0 & 7 & 7 \\ 0 & 0 & 0\end{array}$

ON $\ln$ Ln Ln 600 Ln 0 in 6 H $M N N N$ N $N$ N

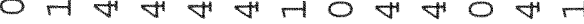

○ 0 O

H $N$ \%

L $00 \%$

- 10 ,

00000

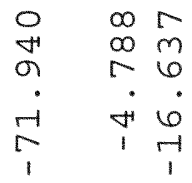

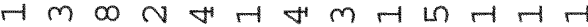

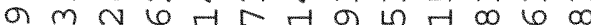
ง 4 ! m $\dot{0} \dot{0} \dot{0} \dot{0} \dot{0} \dot{0} \dot{0}$ $111,1,1,1,1,4$

$m \ln 6 \pi$

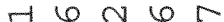
0 の $\infty$ म म * $\dot{1} \dot{0} \dot{0} \dot{0}$ $\begin{array}{llll}1 & 1 \\ 1 & 1\end{array}$

O NO H

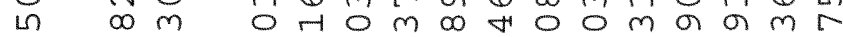

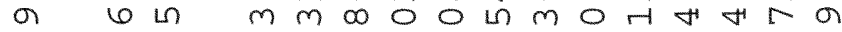

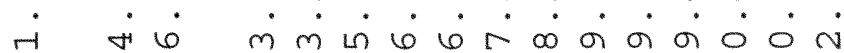

$\pi \quad 1 \%$

$\begin{array}{llllllllll}9 & 0 & 0 & 0 & 9 & 0 & 0 & 0 & & \end{array}$

a $m \sim r o$

L 6 H

L $\infty \sim+\infty$

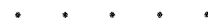

$\begin{array}{lllll}1 & 1 & 0 & 4 \\ 4 & 0 & 0 & 4\end{array}$

11,1

$\begin{array}{lll}0 & \text { L } & 0 \\ 0 & 0 & -1 \\ + & 1 & 1 \\ 0 & 0 & 0 \\ 0 & 0 & 0 \\ 0 & \text { N } & 0 \\ 0 & 0 & m \\ 0 & \text { - } & \text { i }\end{array}$

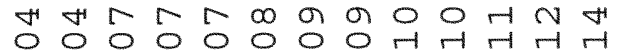
$\begin{array}{lllllllllllll}1 & 1 & 1 & 1 & 1 & 1 & 1 & 1 & 1 & 1 & 1 & 1 & 1 \\ 0 & 0 & 0 & 0 & 0 & 0 & 0 & 0 & 0 & 0 & 0 & 0 & 0\end{array}$

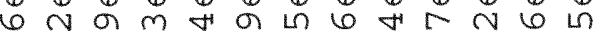

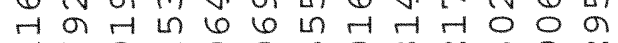
H 6 \% $00000 \mathrm{~N}$ \%

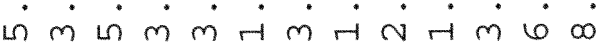

m 05000 $111++$ (1) 1100000 in $\rightarrow 00$ 0 \% 00 N कं

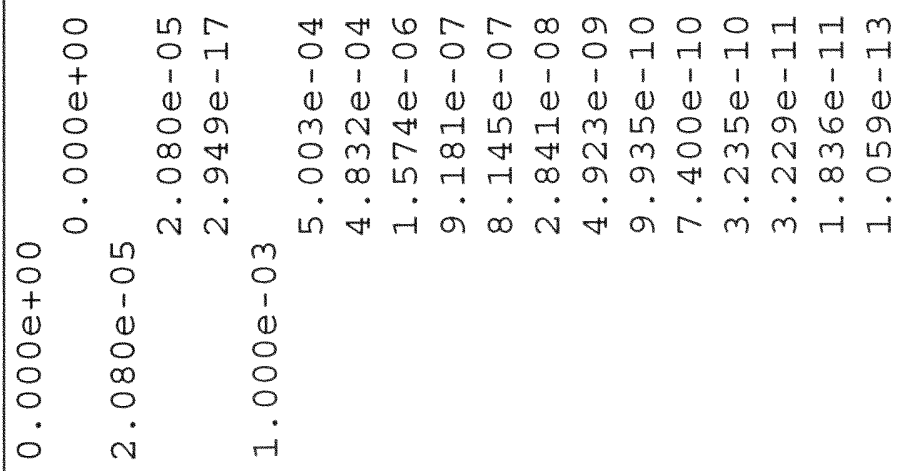

Nmsoo 00000 (1) $1+1$ $\begin{array}{lllll}1 & 0 & 0 & 0 & 0\end{array}$ NNOOO $6 N H 00$ rm 00 N त

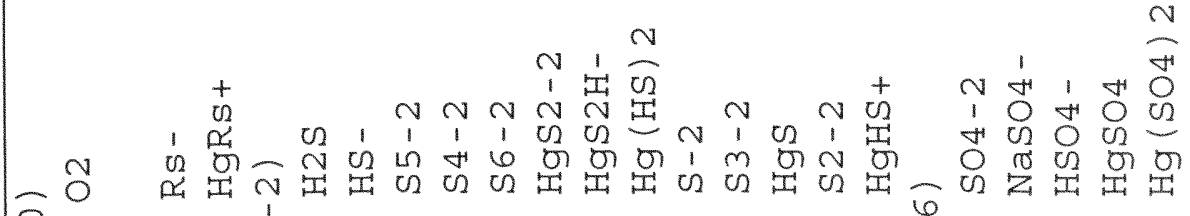

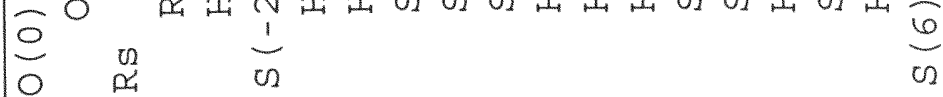




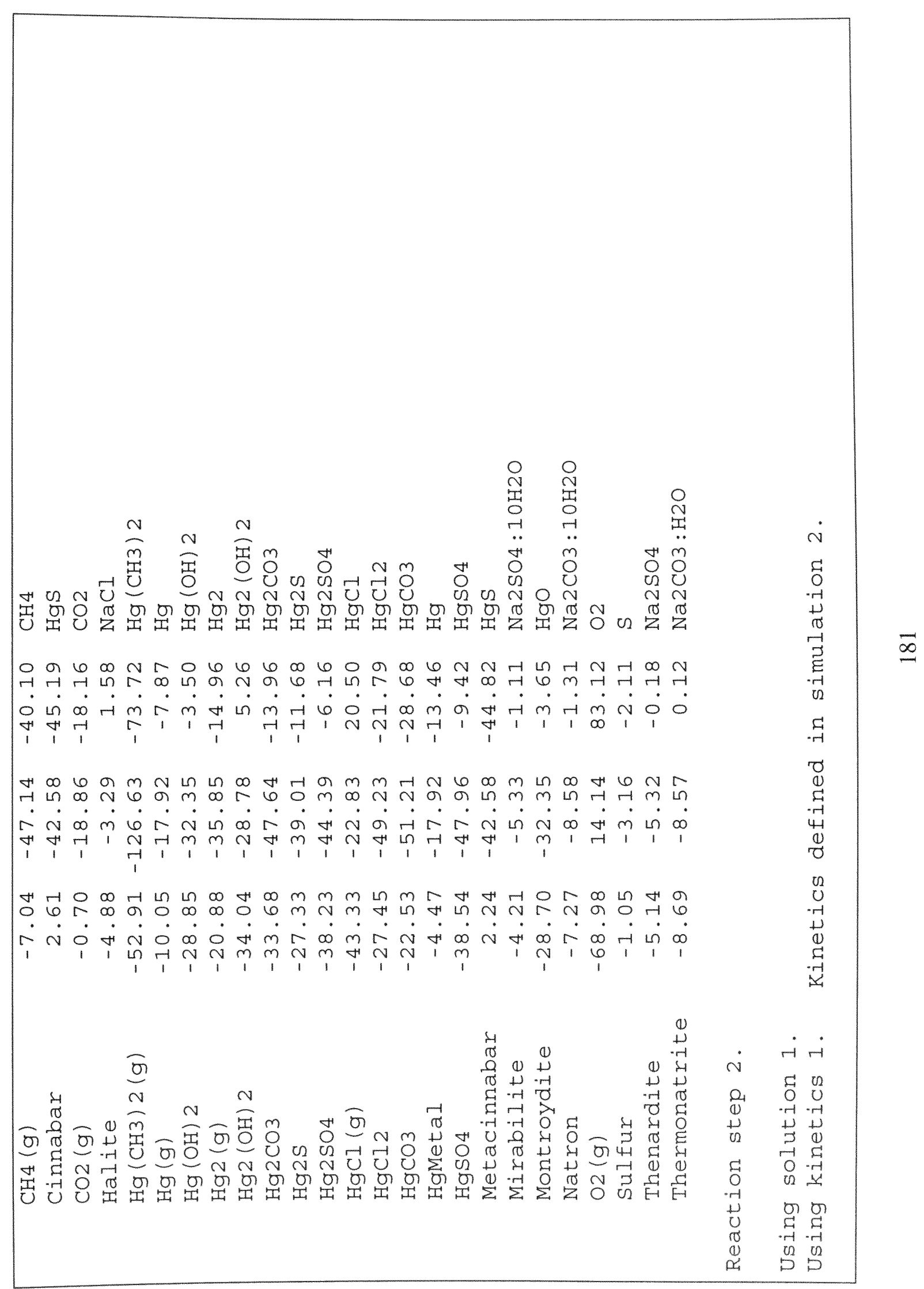




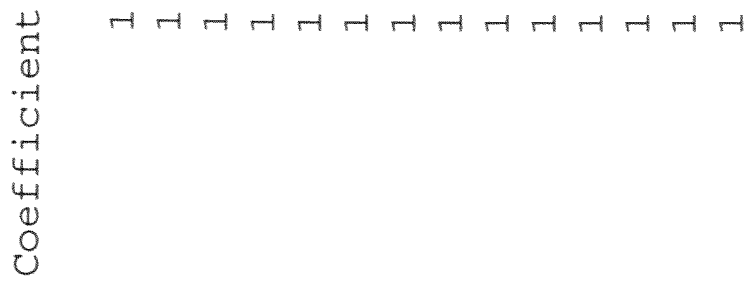

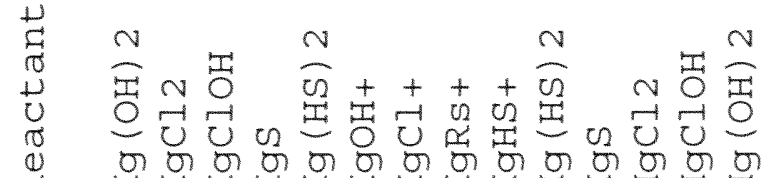

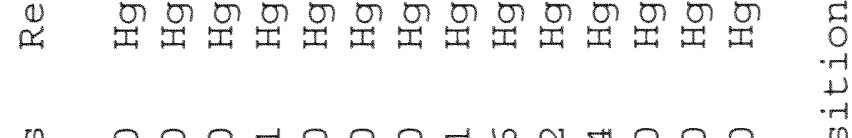

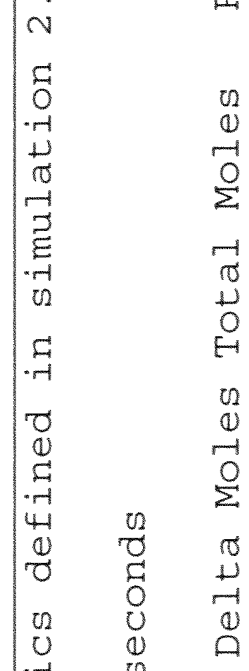

+
0
0

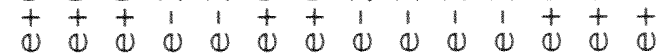

$0000,00 n$ m

$000 \mathrm{l} 000 \mathrm{~m}$ a $\mathrm{m} 000$

$000 \pi \mathrm{N} 00 \mathrm{~m}$ a $m$ m 000

O 0 O

$\frac{0}{0}$

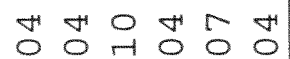

$\infty$

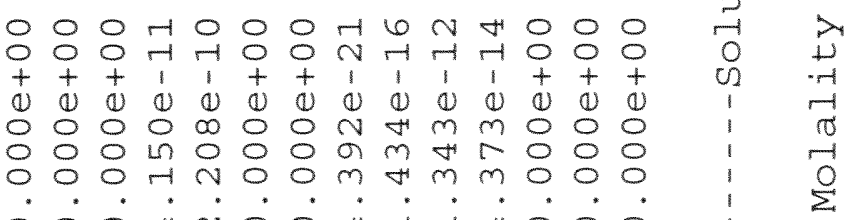

$\begin{array}{llllll}1 & 1 & 1 & 1 & 1 & 1 \\ 0 & 0 & 0 & 0 & 0 & 0\end{array}$

$\begin{array}{llllll}\circ & \circ & m & \circ & 0 & 0 \\ \circ & 0 & 6 & 0 & 0 & 0\end{array}$

$00 \mathrm{~m} 000$

$m m \sim M N M$

i

- 11 $\begin{array}{llllll}1 & 0 & 0 & 0 & 0 & 0\end{array}$

$00 \mathrm{mo} 00$

006000

o o mo o o

$m m \sim m \sim$

\section{$\stackrel{0}{\supset} \stackrel{0}{\supset}$}

$\stackrel{\circ}{\sim}$

다글

至

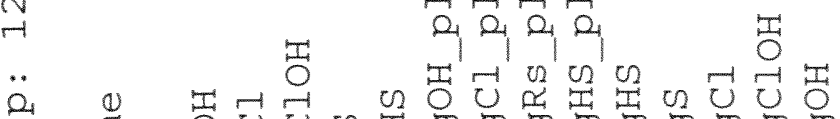

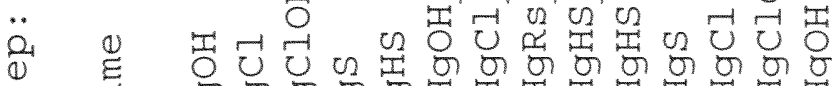

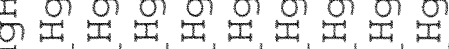

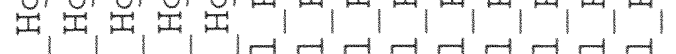

$\underset{E}{\mathbb{E}} \stackrel{0}{+\infty}$

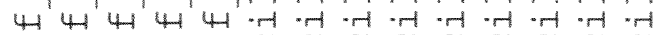

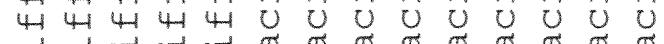

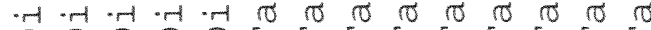

$\frac{0}{4}$

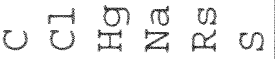




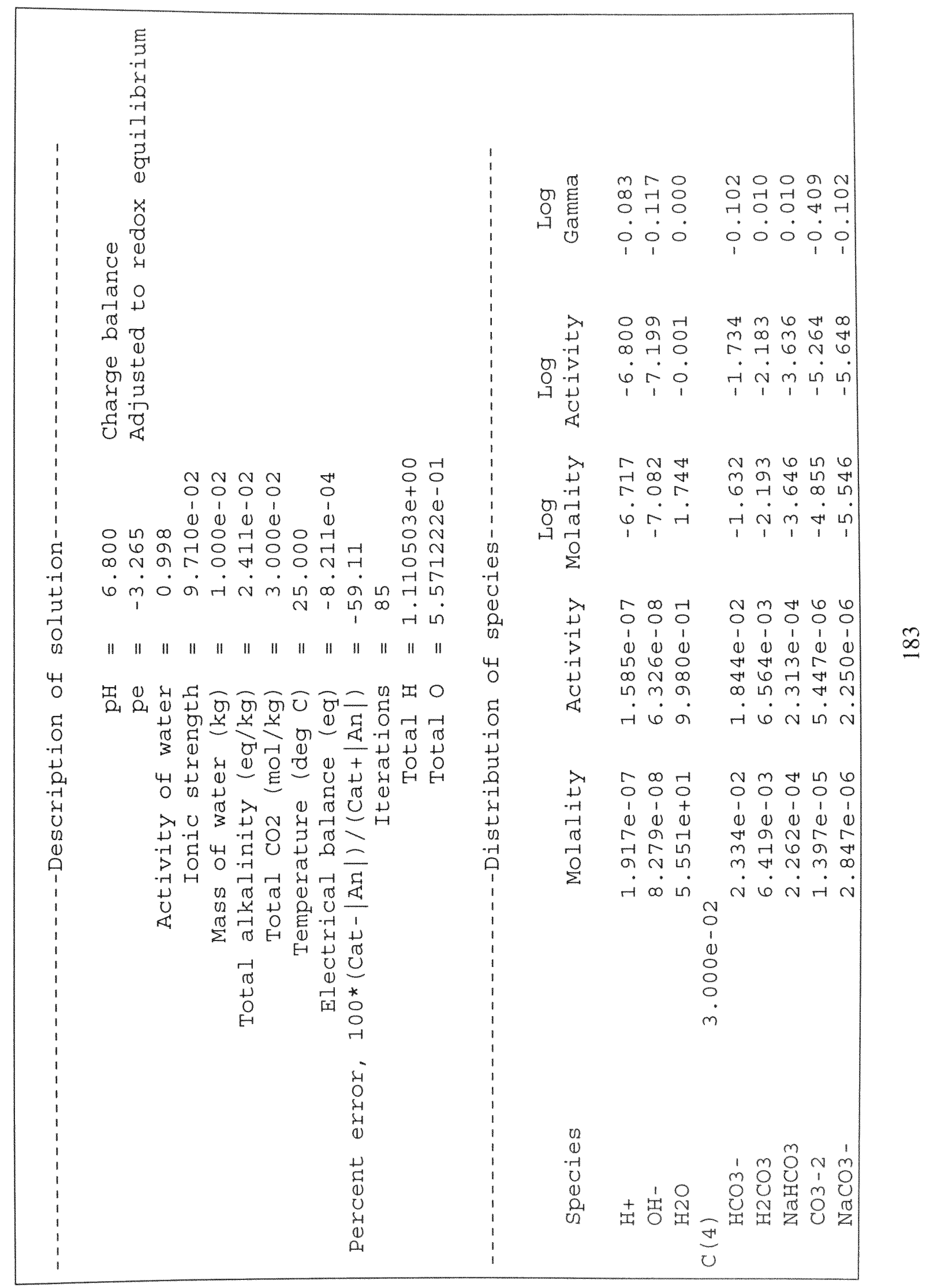




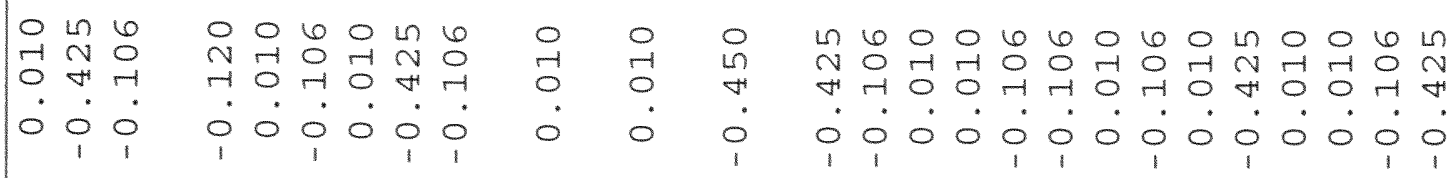

细 m

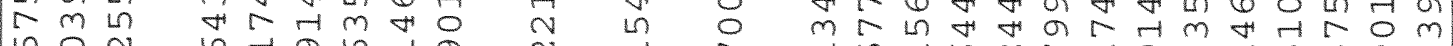

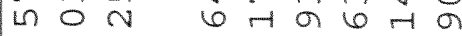

सं $\dot{0} \dot{0}$ मं

$m m m i m m m$

CH

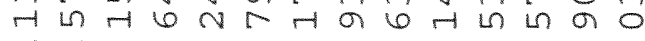

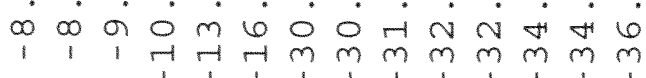

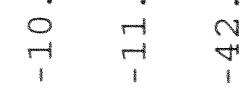

$\ln \&$

$\infty+\infty$

느 6

$m m \infty$ in

$\sim \infty 0+\pi \sigma$

$\ln \rightarrow \infty \mathrm{N}$

ti $\ln 6$ तं

$1 m m m$

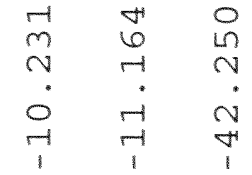

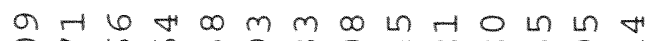

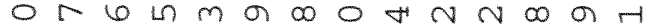
$\therefore$.

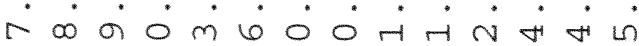

$m m_{1}$

$\ln r$ $m m m$

$\begin{array}{lll}1 & 1 & 1 \\ 0 & 0 & 0\end{array}$

तो

6 ㄴ

$6+40$

त 10 N

$N \rightarrow n m$ in $0 m m m m$ $\begin{array}{llllll}1 & 1 & 1 & 1 & 1 & 1 \\ 0 & 0 & 0 & 0 & 0 & 0\end{array}$ 6 의 $\infty \quad \infty$ r 0 H $N \mathrm{NMH} N$

$\begin{array}{ccc}H & N & 0 \\ H & H & 0 \\ 1 & 1 & 4 \\ 4 & 0 & 0 \\ 4 & 6 & 0 \\ 0 & 0 & 0 \\ 0 & 0 & 0\end{array}$

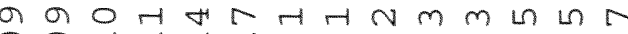
$00 H H H H m m m m m$

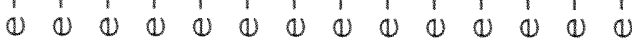

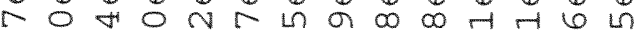
$\forall$ in $0 \times 0$ D 0 H mb $6 N \mathrm{~N} N \mathrm{NM}$ H $6 \mathrm{NH}$

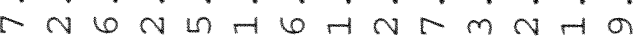

L 61 $m m m$

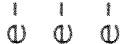
1) 00 om $\mathrm{m}$

$6+0$

$\mathrm{NH} N \mathrm{~m}$ ก $0 \mathrm{~m} m \mathrm{~m}$ 1111 Q 00000 0 r $6 r 04$ 0 แ $n$ in 0

$N \sim N$

$\infty$

- $i$ i

$\dot{m} \dot{\mathrm{N}} \mathrm{N}$

1
0
0
0

$\begin{array}{ccc}H & N & 0 \\ -1 & H & 0 \\ 1 & 1 & 1 \\ 0 & 0 & 0 \\ -1 & -1 & 0 \\ \infty & 6 & 0 \\ \infty & \infty & 0\end{array}$

$\infty$ O $00 H H H M m m m m m$ $111,1,1,1,1111$ $\begin{array}{llllllllllllll}1 & 0 & 0 & 0 & 0 & 0 & 0 & 0 & 0 & 0 & 0 & 0 & 0\end{array}$ m

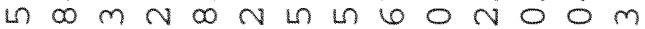

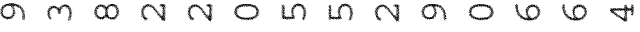

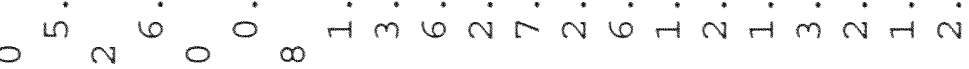

$\begin{array}{llll}-1 & -1 & 0 \\ 1 & 1 & + & 0\end{array}$

$\begin{array}{llll}1 & 0 & 0 & 0 \\ 0 & 0 & 0\end{array}$

$\begin{array}{lll}6 & 0 & 0 \\ -1 & \infty & 0\end{array}$

i $\dot{0} \dot{0} \dot{N}$

i

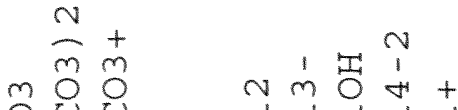

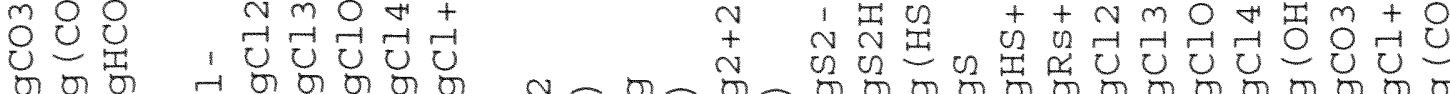

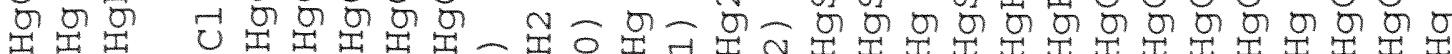
0

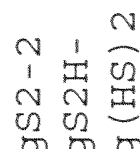


66 ᄂ $60 \mathrm{Ln}$ 00 त 0 म H $0_{1}^{0} 0_{1} 0_{1}^{\circ} 0^{\circ} 0_{1}^{\circ}$

ก $N$ H IN $\mathrm{H} M \mathrm{~m}$ N $60 \mathrm{~N} 6 \mathrm{6}$ ம $\begin{array}{llll}1 & 1\end{array}$

o $6 \mathrm{~N} 90 \mathrm{~m}$ $\begin{array}{llllll}4 & 0 & 0 & 0 & 4 & 4\end{array}$ $\pi$ ก $1266 \pi$ ம $\dot{0}$ م $\dot{0} 0 \dot{0}$ $m m m$ म

r r o o o o m moo o o (1) $1+++t$ $\rightarrow$ in 0000 in 40000 I 40000 in $\dot{0} 0 \dot{0} 0$

r roo o 0 $m m+100$ $\begin{array}{llllll}1 & 1 & 1 & + & + & + \\ 0 & 0 & 0 & 0 & 0 & 0\end{array}$ M N $\mathrm{N} 00$ न त क 000 0 H - $\dot{0}$ i

$\begin{array}{rr}m & 000 \\ & 0 \\ & 0 \\ & 0 \\ & 0\end{array}$

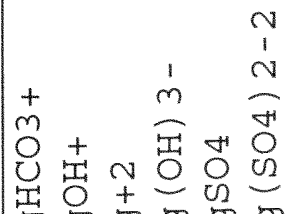
or on का का का

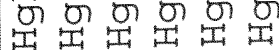

$\ln \mathrm{O} O \mathrm{~N}$

$00=0$

H $\mathrm{HOH}$

0000 $\begin{array}{lll}0 & 6 & 6 \\ -1 & 0 & 0\end{array}$

O

० $0_{1}^{\circ}$

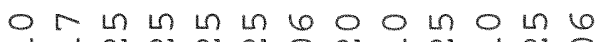
$\mathrm{H} N \mathrm{~N} N \mathrm{~N} N \mathrm{~N} N \mathrm{~N}$

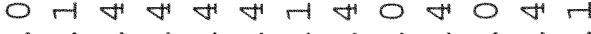

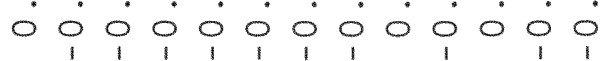

N $\ln \infty$ แn $6 \mathrm{~m}$ $6 \% 6$ त ल लं 1,11

N $m 66$ 4. in $\infty 6 \mathrm{~L}$

. . . HN $\mathrm{m}$ in

$N m H \omega$ 0000 (1) 1101 $\infty$ in N $\infty$ in .4 .4 $\mathrm{N} N \mathrm{~N}$ NO M

$\infty$ o

$\infty$ a

$r$

मi

17

in

$\mathrm{Nm}$

$\infty$ o

610

H

H $6 m \mathrm{r}$ \%

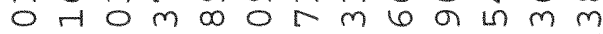
$m m \infty 0 \%$ H

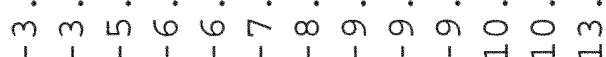

$\pi m \infty n+4 \pi+4 \pi$

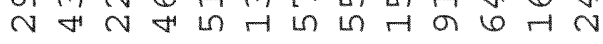

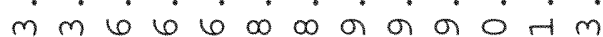
$111,11111,1,310$

0 In H $+01$ (1) 00

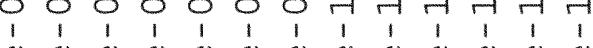

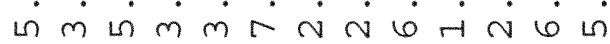

$\begin{array}{llll}N & m & 4 & 6 \\ 0 & 0 & 0 & 0\end{array}$ (1) 1111 0200 $\log _{4} \mathrm{~N}$ $\infty \mathrm{N} \infty$ Nं $\dot{N} \infty$ 0
0
1
0
0
0
$m$ i . is $+0$ ○े $+02 \mathrm{I}$ 范范范 $\mathbb{Z}$ a 1

$\sim \infty$

6 in

-i

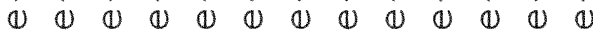

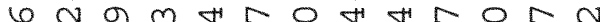

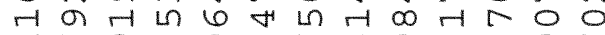

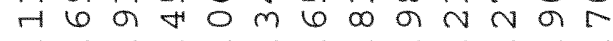

$0 \pi$ (1) 0 00 $0 \mathrm{r}$

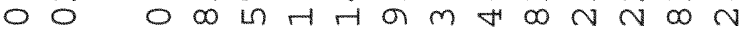
$\cdot \circ$ $m$

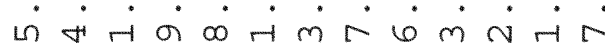

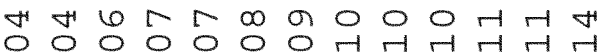
$\begin{array}{lllllllllllll}1 & 1 & 1 & 1 & 1 & 1 & 1 & 1 & 1 & 1 & 1 & 1 & 1\end{array}$

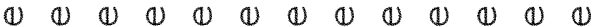

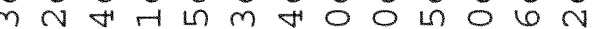


* No 0 in

I $00 \mathrm{H}$

मत

100000

m ᄂ

H $6 \mathrm{Nm}$

o 066

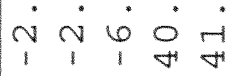

O m N O m

in 6 म

L $\infty \pi 6 N$

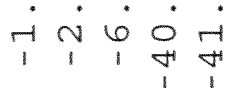

mmroo

00000

$\begin{array}{lllll}1 & 1 & 1 & + & + \\ 0 & 0 & 0 & 0 & 0\end{array}$

in $m o 0$

0 o 000

ro 000

के

NmRoo

NOSOO

(1) 1000

M N 00

$6 \pi+00$

- Ma 00

लं

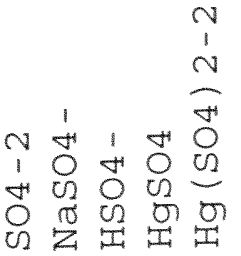

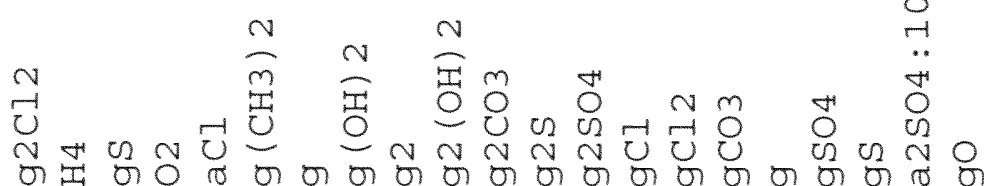

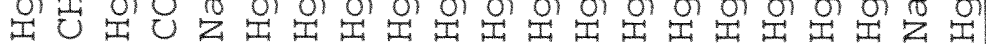

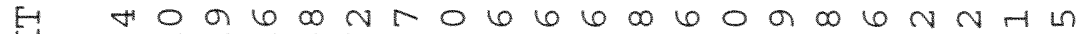

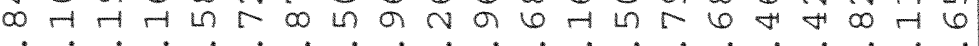

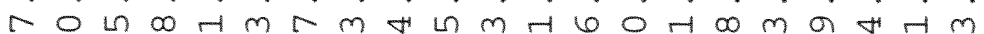
तम ब

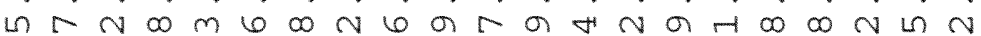

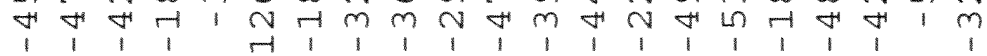

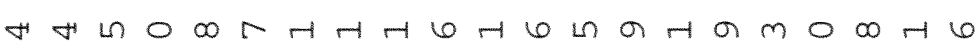
HOHI

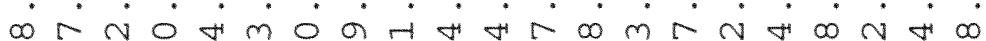

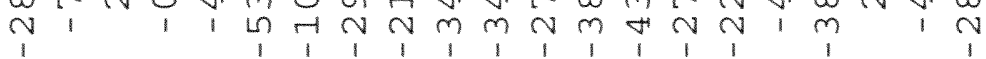

\section{क़}

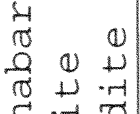

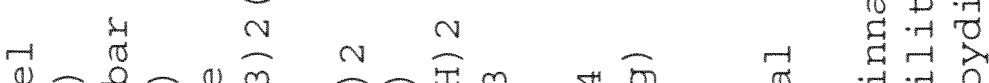

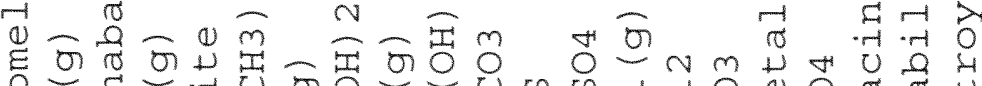
- $=-10$ का

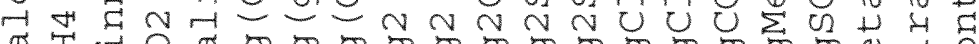

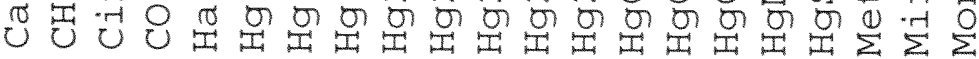




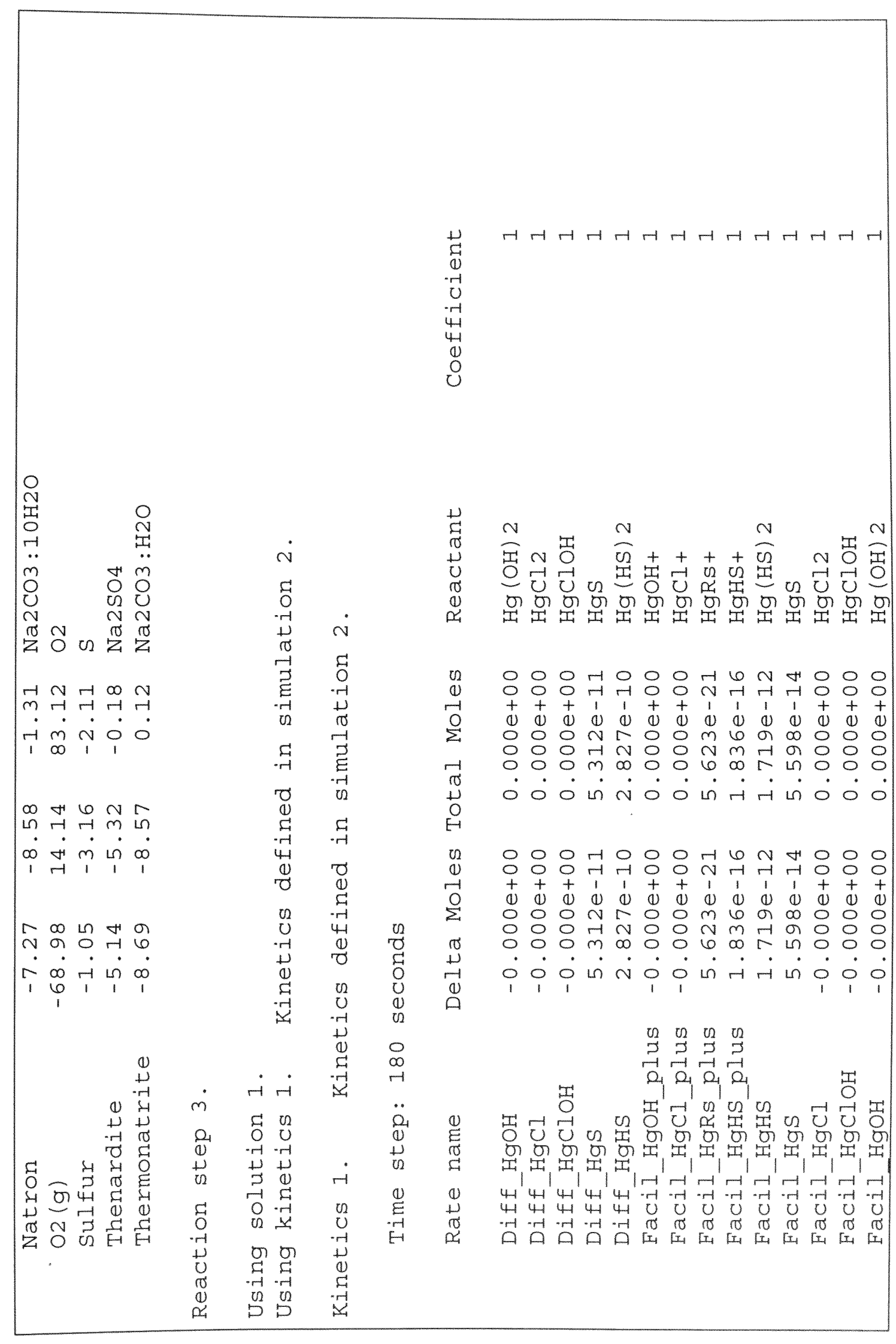




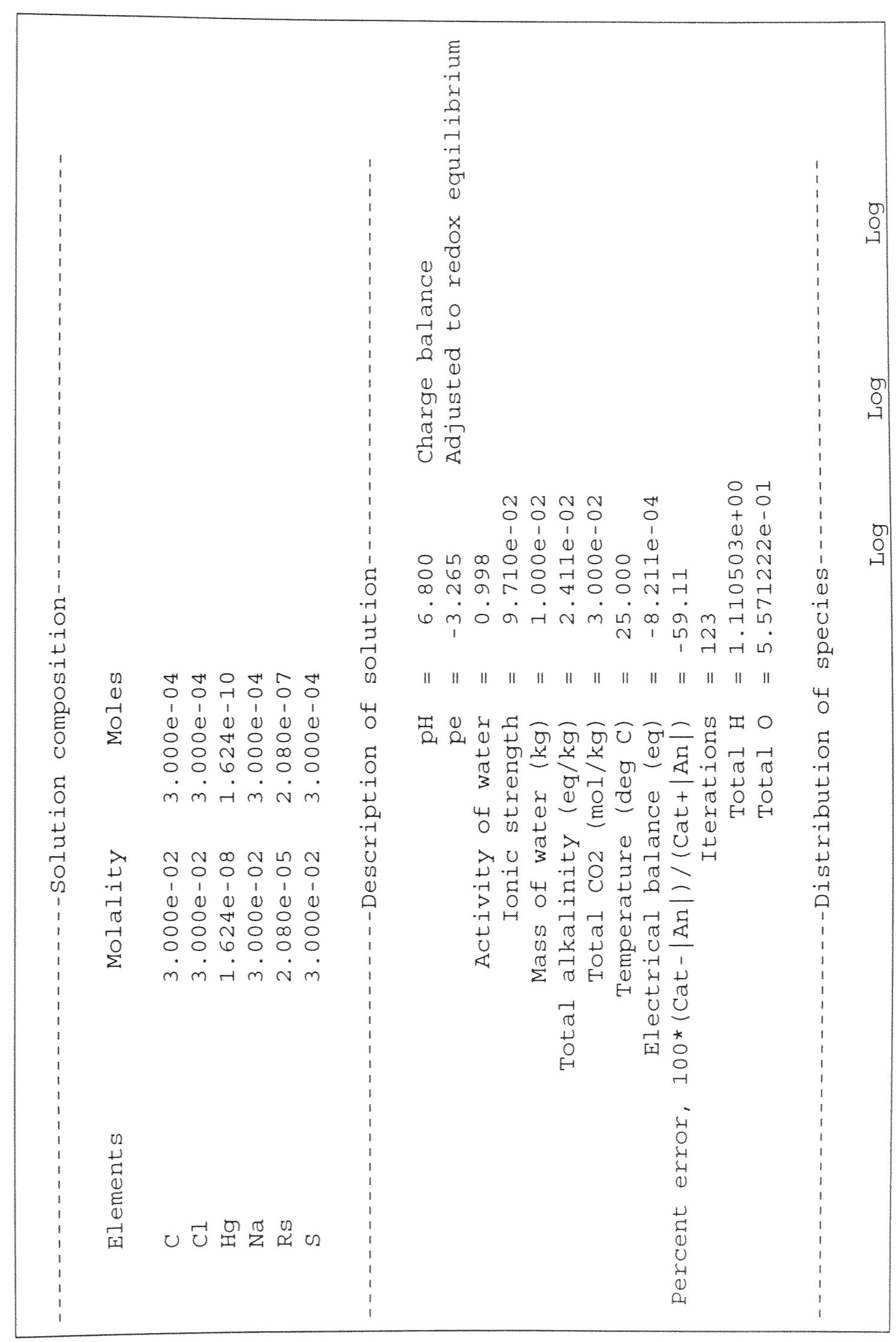




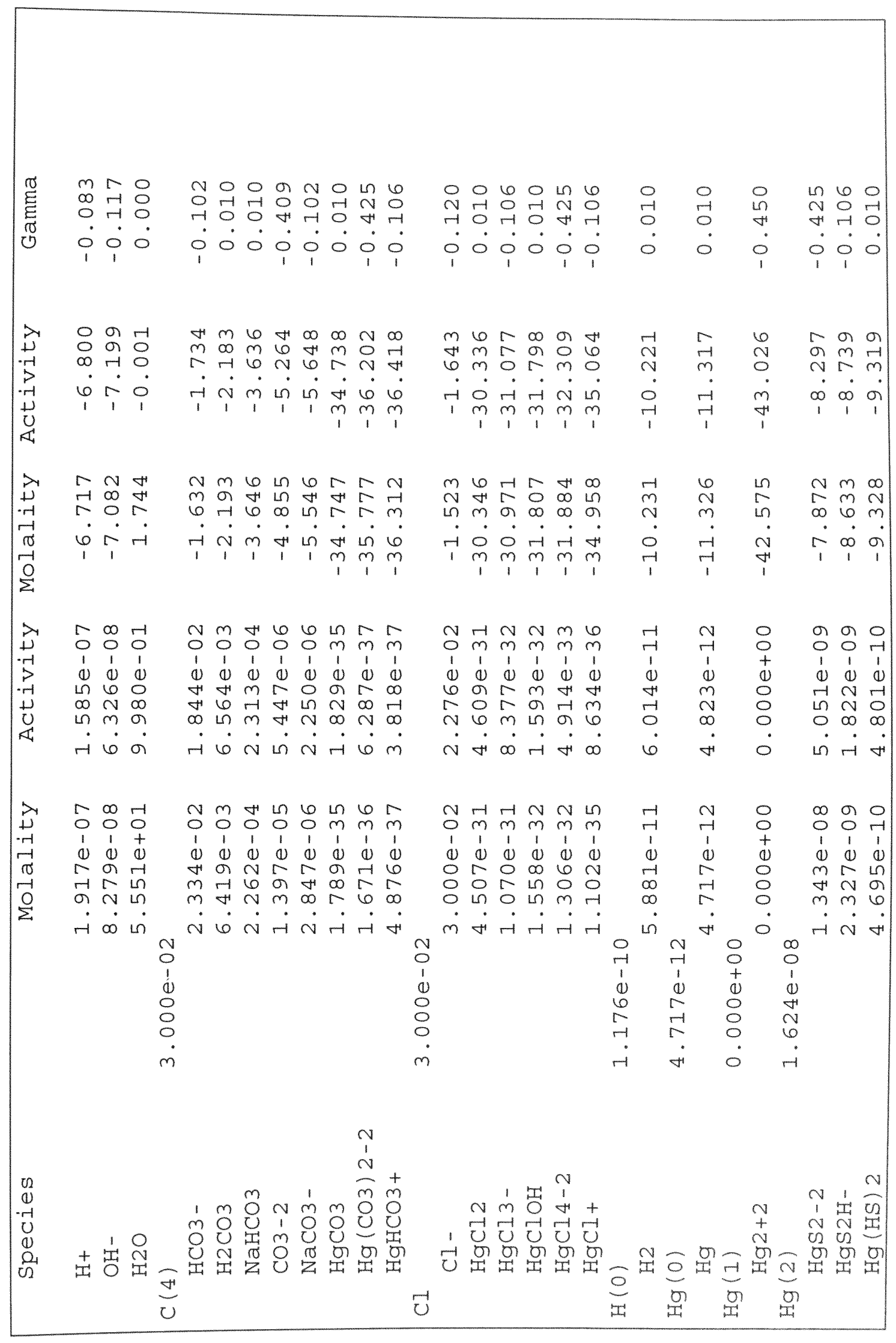




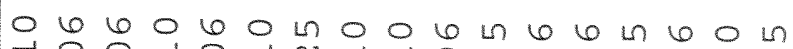

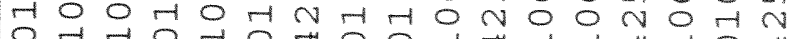
0 H 0

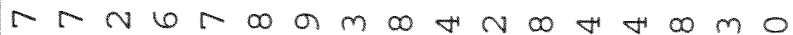
O $06 \mathrm{~m}$. -

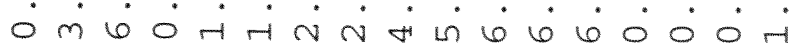
$H-H m m m m m m m m$ m

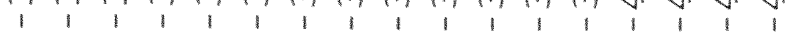

6 W 6 .

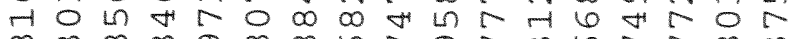

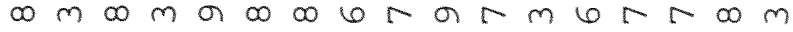

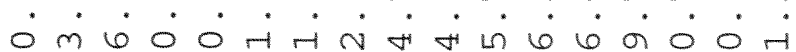
$H H \mu m m m m m m m$ m

$H N N N$ N H.

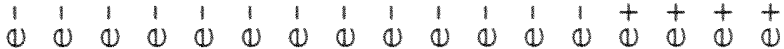

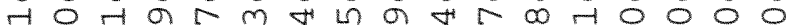

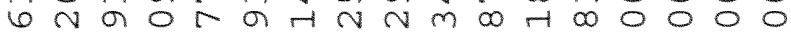

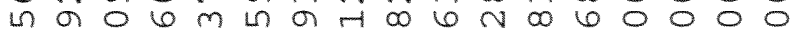

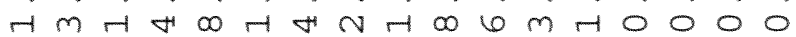

HANHHNNMLU

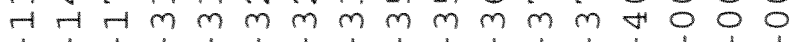

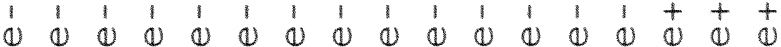

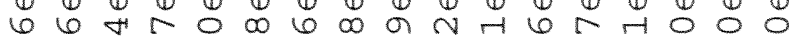

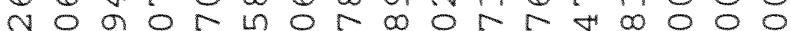

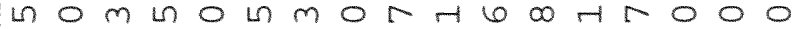
ति

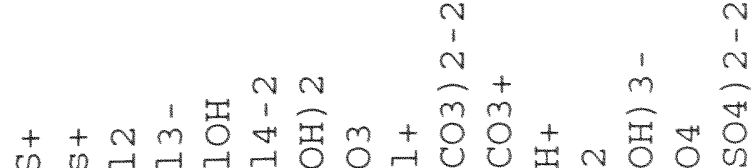

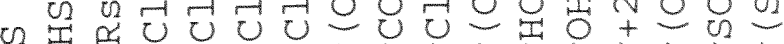

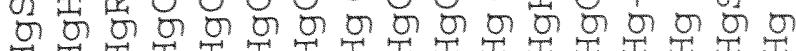
0000 0ं

ก ᄂ $6 \infty$ in $6 \mathrm{~m}+$ $\omega \% 66$ $\rightarrow \mathrm{N}$ in तi m

$\operatorname{rob} 6$ सi 6 \& 4 in $\infty 6 \mathrm{~L}$ -i mं त)

$\mathrm{cm}+\mathrm{O}$ 0000 (1) 0 (1) 0 $\infty$ im 0 $\triangle \infty$ in $N o m N$

$\dot{\sim} \dot{\sim} \dot{\sim}$

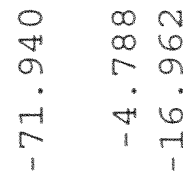

$\begin{array}{ll}0 & 0 \\ 0 & 0 \\ -1 & 0 \\ 0 & 0\end{array}$

$\begin{array}{lll}0 & 0 \\ 0 & -1 & 4 \\ 0 & 0 & 0 \\ 0 & 0\end{array}$

in

No $\quad-16 m$

$\begin{array}{llllll}n & \infty & L & 0 & 4 & 0 \\ 0 & 0 & \infty & m & m & \infty\end{array}$ चं

$1+1$ $\dot{m} \dot{m} \dot{0}$

11

\%

$1 \quad 1 \quad 1 \quad 1$ (1) 0 (1) 0 ONNR H 16 $\infty m \times \infty$ $\dot{\sim} \dot{\sim} \dot{N}$

0
1
0
0
$m$ 8 100
+000
+000 $\underset{z}{2}$ 
in $\ln \mathrm{L} 6 \mathrm{O} 0$ in in 06 NNMONH N N N Ai A. A H A 0 A 0

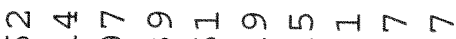
$6 \pi \sigma m$ म $\rightarrow$ त 600

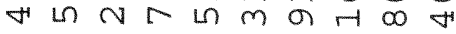
ம் $\dot{\omega} \dot{\infty} \dot{\sigma} \dot{\sigma} \dot{\circ} \dot{0}$ 11111,1 त त

$\operatorname{ranmH}$ ( $m \infty \mathrm{m} m \mathrm{~N}$ \% $\mathrm{H} 0$ $0006 \pi m+r \infty m$

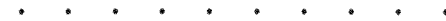
$66, \infty$ \% क क $00 \mathrm{~m}$

No

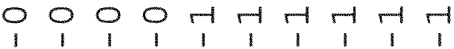

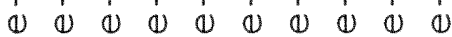

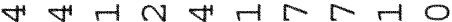

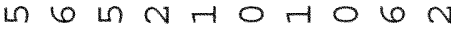

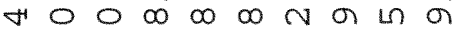
$m m L H N H$

r 000000 H $\begin{array}{cccccccccc}1 & 1 & 1 & 1 & 1 & 1 & 1 & 1 & 1 & 1 \\ 0 & 0 & 0 & 0 & 0 & 0 & 0 & 0 & 0 & 0\end{array}$ $\pi$ in $m+0$ in $\min 66$

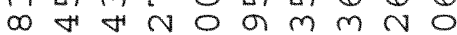
H $H M m$ म $6 N$ in 0

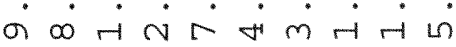
N
1
0
0
0
a
N

mmro 00000 (1) 10 (1) 100 I 0 \% 00 LO H 00 कं मं $\dot{0}$

Nmroo 00000 (1) 0 (1) d) 0 M N NOO or $\rightarrow 00$ $\ln 000$ तं

a $m \pi m$ in Lी $\infty \Gamma \infty m$

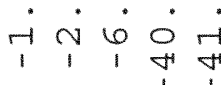

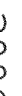

a. 1,2

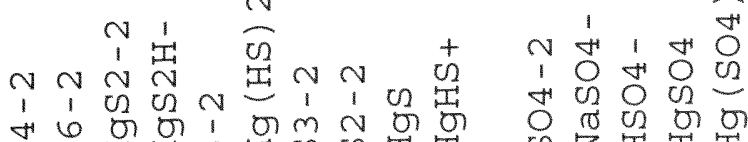

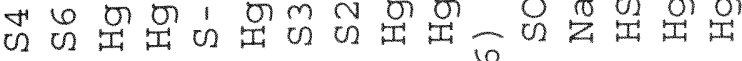
6
U

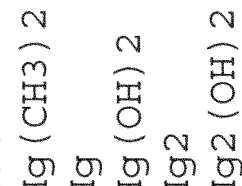

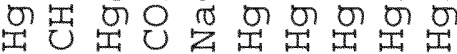

H सं O 6 क N 


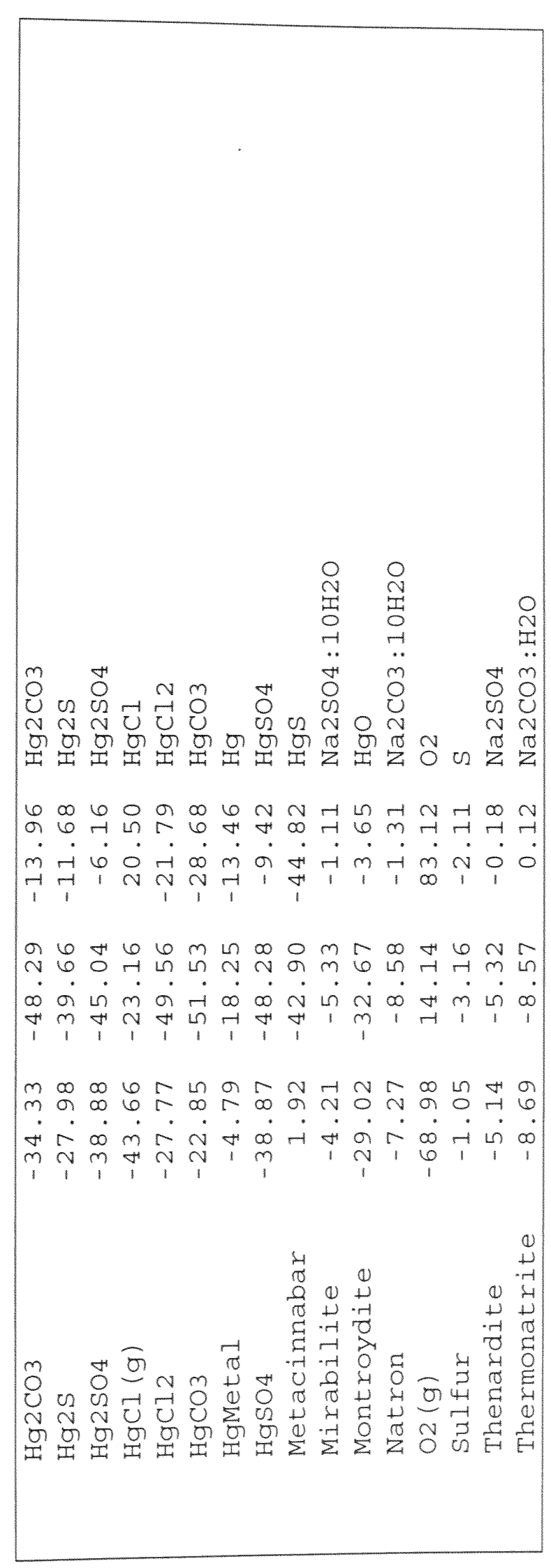

